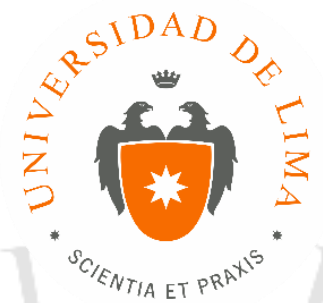

\title{
ESTUDIO DE PREFACTIBILIDAD PARA LA INSTALACIÓN DE UNA PLANTA PRODUCTORA DE DIPS A BASE DE QUINUA Y VEGETALES VERDES
}

Trabajo de investigación para optar el Título Profesional de Ingeniero Industrial

\author{
Carlos Javier Acosta Llaury
}

Código 20100008

Diego Antonio Sebastián Andrade

Código 20101051

Asesor

Shaminy Silvia Molina Quenaya

Lima - Perú

Julio del 2018 


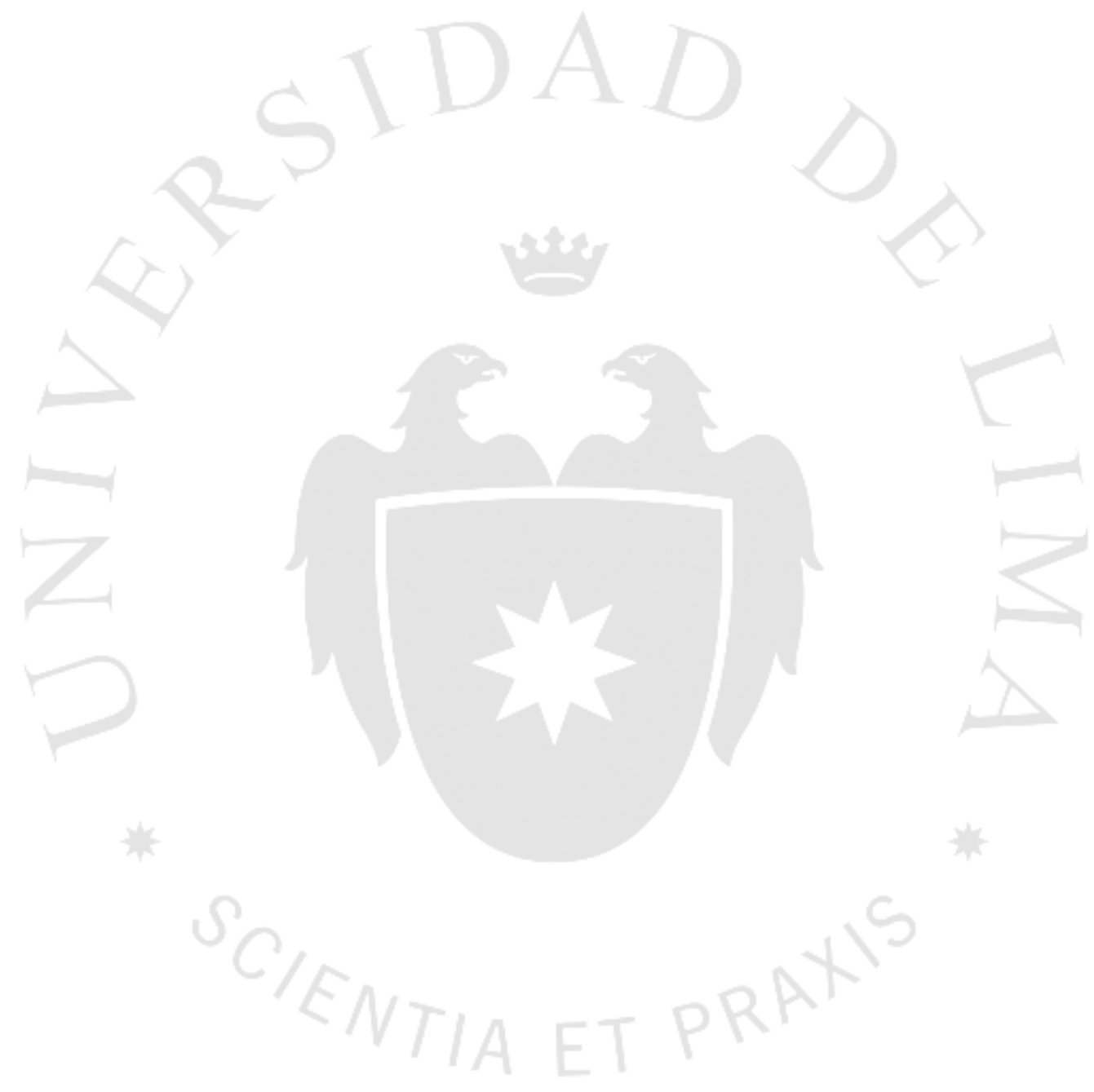




\section{ESTUDIO DE PREFACTIBILIDAD PARA LA}

INSTALACIÓN DE UNA PLANTA PRODUCTORA DE DIPS A BASE DE QUINUA Y VEGETALES VERDES 


\section{TABLA DE CONTENIDO}

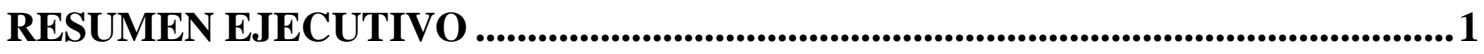

EXECUTIVE SUMMARY ...........................................................................................................2

CAPÍTULO I: ASPECTOS GENERALES.................................................................3

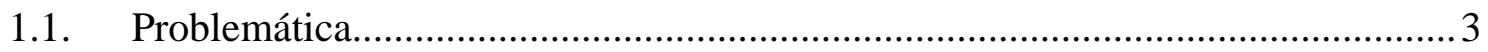

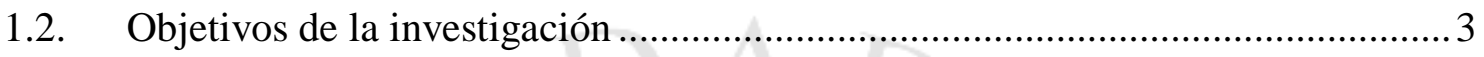

1.3. Alcance y limitaciones de la investigación ................................................... 4

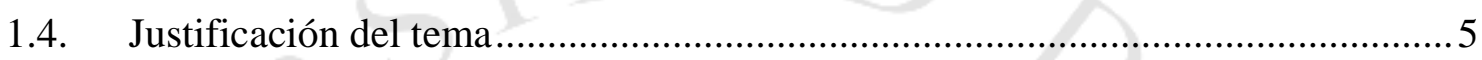

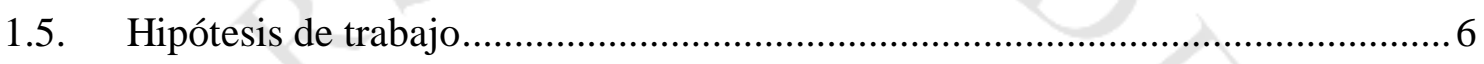

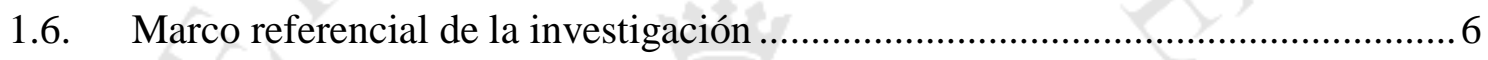

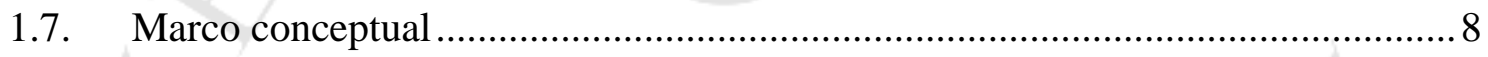

CAPÍTULO II: ESTUDIO DE MERCADO …........................................................... 12

2.1. Aspectos generales del estudio de mercado ..................................................... 12

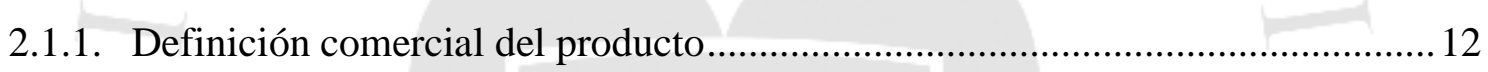

2.1.2. Principales características del producto ...................................................... 13

2.1.3. Determinación del área geográfica que abarcará el estudio............................... 14

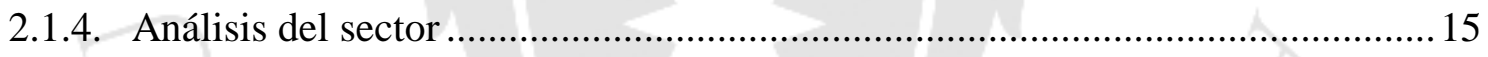

2.1.5. Determinación de la metodología que se empleará en la investigación de mercado

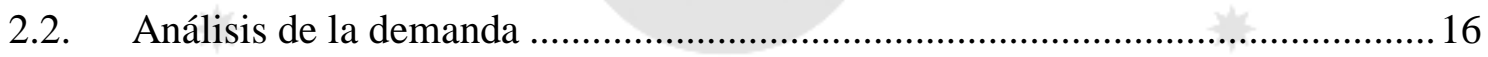

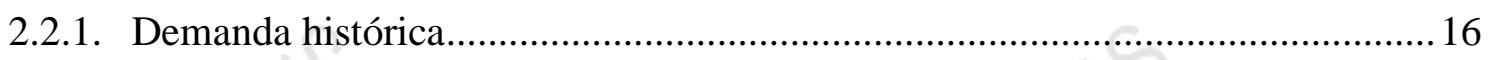

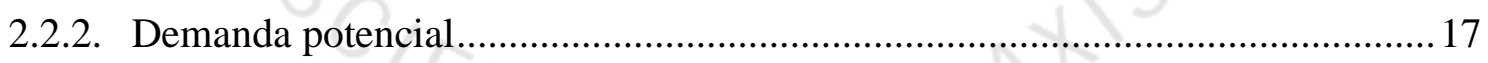

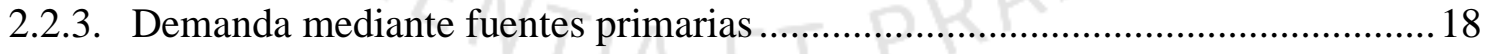

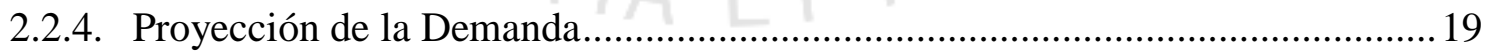

2.2.5. Consideraciones sobre la vida útil del proyecto.................................................2

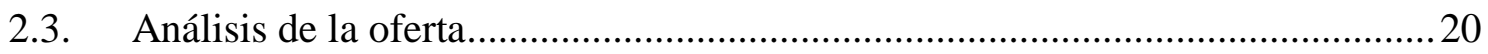

2.3.1. Empresas productoras, importadoras y comercializadoras ................................ 20

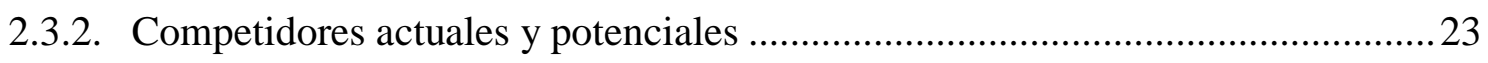

2.4. Determinación de la Demanda para el proyecto ..............................................25

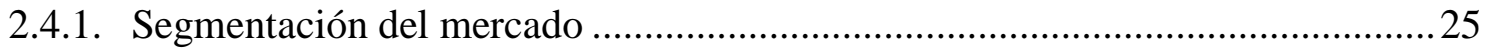

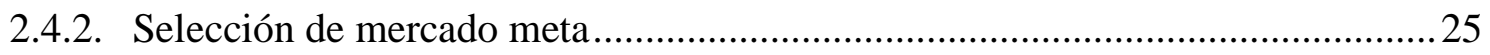




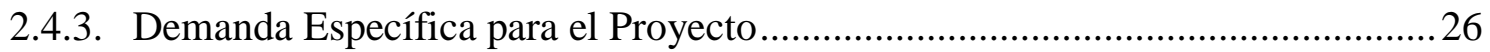

2.5. Definición de la Estrategia de Comercialización ..............................................26

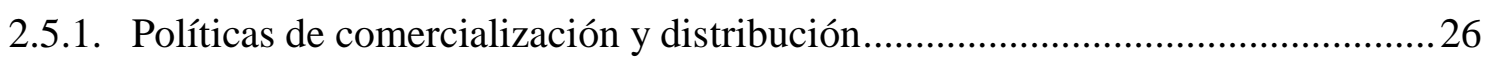

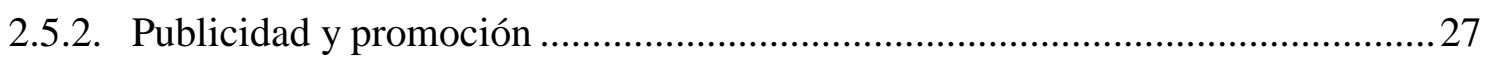

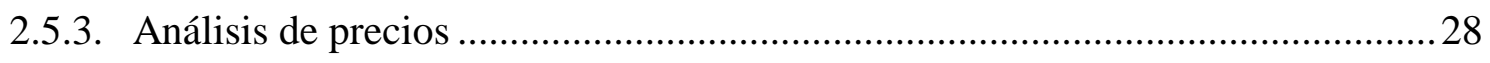

2.6. Análisis de Disponibilidad de los insumos principales ......................................29

2.6.1. Características principales de la materia prima................................................29

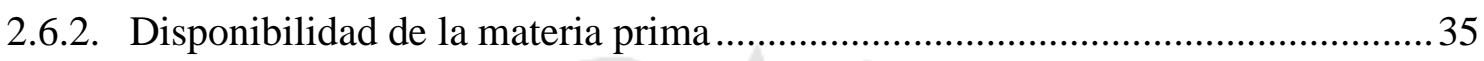

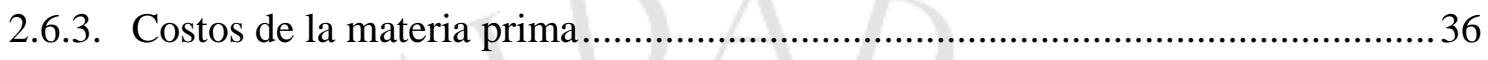

CAPÍTULO III: LOCALIZACIÓN DE PLANTA....................................................38

3.1. Identificación y análisis detallado de los factores de localización....................... 38

3.2. Identificación y descripción de las alternativas de localización ..........................40

3.3. Evaluación y selección de localización............................................................ 47

3.3.1. Evaluación y selección de la macro localización .............................................. 47

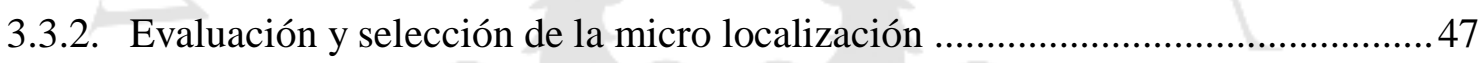

CAPÍTULO IV: TAMAÑO DE PLANTA .................................................................5 52

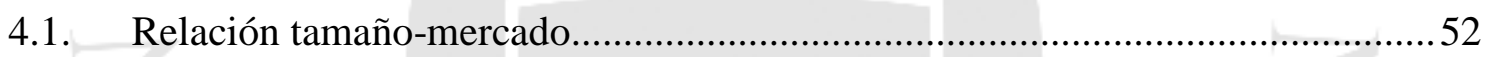

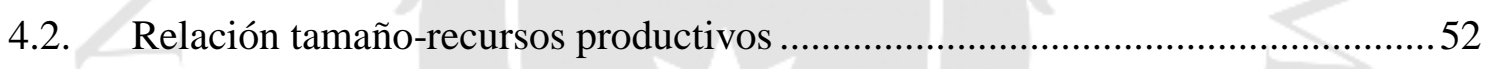

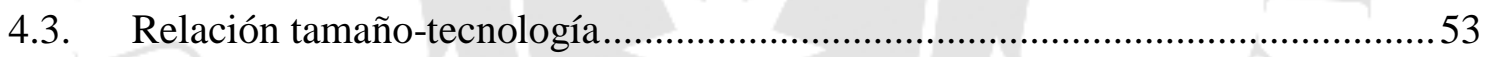

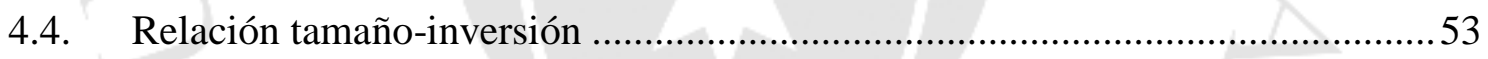

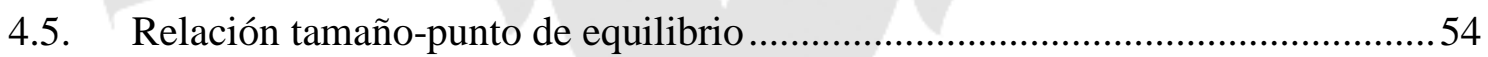

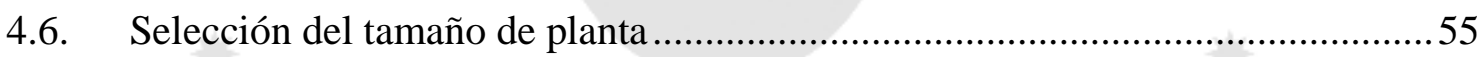

CAPÍTULO V: INGENIERÍA DEL PROYECTO.......................................................56

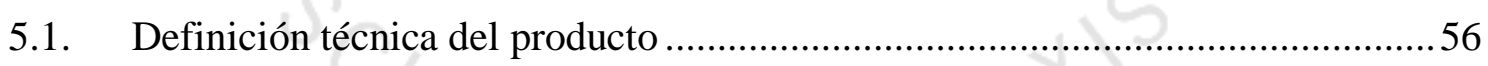

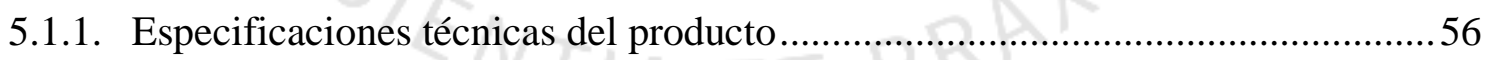

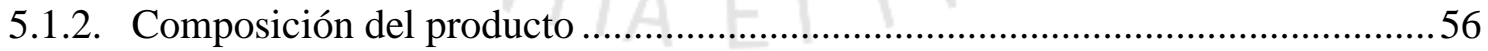

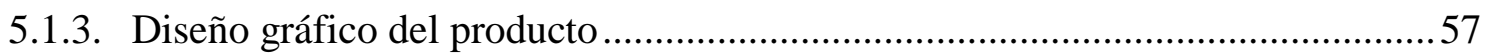

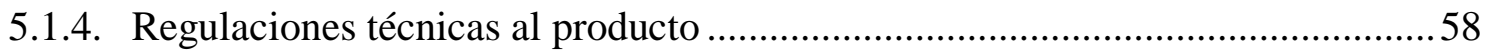

5.2. Tecnologías existentes y procesos de producción..............................................58

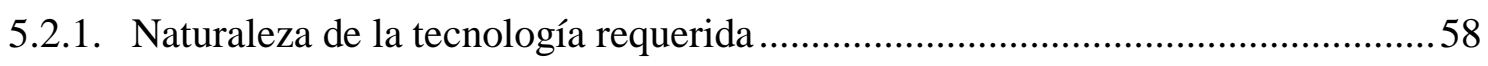

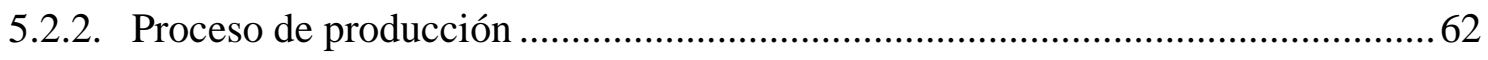

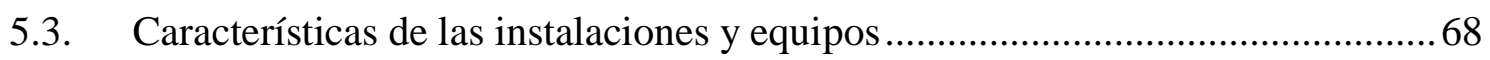

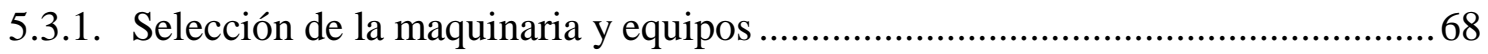


5.3.2. Especificaciones de la maquinaria .69

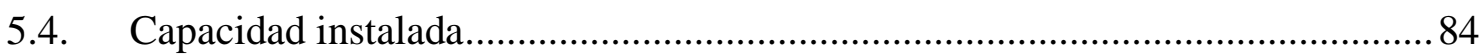

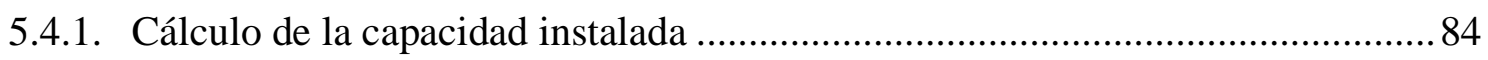

5.4.2. Cálculo detallado del número de máquinas requeridas .................................... 87

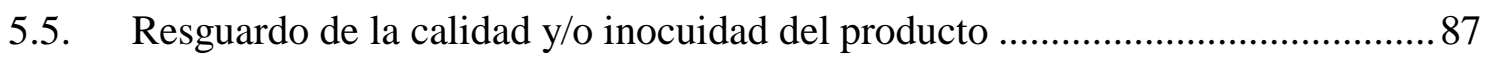

5.5.1. Calidad de la materia prima, insumos, proceso y producto ............................... 88

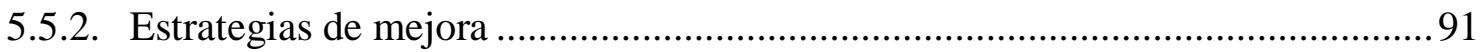

5.6. Estudio de Impacto Ambiental.......................................................................... 91

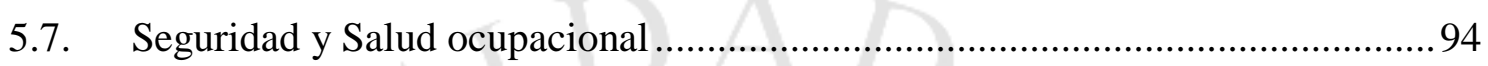

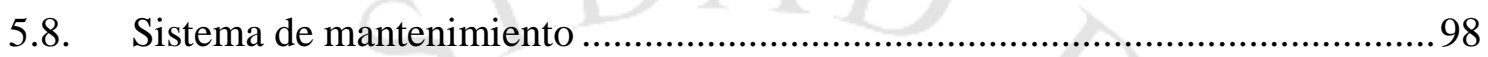

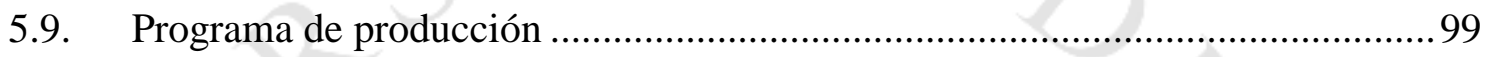

5.9.1. Factores para la programación de la producción .............................................99

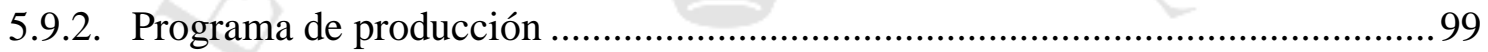

5.10. Requerimiento de insumos, servicios y personal .......................................... 100

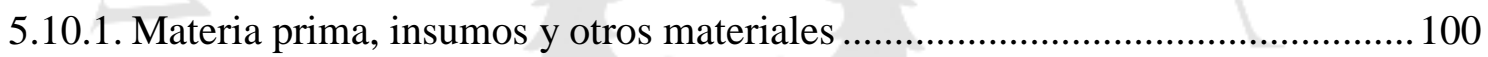

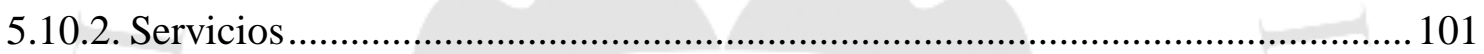

5.10.3. Determinación del número de operarios y trabajadores indirectos ................... 103

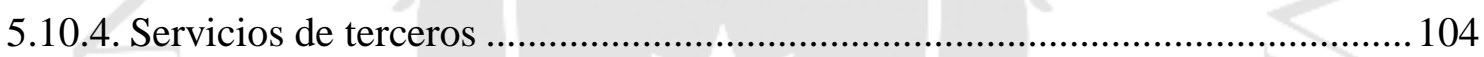

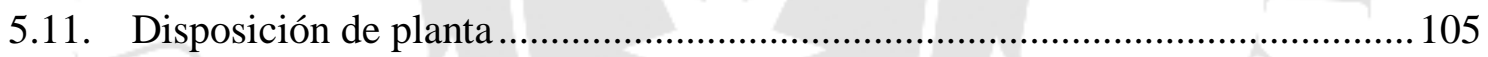

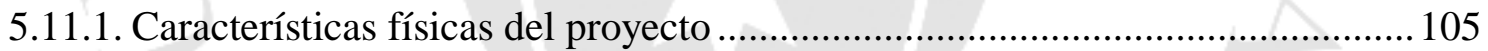

5.11.2. Determinación de las zonas físicas requeridas............................................... 108

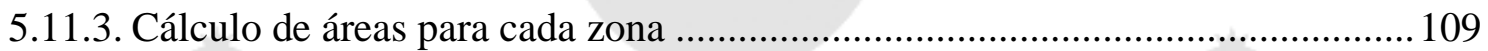

5.11.4. Dispositivos de seguridad industrial y señalización .......................................111

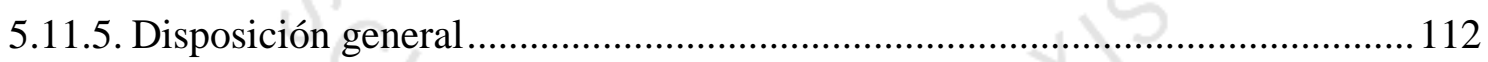

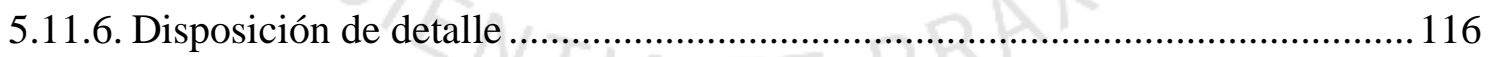

5.12. Cronograma de implementación del proyecto ................................................ 117

CAPÍTULO VI: ORGANIZACIÓN Y ADMINISTRACIÓN...................................118

6.1. Formación de la Organización empresarial ........................................................ 118

6.2. Requerimientos de personal directivo, administrativo y de servicios...............118

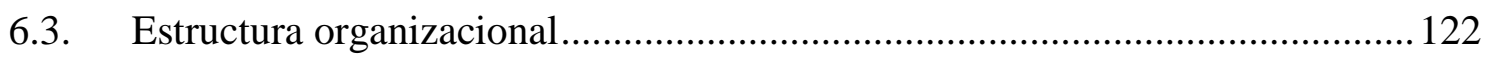

CAPÍTULO VII: ASPECTOS ECONÓMICOS Y FINANCIEROS.......................123

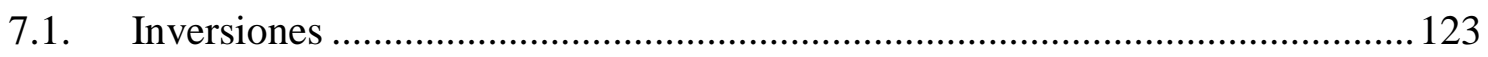

7.1.1. Estimación de las inversiones de largo plazo................................................... 123 
7.1.2. Estimación de las inversiones de corto plazo.

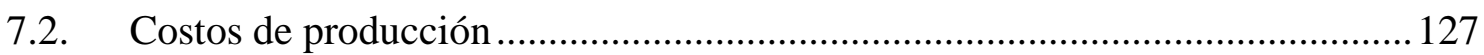

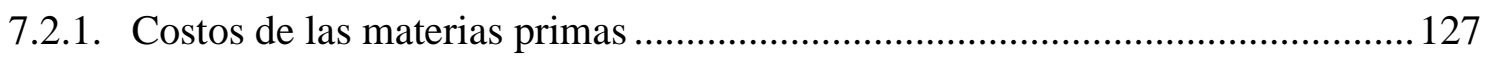

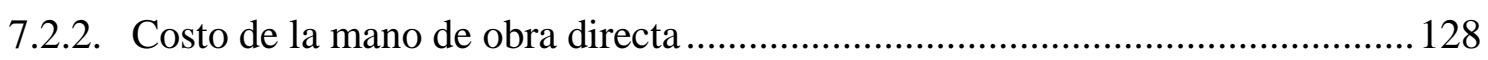

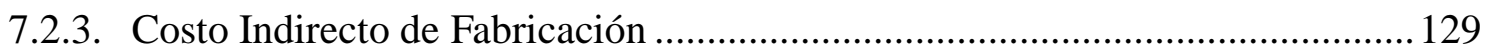

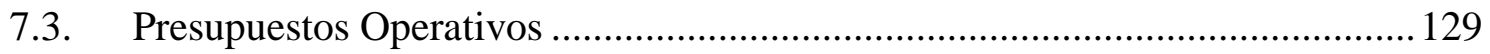

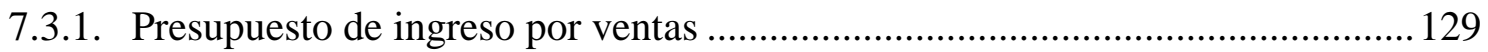

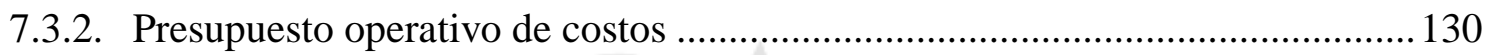

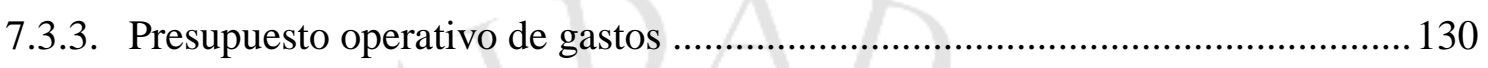

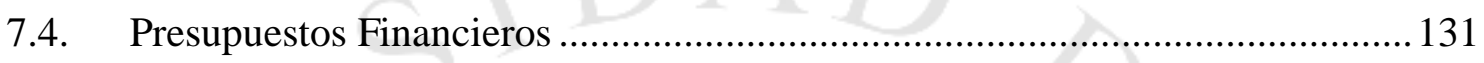

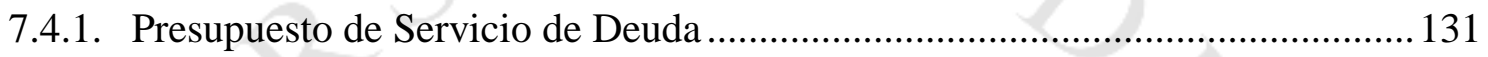

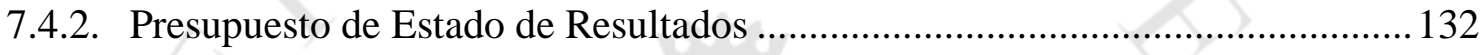

7.4.3. Presupuesto de Estado de Situación Financiera ................................................ 133

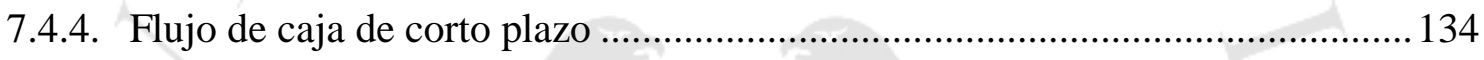

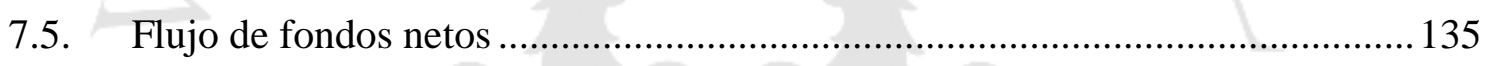

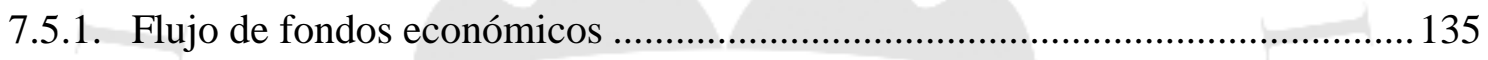

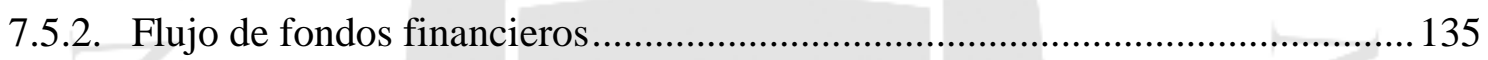

CAPÍTULO VIII: EVALUACIÓN ECONÓMICA Y FINANCIERA DEL

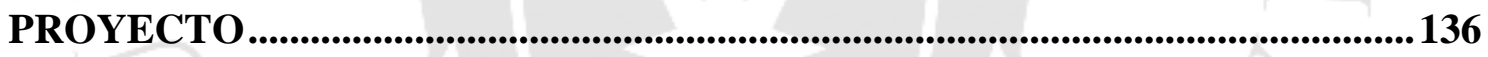

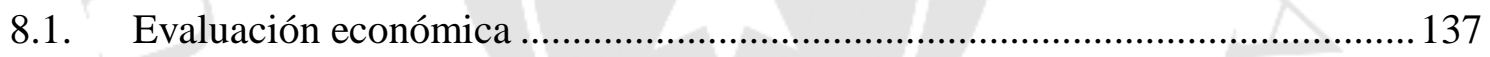

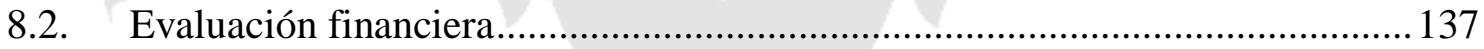

8.3. Análisis de ratios e indicadores económicos y financieros del proyecto ........... 138

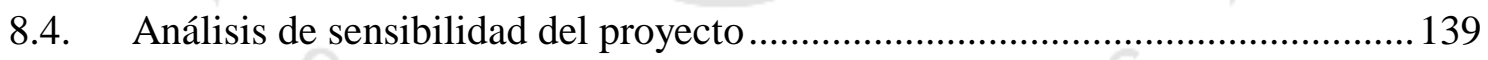

CAPÍTULO IX: EVALUACIÓN SOCIAL DEL PROYECTO ................................141

9.1. Identificación de las zonas y comunidades de influencia del proyecto ............. 141

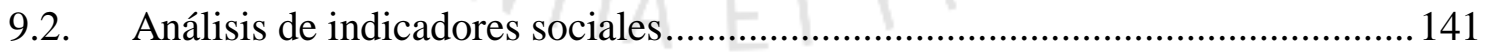

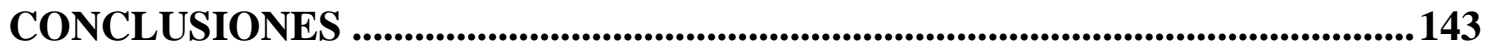

RECOMENDACIONES ............................................................................................ 144

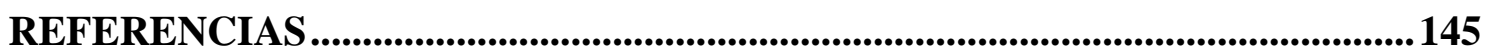

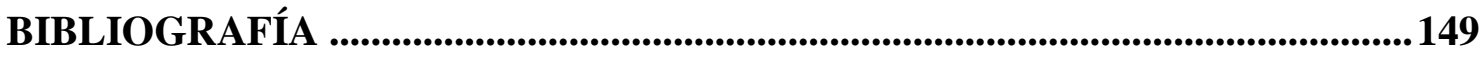




\section{ÍNDICE DE TABLAS}

Tabla 1.1. Contenido Mineral de la Quinua y otros alimentos(mg/100g) ..................... 10

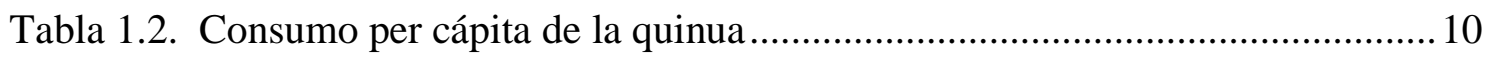

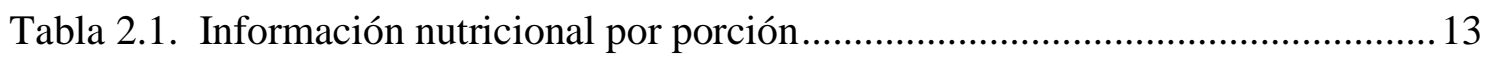

Tabla 2.2. Incremento de la población en el Perú ............................................................ 17

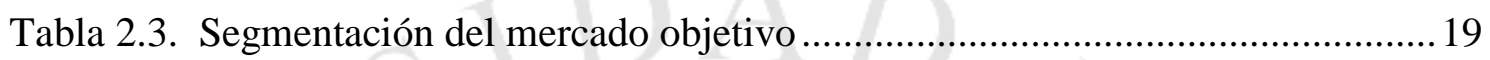

Tabla 2.4. Proyección de la demanda 2018 al 2022 ....................................................20

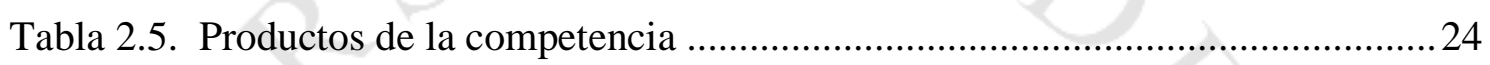

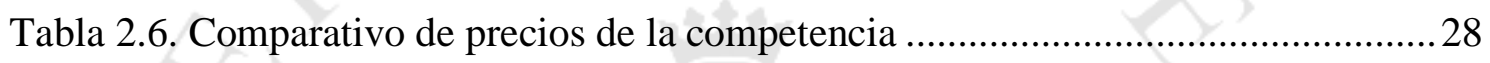

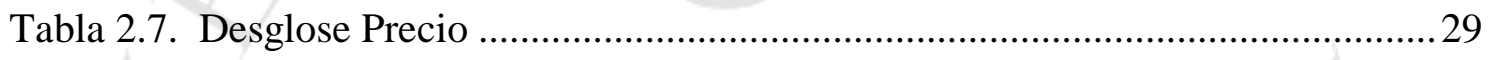

Tabla 2.8. Composición Nutricional de la Quinua ....................................................... 31

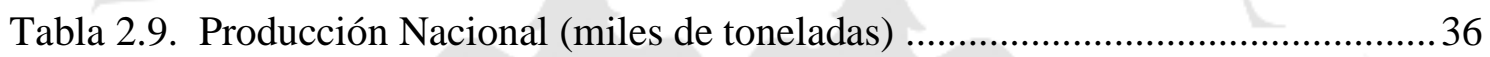

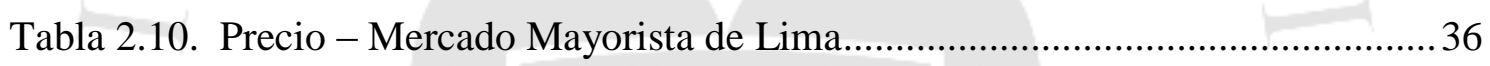

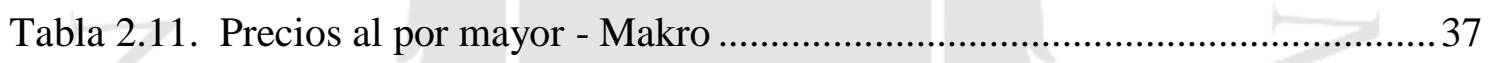

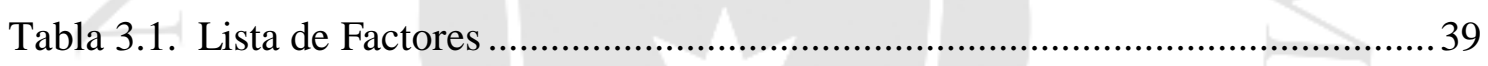

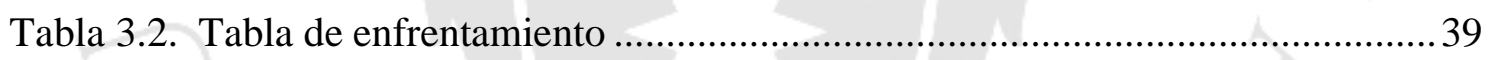

Tabla 3.3. Distancias entre Departamentos y mercado objetivo.................................... 40

Tabla 3.4. Tarifas de agua de las principales empresas por Departamento .....................44

Tabla 3.5. Tarifas BT3 de energía eléctrica de las principales empresas ....................... 45

Tabla 3.6. Empresas de Transporte de Carga autorizadas .......................................... 46

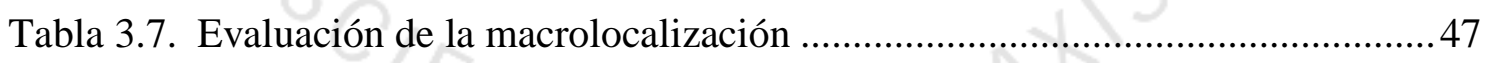

Tabla 3.8. Número de delitos por provincia ............................................................. 49

Tabla 3.9. Precios de terreno por Provincia............................................................... 49

Tabla 3.10. Índice de Desarrollo Humano y sus componentes por provincia ...............50

Tabla 3.11. Tabla de enfrentamiento para Microlocalización .........................................51

Tabla 3.12. Evaluación de la Microlocalización..................................................................51

Tabla 4.2. Requerimiento de Quinua y Espárrago ....................................................52

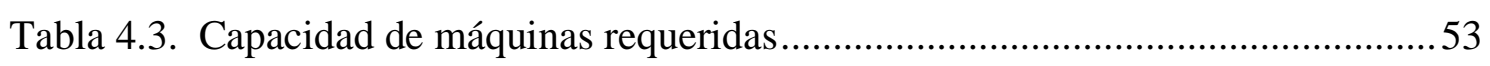

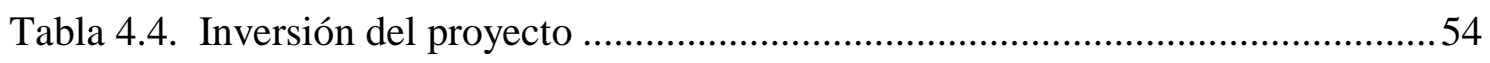

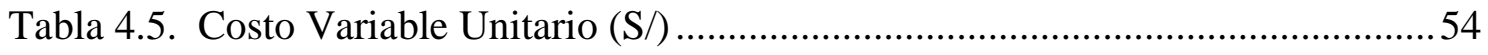


Tabla 5.1. Composición del producto .56

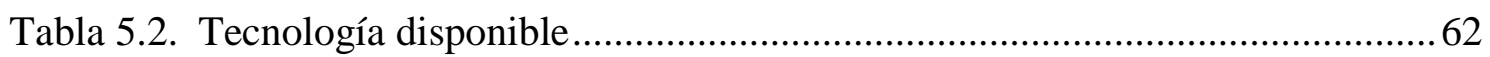

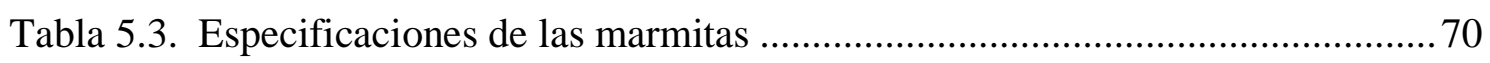

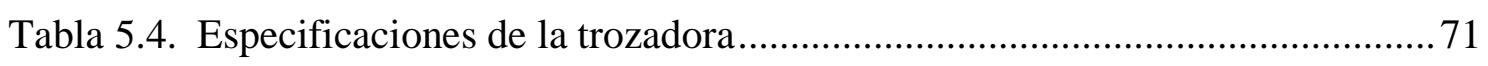

Tabla 5.5. Especificaciones de la máquina envasadora ............................................. 72

Tabla 5.6. Especificaciones de la máquina codificadora ............................................ 73

Tabla 5.7. Especificaciones de la bomba de transferencia........................................... 74

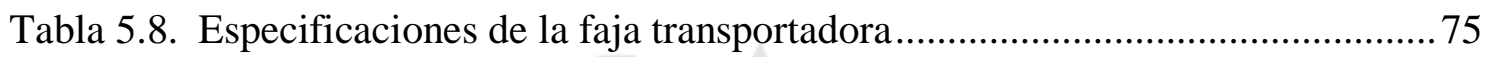

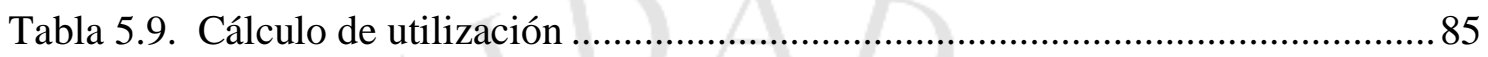

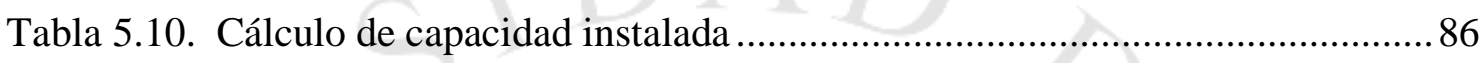

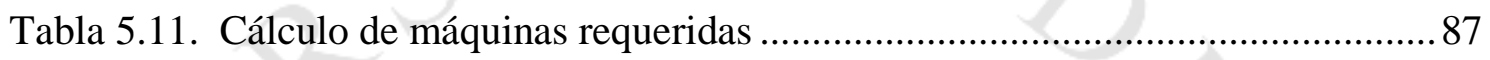

Tabla 5.12. Puntos críticos de control - HACCP ...................................................... 90

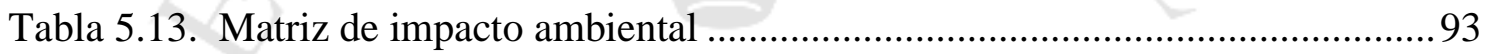

Tabla 5.14. Parámetros de principales agentes físicos................................................. 95

Tabla 5.15. Matriz de Identificación de Peligros y Evaluación de Riesgos ................... 97

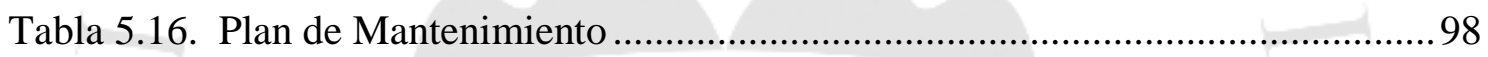

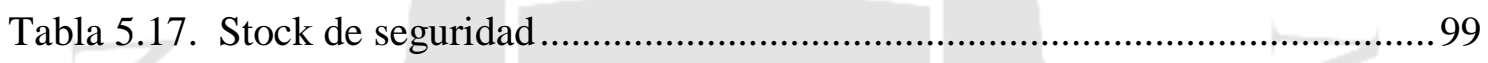

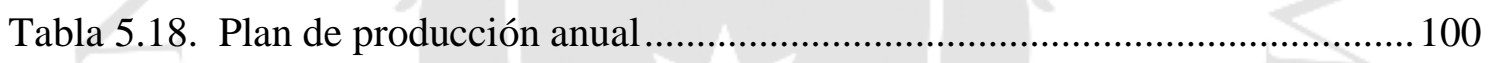

Tabla 5.19. Requerimiento de materia prima e insumos ........................................... 100

Tabla 5.20. Requerimiento de otros materiales (unidades)........................................ 101

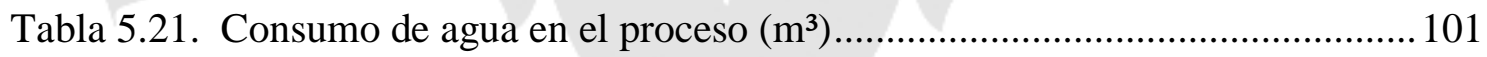

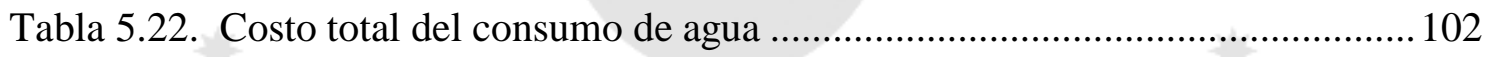

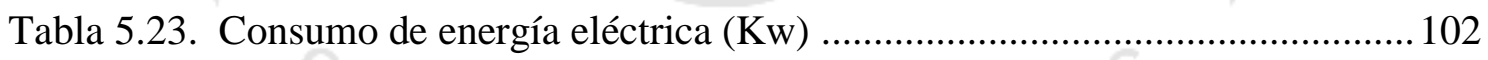

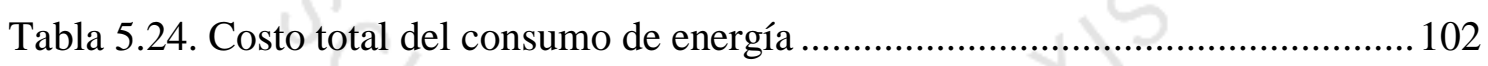

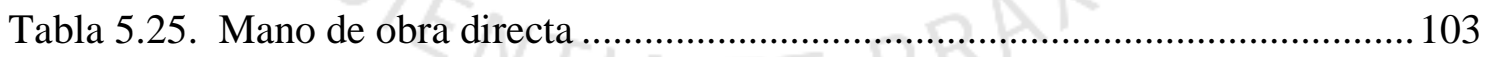

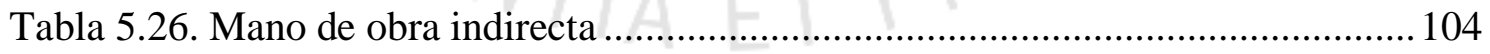

Tabla 5.27. Área mínima requerida según método de Guerchet.................................. 109

Tabla 5.28. Tabla de elementos móviles..................................................................... 110

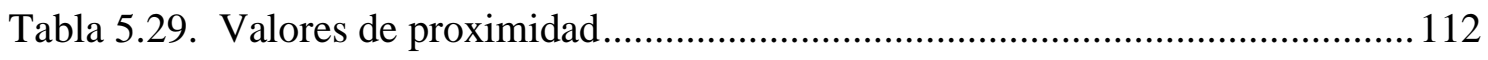

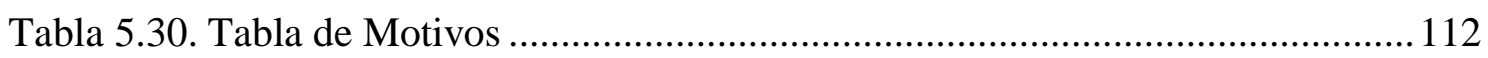

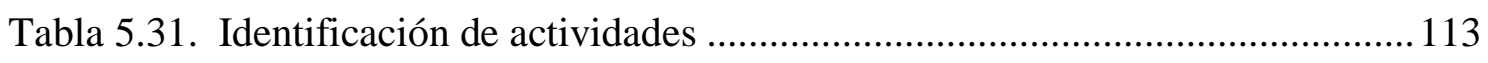

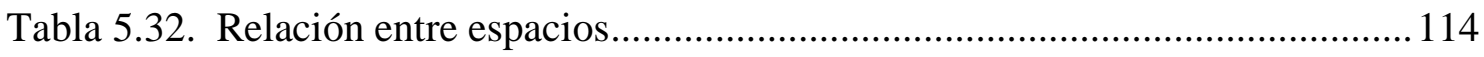

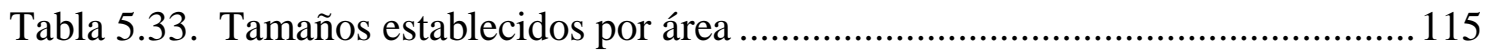




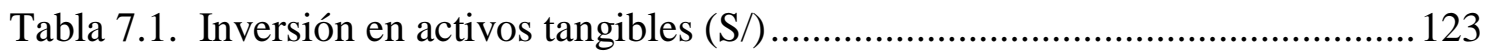

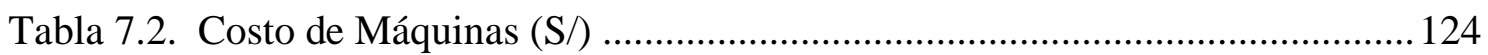

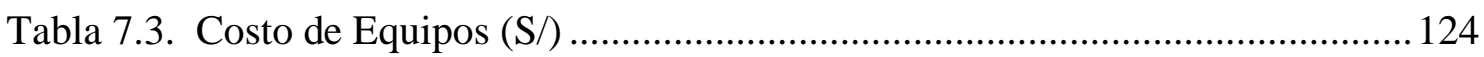

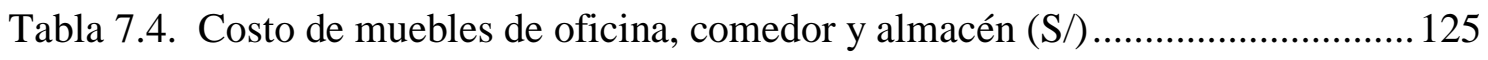

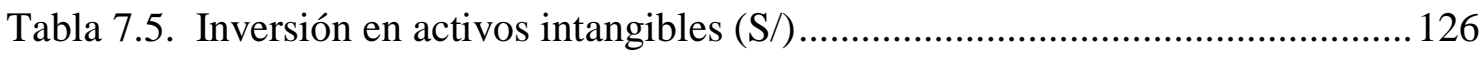

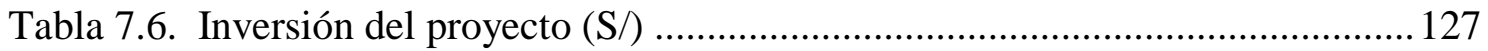

Tabla 7.7. Variación anual promedio del IPC - Alimentos y Bebidas .........................127

Tabla 7.8. Costo de materia prima e insumos $(\mathrm{S} /)$........................................................ 128

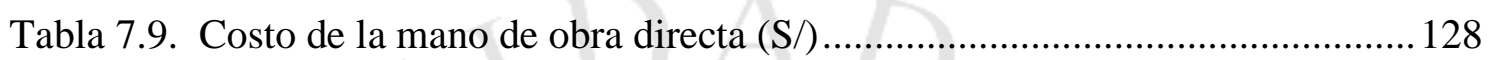

Tabla 7.10. Costos Indirectos de Fabricación (S/) .......................................................129

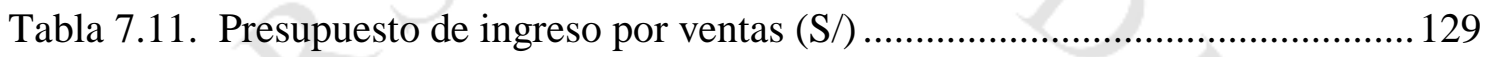

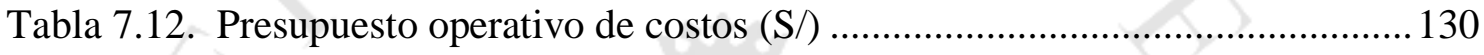

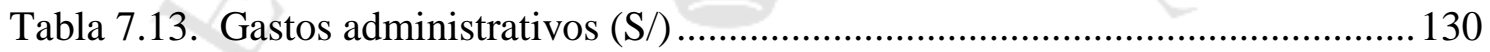

Tabla 7.14. Gastos de ventas y distribución (S/) ......................................................... 131

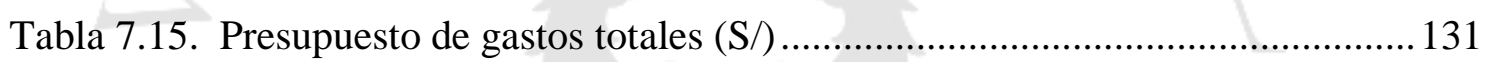

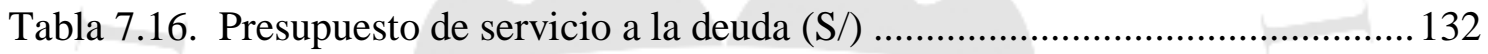

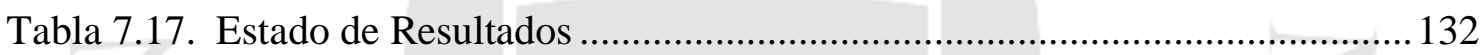

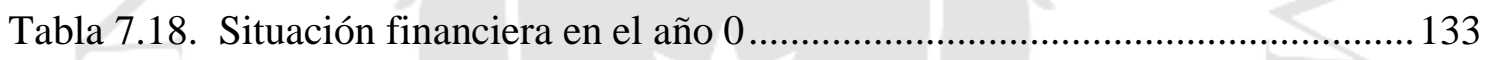

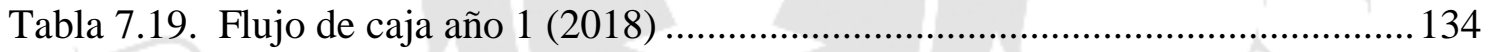

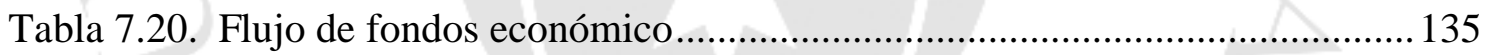

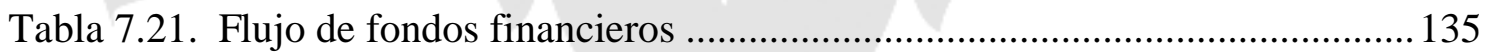

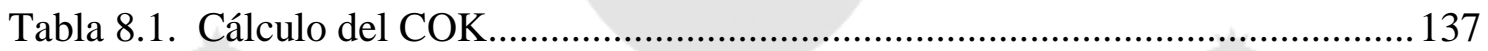

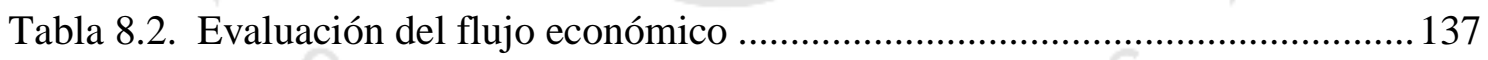

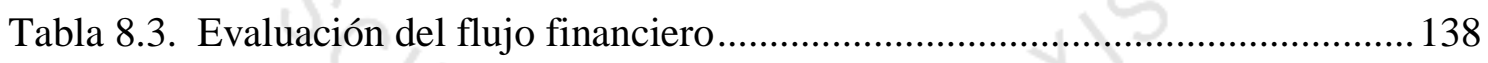

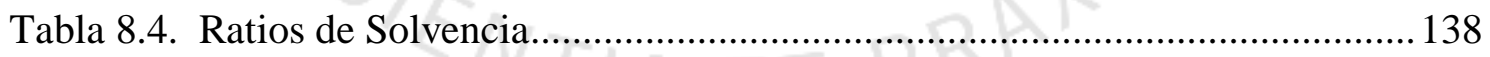

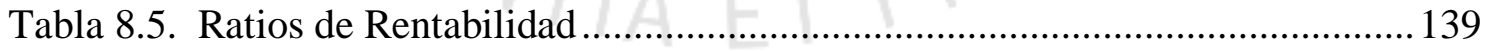

Tabla 8.6. Presupuesto de ventas en escenario optimista ...........................................139

Tabla 8.7. Evaluación económica y financiera en escenario optimista ........................ 140

Tabla 8.8. Presupuesto de ventas en escenario pesimista .......................................... 140

Tabla 8.9. Evaluación económica y financiera en escenario pesimista ....................... 140

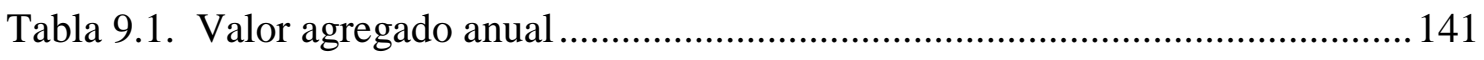




\section{ÍNDICE DE FIGURAS}

Figura 1.1. Población mayor a 15 años con obesidad............................................... 8

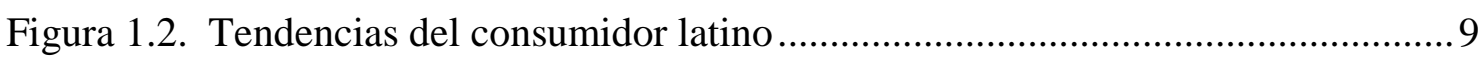

Figura 1.3. Búsquedas relacionadas a alimentación saludable .................................... 9

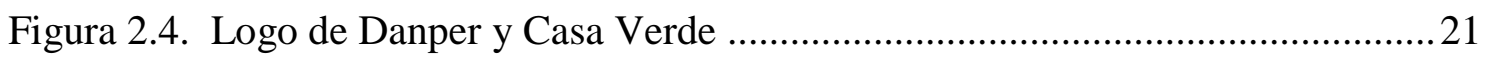

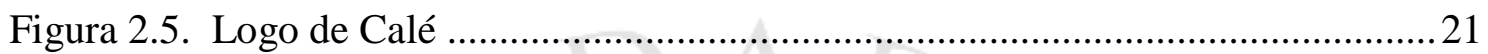

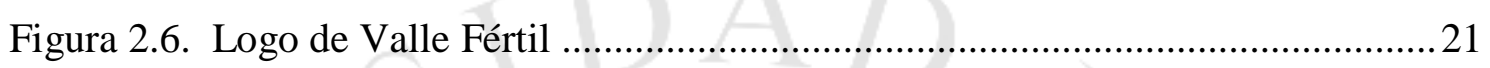

Figura 2.7. Logo de Pachamama Gourmet y Native \& Natural .................................... 22

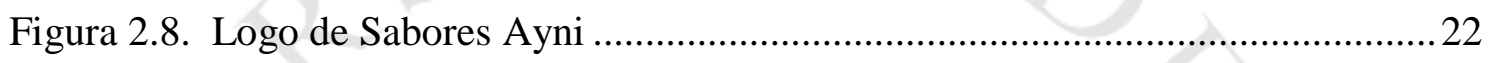

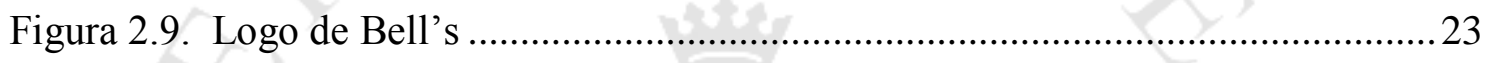

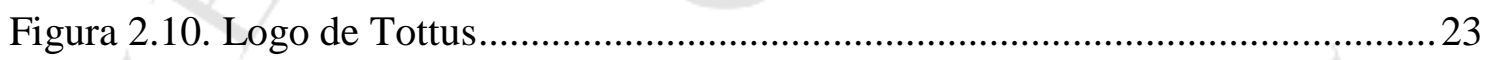

Figura 2.11. Distribución de personas según NSE 2016 - Lima Metropolitana .............25

Figura 2.12. Variedades de plantas de Quinua ......................................................... 30

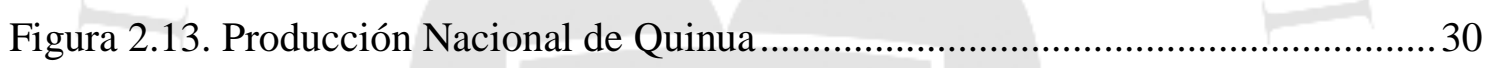

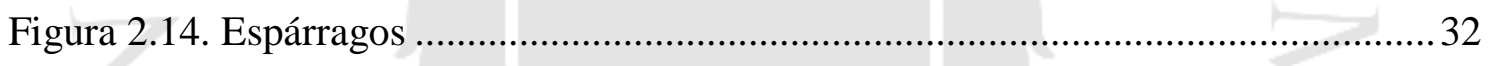

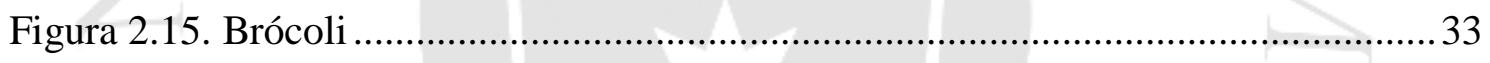

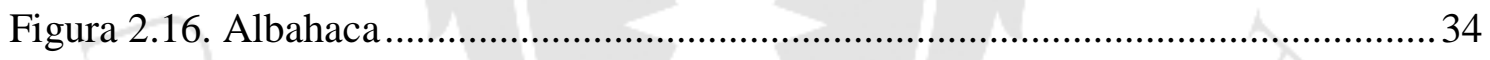

Figura 3.17. Producción de Quinua por Departamento 2014 ........................................ 41

Figura 3.18. Mapa de producción de espárrago .......................................................... 42

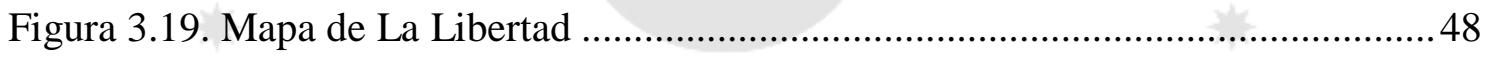

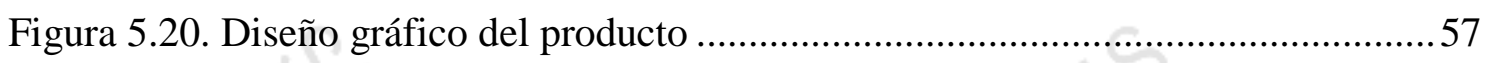

Figura 5.21. Diagrama de operaciones de proceso para la elaboración de un dip a base de

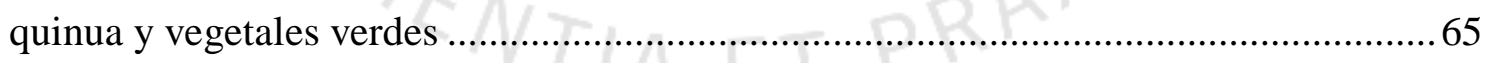

Figura 5.22. Balance de materia de la producción del año 2022 .................................67

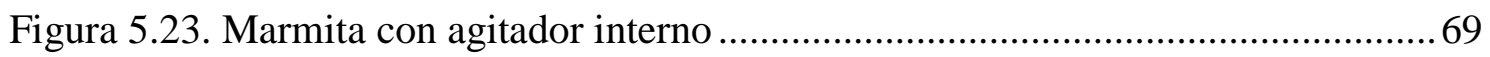

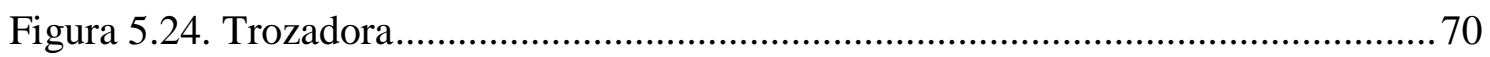

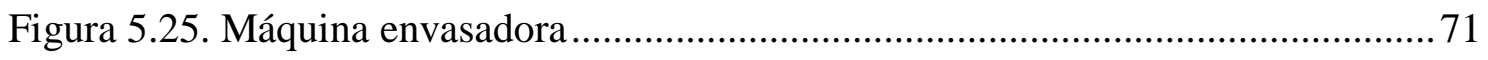

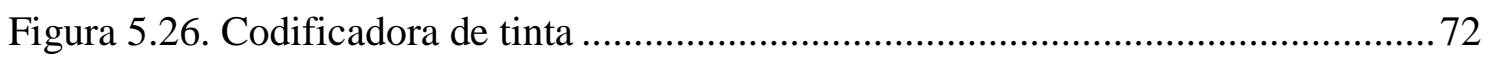

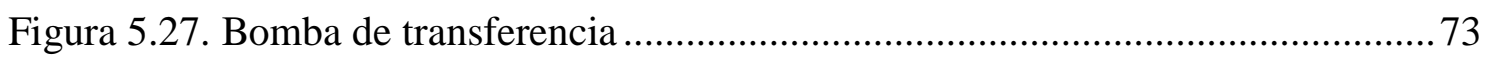

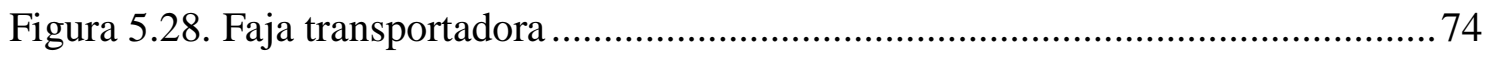

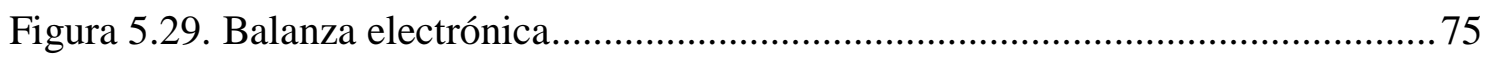




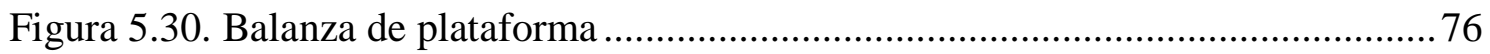

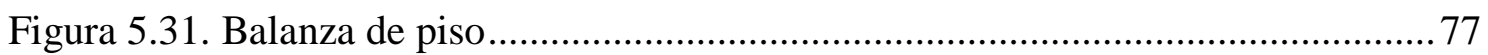

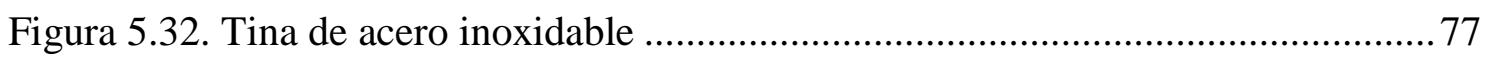

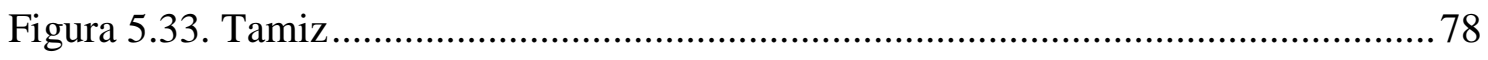

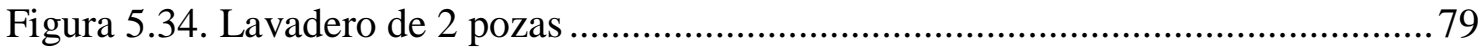

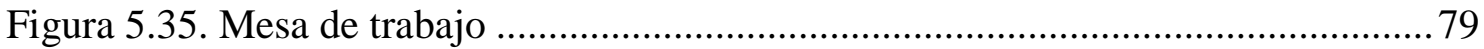

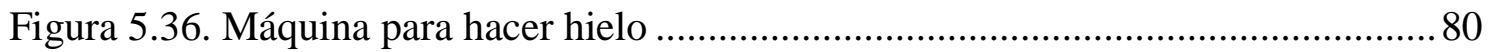

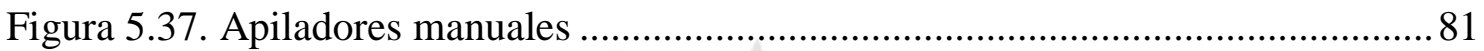

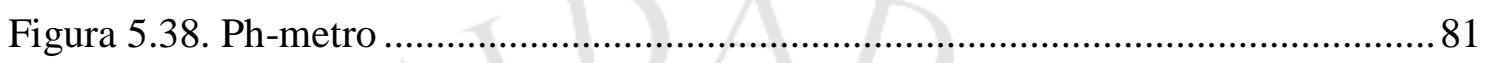

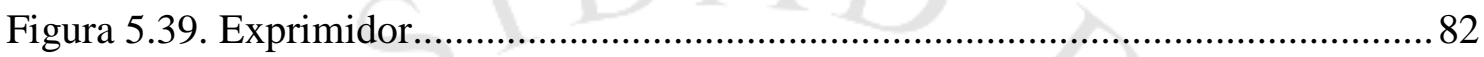

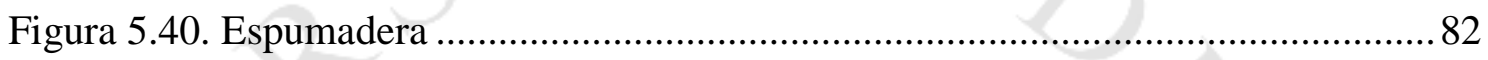

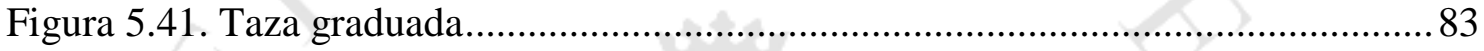

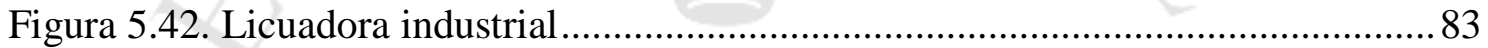

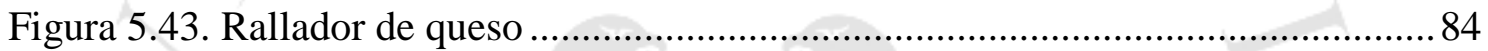

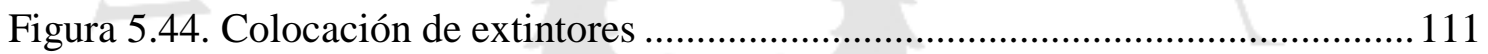

Figura 5.45. Tabla relacional de actividades ...................................................... 113

Figura 5.46. Diagrama relacional de actividades................................................... 114

Figura 5.47. Plano de distribución de planta .......................................................... 116

Figura 5.48. Cronograma de implementación del proyecto......................................... 117

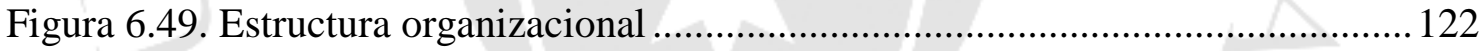




\section{ÍNDICE DE ANEXOS}

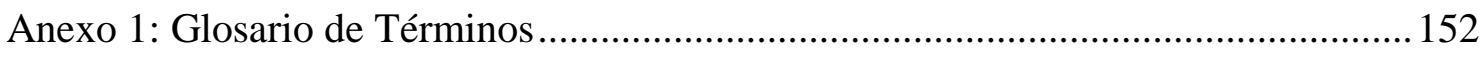

Anexo 2: Información Nutricional Completa .............................................................. 153

Anexo 3: Segmentación de Mercado Objetivo .......................................................... 154

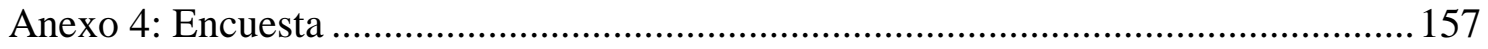

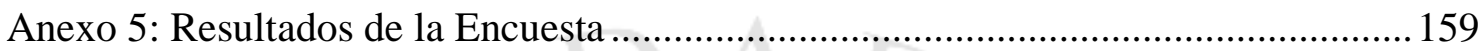




\section{RESUMEN EJECUTIVO}

El presente trabajo de investigación busca determinar la prefactibilidad para la instalación de una planta productora de dips a base de quinua y vegetales verdes. Este producto planea desarrollar un mercado no atendido y aprovechar una de las principales tendencias: el consumo saludable.

En los primeros tres capítulos se fijan principalmente los aspectos generales como: los objetivos, alcance, limitaciones e hipótesis de la investigación; además, se desarrolla el estudio de mercado con el que se determinó como demanda objetiva para el primer año 807274 unidades de 180 gr en los NSE A y B de la ciudad de Lima en las zonas 6 y 7. También, luego del análisis de ranking de factores, se eligió como localización óptima para las operaciones a Trujillo.

Durante el capítulo IV, se puede comprobar que no existen limitaciones para el proyecto en cuanto a la tecnología y recursos. Sin embargo, variables críticas del mercado llevan a concluir que 1014406 dips para el 2022 es el tamaño óptimo de planta.

El capítulo V, clave en el desarrollo de la investigación, muestra a detalle la ingeniería del proyecto. A través del DOP, Diagrama Relacional y método Guerchet, se calculó el área mínima requerida y se definió la disposición de planta.

Por último, en los capítulos VI, VII y VIII se analiza la viabilidad económica y financiera a través de los Flujos de Fondos, Balance General y Estado de Resultados. A partir de una inversión de S/. 1819507 se obtiene un VAN de S/. 918 065, TIR de 80.11\% superior al COK y un periodo de recupero al cabo de 1 año y 10 meses. Finalmente, en el capítulo IX se evaluará el impacto social del proyecto. 


\section{EXECUTIVE SUMMARY}

The present study seeks to determine the prefeasibility for the installation of a quinoa and green vegetables dips manufacturing plant. This product plans to develop an unattended market and take advantage of one of the main trends: healthy consumption.

In the first three chapters, the general aspects are mainly fixed as: the objectives, scope, limitations and hypothesis of the investigation; In addition, a market study was carried out with which 807274 units of 180 gr were determined as objective demand for the first year in SES (Socioeconomic Status) A and B of sixth and seventh Lima zones. Also, after the analysis of pair-wise ranking, Trujillo was chosen as the optimal location for operations.

During chapter IV, it can be verified that there are no limitations for the project about technology and resources. However, critical market variables lead to the conclusion that the optimum plant size for 2022 is 1014406 units.

Chapter V, key in the development of the investigation, shows in detail the engineering of the project. Through DOP, Relational Diagram and Guerchet method, the minimum required area was calculated and the plant layout was defined.

Finally, chapters VI, VII and VIII analyze the economic and financial viability of the Cash Flow, Balance Sheet and Income Statement. Obtaining, from an investment of S /. 1819 507, a NPV (Net Present Value) of S /. 918 065, IRR (Internal Rate of Return) of $80.11 \%$ higher than Opportunity cost and a recovery period after 1 year and 10 months. Finally, in chapter IX, the social impact of the project will be evaluated. 


\section{CAPÍTULO I: ASPECTOS GENERALES}

\subsection{Problemática}

El presente proyecto busca aprovechar el buen momento gastronómico del Perú y la relevancia que han ido adquiriendo los productos e insumos para el consumidor local, quien apuesta por el país y orienta su preferencia a productos sofisticados.

Se busca ofrecer una alternativa diferente, conquistando espacios no atendidos o no desarrollados por la oferta actual, que en su mayoría son productos a base de un solo ingrediente y no aportan los mismos beneficios que el Dip propuesto. La poca variedad hace que este producto sea una alternativa a tomar en cuenta por los clientes potenciales.

Se ofrece la oportunidad de contar con un producto que ha sido elaborado en las mejores condiciones de seguridad y limpieza, contando con un sabor constante; ventaja que permite captar a los consumidores que frecuentemente preparan esta salsa de manera casera.

Por último, se busca el desarrollo sostenido de regiones relacionadas con la producción de los insumos y el respeto por los clientes y proveedores tanto internos como externos.

\subsection{Objetivos de la investigación}

\section{Objetivo general:}

Establecer la viabilidad técnica, económica y social para la instalación de una planta para la elaboración de Dip a base de quinua y vegetales verdes.

\section{Objetivos específicos:}

- Elaborar un estudio de mercado con el fin de determinar el perfil del público objetivo, precio referencial, plan de marketing y análisis de competencia.

- Determinar la ubicación óptima para la instalación de la planta, la cual deberá garantizar el abastecimiento de la materia prima e interacción con el mercado objetivo.

- Determinar el tamaño adecuado para la planta considerando las dimensiones de las máquinas y espacio suficiente para el desarrollo de las operaciones. 
- Determinar la distribución de la planta que permita agilizar el flujo de materiales durante el proceso.

- Determinar el método más adecuado para los subprocesos de lavado, trozado, cocción, enfriado, mezclado, envasado y codificado; acorde a las características de los insumos, conservando su calidad y haciendo uso eficiente de los recursos.

- Determinar el tipo de estructura organizacional y el requerimiento de personal.

- Analizar la rentabilidad de la realización del proyecto y el tiempo de retorno de la inversión.

- Analizar y determinar el impacto social en zonas de influencia del proyecto.

\subsection{Alcance y limitaciones de la investigación}

El área geográfica que abarca la investigación evaluará 3 factores principales: la disponibilidad y acceso a la materia prima, las condiciones de mercado y la localización de planta, cada factor requiere un análisis minucioso. En ese sentido, para la materia prima, se estudiará estacionalidad, producción, rendimiento y costo; en el caso de mercado, los patrones de consumo, PBI, rangos de edad, análisis del sector; y finalmente, para la ubicación de planta será de vital importancia la evaluación de factores a nivel de macro y microlocalización.

Antes del desarrollo del proyecto, se llevará a cabo la recolección de datos y búsqueda de información relevante durante 4 semanas con el fin de poder continuar con las etapas siguientes de manera ininterrumpida. El desarrollo del proyecto tomará 28 semanas adicionales, definidas por cada capítulo con duraciones variables, teniendo un total de 32 semanas ( 8 meses aproximadamente) como tiempo estimado.

La población objetivo para el estudio son personas mayores de 18 años pertenecientes a los niveles socioeconómicos $\mathrm{A}-\mathrm{B}$, quienes representan un $26.5 \%$ del total de Lima Metropolitana. (APEIM, 2016)

Finalmente, se ha considerado como limitante el acceso a la información de producción y comercio exterior de productos sustitutos. 


\subsection{Justificación del tema}

\section{Técnica:}

La producción de un dip a base de quinua y vegetales verdes es viable desde el punto técnico ya que existen productos similares en el mercado que son fabricados por empresas locales, lo que lleva a concluir que existe la tecnología necesaria para operar. Esto fue verificado a través de visitas y consultas a representantes de dos de las principales empresas agroindustriales.

Se deberá evaluar la maquinaria para que se adapte a la producción estimada, que sea de fácil mantenimiento y limpieza para cuidar el tema de inocuidad y se pueda conseguir un producto que cumpla las expectativas y regulaciones.

\section{Económica:}

El Perú es uno de los países de la región con crecimiento positivo y que sigue una tendencia al alza para los próximos años. Además, se puede resaltar el nuevo impulso en busca del crecimiento sostenido con el objetivo de ser miembro de la Organización para la Cooperación y el Desarrollo Económico (OCDE) para el 2021. Esto permitirá dinamizar el crecimiento del país, avanzar en el proceso de formalización y luchar directamente contra la corrupción. (Diario El Peruano, 2018, párr. 3)

Luego de un inicio de año golpeado por el Fenómeno de El Niño y el caso Odebrecht, se mantiene el optimismo en la economía peruana. Las proyecciones de crecimiento de PBI para el 2017 es de $3.3 \%$ y $4.2 \%$ para el 2018 . Se tiene planificado que la reconstrucción demoraría 3 trimestres y que para el 2018 el consumo debería restablecerse (Diario Gestión, 2017, párr. 1).

A esto se suma el crecimiento sostenible de la quinua, ingrediente estrella, un grano que día a día es probado por nuevos paladares y se vuelve más requerido en todo el mundo; en ese sentido, se presenta una oportunidad en el mejor momento para generar valor agregado a insumos del país.

Finalmente, durante el 2017 una de las principales tendencias del mercado es llevar una vida saludable (alimentación, rutina de ejercicios, entre otros) como símbolo de status (Euromonitor, 2017). 


\section{Social:}

Este proyecto planea ser la herramienta de dinamización del desarrollo rural y de la reducción de la pobreza, pues generará nuevos puestos de trabajo para personal técnico y profesional. Se requerirá personal a nivel operativo para actividades manuales y automáticas.

Además, contribuirá al desarrollo y a la formalización de pequeños comerciantes de quinua y demás ingredientes, impulsará el biocomercio, cuidado del medio ambiente, y buscará concientizar al mercado sobre el consumo de productos saludables y de producción local.

\subsection{Hipótesis de trabajo}

La instalación de una planta para la elaboración de Dip a base de quinua cocida es factible, pues existe una creciente demanda de productos saludables; además se cuenta con la tecnología adecuada y es económicamente viable.

\subsection{Marco referencial de la investigación}

Se han revisado fuentes de información que sirven como referencia al presente estudio. A continuación, se detalla los datos más relevantes.

- Lira Sumaria, C. (2010). Estudio de prefactibilidad para la instalación de una empresa procesadora de pasta de alcachofa (trabajo de investigación para optar el título profesional de Ingeniero Industrial). Universidad de Lima.

El procesamiento de la pasta de alcachofa es muy similar al del presente plan de investigación, siendo un poco más simple por el uso de un solo ingrediente. $\mathrm{Su}$ presentación es en envases de vidrio de 300 gr. y el plan de comercialización está dirigido al mercado americano. El proceso se explica muy brevemente y no contempla detalles como el líquido de gobierno, temperatura, presión ni $\mathrm{pH}$ como variables.

- Agurto, A., Bendezú, J., Del Pozo, M. y Díaz, M. (2015). Plan de Negocio: "Producción y Comercialización de Salsas y Tapenades Orgánicos" 
(trabajo de investigación para optar el título profesional de Máster en Administración). ESAN.

El producto en la tesis mencionada incluye también insumos con gran valor nutricional, pero en formato de pasta, y no presenta la textura de los ingredientes; valor que se considera tiene gran apreciación por el consumidor. Un punto importante de este estudio es que se busca el desarrollo del mercado nacional, específicamente el sector A-B y teniendo como distribución final a los supermercados y tiendas especializadas.

- Francia Simauchi, F. (2015). Estudio de prefactibilidad para la instalación de una planta productora de salsa pesto instantánea (trabajo de investigación para optar el título profesional de Ingeniero Industrial). Universidad de Lima.

Este estudio utiliza como insumo básico a hortalizas (albahaca y espinaca), además de ingredientes similares para la mezcla y conservación. El producto final es una salsa homogénea en presentación de doypack de 300 gr y con preservantes. En cambio, el nuevo producto plantea poder sentir la textura de cada uno de sus ingredientes, entre ellos la quinua y los vegetales verdes, y usará preservantes naturales como el limón y aceites. Se tomará como referencia los costos de insumos, maquinaria e inversión total.

- Bojanic, A. (2011). La quinua, cultivo milenario para contribuir a la seguridad alimentaria mundial. Recuperado del sitio de internet de la Organización de las Naciones Unidas para la Alimentación y Agricultura: http://www.fao.org/docrep/017/aq287s/aq287s.pdf

Presenta la oportunidad de la quinua como alimento para los países con difícil acceso a fuentes de proteínas o donde existen problemas con la producción; resaltando sus propiedades nutritivas y su adaptabilidad a las diferentes condiciones climáticas y suelos. Menciona a Perú como principal productor y su expansión a países de Europa e indica que hay nuevos procesos de producción que permiten obtener aceites, concentrados, colorantes y más derivados a partir de quinua que pueden ser usados para las industrias química, cosmética y farmacéutica. 


\subsection{Marco conceptual}

A nivel mundial, uno de cada 5 adultos es obeso y cerca de uno de cada seis niños tiene sobrepeso o es obeso (OECD, 2017). En Latinoamérica, alrededor de 360 millones de personas tienen un peso mayor al recomendado (FAO, 2017); equivalente a un 58\% de la población total de la región. Por su parte, Perú es el tercer país con mayor obesidad en Latinoamérica luego de México y Chile (Perú 21, 2017).

Figura 1.1.

Población mayor a 15 años con obesidad
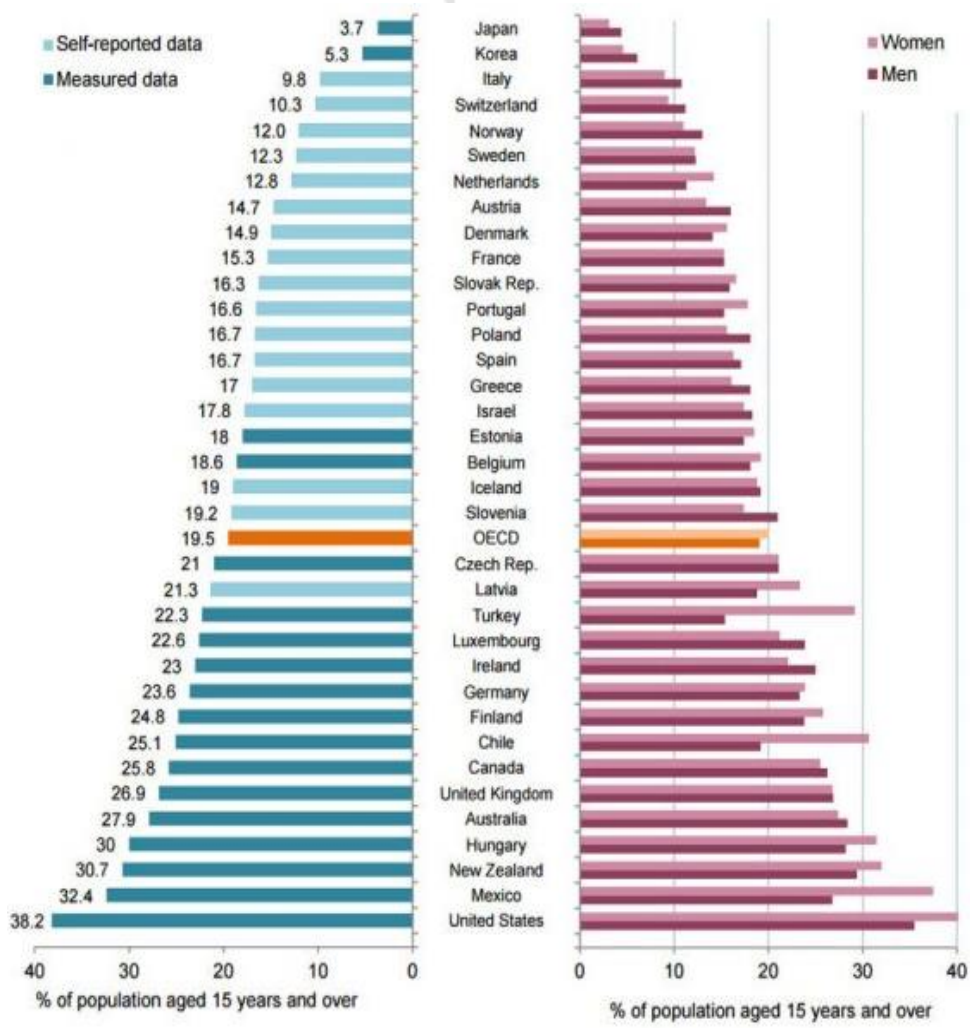

Fuente: Obesity Update (2017)

En ese sentido, los gobiernos de muchos países, a raíz de una invitación de la OMS en el 2016, han desarrollado diversas políticas para combatir la obesidad: leyes de rotulación de alimentos, campañas de consumo saludable, entre otros. Los consumidores no han sido la excepción; pues, ahora son muy activos frente a la decisión de compra de alimentos. Además, búsquedas relacionadas a "comida saludable" se duplicaron entre octubre del 2013 y 2015 (Think with Google, 2016). 
Figura 1.2.

Tendencias del consumidor latino
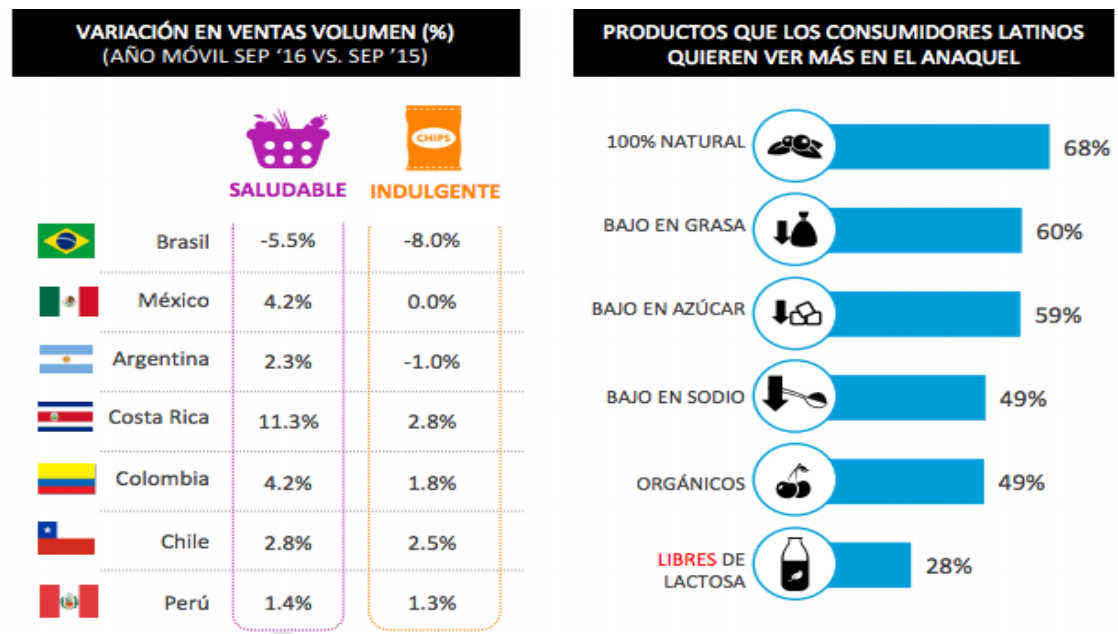

Fuente: Nielsen (2017)

Casi un $100 \%$ de los usuarios de Internet en Perú, Chile y México se conecta al menos una vez por semana para conocer más sobre un tema en particular (Kantar TNS, 2015).

Figura 1.3.

Búsquedas relacionadas a alimentación saludable

\section{Los hispanoamericanos demuestran un interés sostenido} en una alimentación sana.

Interés en búsquedas relacionadas a los términos "dieta saludable"
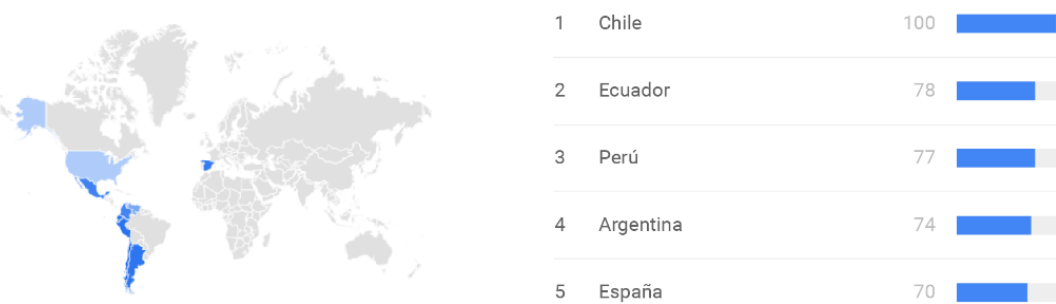

Fuente: Kantar TNS (2015)

Se confirma el auge del fenómeno: en América Latina, el 17\% de la canasta familiar corresponde a productos saludables, con países como Brasil, Chile y México creciendo a una tasa superior al 8\% anual en esa categoría. En Argentina, 7 de cada 10 personas reconocen un "alto nivel de preocupación" por su salud y bienestar, con un $31 \%$ 
poniendo especial énfasis en la alimentación. Se trata de una tendencia global con impacto en toda la región que involucra "modificar hábitos alimenticios", con familias de ingresos elevados y medios, así como parejas con pocos hijos y alto nivel educativo encabezando la tendencia (Kantar TNS, 2015).

La quinua ofrece múltiples beneficios a la salud, donde resalta el gran aporte de fibra, proteínas y mayor presencia de vitaminas y minerales frente a otros cereales. Además, es un alimento libre de gluten por lo que su consumo es apto para las personas intolerantes.

Tabla 1.1.

Contenido Mineral de la Quinua y otros alimentos(mg/100g)

\begin{tabular}{ccccc}
\hline Mineral/alimento & Quinua & Maíz & Arroz & Trigo \\
\hline Calcio & 148.7 & 17.1 & 6.9 & 50.3 \\
Hierro & 13.2 & 2.1 & 0.7 & 3.8 \\
Magnesio & 249.6 & 137.1 & 73.5 & 169.4 \\
Fósforo & 383.7 & 292.6 & 137.8 & 467.7 \\
Potasio & 926.7 & 377.1 & 118.3 & 578.3 \\
Zinc & 4.4 & 2.9 & 0.6 & 4.7 \\
\hline
\end{tabular}

Fuente: Koziol (1992)

Elaboración propia

La búsqueda de una alimentación saludable y mayor aprobación hacia productos locales, se ve reflejado en el aumento del consumo per cápita de quinua por parte del consumidor peruano en los últimos años, llegando incluso a duplicar la cantidad en el año 2014

Tabla 1.2.

Consumo per cápita de la quinua

\begin{tabular}{cccc}
\hline Año & DIA & Población & CPC \\
\hline 2010 & 36,358 & $29,461,933$ & 1.23 \\
2011 & 33,613 & $29,797,694$ & 1.13 \\
2012 & 33,810 & $30,135,875$ & 1.12 \\
2013 & 33,826 & $30,475,144$ & 1.11 \\
2014 & 78,120 & $30,814,175$ & 2.54 \\
2015 & 78,031 & $31,151,643$ & 2.50 \\
\hline
\end{tabular}

Fuente: MINAGRI (2016)

Elaboración propia 
El proyecto busca ofrecer un producto diferente a los que se encuentran comúnmente en los supermercados, combinando insumos de primera calidad con excelentes beneficios para la salud y a un precio competitivo. Se promoverá el consumo de quinua a través de campañas publicitarias con el fin de desarrollar el potencial de este grano, que aún tiene un consumo per cápita muy bajo en el país y que en su mayoría los productores utilizan para autoconsumo. 


\section{CAPÍTULO II: ESTUDIO DE MERCADO}

\subsection{Aspectos generales del estudio de mercado}

\subsubsection{Definición comercial del producto}

El producto desarrollado en el presente proyecto es un dip a base de quinua y vegetales verdes: espárrago, brócoli y albahaca en un doypack de $180 \mathrm{~g}$. A continuación, se definirá el producto a través de los tres niveles de marketing.

\section{Niveles del Producto:}

\section{- Producto Básico}

El producto básico es una salsa a base de quinua cocida y vegetales verdes:

(i) espárragos, (ii) brócoli, y (iii) albahaca, conocido como dip, utilizado como aperitivo saludable. Tiene como propósito satisfacer la necesidad de consumidores muy cuidadosos de su alimentación al ofrecer un producto con alto valor nutricional, vegano y de consumo familiar y social.

\section{- Producto Real}

El dip se encontrará en una presentación de 180 g. (con la finalidad que sea consumido en una sola oportunidad) dentro un envase doypack, que contará con la información requerida por ley, que incluye: nombre del producto, país de fabricación, fecha de fabricación y vencimiento, condiciones de conservación, contenido neto, y nombre, dirección y RUC de la empresa. Adicionalmente, se mostrará algunas sugerencias para su consumo, el cual puede ser como acompañamiento de ensaladas, con galletas, tostadas y diversos piqueos.

El código CIIU correspondiente es: 1030 Elaboración y conservación de frutas, legumbres y hortalizas. 
Tabla 2.1.

Información nutricional por porción

\begin{tabular}{lc}
\hline \multicolumn{2}{c}{ Información Nutricional } \\
\hline \multicolumn{2}{c}{ Contenido neto 180g (4 porciones) } \\
\hline \multicolumn{2}{c}{ Cantidad por porción: $\mathbf{4 5 g}$} \\
\hline Calorías & $60.4 \mathrm{kcal}$ \\
Proteínas & $1.52 \mathrm{~g}$ \\
Carbohidratos totales & $4.13 \mathrm{~g}$ \\
Fibra Alimentaria & $1.38 \mathrm{~g}$ \\
Grasas totales & $4.79 \mathrm{~g}$ \\
Grasas Saturadas & $0.45 \mathrm{~g}$ \\
Grasas Trans & $0 \mathrm{~g}$ \\
Colesterol & $0 \mathrm{mg}$ \\
Calcio & $26.70 \mathrm{mg}$ \\
Fósforo & $25.84 \mathrm{mg}$ \\
Hierro & $0.58 \mathrm{mg}$ \\
\hline Fuente: Instituto Nacional de Salud (2017)
\end{tabular}

Los cálculos a detalle del contenido nutricional se pueden revisar en el anexo II.

\section{- Producto Aumentado}

Se contará con una línea telefónica y página web de la empresa a través de las cuales se atenderán consultas, reclamos y quejas. Adicional a la información impresa en el doypack, se compartirá con mayor detalle los ingredientes, beneficios, lugares de compra, recetas y publicidad.

\subsubsection{Principales características del producto}

\subsubsection{Usos y características del producto}

El producto será usado para la alimentación de personas que gusten de un piqueo o acompañamiento saludable y ofrezca una experiencia diferente al ser un producto Premium.

Características principales:

El dip o salsa, tendrá un color verde claro por los vegetales usados en su fabricación y será de consistencia uniforme gracias a la quinua. Además, contará con una mezcla de sabores agradables con predominación del espárrago y el aceite de oliva. 
Se buscará el equilibrio perfecto entre sus ingredientes, teniendo como resultado una mezcla homogénea y sin grumos.

El producto no usará conservantes y tendrá una durabilidad de 1 año mientras se mantenga cerrado y en buenas condiciones de almacenamiento; una vez abierto se deberá mantener refrigerado y tendrá una duración máxima de 7 días.

\subsubsection{Bienes sustitutos y complementarios}

Los productos sustitutos serán aquellos que tengan preparación untable y se orienten al consumo social principalmente. Con estas consideraciones la principal competencia serían los dips y tapenades de ingredientes vegetales con y sin quinua; y con menor medida estarían los quesos crema de diferentes sabores y patés, los cuales no cumplen con la característica de ser un producto vegano, pero si podría ser reemplazable en una posible compra.

Un complemento para el dip podría ser cualquier alimento, puede ser usado inclusive como acompañamiento en el almuerzo; sin embargo, los principales a considerar serían las tostadas, galletas, ensaladas, papas cocktail y piqueos en general.

\subsubsection{Determinación del área geográfica que abarcará el estudio}

El estudio abarcará el análisis principal de dos áreas geográficas: el área de comercialización del producto y el área para la ubicación de la planta, la cual incluye el área de producción de la materia prima como uno de sus factores a evaluar.

Para el área de comercialización del producto se evaluará a Lima Metropolitana debido a que concentra gran parte de la población del Perú, incluyendo a la mayoría del sector socio-económico A-B, que serían las personas dispuestas a pagar por el producto. En el futuro, dependiendo de la acogida del producto en la ciudad de Lima se buscará incursionar en provincias que concentren los mayores ingresos y con el público objetivo.

En cuanto al área de ubicación de la planta, se evaluarán varios factores que permitan una elección óptima que equilibre las distancias entre la producción y la comercialización. 


\subsubsection{Análisis del sector}

El sector de productos gourmet viene teniendo un crecimiento importante en los últimos años debido a que los clientes están en la búsqueda de productos de fácil consumo y que aporten beneficios a la salud.

Para hacer frente a esta creciente demanda de productos gourmet se han creado ecoferias, tiendas especializadas o delicatesen, sistemas de venta en línea y entregas a domicilio; a esto se suman los canales masivos como supermercados y tiendas de conveniencia en los grifos que, con su expansión, permiten que el consumidor tenga mayor facilidad para adquirirlos, generándose un mayor consumo y un dinamismo sin precedente.

Una de las principales comunidades orgánicas en el país es Lima Orgánica, la cual presenta alternativas saludables en distintas categorías como alimentación (restaurantes, tiendas/markets y productos), hogar, belleza \& cuidado personal, deporte \& salud y ropa \& accesorios, agrupadas en la web y redes sociales. Para abril del 2017 cuentan con 60,000 seguidores en Facebook, tres veces el mismo indicador a la misma fecha del año anterior.

Por otro lado, se está dando prioridad a productos elaborados con insumos nacionales, siguiendo con la ideología de la campaña Marca Perú ${ }^{1}$ que busca promover el consumo de productos hechos en el país. También, existe una notable preferencia hacia los productos orgánicos, naturales, libres de gluten e innovadoras combinaciones de gran sabor que de igual manera aporten beneficios saludables.

\subsubsection{Determinación de la metodología que se empleará en la investigación de mercado}

Para poder determinar el mercado objetivo, perfil y plan de marketing a seguir se requiere inicialmente del desarrollo de una encuesta, de la cual se pueda obtener las preferencias, hábitos y frecuencia de consumo, esperando la aceptación del producto. Al ser una encuesta virtual, esta técnica cuantitativa permite llegar a un mayor número de personas

\footnotetext{
${ }^{1}$ Marca Perú: Campaña realizada en el año 2012
} 
en menor tiempo y costo. Para el análisis de los resultados obtenidos se requiere de histogramas y gráficos de dispersión.

Adicionalmente, se van a realizar pruebas de campo para determinar los sabores y la compatibilidad de los ingredientes en el producto final.

\subsection{Análisis de la demanda}

\subsubsection{Demanda histórica}

\subsubsection{Importaciones/exportaciones}

La información de comercio exterior ha sido revisada en diversas bases de datos como Cobus Group, Veritrade, Datatrade y Euromonitor, teniendo como resultado una búsqueda no exitosa debido a que este producto y similares no cuentan con data histórica por ser relativamente nuevos e innovadores.

\subsubsection{Producción Nacional}

Al igual que en el punto anterior, la información cuantitativa acerca de la producción nacional de dips es escasa. Sin embargo, se cuenta con algunos datos relevantes que permiten concebir una idea de lo que está pasando con los productores y el mercado nacional.

La riqueza de recursos naturales en el Perú permite ofrecer al consumidor un producto único a partir de innovadoras combinaciones de ingredientes con gran valor agregado.

Existe una tendencia por el consumo de alimentos más saludables y con la menor alteración durante el proceso productivo. El consumidor ha cambiado sus preferencias y está dispuesto a pagar más por un producto de calidad.

Con miras a la exportación de alimentos especializados, los mercados con una cultura de consumo más sofisticada como Norteamérica y Europa, constituyen una gran oportunidad de demanda.

La producción de dips y tapenades en el Perú está comprendida principalmente por las grandes Agroindustrias que manejan su portafolio de productos como Danper, Virú, El Olivar, entre otros, quienes se encargan de distribuir bajo su propia marca; y 
producir para terceros, los cuales están conformados por supermercados, tiendas especializadas y empresas que encargan su producción.

\subsubsection{Demanda Interna Aparente (DIA)}

La DIA resulta de sumar la producción nacional más las importaciones y restando las cantidades exportadas en un año calendario, e indica la cantidad disponible aparentemente para el consumo interno. Sin la posibilidad de acceso a la información necesaria, no será posible su cálculo. Por dicha razón, la demanda se calculará a través de fuentes primarias por medio de la aplicación de una encuesta.

\subsubsection{Demanda potencial}

\subsubsection{Patrones de consumo}

Incremento poblacional

La población en el Perú ha tenido un crecimiento constante con una pequeña desaceleración como se puede revisar en el cuadro siguiente.

Tabla 2.2.

Incremento de la población en el Perú

\begin{tabular}{cccccc}
\hline Año & $\mathbf{2 0 1 2}$ & $\mathbf{2 0 1 3}$ & $\mathbf{2 0 1 4}$ & $\mathbf{2 0 1 5}$ & $\mathbf{2 0 1 6}$ \\
\hline Población & $30,135,875$ & $30,475,144$ & $30,814,175$ & $31,151,643$ & $31,488,625$ \\
Incremento & - & $1.13 \%$ & $1.11 \%$ & $1.10 \%$ & $1.08 \%$ \\
\hline
\end{tabular}

Fuente: INEI (2017)

Se estima que al 2021, año del bicentenario de la independencia, se supere los 33 millones de peruanos, teniendo así un crecimiento anual de 333 mil nuevas personas.

\section{Consumo per cápita}

El consumo per cápita se intensifica por cinco razones principales: la búsqueda de una alimentación saludable, el aumento de poder adquisitivo en los últimos años, mayor presencia de lugares de venta (supermercados, tiendas especializadas, grifos y bodegas), mejoras en las condiciones de biocomercio y apreciación de la gastronomía peruana e insumos. 


\section{$\underline{\text { Estacionalidad }}$}

El producto no presenta estacionalidad, es decir no pasa por un proceso de variación cíclica predecible según la época del año, por esta razón la venta será constante durante todos los meses.

\subsubsection{Determinación de la demanda potencial}

Los dips y tapenades son considerados productos nuevos en Latinoamérica y en el resto del mundo en general; por dicha razón no existen estudios acerca de los consumos en los países de la región.

Como no es posible obtener una demanda potencial en base a los consumos de otro país y relacionarlo con la población peruana, se ha decidido calcular considerando al $100 \%$ de la población de Lima Metropolitana, sin restricciones; además de una intención de compra de $52 \%$ y una intensidad de $73 \%$ obtenido del resultado de las encuestas.

$$
10^{\prime} 012,437 \text { habitantes } * 0.52 * 0.73 * 4 \frac{\text { envases }}{a \tilde{n} o}=15,202,885 \text { envases } / \text { año }
$$

\subsubsection{Demanda mediante fuentes primarias}

\subsubsection{Diseño y Aplicación de Encuestas u otras técnicas}

Se realizó una encuesta a 400 personas de la ciudad de Lima con el objetivo de obtener información acerca de sus preferencias en el consumo de dips y así poder calcular la demanda. El documento con las preguntas se encuentra en el Anexo IV.

Dicho tamaño de muestra se calculó de acuerdo a la fórmula siguiente, donde:

$\mathrm{N}=$ tamaño de la población total

$\mathrm{z}=$ valor obtenido mediante el nivel de confianza (95\%)

e = límite aceptable de error muestral (5\%)

$\mathrm{p}=$ probabilidad de éxito $(50 \%)$

$n=\frac{\frac{\left(z^{2} \times p(1-p)\right)}{e^{2}}}{1+\left(\frac{z^{2} \times p(1-p)}{e^{2} N}\right)}=\frac{\frac{\left(1.96^{2} \times 0.5(1-0.5)\right)}{0.05^{2}}}{1+\left(\frac{1.96^{2} \times 0.5(1-0.5)}{0.05^{2}(10,012,437)}\right)}=385$ 
El número hallado es el mínimo de personas que se debe encuestar para obtener un resultado cercano a la realidad según las condiciones dadas en cuanto a margen de error y nivel de confianza. Para redondear la cifra e incluso tener una mayor aproximación, se decide tener 400 encuestados como número final.

\subsubsection{Determinación de la Demanda}

La demanda se calculará en base a los resultados obtenidos a través de la encuesta y a los datos mostrados a continuación sobre segmentación geográfica y demográfica obtenidos del estudio de Niveles Socioeconómicos 2016 de APEIM. Ver resultados en el anexo V.

Zona 6: Jesús María, Lince, Pueblo Libre, Magdalena, San Miguel.

Zona 7: Miraflores, San Isidro, San Borja, Surco, La Molina.

Total de habitantes: $10^{\prime} 012,437$

Segmentación: $5.31 \%$

Intención: $52 \% \quad$ Intensidad: $73 \%$

Frecuencia: 4 envases/año

Tabla 2.3.

Segmentación del mercado objetivo

\begin{tabular}{ccccc}
\hline NSE & \% Población LM & Zona 6 y 7 & $\mathbf{1 8 - 5 5}$ años & Resultado \\
\hline A & $4.8 \%$ & $70.6 \%$ & $54.0 \%$ & $1.83 \%$ \\
B & $21.7 \%$ & $28.5 \%$ & $56.3 \%$ & $3.48 \%$ \\
& & & Total & $\mathbf{5 . 3 1 \%}$ \\
\hline
\end{tabular}

Fuente: APEIM (2016)

Elaboración propia

De esta manera se procede a multiplicar los factores previamente mencionados:

$$
\begin{gathered}
10^{\prime} 012,437 \text { habitantes } * 0.0531 * 0.52 * 0.73 * 4 \frac{\text { envases }}{a \tilde{n} o} \\
=807,274 \text { envases } / a \tilde{n} o
\end{gathered}
$$

Cada frasco contiene 180 gramos, teniendo como resultado una producción anual de $145,309 \mathrm{~kg}$ de producto.

\subsubsection{Proyección de la Demanda}

El crecimiento poblacional proyectado de Lima Metropolitana a utilizar será tomado como referencia del estudio "Proyecciones poblacionales para Lima Metropolitana a los años horizonte 2018-2021-2025 y 2035 a nivel distrital", elaborado por el Instituto 
Metropolitano de Planificación (IMP), el cual estima que en el año 2020 se superen los 11 millones de habitantes.

Tabla 2.4.

Proyección de la demanda 2018 al 2022

\begin{tabular}{cccc}
\hline Año & Habitantes & $\begin{array}{c}\text { Demanda } \\
\text { (envases) }\end{array}$ & $\begin{array}{c}\text { Demanda } \\
(\mathbf{k g})\end{array}$ \\
\hline 2018 & $10,012,437$ & 807,274 & 145,309 \\
2019 & $10,433,555$ & 854,710 & 153,848 \\
2020 & $10,649,104$ & 904,933 & 162,888 \\
2021 & $10,872,236$ & 958,107 & 172,459 \\
2022 & $11,100,048$ & $1,014,406$ & 182,593 \\
\hline
\end{tabular}

Elaboración propia

\subsubsection{Consideraciones sobre la vida útil del proyecto}

Para efectos del estudio preliminar se considerará una vida útil de 5 años con el objetivo de poder evaluar su rentabilidad; sin embargo, como toda empresa es ideal encontrar la manera de superar ese horizonte de tiempo y conseguir ser sostenible con el paso de los años.

Asimismo, para poder realizar un análisis más detallado solo se considera la fabricación de un solo producto, lo cual en el mundo competitivo actual no es muy factible debido al cambio constante de las preferencias de los consumidores. Por esta razón, se debe evaluar la alternativa de ampliar el portafolio de productos, incluyendo similares en base a alcachofa, aceituna, pimiento y otros vegetales con beneficios superiores. Además, de ser necesario y conveniente, se ofrecerá el servicio de maquila a terceros.

\subsection{Análisis de la oferta}

\subsubsection{Empresas productoras, importadoras y comercializadoras}

\section{Danper - Casa Verde}

Empresa de capitales daneses y peruanos localizada en La Libertad, con más de 20 años de experiencia en la agroindustria, cuenta con más de 6,500 trabajadores y 7,000 hectáreas de cultivos a lo largo del Perú. La línea de sus productos gourmet y conservas se distribuye bajo la marca propia Casa Verde. 
Figura 2.4.

Logo de Danper y Casa Verde
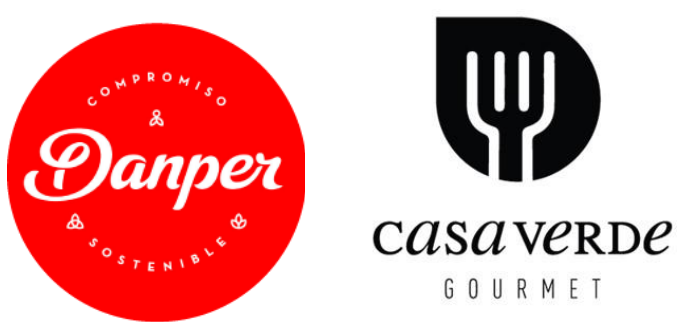

Fuente: Danper (2018)

\section{Calé}

Es la marca gourmet de Agroindustrias Nobex, cuyo negocio principal son las aceitunas, siendo los primeros exportadores del Perú. Su propuesta va enfocada al ama de casa para facilitar la preparación de piqueos o recetas.

Figura 2.5.

Logo de Calé

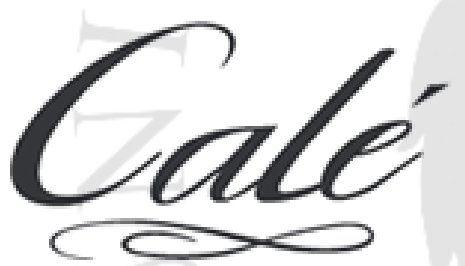

Fuente: Agroindustrias Nobex (2018)

\section{Valle Fértil}

Es una empresa peruana que inició sus operaciones en el año 1999 y atiende al mercado local e internacional. Cuenta con un amplio portafolio que incluye aliños, dips, aceite de oliva, conservas y salsas; dicha presencia se ve reflejada con la mayor participación de mercado en alimentos gourmet.

Figura 2.6.

Logo de Valle Fértil

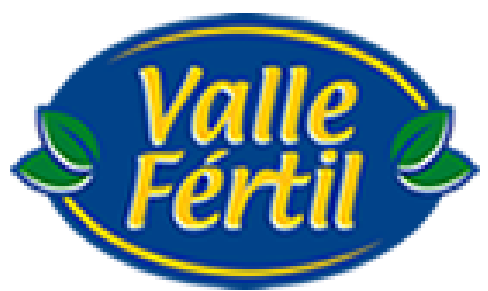

Fuente: Valle Fértil (2018) 


\section{Pachamama Gourmet}

Empresa peruana establecida en el año 2007 con un amplio portafolio de productos elaborados a partir de insumos nativos de las tres regiones del país. Su marca Native \& Natural comprende una variedad de tapenades, salsas, vinagretas, mousses y demás, que han sido fabricados sin preservantes y saborizantes artificiales.

Figura 2.7.

Logo de Pachamama Gourmet y Native \& Natural
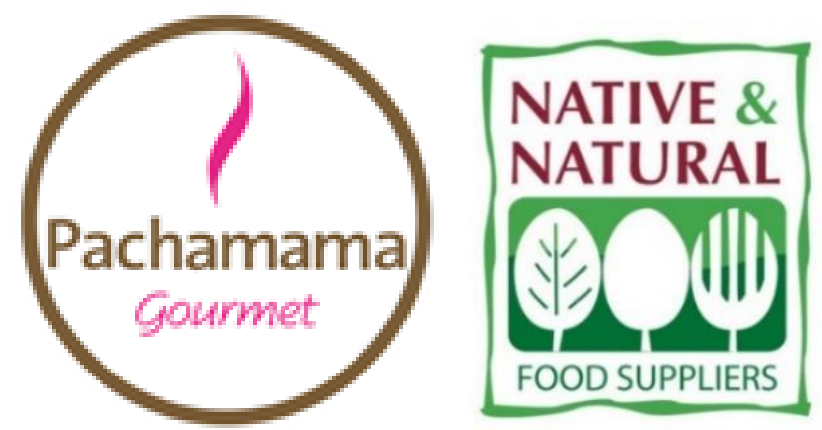

Fuente: Pachamama Gourmet (2018)

\section{Sabores Ayni}

Es una nueva propuesta que comenzó a finales del 2015 ofreciendo productos en base a insumos $100 \%$ peruanos y naturales. Se encuentra en tiendas especializadas y en venta online.

Figura 2.8.

Logo de Sabores Ayni

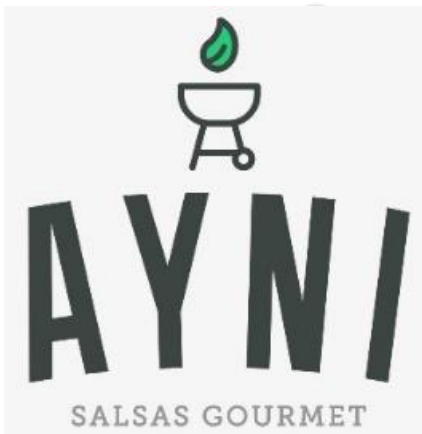

Fuente: Lima Orgánica (2018) 


\section{Bell's}

Es la marca propia de Plaza Vea, incluye muchas categorías, dentro de ellas dips y conservas. Uno de sus principales fabricantes de tapenades es la empresa Productos Encurtidos SAC.

Figura 2.9.

Logo de Bell's

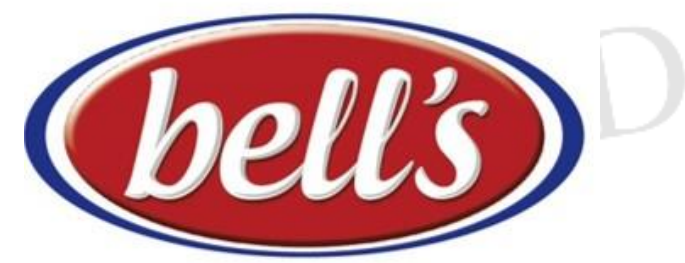

Fuente: Supermercados Peruanos (2018)

\section{Tottus}

Es la marca del supermercado del mismo nombre. Ofrece mayor variedad de conservas en lata y dips, dichos productos son maquilados por empresas del medio local, entre ellos DANPER.

Figura 2.10.

Logo de Tottus

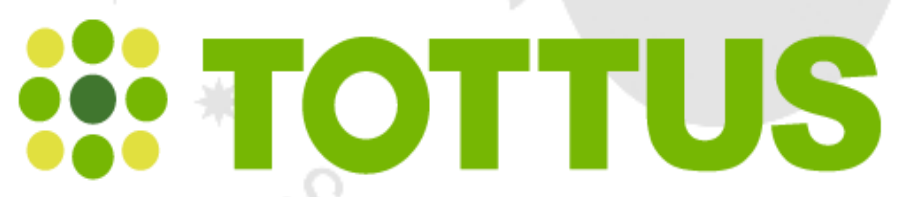

Fuente: Hipermercados Tottus (2018)

\subsubsection{Competidores actuales y potenciales}

La competencia en el mercado local está conformada por empresas peruanas que han encontrado la oportunidad de proveer alimentos naturales a un consumidor más sofisticado. Se consideran como competidores directos a los Dips y Tapenades de uno o más ingredientes. 
Tabla 2.5.

Productos de la competencia

\begin{tabular}{|c|c|c|}
\hline Empresa & Productos & $\begin{array}{c}\text { Peso neto } \\
\text { (gramos) }\end{array}$ \\
\hline \multirow{8}{*}{ Casa Verde } & Dip de Pimiento y Quinua & 235 \\
\hline & Dip de Alcachofa y Quinua & 235 \\
\hline & Pesto Genovés y Quinua & 235 \\
\hline & Pesto de Espárrago & 180 \\
\hline & Pesto de Alcachofa & 180 \\
\hline & Tapenade Pimiento & 180 \\
\hline & Tapenade Espárrago & 180 \\
\hline & Tapenade Alcachofa & 180 \\
\hline \multirow{4}{*}{ Calé } & Tapenade Aceitunas Agridulce & 185 \\
\hline & Tapenade Aceitunas al Ají & 185 \\
\hline & Tapenade Aceituna y Alcachofa & 185 \\
\hline & Tapenade Alcachofa a la Italiana & 185 \\
\hline \multirow[b]{4}{*}{ Valle Fértil } & \multirow{2}{*}{ Hummus Dip Tradicional } & 240 \\
\hline & & 460 \\
\hline & Hummus Dip Pimiento & $\begin{array}{l}240 \\
460\end{array}$ \\
\hline & \multirow[b]{2}{*}{ Hummus Dip Alcachofa } & $\begin{array}{l}400 \\
240\end{array}$ \\
\hline mased & & 460 \\
\hline & \multirow{2}{*}{ Hummus Dip Ajo } & 240 \\
\hline & & 460 \\
\hline 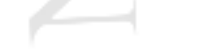 & Tapenade de aceitunas negras con pasas y castañas & 196 \\
\hline \multirow{3}{*}{ El Olivar } & Tapenade de aceitunas negras con castañas y hierbas aromáticas & 196 \\
\hline & Tapenade de aceitunas verdes con pimiento y castaña & 196 \\
\hline & Tapenade picante de aceitunas verdes con rocoto, castañas y pasas & 196 \\
\hline Sabores Ayni & Dip de Quinua con Ají Limo & 170 \\
\hline \multirow{2}{*}{$\begin{array}{c}\text { Native \& } \\
\text { Natural }\end{array}$} & Tapenade Alcachofas y Palmitos & 210 \\
\hline & Tapenade Verduras Grilladas & 210 \\
\hline Bell's & Tapenade Mixtura picante & 300 \\
\hline \multirow{2}{*}{ Tottus } & Tapenade Espárrago Verde & 195 \\
\hline & Tapenade Alcachofa & 195 \\
\hline
\end{tabular}

Fuente: Supermercados (2017)

Elaboración propia

Los competidores potenciales son las pequeñas marcas que están buscando posicionarse como un producto altamente gourmet y premium destinado a consumidores selectos que tienen la posibilidad de asumir el elevado precio. Las marcas Sabores Ayni y Native \& Natural aparecen como nuevos participantes de este innovador mercado y cada vez son más las propuestas que se suman a esta oferta. 
Los productos se comercializan a través de supermercados y tiendas especializadas o tiendas gourmet; que se dedican a la venta de productos Premium y orgánicos para un sector puntual de la población.

\subsection{Determinación de la Demanda para el proyecto}

\subsubsection{Segmentación del mercado}

Segmentación Geográfica: Para el estudio se consideró sólo a la región de Lima Metropolitana debido a que es donde se concentra la mayoría de la población objetivo y cuenta con una amplia población de 10’012,437 habitantes según proyecciones de INEI.

Segmentación Demográfica: Destinado a personas de clase económica A y B que buscan una alternativa saludable como piqueo y/o acompañamiento. Esta selección considera a la población con mayores ingresos, siendo la minoría el NSE A con un $4.8 \%$ y el B con $21.7 \%$, teniendo en total el $26.5 \%$ de Lima Metropolitana. Del mismo modo, este público objetivo cuenta con un alto presupuesto para destinar a la compra de productos gourmet.

Figura 2.11.

Distribución de personas según NSE 2016 - Lima Metropolitana

\begin{tabular}{|c|c|c|c|c|c|c|}
\hline \multirow{3}{*}{ NSE A } & \multicolumn{2}{|c|}{ № PERSONAS $10^{\prime} 012,437^{*}$} & \multirow{3}{*}{$\begin{array}{l}\text { NSE } \\
\text { A }\end{array}$} & \multirow{2}{*}{$\begin{array}{c}\text { Estrato } \\
\text { A1 }\end{array}$} & \multicolumn{2}{|c|}{ Porcentaje } \\
\hline & \multirow{2}{*}{4.8} & & & & 0.7 & \multirow{2}{*}{4.8} \\
\hline & & & & A2 & 4.1 & \\
\hline \multirow{2}{*}{ NSE B } & \multirow{2}{*}{21.7} & \multirow{2}{*}{$68.9 \%$} & \multirow{2}{*}{ B } & B1 & 8.3 & \multirow{2}{*}{21.7} \\
\hline & & & & B2 & 13.4 & \\
\hline \multirow{2}{*}{ NSE C } & \multirow{2}{*}{42.4} & & \multirow{2}{*}{ c } & C1 & 27.9 & \multirow{2}{*}{42.4} \\
\hline & & & & C2 & 14.5 & \\
\hline NSE D & 23.8 & & D & D & 23.8 & 23.8 \\
\hline NSE E & 7.3 & & E & E & 7.3 & 7.3 \\
\hline
\end{tabular}

Fuente: APEIM (2016)

\subsubsection{Selección de mercado meta}

De acuerdo con un estudio sobre preocupaciones y consumo, las personas que se preocupan por su alimentación se caracterizan por ser de niveles socioeconómicos altos y medios (Kantar, 2016). De esta manera se concluye que el mercado meta son los 
habitantes de Lima Metropolitana pertenecientes a los niveles socioeconómicos A y B; es decir, en total son 10’012,437 habitantes quienes representan el 26.5\% (APEIM, 2016).

\subsubsection{Demanda Específica para el Proyecto}

Buscando ser más objetivos en el cálculo de la demanda específica para el proyecto se han considerado otros factores como edad (mayores de 18 años) y lugar de vivienda (zonas 6 y 7 de Lima Metropolitana), detallados en el punto 2.2.3.2. Determinación de la Demanda.

\subsection{Definición de la Estrategia de Comercialización}

\subsubsection{Políticas de comercialización y distribución}

El mercado del dip es nuevo y se encuentra en desarrollo, como se mencionó anteriormente este producto está dirigido al nivel socioeconómico A y B; por lo que es sumamente importante conocer los lugares con mayor frecuencia de visita y compra del público objetivo.

Inicialmente, se utilizará como principal canal de distribución los supermercados; con la ayuda de la encuesta realizada, se determinó que son los lugares preferidos (68\%). Entre Enero y Abril del 2017, los supermercados producto del Fenómeno de El Niño crecieron en valor de precios y volumen mayor que el canal tradicional después de mucho tiempo. El consumo en supermercados creció 8\%; mientras un $0.1 \%$ en bodegas y mercados. Esta tendencia se mantendría hacia futuro. Sin embargo, el canal tradicional continuaría líder con un 71\% de las ventas en canales de compra (Perú Retail, 2017).

Además, Perú lidera el desarrollo del sector retail en América Latina; seguido por Colombia, República Dominicana, Brasil y Paraguay (ATKearney, 2016).

Se debe tener claro que este producto no es de gran consumo y requiere de un empuje especial en el punto de venta. En ese sentido, se planea contar con impulsadoras en piso, quienes a través de degustaciones intentarán dar a conocer el sabor diferenciado frente a la competencia y sustitutos. Es a través de esta venta secundaria, como se busca posicionar la marca en el mercado.

Adicionalmente, se utilizará como canal alternativo las tiendas especializadas gourmet. En este tipo de tiendas se encuentran las marcas de la competencia; sin embargo, 
generan mayor valor al producto al dedicar el tiempo necesario para realizar la venta e informar al cliente de los principales beneficios de los insumos.

En cuanto a la política de comercialización, se manejarán márgenes diferenciados para cada canal. Un autoservicio es un canal de consumo masivo y el producto no es parte de la canasta familiar, por lo que se necesitará de un precio atractivo que permita al canal obtener un buen margen por la venta; para este tipo de acciones se necesitará negociar volúmenes y notas de crédito. Por otro lado, una tienda especializada mantendrá un volumen de venta muy por debajo de lo esperado en el canal moderno; pero el precio podrá equilibrar la utilidad.

\subsubsection{Publicidad y promoción}

El plan de publicidad y promoción considera una inversión realmente importante como gasto de ventas. El objetivo debe ser impulsar la marca, incrementar e incentivar el consumo del producto, facilitando el comercio del mismo.

Para la publicidad se utilizarán las estrategias ATL (Above The Line) y BTL (Below The Line) de acuerdo al objetivo de la campaña. Inicialmente, el objetivo es impulsar la marca y darla a conocer; para esto, se requerirá de medios de comunicación masivos dirigidos al público objetivo como, por ejemplo: avisos de prensa en El Comercio, Gestión, La República y Publimetro. No se planea tener pautas en televisión por el alto costo que representa; sin embargo, si se buscará tener menciones en programas de alta cocina que fomenten el consumo de los alimentos naturales. Además, las revistas serán de gran ayuda como los volantes. Por otro lado, se buscará tener un contacto directo con el cliente final o consumidor a través de activaciones en los puntos de venta con anfitrionas y promociones potentes. Asimismo, las redes sociales serán el principal medio de comunicación de los complementos para el producto. Las alianzas estratégicas serán de vital importancia para poder acelerar el consumo; y por ende, la aceptación. Además de optimizar gastos y acompañar a los aliados con años de experiencia en el mercado.

El merchandising se realizará a través de distintos elementos: se buscará negociar con el canal de venta posiciones preferentes para el producto, señalizadas por material POP como stoppers, vibrines y acompañados de exhibidores temporales. 


\subsubsection{Análisis de precios}

\subsubsection{Tendencia histórica de los precios}

Los precios de los productos similares no han sufrido mayor variación ya que su presencia en el mercado es reciente. Como referencia se tomó información de los supermercados, teniendo como registro alza de precios entre $\mathrm{S} / 0.10$ y S/ 0.50 en los últimos 2 años.

\subsubsection{Precios actuales}

Las marcas ofrecen productos de sabores variados y son vendidos al mismo precio. Por ejemplo: Calé vende Tapenade de 4 variedades: Aceitunas Agridulce, Aceitunas Al Ají, Aceitunas con Alcachofa y Alcachofa a la italiana; todos al mismo precio de S/. 7.25 por un frasco de 185 gr en el supermercado. Por esta razón para el análisis de precios en el siguiente cuadro comparativo, se va a considerar solo una variedad como base.

Tabla 2.6.

Comparativo de precios de la competencia

\begin{tabular}{clccc}
\hline Empresa & \multicolumn{1}{c}{ Producto } & $\begin{array}{c}\text { Peso neto } \\
\text { (gramos) }\end{array}$ & $\begin{array}{c}\text { Precio } \\
\text { real }\end{array}$ & $\begin{array}{c}\text { Precio } \\
\text { por 180g }\end{array}$ \\
\hline Native \& Natural & Tapenade Alcachofas y Palmitos & 210 & $\mathrm{~S} / 19.89$ & $\mathrm{~S} / 17.05$ \\
Sabores Ayni & Dip de Quinua con Ají Limo & 170 & $\mathrm{~S} / 16.00$ & $\mathrm{~S} / 16.94$ \\
Native \& Natural & Tapenade Verduras Grilladas & 210 & $\mathrm{~S} / 15.95$ & $\mathrm{~S} / 13.67$ \\
Valle Fértil & Hummus Dip - variado & 240 & $\mathrm{~S} / 15.50$ & $\mathrm{~S} / 11.63$ \\
Valle Fértil & Hummus Dip - variado & 460 & $\mathrm{~S} / 27.85$ & $\mathrm{~S} / 10.90$ \\
Casa Verde & Pesto de Espárrago & 180 & $\mathrm{~S} / 8.85$ & $\mathrm{~S} / 8.85$ \\
El Olivar & Tapenade de aceitunas - variado & 196 & $\mathrm{~S} / 8.55$ & $\mathrm{~S} / 7.85$ \\
Casa Verde & Tapenade Alcachofa & 180 & $\mathrm{~S} / 7.70$ & $\mathrm{~S} / 7.70$ \\
Casa Verde & Dip de Pimiento y Quinua & 235 & $\mathrm{~S} / 9.50$ & $\mathrm{~S} / 7.28$ \\
Calé & Tapenade Aceituna y Alcachofa & 185 & $\mathrm{~S} / 7.25$ & $\mathrm{~S} / 7.05$ \\
Tottus & Tapenade Espárrago Verde & 195 & $\mathrm{~S} / 5.95$ & $\mathrm{~S} / 5.49$ \\
Tottus & Tapenade Alcachofa & 195 & $\mathrm{~S} / 5.95$ & $\mathrm{~S} / 5.49$ \\
Bell's & Tapenade Mixtura picante & 300 & $\mathrm{~S} / 8.99$ & $\mathrm{~S} / 5.39$ \\
\hline Fuente: Supermercados & & &
\end{tabular}

Fuente: Supermercados (2017)

Luego del análisis de la tendencia y actualidad de precios, se concluyó que el precio de venta al público a través del supermercado sea S/. 7.89 incluido IGV; considerando un margen del $27 \%$ para el canal (margen promedio en la categoría snacks en supermercados) y un $40 \%$ para el productor. 
Cabe resaltar que el precio sugerido es uno intermedio, aproximadamente $47 \%$ sobre el mínimo del mercado. No es un factor crítico al momento de la decisión de compra, pues no se busca posicionar el producto como económico con la finalidad de aumentar la cantidad de ventas.

Tabla 2.7.

Desglose Precio

\begin{tabular}{cc}
\hline Desglose Precio & S/. \\
\hline Costo Unitario Producción & 2.95 \\
Precio de venta al Canal & 4.90 \\
Margen de Contribución & $\mathbf{4 0 \%}$ \\
Precio de venta al Canal & 4.90 \\
Precio de venta al Público & 6.69 \\
Margen del Canal & $\mathbf{2 7 \%}$ \\
Precio de venta al Público & 6.69 \\
IGV & 1.20 \\
Precio de venta al Público inc. IGV & $\mathbf{7 . 8 9}$ \\
\hline
\end{tabular}

Elaboración propia

\subsection{Análisis de Disponibilidad de los insumos principales}

\subsubsection{Características principales de la materia prima}

\section{Quinua}

La quinua, cuyo nombre científico es Chenopodium quinoa, es un grano muy nutritivo proveniente de una planta herbácea que es cultivada principalmente en la Cordillera de los Andes, donde Perú y Bolivia son considerados como los mayores productores del mundo.

La planta tiene un tamaño entre 0.5 y $2 \mathrm{~m}$ de altura, posee un tallo recto que contiene las semillas (granos) de diferentes colores, entre ellos: café, amarillo, rosado, rojo, negro y blanco, el cual es más común y será usado en la fabricación del dip. El rendimiento promedio por hectárea es superior a los $1,500 \mathrm{~kg}$. 
Figura 2.12.

Variedades de plantas de Quinua

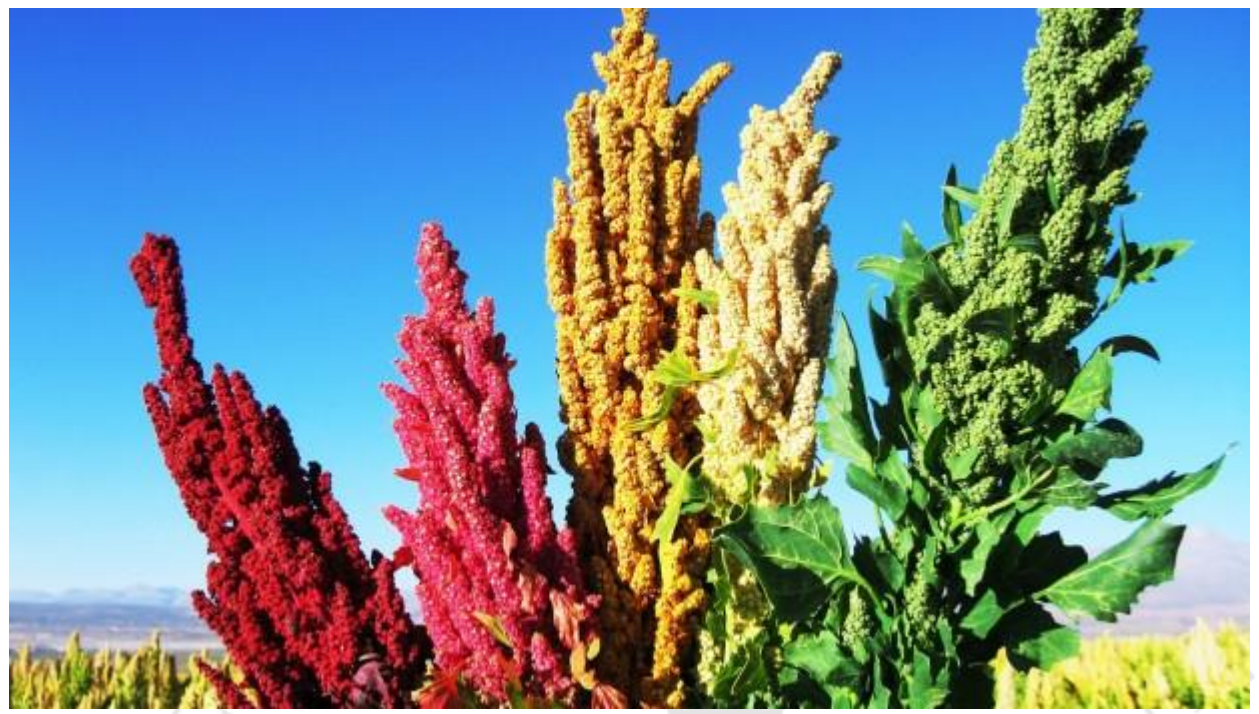

Fuente: Quinua (2017)

Existen más de 100 variedades de Quinua (Instituto Nacional de Innovación Agraria, 2013); el INIA ha puesto a disposición de los productores nacionales 7 variedades que cuentan con mayor rendimiento, calidad y cualidades agroindustriales.

Las regiones con mayor producción de quinua son Puno con $37 \%$ de participación, Arequipa (20\%) y Ayacucho (14\%).

Figura 2.13.

Producción Nacional de Quinua

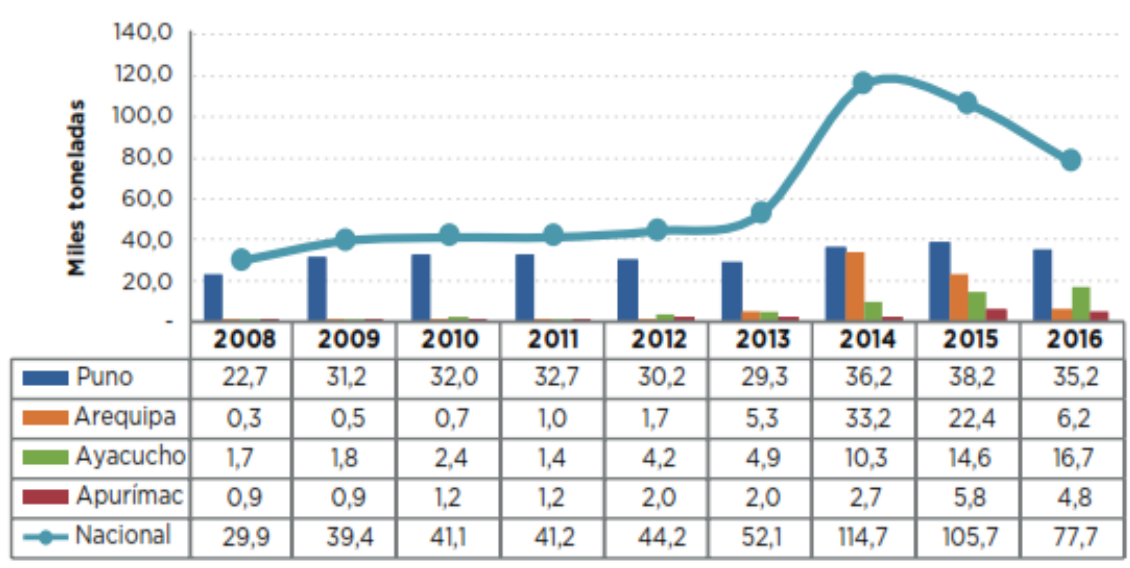

Fuente: Minagri (2017)

La mayor parte de la quinua está compuesta por hidratos de carbono que a su vez están formados por almidón, estos pueden ser consumidos por personas que padecen de 
diabetes ya que poseen una estructura compleja y son de absorción lenta, lo cual no genera picos de glucosa en la sangre.

Su contenido de proteínas es superior al de la mayoría de los cereales, el cual puede oscilar entre 10.4 y $17 \%$, incluso fuentes señalan que puede llegar hasta $22 \%$, según la calidad de la quinua; esto también va ligado a la presencia de 8 aminoácidos esenciales que tienen valores cercanos a lo que necesita la nutrición humana. Por dicha razón, esta organización cumple con un papel activo en la divulgación de los beneficios de la quinua para aumentar su consumo mundial y proteger a países con altos índices de desnutrición y pobreza (FAO, 2011)

La quinua es buena fuente de vitaminas E, B2 y B9, y minerales como Potasio, Calcio, Hierro y Magnesio; en ambas medidas es superior a otros cereales como trigo y arroz.

Tabla 2.8.

Composición Nutricional de la Quinua

\begin{tabular}{cc}
\hline Elemento & Valor \\
\hline Agua & $12.7 \%$ \\
Proteínas & $13.8 \%$ \\
Grasas & $5.0 \%$ \\
Carbohidratos & $59.7 \%$ \\
Ceniza & $3.4 \%$ \\
Celulosa & $4.4 \%$ \\
Fibra & $4.1 \%$ \\
\hline
\end{tabular}

Fuente: InkaNatural (2013)

Una de sus principales ventajas es que es considerado un pseudocereal, lo cual aumenta sus posibilidades de consumo.

\section{Espárrago}

El espárrago es un brote de la Esparraguera que pertenece a la familia de las Liliáceas.

Los espárragos contienen $95 \%$ de agua y son considerados dentro de los 20 mejores alimentos de la puntuación ANDI (índice de densidad de nutrientes agregados), donde se mide la relación entre la presencia de nutrientes y el aporte calórico. Esto se debe a que son fuente importante de fibra y ácido fólico (vitamina B9), y en menor proporción otras vitaminas de los complejos A, B, C, E y K. 
Las vitaminas B ayudan a mantener un alto nivel energético, lo cual resulta beneficioso para la salud física y mental. La Vitamina C colabora con la función antioxidante y a prevenir el cáncer y trastornos oculares. Además, funciona como un diurético natural ayudando a controlar la presión y el sistema urinario.

Durante el 2017, Perú produjo 390 mil toneladas de espárragos, un crecimiento de 3.3\% frente al año pasado. La región de Ica representa el 45\% de la producción, La Libertad concentra el 43\%, mientras que Lima y regiones del sur representan la producción restante (Servicio Nacional de Sanidad Agraria, 2017).

Las dos formas más comunes de comercialización son en conserva y frescos, estos últimos deben seguir una cadena de frío y las mayores condiciones de inocuidad para mantenerse en buen estado.

Figura 2.14.

Espárragos

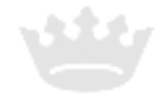

\section{Espárragos}

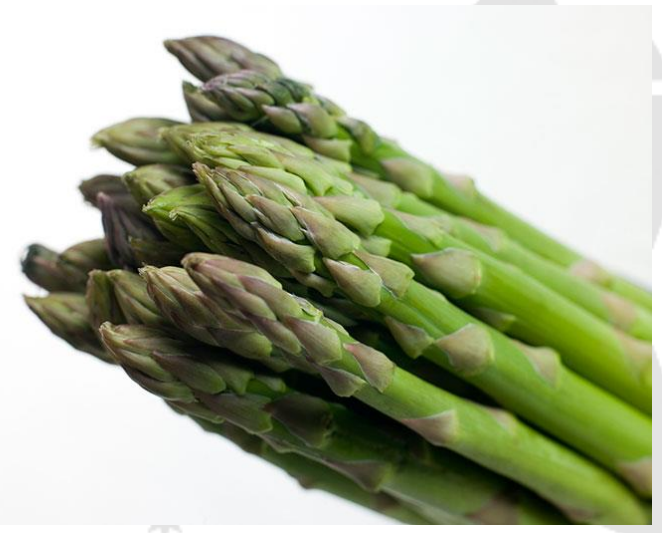

Fuente: Biotrendies (2016)

\section{Brócoli}

El brócoli es un vegetal perteneciente a la familia de las brasicáceas, donde también pertenece la col, coliflor, el nabo y el rábano.

Es conocido principalmente porque ayuda a reducir el riesgo de cáncer a través de los compuestos fitoquímicos, el sulforafano y los indoles; especialmente el colorrectal y de próstata según los expertos. Estos fitoquímicos o fitonutrientes también disminuyen el riesgo de otras enfermedades al corazón, diabetes y artritis.

Es una fuente importante de nutrientes, vitaminas y minerales. Por dar un ejemplo, 100 gramos de brócoli representarían el $150 \%$ de la vitamina $\mathrm{C}$ que se debe consumir 
diariamente, además de proveer vitaminas del complejo A y B, hierro, magnesio, proteína, fibras, entre otros.

Figura 2.15.

Brócoli
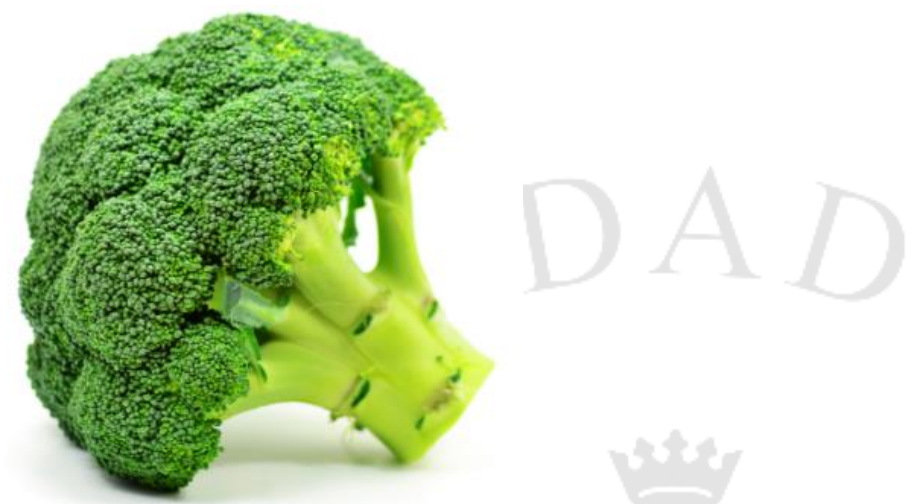

Fuente: Feria Vegetal (2016)

\section{Albahaca}

Con origen en India y perteneciente a la familia de las lamiaceas, la albahaca cuyo nombre científico es Ocimum basilicum, es una planta aromática de tallo recto y delgado con hojas alargadas de unos 3 a $5 \mathrm{~cm}$. Tiene un color verde brillante, textura suave y su altura está en un rango de 30 a $130 \mathrm{~cm}$.

Su cultivo se debe realizar en climas tropicales de preferencia, ya que es muy sensible a bajas temperaturas y el sol es muy importante para lograr un crecimiento óptimo.

Es usada principalmente en el ámbito gastronómico y medicinal. En el primer punto, es muy usada para dar sabor a guisos y carnes debido a su fuerte aroma y también para ensaladas, donde resalta la ensalada Capresse que viene acompañada de tomate y queso mozzarella; también es el ingrediente principal en la preparación de la salsa Pesto. En el uso médico, es considerada muy beneficiosa para remedios naturales principalmente en los países asiáticos, donde resaltan su poder en ayudar a calmar los nervios, prevenir resfriados, calmar la tos, disminuir los cálculos renales y a reducir la hinchazón en el caso de picaduras de insectos. 
Figura 2.16.

Albahaca

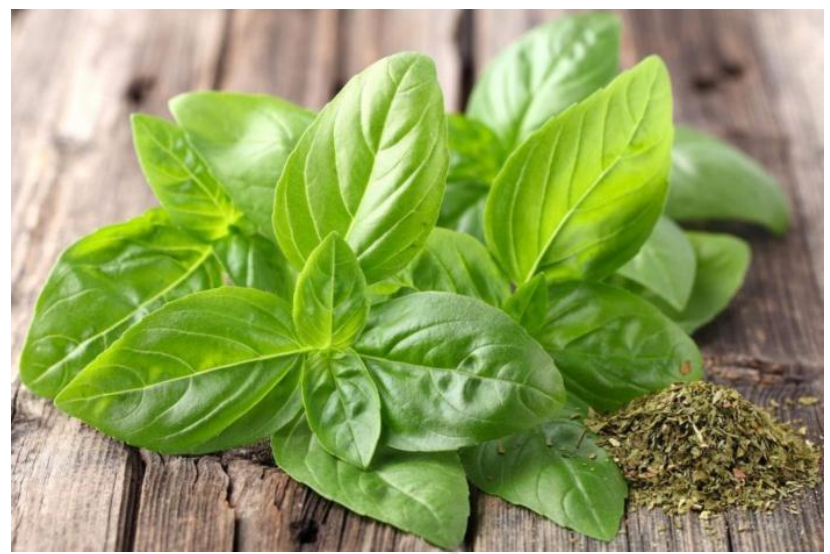

Fuente: Natursan (2016)

\section{Otros ingredientes:}

\section{Aceite de Oliva}

Es un aceite vegetal obtenido de las olivas o aceitunas verdes, con un olor fuerte y característico, consumido por una variedad de beneficios como la estimulación del tránsito intestinal, favorecimiento de la absorción de nutrientes, reducción de la acidez gástrica y adelgazamiento. Se usará la clasificación Extra Virgen ya que es de máxima calidad y es adecuado para la alimentación. Funciona como un conservante natural, al igual que el aceite de girasol, limón y sal.

\section{Aceite de Girasol}

Es un aceite de origen vegetal que se obtiene de la extracción de semillas de girasol. Tiene un sabor y olor ligeramente suaves, es fuente de ácidos grasos esenciales y vitamina $\mathrm{E}$; lo cual sumado a su bajo precio permite que sea el acompañante ideal del aceite de oliva para la preservación del producto.

\section{Queso Parmesano}

Es un queso de origen italiano, muy apreciado en la gastronomía por su sabor y aroma, mayormente se usa rallado o gratinado ya que cuenta con una consistencia dura y no presenta con agujeros. Es rico en proteínas, calcio, fósforo y vitamina B2. 


\section{Cebolla}

Es un bulbo subterráneo, compuesto por el $91 \%$ de agua y gran receptor de vitaminas y minerales. Se usa comúnmente en la gastronomía y en el ámbito medicinal, ya que colabora con muchos beneficios a la salud humana, tales como: disminuye los niveles de azúcar en la sangre, controla la hipertensión, combate el estreñimiento y funciona como antioxidante, adelgazante y expectorante natural.

\section{Limón}

Es una fruta cítrica de sabor ácido muy rica en vitamina C. Es conocido por su uso en la alimentación, su gran poder antioxidante y algunas propiedades curativas adicionales como resfriados, limpieza intestinal, diabetes y cicatrizante de heridas.

En el dip cumple con la función de preservante natural, reemplazando al ácido cítrico dentro de la composición.

\section{Sal}

También conocida como cloruro de sodio, se usa en la alimentación como condimento o conservante, dichas funciones son el principal motivo para su inclusión en la fórmula del dip de quinua y vegetales verdes.

Ajo

El ajo es rico en vitamina C, B6, Manganeso y contiene muy pocas calorías. En el ámbito medicinal, ayuda combatiendo el Alzheimer, mejora los niveles del colesterol y la presión sanguínea. Es muy valorado en la gastronomía por su sabor fuerte y un poco picante.

\subsubsection{Disponibilidad de la materia prima}

Todos los insumos requeridos para la preparación del Dip son producidos localmente de manera constante durante todo el año, resaltando que Perú es el mayor productor y exportador de quinua y espárrago a nivel mundial. A esto se debe agregar la producción de otros insumos con gran demanda, que ha permitido al país colocarse dentro de las diez primeras naciones proveedoras de alimentos y lograr un crecimiento promedio de $3.2 \%$ anual en agricultura. 
A continuación, se muestra la producción nacional de los años 2013 al 2016 de los insumos requeridos.

Tabla 2.9.

Producción Nacional (miles de toneladas)

\begin{tabular}{lcccc}
\hline \multicolumn{1}{c}{ Producto } & $\mathbf{2 0 1 3}$ & $\mathbf{2 0 1 4}$ & $\mathbf{2 0 1 5}$ & $\mathbf{2 0 1 6}$ \\
\hline Quinua & 52.1 & 114.7 & 105.7 & 79.3 \\
Espárrago & 383.1 & 377.7 & 369.0 & 378.3 \\
Brócoli & 43.4 & 48.8 & 54.5 & 55.2 \\
Albahaca & 6.5 & 6.5 & 5.5 & 5.3 \\
Cebolla & 747.9 & 758.2 & 760.2 & 705.6 \\
Limón & 228.5 & 263.8 & 268.0 & 270.3 \\
Olivo & 57.8 & 151.9 & 38.4 & 56.2 \\
Ajo & 81.41 & 81.5 & 89.8 & 78.2 \\
\hline
\end{tabular}

Fuente: Ministerio de Agricultura y Riego (2017)

\subsubsection{Costos de la materia prima}

Los costos de los insumos fueron obtenidos del Sistema de Abastecimiento y Precios (SISAP) del Ministerio de Agricultura. Se consideran los precios promedios del día 09/09/2017 correspondientes al Gran Mercado Mayorista de Lima.

Tabla 2.10.

Precio - Mercado Mayorista de Lima

\begin{tabular}{lc}
\hline Producto & Precio (S/ / kg) \\
\hline Quinua & 5.83 \\
Espárrago & 9.00 \\
Brócoli & 1.25 \\
Albahaca & 6.52 \\
Cebolla & 1.88 \\
Limón & 8.33 \\
Ajo criollo & 2.83 \\
\hline
\end{tabular}

Fuente: Ministerio de Agricultura y Riego (2017)

De igual manera, se realizó una visita a Makro para tener los costos referenciales de los insumos al por mayor y de fácil acceso. 
Tabla 2.11.

Precios al por mayor - Makro

\begin{tabular}{lc}
\hline MP / Insumo & Precio (S/ / kg) \\
\hline Quinua & 11.50 \\
Esparrago & 9.00 \\
Brócoli & 5.25 \\
Albahaca & 6.52 \\
Cebolla & 2.19 \\
Limón & 8.99 \\
Queso Parmesano & 55.00 \\
Aceite de Oliva & 24.12 \\
Aceite de Girasol & 4.51 \\
Sal & 0.88 \\
Ajo molido & 14.84 \\
Doypack (und) & 0.35 \\
Cajas (und) & 2.90 \\
\hline
\end{tabular}

Fuente: Makro (2017) 


\section{CAPÍTULO III: LOCALIZACIÓN DE PLANTA}

\subsection{Identificación y análisis detallado de los factores de localización}

Para determinar la ubicación óptima de la planta productora se tuvo en cuenta diversos factores a nivel macro y micro de las posibles alternativas. Los factores fueron elegidos según la importancia de los requerimientos para la instalación de la planta, siendo estos: cercanía al mercado objetivo, disponibilidad de materia prima, costo de servicios, costo de terrenos y aspectos culturales-económicos.

\section{Cercanía al mercado objetivo}

Es conveniente que la localidad a escoger se encuentre cerca al mercado objetivo, en este caso Lima Metropolitana, ya que permite lograr ahorros en transporte y tiempo, garantizando también un abastecimiento constante a los lugares de distribución. Al mismo tiempo, permite reaccionar de una manera más rápida frente a una situación inusual de la demanda.

\section{Disponibilidad de materia prima}

Si bien es cierto que el Perú es un país productor de los insumos del proyecto, es necesario contar con un abastecimiento continuo ya que, de no ser así, se incurriría en sobrecostos y se podría interrumpir la producción. Esto va a acompañado a la obtención de insumos de primera calidad, que permita generar la menor merma posible y que estén a la par con el grado de calidad que se busca en el producto final.

\section{Costo de servicios}

Se debe contar con los servicios básicos como energía eléctrica y agua, lo cual garantice la operación continua de la planta. Adicionalmente, se debe evaluar la variación de costos según localidad. El factor es de importancia baja ya que en la mayoría de zonas industriales se cuenta con ellos. 


\section{Costo de terrenos}

Hallar el terreno ideal en tamaño y precio permitirá contar con diversas ventajas como la optimización de espacios y mejor manejo económico al contar con menos inversión inicial. La búsqueda es compleja debido a la escasez de terrenos en zonas industriales cercanas y a la sobrevaloración generada por el boom inmobiliario.

\section{Aspectos culturales - económicos}

Debe ser importante que las localidades tengan la menor cantidad de problemas sociales o huelgas que puedan afectar la continuidad del proyecto o la integridad de las instalaciones. Del mismo modo, se considera como una ventaja que las principales actividades económicas de la localidad sean la agroindustria y manufactura.

A continuación, se establece una ponderación de los factores de acuerdo a su relevancia con el proyecto, siendo 1 "igual o más importante" y 0 "menos importante".

Tabla 3.1.

Lista de Factores

\begin{tabular}{cc}
\hline Letra & Factor \\
\hline A & Cercanía al mercado objetivo \\
B & Disponibilidad de materia prima \\
C & Costo de terreno \\
D & Costo de servicios \\
E & Aspectos culturales y económicos \\
\hline Elaboración propia
\end{tabular}

Tabla 3.2.

Tabla de enfrentamiento

\begin{tabular}{cccccccc}
\hline Factor & A & B & C & E & F & Conteo & Ponderación \\
\hline A & & 1 & 1 & 1 & 1 & 4 & $33 \%$ \\
B & 1 & & 1 & 1 & 1 & 4 & $33 \%$ \\
C & 0 & 0 & & 1 & 1 & 2 & $17 \%$ \\
D & 0 & 0 & 0 & & 1 & 1 & $8 \%$ \\
E & 0 & 0 & 0 & 1 & & 1 & $8 \%$ \\
& & & & & Total & $\mathbf{1 2}$ & $\mathbf{1 0 0 \%}$ \\
\hline
\end{tabular}

Elaboración propia 


\subsection{Identificación y descripción de las alternativas de localización}

Después de haber analizado diversas condiciones de competitividad, se llegó a la conclusión que las tres alternativas a evaluar serían Arequipa, La Libertad y Lima.

\section{Cercanía a mercado objetivo}

Como se describió en los capítulos anteriores, el mercado objetivo para este proyecto es Lima Metropolitana por ser la ciudad con más habitantes, con mayores ingresos y de mayor proyección para los negocios.

Tabla 3.3.

Distancias entre Departamentos y mercado objetivo

\begin{tabular}{cccc}
\hline Ubicación & Arequipa & La Libertad & Lima \\
\hline Distancia a mercado objetivo $(\mathrm{km})$ & 1020 & 559 & 50 \\
\hline Fuente: Google & & &
\end{tabular}

Fuente: Google Maps (2017)

Para el cálculo de las distancias se utilizó la aplicación Google Maps, considerando como destino la capital de cada departamento y tomando la ruta más directa; en el caso de Lima se considera $50 \mathrm{~km}$ para desplazamientos entre la posible ubicación de la planta y el mercado objetivo.

\section{Disponibilidad de materia prima}

Los insumos con mayor presencia en la composición del dip (Ver Tabla 5.1) son la quinua (37.78\%) y el espárrago (24.4\%), por esta razón se evaluará este factor según la producción de ambos en las alternativas escogidas o localidades vecinas.

En el caso de la quinua, la alternativa de mayor producción es Arequipa; en el año 2014 estuvo muy cerca de igualar la cantidad producida por la región líder Puno con 33.137 toneladas, más atrás se encuentra La Libertad con 4.006 toneladas y Lima que no se caracteriza por ser una región productora, sino más bien un comprador directo y por ser el lugar donde se transforma este grano en productos como hojuelas, harina, galletas, chocolates, panes, jugos, entre otros. (Ministerio de Agricultura y Riego, 2014) 
Figura 3.17.

Producción de Quinua por Departamento 2014

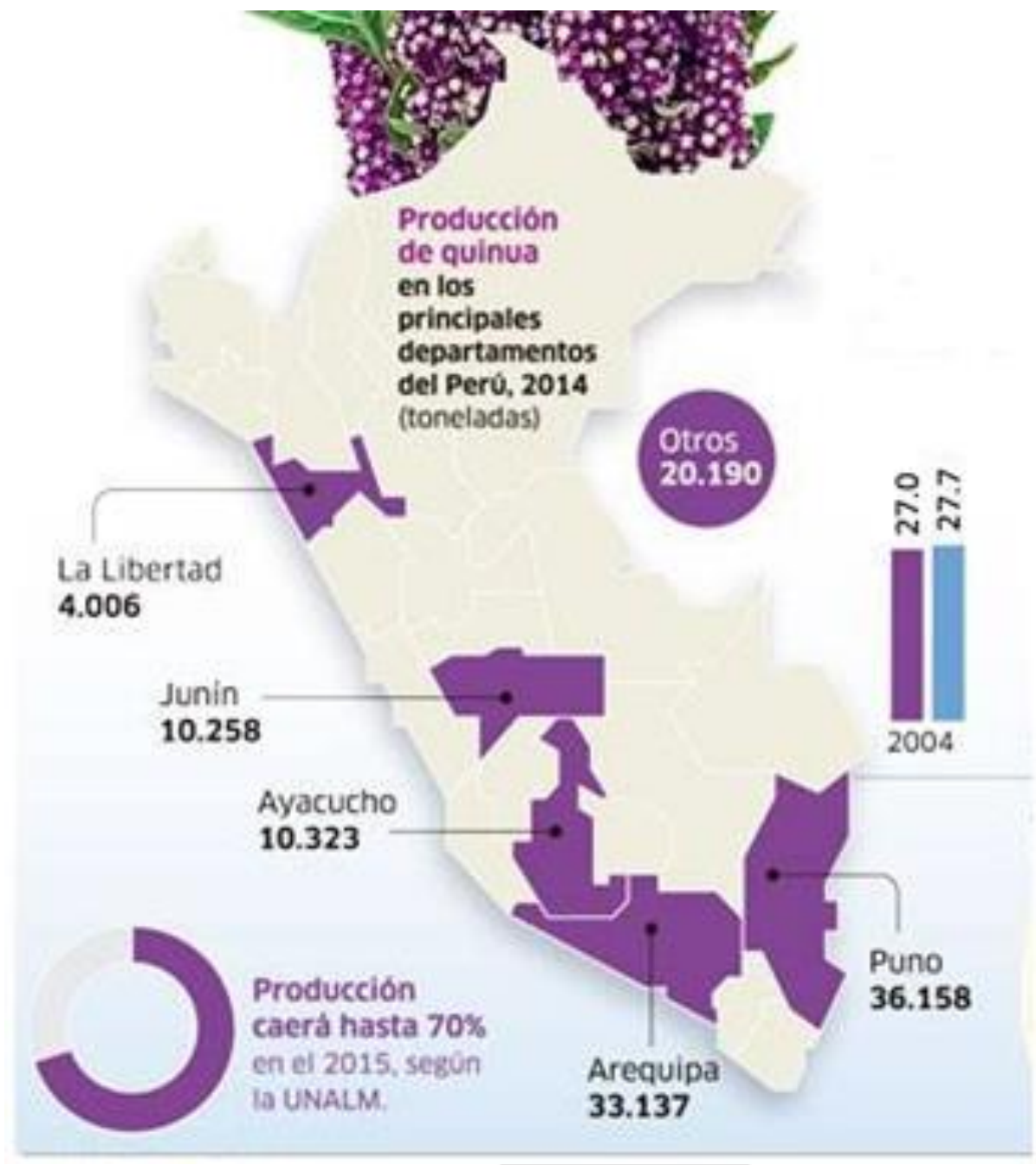

Fuente: Ministerio de Agricultura y Riego (2014)

La Libertad es considerada como líder nacional en producción agrícola gracias a la fertilidad de sus suelos y a las condiciones climáticas que permite que sea posible el cultivo de diversos productos agrícolas. Como se puede comprobar en la figura 3.2., La Libertad es uno de los departamentos dominantes en cuanto a la producción de espárrago, llegando a superar las 191 mil toneladas y reflejando una participación de más del 50\% (Diario La República, 2015). 
Figura 3.18.

Mapa de producción de espárrago

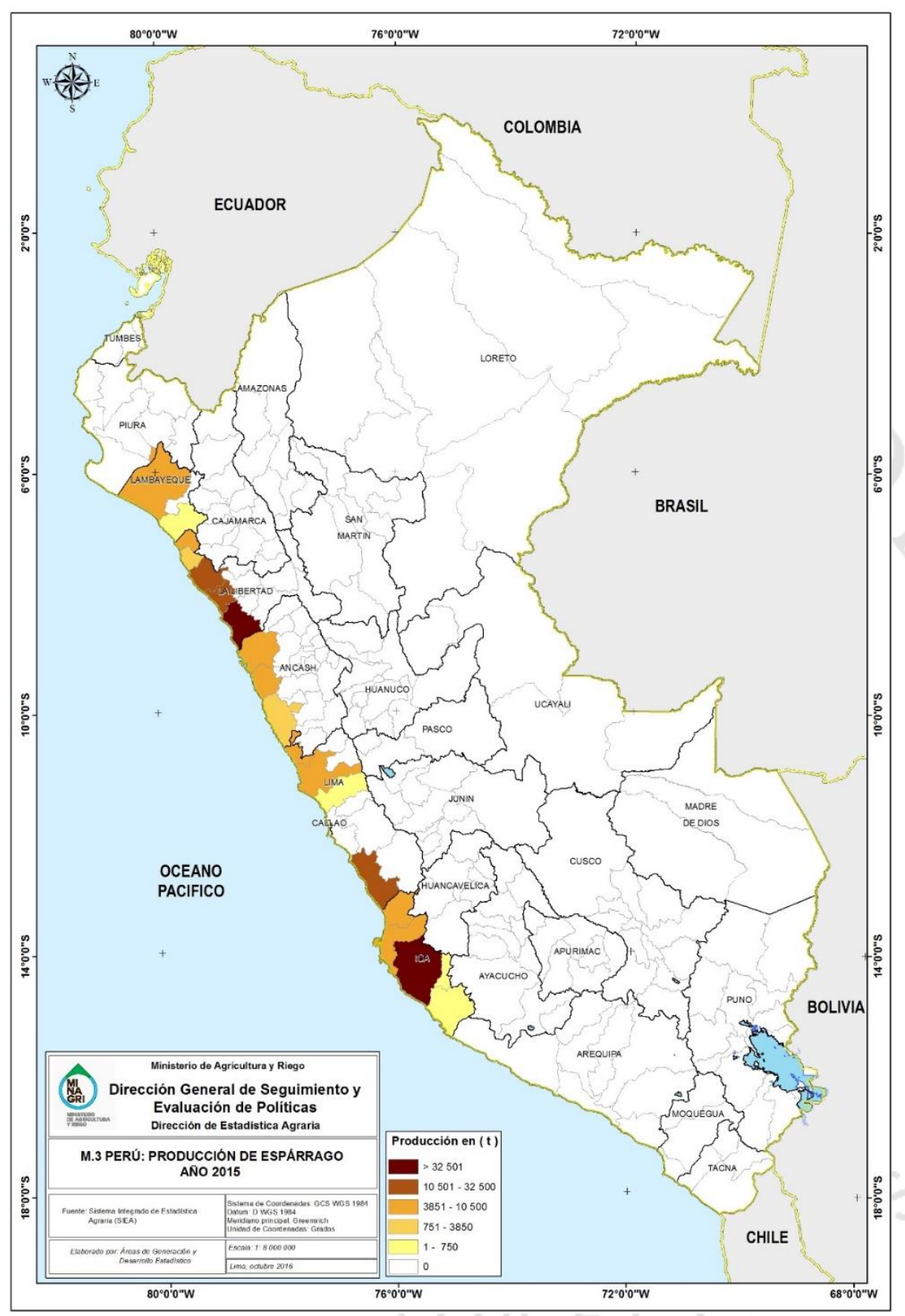

Fuente: Ministerio de Agricultura y Riego (2016)

\section{Costo de terrenos}

Tres factores importantes a considerar en la búsqueda del terreno para la planta son el tamaño, la ubicación y el precio por $\mathrm{m}^{2}$.

Las zonas industriales de Lima, ubicadas principalmente en el Callao, Huachipa y Lurín están casi al tope de su capacidad y los terrenos disponibles en alquiler o venta sugieren cifras muy costosas que afectarían directamente a la factibilidad del proyecto. 
Arequipa cuenta con un parque industrial de 52 hectáreas cerca de la carretera Panamericana, que fue habilitado en la época de 1960 como un plan de rehabilitación tras los daños ocasionados por el terremoto de ese año. Los precios son un poco menores comparados con Lima, pero al ser lotes industriales, su tamaño supera lo que debería demandar la presente planta de producción.

Por el lado de La Libertad, la zona industrial se encuentra apenas a la salida de Trujillo con destino a Lima y a la Sierra de La Libertad, esta distancia puede tomar tan solo veinte minutos desde el centro de la ciudad. Con suelos fértiles y menores precios por $\mathrm{m}^{2}$, esta alternativa resalta también por la flexibilidad en la porción de terreno a adquirir, convirtiéndose así en la opción más adecuada.

\section{Costo de servicios}

La evaluación de la disponibilidad de servicios se basa en la cobertura por parte de la empresa principal de cada localidad. Adicionalmente, se tomará en cuenta las tarifas para la calificación en el ranking de factores, usando una medida estándar para lograr que los valores sean comparables.

\section{Agua}

Contar con un servicio de agua de bajo costo es esencial para un buen rendimiento en la operación de planta ya que representa un costo fijo. Las tres alternativas de departamentos para la ubicación, cuentan con grandes empresas y redes de alcantarillado para su buen funcionamiento, por lo que el tema de la cobertura no sería problema. Cabe mencionar que este servicio se usaría en la limpieza y cocción de insumos, higiene del personal, comedor, servicios higiénicos y para la limpieza general de la planta.

Los valores mostrados en la tabla siguiente, correspondientes a las tarifas No Residenciales - Categoría Industrial por $\mathrm{m}^{3}$, reflejan que las empresas del sur del país llevan una ventaja frente a los costos de La Libertad. Sin embargo, el proyecto de irrigación Chavimochic, que actualmente se encuentra en su III etapa, permite abastecer del recurso hídrico al departamento y habilitará 63 mil hectáreas de tierras nuevas a la agricultura y mejorará el riego de otras 48 mil. 
Tabla 3.4.

Tarifas de agua de las principales empresas por Departamento

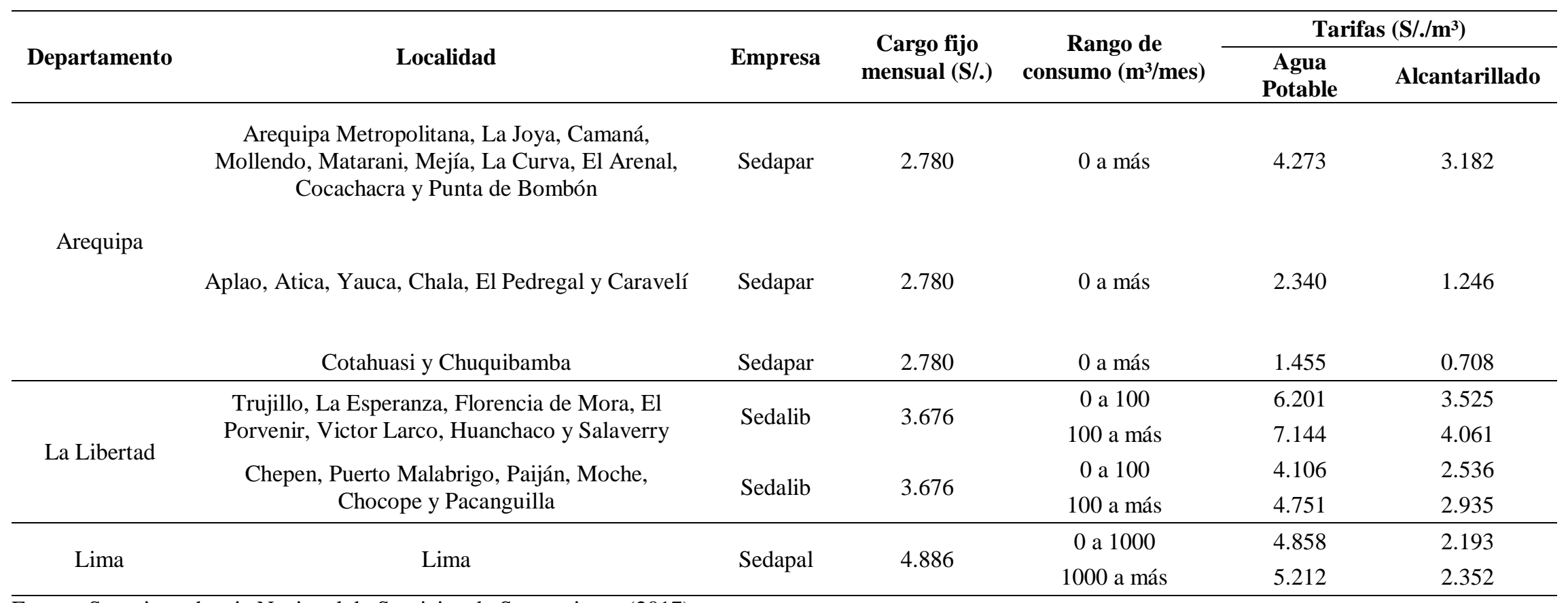

Fuente: Superintendencia Nacional de Servicios de Saneamiento (2017)

Elaboración propia 


\section{Energía Eléctrica}

El servicio de energía eléctrica contribuye a la normal operación de la planta, lo cual incluye maquinaria, equipos, oficinas y demás ambientes que necesiten de iluminación. Asegurar un abastecimiento continuo de electricidad permite evitar incurrir en sobrecostos por generación de energía y lo más importante, evitar la paralización de la planta. Según las diversas ofertas que tienen las empresas de energía eléctrica, la tarifa que más se ajusta a los requerimientos de la planta es la tarifa en baja tensión BT3, la cual cuenta con doble medición de energía activa y una potencia.

Tabla 3.5.

Tarifas BT3 de energía eléctrica de las principales empresas

\begin{tabular}{|c|c|c|c|c|}
\hline \multirow{2}{*}{ Concepto } & \multirow{2}{*}{ Unidad } & \multirow{2}{*}{$\begin{array}{c}\text { Arequipa } \\
\text { Seal }\end{array}$} & \multirow{2}{*}{$\begin{array}{c}\text { La Libertad } \\
\text { Hidrandina }\end{array}$} & \multirow{2}{*}{$\begin{array}{c}\text { Lima } \\
\text { Luz del Sur }\end{array}$} \\
\hline & & & & \\
\hline Cargo Fijo Mensual & S/. / cliente & 6.51 & 6.51 & 3.73 \\
\hline Cargo por Energía Activa en Horas Punta & cent. S/. /kW.h & 22.80 & 22.3 & 26.77 \\
\hline Cargo por Energía Activa en Horas Fuera de Punta & cent. S/. /kW.h & 18.19 & 17.82 & 22.09 \\
\hline \multicolumn{5}{|l|}{ Cargo por Potencia Activa de Generación } \\
\hline - Presentes Punta & $\mathrm{S} / . / \mathrm{kW}$-mes & 43.36 & 43.34 & 56.89 \\
\hline - Presentes Fuera de Punta & $\mathrm{S} / . / \mathrm{kW}$-mes & 28.41 & 28.4 & 38.96 \\
\hline \multicolumn{5}{|l|}{ Cargo por Potencia Activa por uso de Redes de Distribución } \\
\hline - Presentes Punta & $\mathrm{S} / . / \mathrm{kW}$-mes & 47.35 & 55.05 & 53.27 \\
\hline - Presentes Fuera de Punta & $\mathrm{S} / . / \mathrm{kW}$-mes & 42.20 & 48.86 & 48.78 \\
\hline Cargo por Energía Reactiva que exceda el $30 \%$ del total de Energía Activa & Cent. S/. /kVAR.h & 4.21 & 4.21 & 4.97 \\
\hline
\end{tabular}

Fuente: Osinergmin (2017)

Elaboración propia 


\section{Transporte}

La búsqueda de un servicio de transporte confiable que respete los tiempos y acuerdos, es difícil de encontrar ya que normalmente la formalidad del mismo, no depende de la empresa sino de sus trabajadores.

Este servicio será necesario para transportar la mercadería desde la planta hacia los clientes y/o centros de distribución.

En el cuadro a continuación, se puede ver el crecimiento acelerado que viene desempeñando este rubro, donde al igual que en muchos sectores hay una muy marcada brecha entre Lima y el resto de departamentos del país debido a la centralización y dinamismo que representa al ser la capital.

Tabla 3.6.

Empresas de Transporte de Carga autorizadas

\begin{tabular}{cccccc}
\hline Departamento & $\mathbf{2 0 1 2}$ & $\mathbf{2 0 1 3}$ & $\mathbf{2 0 1 4}$ & $\mathbf{2 0 1 5}$ & $\mathbf{2 0 1 6}$ \\
\hline Arequipa & 6,698 & 7,466 & 8,188 & 8,574 & 9,430 \\
La Libertad & 5,871 & 6,099 & 6,296 & 6,244 & 6,869 \\
Lima & 32,369 & 38,610 & 43,532 & 46,486 & 52,765 \\
\hline
\end{tabular}

Fuente: Ministerio de Transportes y Comunicaciones (2017)

Elaboración propia

El resto de servicios, entre ellos telefonía e internet, no tendrán un cuadro comparativo debido a que los operadores más importantes tienen similar cobertura y los mismos precios en las localidades en estudio.

\section{Aspectos culturales - económicos}

Ninguna de las alternativas tiene problemas significativos en cuanto a huelgas, levantamiento de la población, paros vehiculares, actos de terrorismo, etc. como ocurren en otras regiones del país donde la población se amotina y va en contra de grandes proyectos mineros o industriales que creen que afectarán su estilo de vida, territorio $\mathrm{u}$ ecosistema.

La Libertad es agroindustrial por excelencia, en Arequipa resalta la actividad minera y agroindustria y en Lima, si bien concentra todo tipo de actividades económicas, se puede resaltar el sector industrial que cubre el $57 \%$ de la industria peruana. 


\subsection{Evaluación y selección de localización}

Para la calificación de las alternativas de localización se utilizará un puntaje de 2 a 10 , siendo los valores más altos los que reflejen condiciones óptimas y considerando una escala que va de deficiente a excelente.

\subsubsection{Evaluación y selección de la macro localización}

En la selección de la alternativa de macrolocalización, el método adecuado y escogido es el Ranking de Factores, el cual a través de la ponderación hallada en la tabla de enfrentamiento y la calificación en base a una escala que va de Deficiente a Excelente, siendo 10 el mayor valor.

Tabla 3.7.

Evaluación de la macrolocalización

\begin{tabular}{ccccccccc}
\hline & & \multicolumn{2}{c}{ Arequipa } & \multicolumn{2}{c}{ La Libertad } & \multicolumn{2}{c}{ Lima } \\
\cline { 3 - 8 } Factor & Ponderación & Calificación & Puntaje & Calificación & Puntaje & Calificación & Puntaje \\
\hline Cercanía & $33 \%$ & 4 & 1.33 & 6 & 2.00 & 8 & 2.67 \\
Materia prima & $33 \%$ & 6 & 2.67 & 8 & 2.67 & 6 & 2.00 \\
Terreno & $17 \%$ & 4 & 0.67 & 6 & 1.00 & 4 & 0.67 \\
Servicios & $8 \%$ & 6 & 0.50 & 6 & 0.50 & 6 & 0.50 \\
Aspectos cult. y econ. & $8 \%$ & 6 & 0.50 & 6 & 0.50 & 4 & 0.33 \\
& & & 5.00 & & $\mathbf{6 . 6 7}$ & & 6.17 \\
\hline
\end{tabular}

Elaboración propia

\subsubsection{Evaluación y selección de la micro localización}

El departamento de La Libertad está dividido en 12 provincias y 83 distritos, y abarca las regiones de la Costa y Sierra. Con una población aproximada de 1'859,640 habitantes en 2015, es el tercer departamento más poblado después de Lima y Piura (INEI, 2015).

Las provincias más representativas en cuanto a población y producción agrícola para el presente estudio son: Trujillo, Pacasmayo y Virú. Las tres alternativas están ubicadas en la Costa, por lo que cuentan con ventajas en cuanto a la siembra de diversos cultivos incluyendo a los cuatro principales del Dip, los cuales son quinua, espárrago, brócoli y albahaca; esto se debe principalmente a la mayor facilidad de acceso a agua, la disponibilidad de terreno agrícola y a que el relieve terrestre es más favorable que en la 
Sierra donde la geografía es más accidentada y frecuentemente hay muchas pendientes que no permiten el aprovechamiento óptimo del suelo.

Figura 3.19.

Mapa de La Libertad

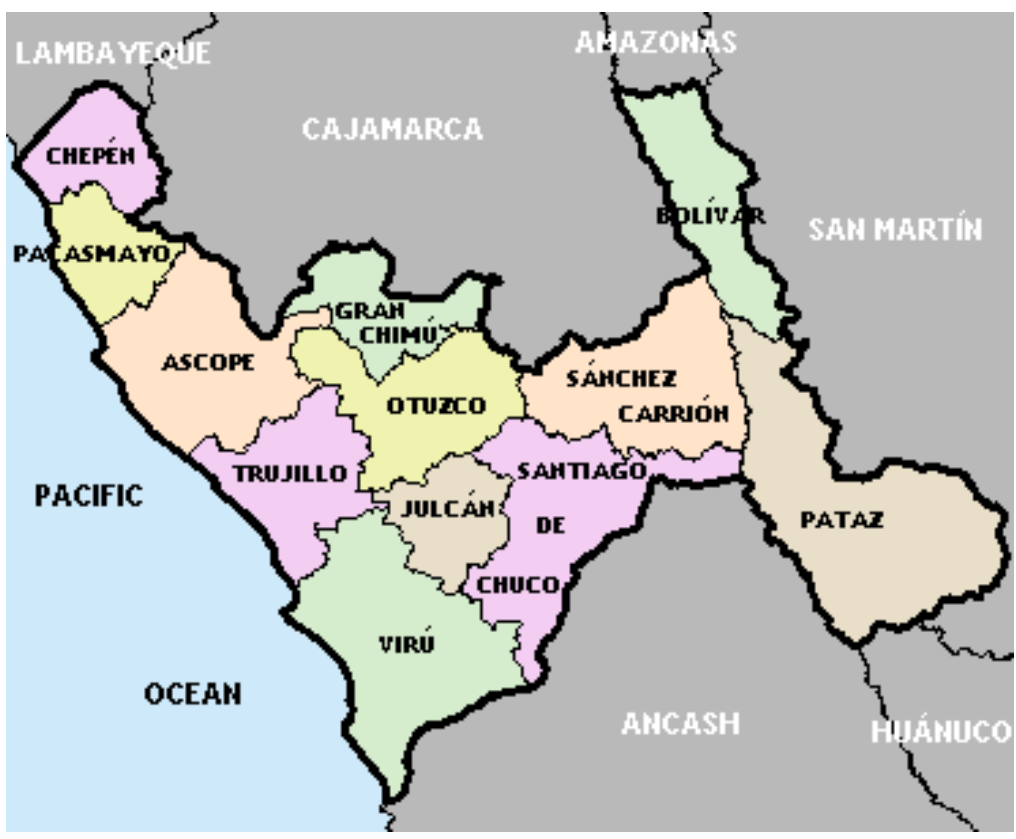

Fuente: Perú Travelling (2017)

Los cuatro factores a evaluar para la microlocalización son vías de acceso, seguridad ciudadana, costo de terreno e índice de desarrollo humano.

\section{Vías de acceso}

Tras el paso del fenómeno del niño costero en el año 2017, quedaron destruidos miles de kilómetros de carreteras a lo largo del país, siendo La Libertad una de las regiones más afectadas con $369 \mathrm{~km}$. perdidos (Gobierno Regional La Libertad, 2017).

La rehabilitación total de las vías está programada a ejecutarse durante los próximos 3 años, y dentro del plan de Reconstrucción con Cambios, se encuentra el mantenimiento y mejoramiento de $120 \mathrm{~km}$ en Virú, $64 \mathrm{~km}$ en Trujillo y $52 \mathrm{~km}$ en Pacasmayo. Muchos de los trabajos estarán a cargo de Provias Descentralizado del Ministerio de Transportes y Comunicaciones; sin embargo, cada municipalidad tendrá un presupuesto destinado a obras viales que dependerá de su gestión y el tamaño de su provincia, siendo Trujillo la localidad más beneficiada. 


\section{Seguridad Ciudadana}

En Trujillo, la comuna edil dio a conocer mediante un informe emitido por la Gerencia de Seguridad Ciudadana que hubo una reducción en la cantidad de homicidios durante el 2017(58) frente al 2016 (76), teniendo una variación de -23.6\%. Agregó también que Trujillo dejó de ser la ciudad que dominaba el índice delictivo a nivel nacional en 2015 y ahora se encuentra en el puesto 14. Además, se inauguró la central de tráfico, riesgo y monitoreo de Trujillo con 200 cámaras ubicadas en puntos estratégicos de la ciudad.

Tabla 3.8.

Número de delitos por provincia

\begin{tabular}{cccc}
\hline Tipo de delito & Trujillo & Virú & Pacasmayo \\
\hline Delitos en general & 19,502 & 1,030 & 1,063 \\
Homicidios & 58 & 13 & 11 \\
Extorsiones & 1,077 & 133 & 82 \\
Hurtos & 3,947 & 189 & 263 \\
Robos & 3,646 & 162 & 139 \\
\hline
\end{tabular}

Fuente: Comité regional de Seguridad Ciudadana (2017)

Elaboración propia

\section{Costo de terreno}

Para evaluar la alternativa de terreno se considera un espacio de por lo menos $576 \mathrm{~m}^{2}$, ubicado en una zona de fácil acceso y no residencial para evitar posibles conflictos con los vecinos. Se ha cotizado terrenos en la capital de cada provincia, ya que son ciudades que cuentan con todos los servicios y facilidades que puedan requerirse.

Tabla 3.9.

Precios de terreno por Provincia

\begin{tabular}{lccc}
\hline & Trujillo & Virú & Pacasmayo \\
\hline Precio referencial $\left(\$ / \mathrm{m}^{2}\right)$ & 200 & 60 & 70 \\
\hline Fuente: Urbania $(2017)$ & & & \\
Elaboración propia & & &
\end{tabular}




\section{Índice de Desarrollo Humano}

Estos indicadores son elaborados por el Programa de Naciones Unidas para el Desarrollo (PNUD) y miden tres aspectos importantes: el logro educativo (educación), la esperanza de vida al nacer (salud) y el ingreso familiar per cápita (nivel de vida).

La Libertad ocupa la posición $13^{\circ}$ en logro educativo, $6^{\circ}$ en esperanza de vida (71,8 años) y $7^{\circ}$ en ingreso familiar per cápita ( $\left.\mathrm{S} / 278\right)$, estos dos últimos por debajo del promedio nacional (73,1 años y S/ 374 respectivamente). Es importante tener en cuenta que esta medición permite tener una idea clara sobre las perspectivas de desarrollo de las provincias y las condiciones en que se encuentran.

Tabla 3.10.

Índice de Desarrollo Humano y sus componentes por provincia

\begin{tabular}{|c|c|c|c|c|c|c|c|}
\hline & \multirow[b]{2}{*}{ IDH } & \multirow[b]{2}{*}{ Orden } & \multicolumn{5}{|c|}{ Ordenamiento según componentes del IDH } \\
\hline & & & $\begin{array}{c}\text { Esperanza } \\
\text { de vida al } \\
\text { nacer (en } \\
\text { años) }\end{array}$ & $\begin{array}{c}\text { Alfabetismo } \\
(\%)\end{array}$ & $\begin{array}{c}\text { Escolaridad } \\
(\%)\end{array}$ & $\begin{array}{c}\text { Logro } \\
\text { educativo } \\
(\%)\end{array}$ & $\begin{array}{c}\text { Ingreso } \\
\text { familiar } \\
\text { per } \\
\text { cápita } \\
\text { (S/) }\end{array}$ \\
\hline $\begin{array}{l}\text { Región La } \\
\text { Libertad 1/ }\end{array}$ & 0,621 & 8 & 6 & 13 & 18 & 13 & 7 \\
\hline \multicolumn{8}{|l|}{ Provincias 2/ } \\
\hline Trujillo & 0.6663 & 4 & 17 & 18 & 78 & 20 & 3 \\
\hline Ascope & 0.6367 & 29 & 35 & 39 & 89 & 39 & 19 \\
\hline Bolivar & 0.5563 & 127 & 71 & 107 & 177 & 134 & 188 \\
\hline Chepén & 0.6253 & 35 & 32 & 57 & 95 & 53 & 37 \\
\hline Julcán & 0.5396 & 158 & 127 & 135 & 179 & 160 & 166 \\
\hline Otuzco & 0.5527 & 134 & 66 & 125 & 193 & 166 & 134 \\
\hline Pacasmayo & 0.6391 & 27 & 12 & 12 & 80 & 41 & 26 \\
\hline Pataz & 0.5376 & 161 & 149 & 149 & 146 & 159 & 151 \\
\hline Sánchez Carrión & 0.5051 & 192 & 152 & 152 & 188 & 193 & 184 \\
\hline Santiago de Chuco & 0.5721 & 94 & 64 & 64 & 158 & 132 & 94 \\
\hline Gran Chimú & 0.5679 & 106 & 106 & 72 & 183 & 133 & 104 \\
\hline Virú & 0.6007 & 57 & 57 & 29 & 174 & 96 & 61 \\
\hline
\end{tabular}

1/ Ordenamiento entre 24 departamentos

2/Ordenamiento entre 195 provincias

Fuente: Informe Económico y Social de la Región La Libertad - BCRP (2017) 
Con la información detallada anteriormente se procede a evaluar cada uno de los factores de acuerdo a su importancia y posteriormente a calificar las localidades propuestas.

Tabla 3.11.

Tabla de enfrentamiento para Microlocalización

\begin{tabular}{ccccccc}
\hline Factor & A & B & C & D & Conteo & Ponderación \\
\hline A & & 1 & 1 & 1 & 3 & $30 \%$ \\
B & 1 & & 1 & 1 & 3 & $30 \%$ \\
C & 0 & 1 & & 1 & 2 & $20 \%$ \\
D & 0 & 1 & 1 & & 2 & $20 \%$ \\
& & & & & 10 & $100 \%$ \\
\hline
\end{tabular}

Elaboración propia

Tabla 3.12

Evaluación de la Microlocalización

\begin{tabular}{cccccccc}
\hline & & \multicolumn{2}{c}{ Trujillo } & \multicolumn{2}{c}{ Virú } & \multicolumn{2}{c}{ Pacasmayo } \\
\cline { 3 - 8 } Factor & Pond. & Calificación & Puntaje & Calificación & Puntaje & Calificación & Puntaje \\
\hline Vías de acceso & $30 \%$ & 8 & 2.40 & 6 & 1.80 & 6 & 1.80 \\
Seguridad ciudadana & $30 \%$ & 4 & 1.20 & 4 & 1.20 & 4 & 1.20 \\
Costo de terreno & $20 \%$ & 4 & 0.80 & 6 & 1.20 & 6 & 1.20 \\
Índice de Desarrollo H. & $20 \%$ & 8 & 1.60 & 4 & 0.80 & 6 & 1.20 \\
& & & $\mathbf{6 . 0 0}$ & & 5.00 & & 5.40 \\
\hline
\end{tabular}

Elaboración propia

Por las razones señaladas anteriormente se escogió a Trujillo, capital de La Libertad, como la localidad que albergará la planta de producción, y que además es donde se tiene mayor presencia de agroindustria y manufactura acorde a lo demandado por el proyecto. 


\section{CAPÍTULO IV: TAMAÑO DE PLANTA}

\subsection{Relación tamaño-mercado}

La relación tamaño-mercado es crucial debido a que, si hay una sobre producción con respecto a la demanda de los consumidores, se tendría un stock sin movimiento, el cual corre el riesgo de vencimiento al ser perecible y se reflejaría en una baja liquidez financiera.

Tabla 4.1.

Demanda del proyecto

\begin{tabular}{cccc}
\hline Año & $\begin{array}{c}\text { Demanda } \\
\text { (envases) }\end{array}$ & $\begin{array}{c}\text { Demanda } \\
(\mathbf{k g})\end{array}$ & $\begin{array}{c}\text { Demanda } \\
\text { (TM) }\end{array}$ \\
\hline 2018 & 807,274 & 145,309 & 145.3 \\
2019 & 854,710 & 153,848 & 153.8 \\
2020 & 904,933 & 162,888 & 162.9 \\
2021 & 958,107 & 172,459 & 172.5 \\
2022 & $1,014,406$ & 182,593 & 182.6 \\
\hline
\end{tabular}

Elaboración propia

Tal como se calculó la demanda en el capítulo II, la proyección de la demanda al quinto año es de 1,014,406 envases.

\subsection{Relación tamaño-recursos productivos}

El abastecimiento de materia prima no es una limitante para este proyecto, esto se debe a que los insumos cuentan con una producción constante durante todo el año en diversas zonas del país. Además, la planta estará ubicada en Trujillo, ciudad con la mayor producción de espárrago a nivel nacional e importante volumen de quinua.

Tabla 4.1.

Requerimiento de Quinua y Espárrago

\begin{tabular}{cccccc}
\hline Año & $\begin{array}{c}\text { Demanda del } \\
\text { proyecto } \\
\text { (TM) }\end{array}$ & $\begin{array}{c}\text { Req. } \\
\text { Quinua } \\
\text { (TM) }\end{array}$ & $\begin{array}{c}\text { Producción } \\
\text { Nacional Quinua } \\
\text { (TM) }\end{array}$ & $\begin{array}{c}\text { Req. } \\
\text { Espárrago } \\
\text { (TM) }\end{array}$ & $\begin{array}{c}\text { Producción } \\
\text { Nacional Espárrago } \\
\text { (TM) }\end{array}$ \\
\hline 2018 & 145.3 & 54.90 & 77,700 & 35.46 & 378,000 \\
2019 & 153.8 & 58.12 & 101,010 & 37.54 & 381,780 \\
2020 & 162.9 & 61.54 & 131,313 & 39.74 & 385,598 \\
2021 & 172.5 & 65.16 & 170,707 & 42.08 & 389,454 \\
2022 & 182.6 & 68.98 & 221,919 & 44.55 & 393,348 \\
\hline
\end{tabular}

Fuente: Ministerio de Agricultura y Riego (2017)

Elaboración propia 


\subsection{Relación tamaño-tecnología}

Teniendo como base la tecnología disponible y necesaria para la elaboración del producto, se procede a seleccionar la máquina que sería el cuello de botella. Como se puede revisar en la tabla 4.3., la envasadora es la máquina con menor capacidad de producción.

Tabla 4.2.

Capacidad de máquinas requeridas

\begin{tabular}{cc}
\hline Máquinas & $\begin{array}{c}\text { Capacidad } \\
(\mathbf{k g} / \mathbf{h})\end{array}$ \\
\hline Marmitas & 200 \\
Trozadora & 200 \\
Envasadora & 162 \\
Codificadora & 324 \\
Bomba de transferencia & 660 \\
\hline Elaboración propia &
\end{tabular}

Se trabajará en 1 turno por día, 8 horas efectivas por turno, 5 días a la semana y 52 semanas al año, obteniendo el siguiente resultado:

$$
\frac{162 \mathrm{~kg}}{\text { hora }} \times \frac{8 \text { horas }}{\text { día }} \times \frac{5 \text { días }}{\text { semana }} \times \frac{52 \text { semanas }}{\text { año }}=336,960 \mathrm{~kg} \text { dip al año }
$$

Comparando la capacidad anual de la envasadora $(336,960 \mathrm{~kg})$ frente a los $182,593 \mathrm{~kg}$ de demanda del proyecto al año 5, se concluye que la tecnología no es limitante.

\subsection{Relación tamaño-inversión}

La inversión total calculada incluye la inversión en activos tangibles e intangibles y el capital de trabajo, cuya suma sin intereses asciende a S/. 1,660,757 y permitirá adquirir la línea de producción con las características previamente mencionadas. El 70\% del monto será financiado a través del BCP con una tasa efectiva anual de $12.5 \%$, por dicha razón no se considera una limitante para el proyecto. 
Tabla 4.3.

Inversión del proyecto

\begin{tabular}{ccc}
\hline Inversión & Monto $(\mathbf{S} /)$. & \% \\
\hline Capital propio & 549,507 & $30 \%$ \\
Financiamiento & $1,270,000$ & $70 \%$ \\
Total & $\mathbf{1 , 8 1 9 , 5 0 7}$ & $\mathbf{1 0 0 \%}$ \\
\hline
\end{tabular}

Elaboración propia

\subsection{Relación tamaño-punto de equilibrio}

Por último, se debe calcular el número de unidades que se debe producir para obtener un beneficio igual a cero, es decir que los costos sean iguales a los ingresos. Se utiliza la siguiente formula:

$$
Q=\frac{\text { Costos Fijos }}{P V u-C V u}
$$

El precio de venta S/ 4.90 corresponde al precio al canal sin igv. El costo variable se obtuvo así:

Tabla 4.4

Costo Variable Unitario (S/)

\begin{tabular}{cc}
\hline & Año 2022 \\
\hline Costo Variable & $2,456,736$ \\
Unidades producidas & $1,020,367$ \\
CV unitario & 2.41 \\
\hline Elaboración propia &
\end{tabular}

Los costos fijos se mantienen igual así no se produzcan unidades e incluyen también los gastos fijos de administración y ventas. Se considera la información del último año.

$$
Q=\frac{534,929+860,857}{4.90-2.41}=560,039 \text { unidades }
$$




\subsection{Selección del tamaño de planta}

Como se puede comprobar en los puntos anteriores, no hay limitaciones para el proyecto en cuanto a recursos productivos ya que Perú es un país productor de la materia prima utilizada, tampoco hay limitación en la tecnología porque existe la maquinaria requerida para la planta y por último la inversión que tampoco llegaría a ser un problema debido a que existen varias alternativas de fuentes de financiamiento.

Debido a las limitaciones del mercado por diversos factores como la aceptación de productos naturales por parte del consumidor peruano y la segmentación geográfica y demográfica de la población, se concluye que el tamaño considerado como óptimo para la planta es de 1,014,406 dips en el año 2022. 


\section{CAPÍTULO V: INGENIERÍA DEL PROYECTO}

\subsection{Definición técnica del producto}

\subsubsection{Especificaciones técnicas del producto}

El proyecto busca cuidar la inocuidad del producto de inicio a fin y encontrarse en óptimas condiciones para el consumo. Es por eso que se debe monitorear, cuidar y cumplir con ciertas variables como el grado de humedad y pH máximo. Además, durante el proceso se asegura eliminar la saponina.

El envasado del producto será en doypack, el cual permite una mejor experiencia en la disposición final del producto, teniendo mayor facilidad para servir y consumir directamente por los clientes. Asimismo, es higiénico y no interfiere con el sabor o composición química del alimento, por lo que la conservación y una vida útil no menor a 18 meses está asegurado. Adicionalmente, esta presentación de 180 gr. al ser vistosa y de mejor presencia en los estantes de supermercados que los envases de vidrio, permitirá mayor exposición para los clientes y aumentará la posibilidad de compra.

\subsubsection{Composición del producto}

Tabla 5.1.

Composición del producto

\begin{tabular}{lccc}
\hline \multicolumn{1}{c}{ Ingrediente } & Cantidad & Unidad & Porcentaje \\
\hline Quinua & 68 & gr & $37.78 \%$ \\
Espárrago & 44 & gr & $24.4 \%$ \\
Brócoli & 37 & gr & $20.6 \%$ \\
Albahaca & 3 & gr & $1.7 \%$ \\
Aceite de oliva* & 10 & gr & $5.6 \%$ \\
Aceite de girasol** & 5 & gr & $2.8 \%$ \\
Cebolla & 4 & gr & $2.2 \%$ \\
Queso parmesano & 2 & gr & $1.1 \%$ \\
Sal & 1 & gr & $0.6 \%$ \\
Limón & 4 & ml & $2.2 \%$ \\
Ajo & 2 & gr & $1.1 \%$ \\
Total & $\mathbf{1 8 0}$ & gr & $\mathbf{1 0 0 \%}$ \\
\hline
\end{tabular}

Elaboración propia

*Calculado en base a la densidad del aceite de oliva: $0.916 \mathrm{~kg} / \mathrm{l}$

**Calculado en base a la densidad del aceite de girasol: 0,918 kg/l. 


\subsubsection{Diseño gráfico del producto}

El doypack que permite una presentación más vistosa del producto en los supermercados, tendrá un fondo blanco con el logo de la marca en la parte frontal, complementado con una franja de quinua blanca y tonos verdes (incluido la tapa) que harán referencia a los vegetales que lleva en su composición.

En la parte posterior se muestran la lista de ingredientes con los porcentajes mayoritarios, la tabla nutricional, sugerencias para su consumo, información de la producción y datos de la empresa.

Las dimensiones serán de $16 \mathrm{~cm}$ de altura, $12 \mathrm{~cm}$ de largo y $3.5 \mathrm{~cm}$ de ancho.

Figura 5.20.

Diseño gráfico del producto

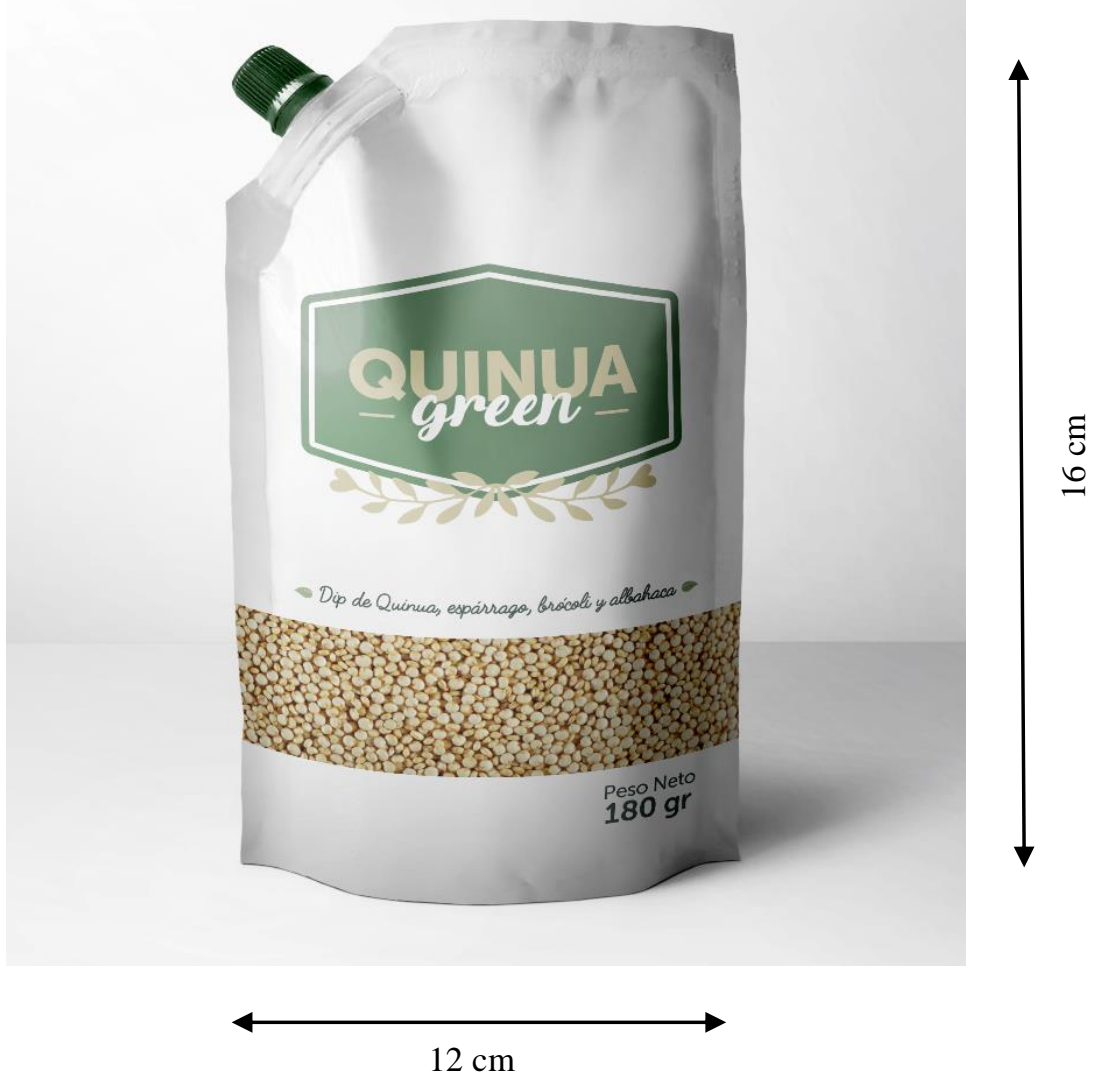

Elaboración propia 


\subsubsection{Regulaciones técnicas al producto}

Para el etiquetado del envase se cumplirá con la ley 28405 - "Ley de rotulado de productos industriales manufacturados" - con el fin de cumplir con el derecho de información de los consumidores. Se incluirá la siguiente información principal:

- Nombre o denominación del producto

- País de fabricación

- Fecha de vencimiento y condiciones de conservación

- Contenido neto

- Nombre y domicilio legal del fabricante

Para complementar, se toma en cuenta también la Norma Técnica Peruana NTP 209.038:2009 ALIMENTOS ENVASADOS. Etiquetado, la cual establece considerar los siguientes puntos en la información del envase:

- Lista de Ingredientes

- Identificación del lote

- Registro sanitario

La información contenida en la etiqueta de este producto y demás productos fabricados en territorio nacional será supervisada y fiscalizada por el Instituto Nacional de Defensa de la Competencia y de la Protección de la Propiedad Intelectual INDECOPI.

\subsection{Tecnologías existentes y procesos de producción}

Debido a que se puede encontrar productos similares en el mercado o productos derivados en base a los ingredientes del dip, se puede afirmar que existe la tecnología necesaria para el desarrollo del proyecto.

\subsubsection{Naturaleza de la tecnología requerida}

\subsubsection{Descripción de las tecnologías existentes}

A continuación, se describe brevemente los métodos disponibles para las principales operaciones unitarias. 


\section{A. Lavado}

Esta actividad constituye una de las más importantes en el proceso, ya que de ella depende poder continuar con una materia prima en óptimas condiciones y libre de microorganismos, suciedad y otras partículas que comúnmente acompañan las cosechas. Los tres posibles métodos son:

Por aspersión: La materia prima pasa por una ducha de agua a presión, y va avanzando a través de una faja transportadora.

Por inmersión: Consiste en introducir la materia prima en un tanque con agua o solución desinfectante y dejar reposar o mover con un agitador por un periodo de tiempo.

Por flotación: se basa en la densidad de la materia prima, donde al ser colocada en un tanque con agua se separará de las impurezas.

\section{B. Trozado}

Los alimentos que componen el dip deben tener un tamaño preciso para que al momento de su consumo, el cliente pueda notar el sabor característico de cada uno de ellos.

Manual: cuando se requiere cortar los insumos de una manera particular y con mayor control. En el caso de alimentos de gran tamaño, se puede realizar como una pre-etapa al trozado mecánico.

Mecánico: se realiza mediante el uso de la máquina trozadora, la cual permite cortar los alimentos en partes de menor tamaño según el ajuste indicado.

\section{Cocción}

Para la cocción de algunos alimentos existe tres métodos principales, estos son: cocción por calor húmedo, cocción por calor seco y cocción mixta; se aplicará la primera alternativa mencionada. Se procede a describir los métodos dentro de este grupo.

Al vapor: los alimentos son cocidos con el vapor generado por la ebullición del agua, nunca entrando en contacto directo. 
Hervir: se introduce el alimento dentro de un tanque con agua en ebullición, teniendo en cuenta el punto exacto de cocción para evitar pérdida del valor nutritivo.

Olla a presión: consiste en introducir los alimentos dentro de una olla especial con cierre hermético y que posee una válvula para eliminar el vapor. El tiempo de cocción es 1/3 del método regular.

\section{Enfriamiento}

Después de la operación de escaldado de los alimentos, con mayor razón al ser vegetales verdes, se debe proceder con el enfriamiento adecuado para conservar el color y la textura.

Por inmersión: Los alimentos previamente cocidos son introducidos a un tanque con agua y hielo, de esta manera se detiene inmediatamente la cocción.

Con Aire: se realiza a temperatura ambiente y puede ser usado en alimentos que no requieren de mucha prisa para continuar con la siguiente actividad del proceso o cuando no se quiere alterar las condiciones físicas y/o químicas del alimento.

\section{E. Mezclado}

Esta operación unitaria tiene como finalidad obtener una mezcla homogénea entre todos los ingredientes del producto. De esto va a depender la forma del recipiente, la técnica, la velocidad y el tiempo a aplicar.

De paletas: dentro de un tanque que contiene una paleta vertical, horizontal o inclinada, se procede a agitar la mezcla. Recomendado para pastas espesas por su buen trabajo y bajo costo.

Hélices: la acción de mezclado nace a partir de unas hélices o aletas helicoidales que empujan la mezcla hacia adelante generando un efecto cíclico dependiendo de la forma del recipiente. Utilizado para líquidos de viscosidad media. 
Con turbinas: también llamado mezclado de impulsor centrífugo, lleva una corona directriz con paletas curvas fijas que impulsan la mezcla con una velocidad elevada que permite alcanzar las partes más alejadas del recipiente. Funciona con líquidos de baja y media viscosidad.

\section{F. Envasado}

Comprende la etapa de llenado de los envases con el posterior sellado, el cual debe evitar la presencia del aire en el interior, permitiendo así una mejor conservación del producto y por lo tanto una mayor vida útil.

Vacío mecánico: este método se basa en retirar el aire del envase con la ayuda de una máquina. En el caso de envases plásticos, se colocan en una cámara la cual aspira el aire, sella y airea. Para las latas o envases de vidrio se procede a ingresarlos a una cámara herméticamente cerrada donde una bomba extrae el aire creando el vacío, inmediatamente se procede a sellar.

Con pistón: La mezcla es transportada a través de una bomba hacia una tolva de dosificación, por la cual a través de un pistón regulado va llenando los envases. La temperatura de la mezcla hará que el aire salga del envase junto con el vapor.

\section{G. Codificado}

Para la codificación de lotes y fechas de vencimiento en los envases doypack es necesario conseguir una máquina que vaya a un ritmo de producción similar a la envasadora.

Laser: usado para envases de cartón, plástico y papel principalmente, esta tecnología permite colocar la información y código de barras sin hacer contacto con la superficie del envase. De preferencia, se usa para la aplicación de pocos caracteres.

Tinta: es una opción más económica que usa gotas de tinta para la impresión de caracteres en los envases. Trabajan sobre cualquier superficie y utilizan una tecnología sin contacto. 


\subsubsection{Selección de la tecnología}

Tras revisar la tecnología existente para cada uno de los procesos, se elige la opción que más se ajusta al proceso para su implementación, basado principalmente en las características de los insumos y cantidades.

Tabla 5.2.

Tecnología disponible

\begin{tabular}{|c|c|c|}
\hline Operación & Tecnología & Justificación \\
\hline Lavado & Inmersión & $\begin{array}{l}\text { Permite mejor lavado mediante inmersión y agitación } \\
\text { suave. }\end{array}$ \\
\hline Trozado & Manual / Mecánico & $\begin{array}{l}\text { Se necesita de ambos cortes para llegar al tamaño } \\
\text { adecuado. }\end{array}$ \\
\hline Cocción & Hervir & $\begin{array}{l}\text { La técnica a utilizar depende de la consistencia del } \\
\text { insumo. }\end{array}$ \\
\hline Enfriamiento & Inmersión / Aire & $\begin{array}{l}\text { La técnica a utilizar depende de la consistencia del } \\
\text { insumo. }\end{array}$ \\
\hline Mezclado & Paletas & Permite conseguir una mezcla más homogénea. \\
\hline Envasado & Pistón & $\begin{array}{l}\text { Se ajusta al envase doypack y a la densidad de la } \\
\text { mezcla. }\end{array}$ \\
\hline Codificado & Tinta & $\begin{array}{l}\text { Se van a imprimir pocos caracteres y es el método más } \\
\text { económico. }\end{array}$ \\
\hline
\end{tabular}

Elaboración propia

\subsubsection{Proceso de producción}

De acuerdo con la información obtenida durante las visitas a la planta de Danper y entrevistas realizadas al gerente de la misma, Ing. Javier Gilardi, durante el 2016 y 2017; complementado con la revisión de fuentes bibliográficas referidas a procesos agroindustriales se pudo determinar el proceso a seguir para el producto elegido.

\subsubsection{Descripción del proceso}

El proceso se inicia con la recepción de cada uno de los insumos en el almacén de materia prima. En la selección, se descartan los insumos que visualmente se verifica que no son aptos para producción, ya sea por tamaño, aspecto físico u otra variable y se procede a pesar de manera individual llevando un registro de ingreso.

Para el lavado de la quinua y vegetales se usará una solución acuosa conformada por agua e hipoclorito de sodio, en proporción de $5 \mathrm{ml}$ de compuesto por litro de solución. 
Esta agua clorada será utilizada dentro del tanque de lavado y tiene como objetivo una limpieza más eficaz frente a los microorganismos.

La quinua blanca, insumo principal, es lavada con agua clorada y filtrada para retirar todas las partículas no deseadas que fueron trasladadas en la etapa de la cosecha. Esta actividad se realiza dos veces con el fin de eliminar el sabor amargo y valor antinutricional de la saponina, la cual representa el $1.9 \%$ de peso en esta variedad (Tellería, 1978). Luego, continua la etapa de hidratación por inmersión, para ello en una tina de acero inoxidable se colocará agua caliente en proporción de 1.5 veces la cantidad de quinua; se debe dejar reposando por 10 minutos. Se filtran los granos con un tamiz y se comprueba que la quinua ha incrementado su peso en $52 \%$. La quinua hidratada se coloca en una marmita, donde se agregará 1.5 litros de agua por cada kilogramo de quinua y se deja cocinar a una temperatura de $95^{\circ} \mathrm{C}$ durante 15 minutos. Durante la etapa de cocción la quinua absorbe toda el agua e incrementa su peso en 1.74 veces. Luego se deja reposar y enfriar a temperatura ambiente, quedando lista la quinua cocida para la etapa de mezclado con otros ingredientes.

El espárrago es lavado con agua a temperatura ambiente para eliminar residuos de la cosecha y se corta en partes, retirando la parte fibrosa inferior denominada "tocón". Para su cocción se procede a colocar el espárrago, previamente pesado para llevar un control, dentro de un tanque con agua en ebullición durante 8 minutos. Al finalizar, será sumergido por un tiempo máximo de 30 segundos dentro de agua con hielo para detener inmediatamente la cocción y mantener la textura y color requerido. Luego, pasa a ser trozado y queda listo para la mezcla.

El brócoli es lavado y desinfectado con agua clorada a temperatura ambiente con el fin de eliminar los rastros de tierra y presencia de carga microbiana. Se corta la parte excesiva del tallo con el cuidado requerido para que no se separe en partes pequeñas. Se procede a introducir en un tanque con agua en ebullición, lo que permite cerrar los poros rápidamente logrando que las vitaminas y minerales no escapen al agua, por un tiempo de 5 a 7 minutos para su cocción. El agua debe contener sal, en ración de 30g por litro, con el fin de hacer frente al dióxido de carbono producido por la cocción y mantener el color verde de la clorofila. Para el enfriamiento del brócoli se usará agua con hielo al igual que con el espárrago. En la etapa de trozado se buscará tener una consistencia similar a la de una pasta para que pueda ingresar a la mezcla. 
La albahaca es lavada con agua clorada y deshojada; descartando los tallos y la parte fibrosa. El trozado en la máquina se lleva a cabo 2 veces con el fin de llegar al tamaño aproximado de $0.5 \mathrm{~cm}$.

El limón a utilizar, es lavado rápidamente por un operario, quien también se encarga de cortar y exprimir de manera manual. Se usa como conservante natural y saborizante.

El queso parmesano es adquirido en bloques de $2 \mathrm{~kg}$, los cuales son cortados en 8 pedazos para disminuir su tamaño y así pasar a ser rallados manualmente.

La cebolla es lavada y cortada de manera manual por el operario, quien reduce en primera instancia una cebolla en 4 partes para luego ingresarla a la licuadora industrial y obtener una pasta. Es preferible el licuado antes que el trozado, para evitar que pequeños trozos de cebolla aparezcan en el producto final.

La materia prima e insumos son pesados individualmente de acuerdo a las proporciones establecidas y se agregan a una marmita con agitador para su mezclado, el cual se llevará a cabo por 15 minutos a una temperatura de $60^{\circ} \mathrm{C}$. De manera simultánea, se adicionan sal, ajo molido, aceite de oliva extra virgen y aceite de girasol; estos ingredientes mejoran el sabor y ayudan en la consistencia del producto final. Cada proceso se realizará en lotes de $200 \mathrm{~kg}$ de producto terminado.

A través de una bomba, la mezcla es alimentada a la tolva de dosificación de la máquina envasadora especial para doypack, la cual obtiene los envases a través de una faja transportadora. La envasadora se encarga de recibir los envases, abrirlos, llenarlos y sellarlos con ayuda de sus cabezales.

Después del cierre de los envases, se procede con la impresión de tinta de la fecha de producción, fecha de vencimiento y número de lote a través de la codificadora. Una vez realizado, el último cabezal suelta el envase para que siga su curso por la faja transportadora hacia una jaba que se encuentra al final de la línea de producción.

Por último, se hace una revisión de los envases a través de un muestreo aleatorio y son llenados de manera manual en cajas de 12 unidades para ser transportados al almacén de productos terminados.

El dip de quinua y vegetales verdes contará con una vida útil de 1 año almacenado a temperatura ambiente y sin exposición solar; una vez abierto, la vida útil se reduce a 7 días refrigerado. 


\subsubsection{Diagrama de proceso: DOP}

Figura 5.21.

Diagrama de operaciones de proceso para la elaboración de un dip a base de quinua y vegetales verdes

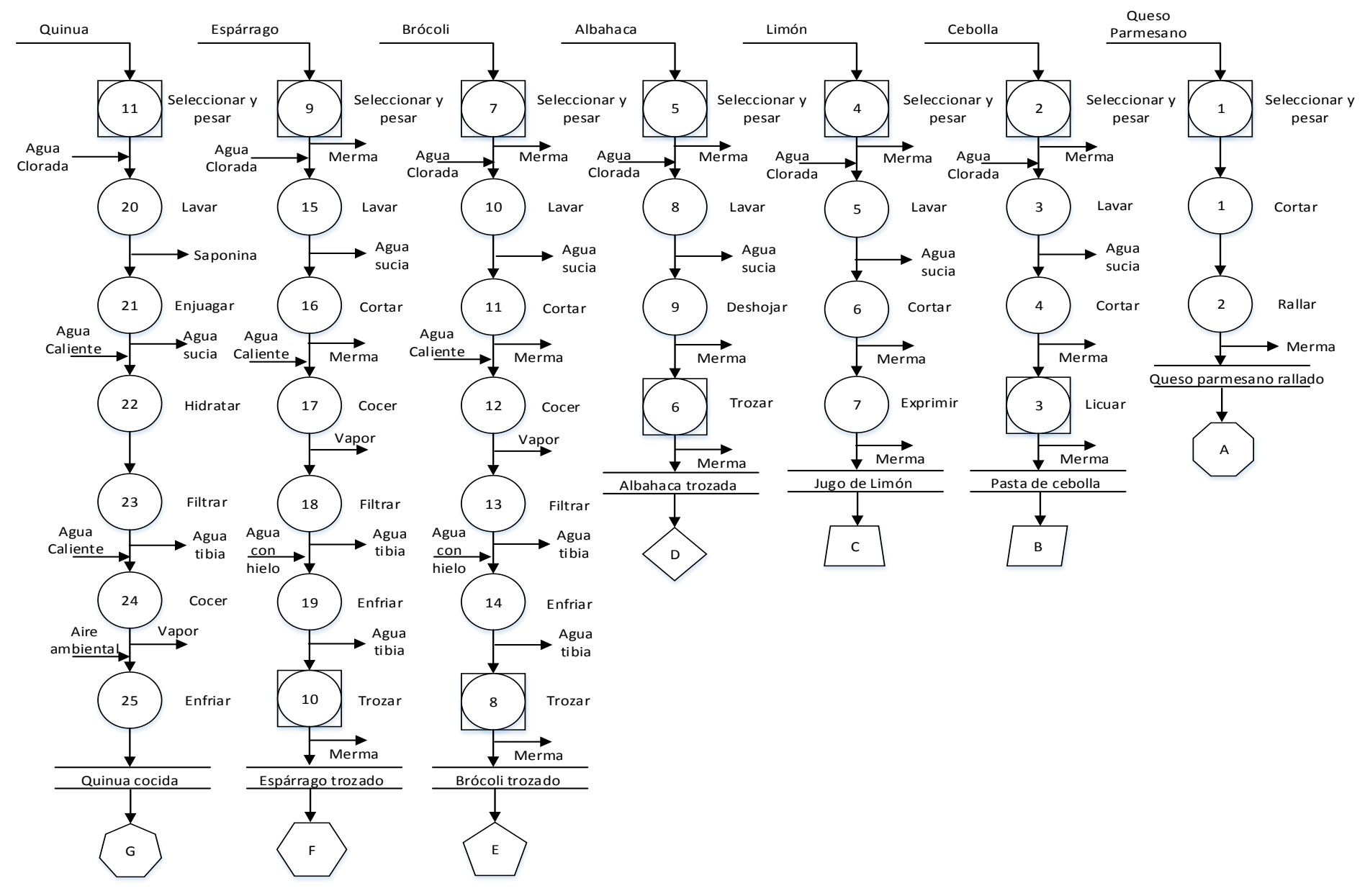



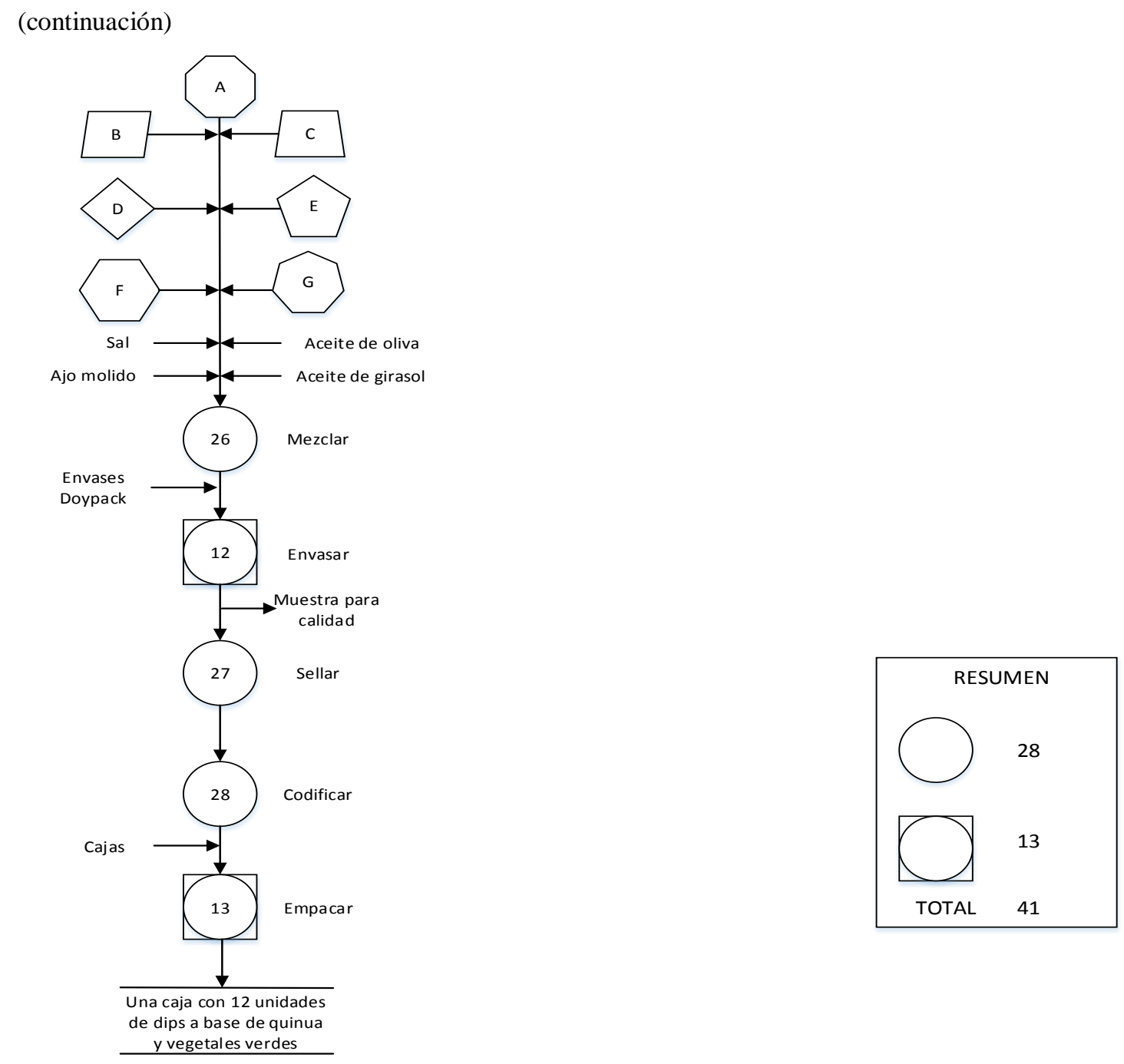

Elaboración propia 


\subsubsection{Balance de materia y energía}

Figura 5.22.

Balance de materia de la producción del año 2022

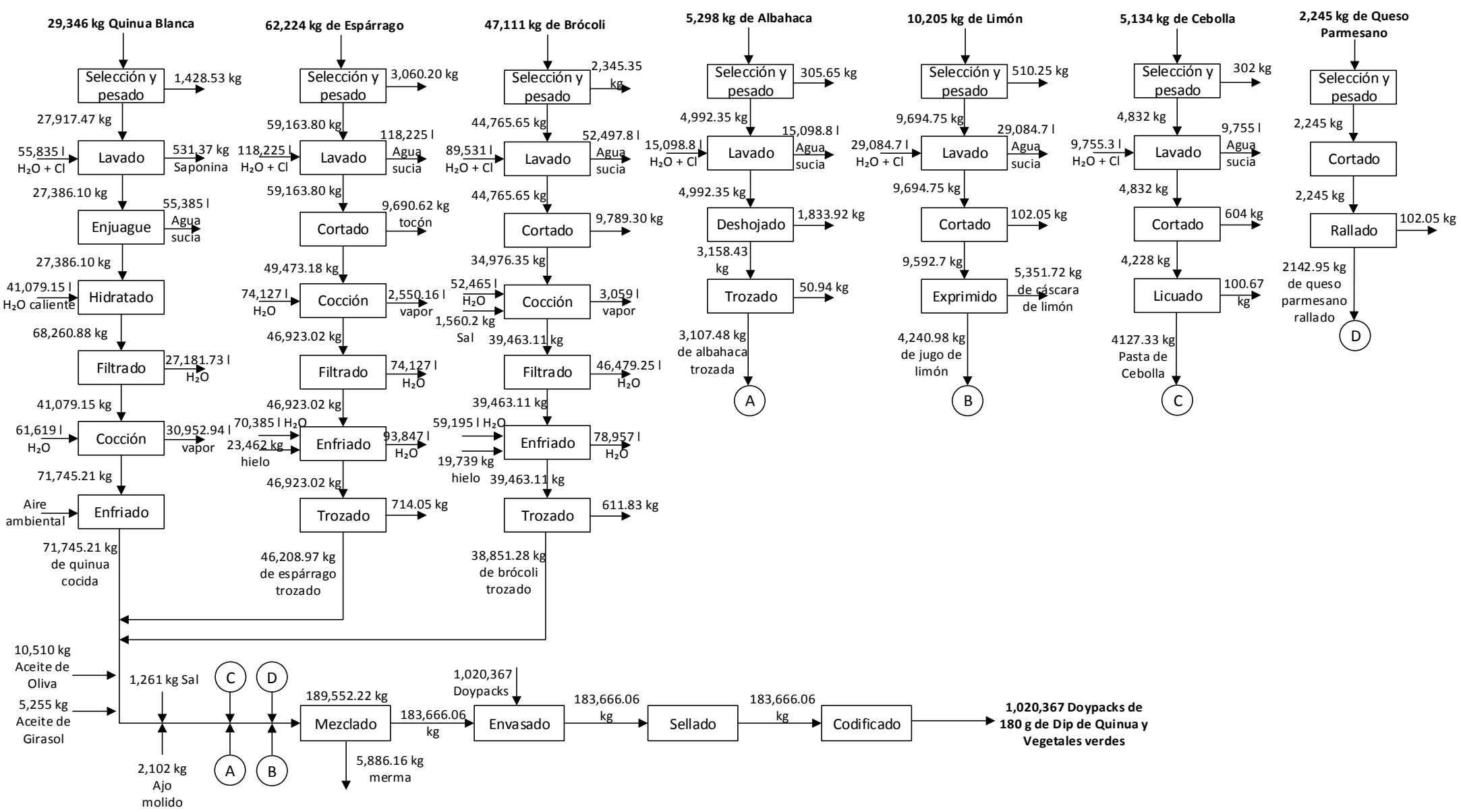

Elaboración propia 


\subsection{Características de las instalaciones y equipos}

\subsubsection{Selección de la maquinaria y equipos}

Una de las etapas más importantes dentro de un proyecto para la instalación de una planta es la selección de la maquinaria y equipos a utilizar. Esto se debe a que esta decisión afecta directamente al plan de inversión, a la capacidad de producción, a la calidad del producto terminado y a la imagen de la empresa frente a auditorías de clientes.

Para realizar una selección idónea es necesario tener como punto de inicio una revisión a detalle de las especificaciones técnicas de cada una de las alternativas, esto incluye material de fabricación, rendimiento o capacidad, potencia, consumo de energía, y dimensiones principalmente. Teniendo claro lo que se está buscando técnicamente se procede a evaluar otros factores relevantes como el precio de la máquina, el servicio postventa y la facilidad de reparación o de adquisición de repuestos.

\section{$\underline{\text { Lista de maquinaria }}$}

02 Marmitas

01 Trozadora

01 Envasadora

01 Codificadora

01 Bomba de transferencia

\section{$\underline{\text { Lista de equipos }}$}

01 Faja transportadora

01 Balanza Electrónica

01 Balanza de plataforma

01 Balanza de piso

01 Tina de acero inoxidable

01 Tamiz

01 Lavadero de 2 pozas

04 Mesas de trabajo

01 Máquina para hacer hielo

04 Apiladores manuales

01 Phmetro 
01 Exprimidor

02 Espumaderas medianas

04 Tazas graduadas $600 \mathrm{cc}$

01 Licuadora industrial

01 Rallador de queso

Lo más recomendable para la industria alimentaria es el uso de acero inoxidable, el cual es un material resistente a la corrosión y a las variaciones térmicas. Una de sus principales ventajas es el tema de la higiene, ya que al tener una superficie totalmente compactada es fácil de limpiar y no aporta partículas por desprendimiento.

\subsubsection{Especificaciones de la maquinaria}

La elección de la maquinaria idónea para la línea de producción del Dip a base de quinua $y$ vegetales verdes requiere de un estudio a detalle de cada una de las alternativas, evaluando sus características técnicas, capacidad, simplicidad, dimensiones y servicio post-venta. A continuación, se detalla una breve descripción de las alternativas:

\section{$\underline{\text { Marmita }}$}

Es un tanque de acero inoxidable con doble chaqueta que llevará un agitador por dentro. Se necesitan 02 unidades, uno para la mezcla de ingredientes del dip y otro para la cocción de los insumos.

\section{Figura 5.23.}

Marmita con agitador interno

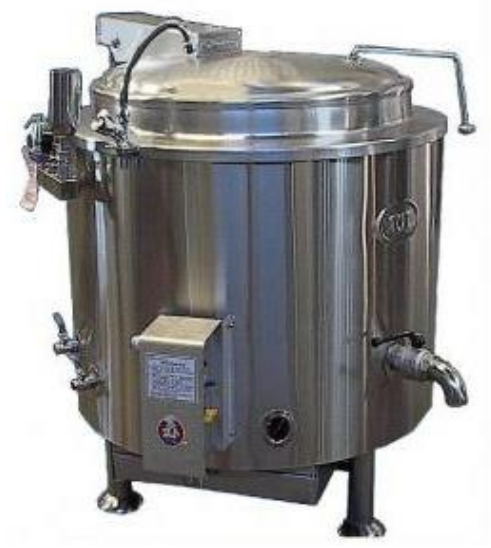

Fuente: Usinox (2017) 
Tabla 5.3.

Especificaciones de las marmitas

\begin{tabular}{cc}
\hline & MARMITA \\
\hline Capacidad & $200 \mathrm{~kg}$ \\
Fabricante & Vulcanotec \\
Modelo & MRV 300 \\
Material & Acero inoxidable \\
Procedencia & Perú \\
Potencia & $2.0 \mathrm{HP}$ \\
Consumo & $27 \mathrm{kw}$ \\
Peso & $185 \mathrm{~kg}$ \\
& Alto: $1.1 \mathrm{~m}$ \\
Dimensiones & Largo: $1.05 \mathrm{~m}$ \\
& Ancho: $1.15 \mathrm{~m}$ \\
\hline
\end{tabular}

Fuente: Usinox (2017)

Elaboración propia

\section{Trozadora}

Permite realizar cortes precisos de hasta $2 \mathrm{~mm}$, esto es posible por la variedad de cuchillas incluidas en el set, son de fácil recambio y pueden cortar en bastones, cubos e incluso rallar. Cuenta con dos entradas, una relativamente grande que puede permitir, en este caso, el fácil ingreso de brócoli y queso parmesano; y otra entrada pequeña pero más larga para el espárrago y albahaca. Aprobada por la FDA.

Figura 5.24.

Trozadora

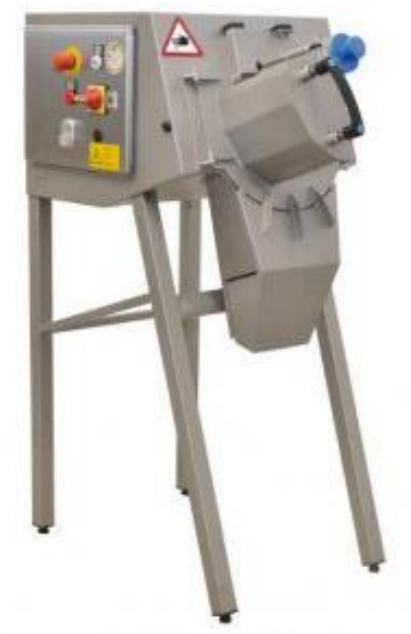

Fuente: Kronen (2017) 
Tabla 5.4.

Especificaciones de la trozadora

\begin{tabular}{cc}
\hline & TROZADORA \\
\hline Capacidad & $200 \mathrm{~kg} / \mathrm{h}$ \\
Fabricante & Kronen \\
Modelo & KSM 100 \\
Material & Acero inoxidable \\
Procedencia & Alemania \\
Consumo & $1.2 \mathrm{~kW}$ \\
Peso & $80 \mathrm{~kg}$ \\
& Alto: $1.235 \mathrm{~m}$ \\
Dimensiones & Largo: $1.003 \mathrm{~m}$ \\
& Ancho: $0.856 \mathrm{~m}$ \\
\hline Fuente: Kronen (2017) \\
Elaboración propia
\end{tabular}

\section{Máquina envasadora}

Permite que se lleve a cabo la etapa de llenado de envases, pasando primero por la etapa de dosificación de mezcla hasta el sellado de los envases.

Figura 5.25.

Máquina envasadora

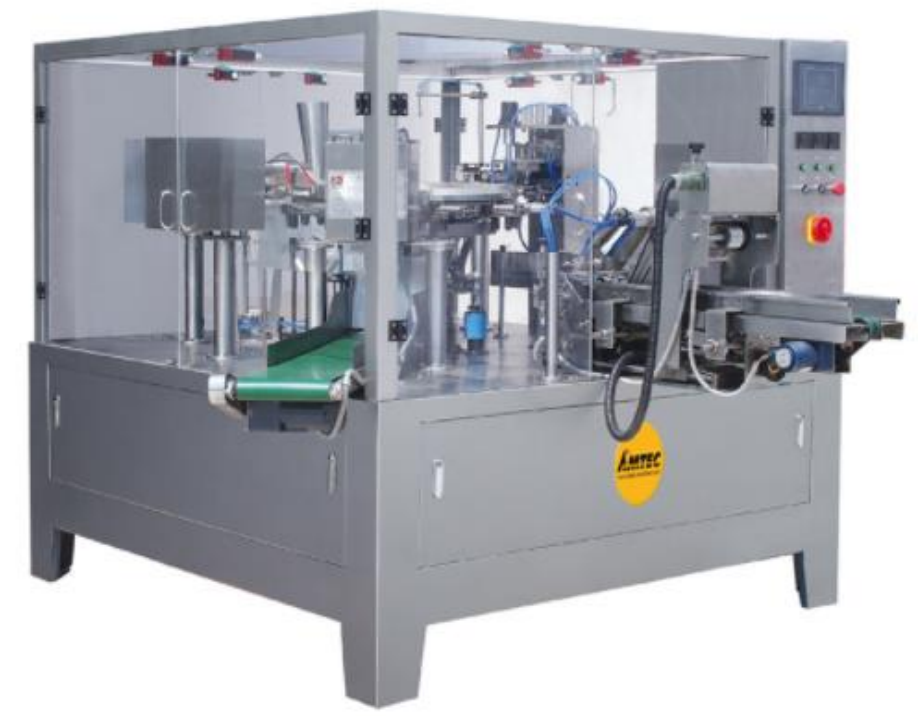

Fuente: Alibaba (2017) 
Tabla 5.5.

Especificaciones de la máquina envasadora

\begin{tabular}{|c|c|}
\hline \multicolumn{2}{|c|}{ MÁQUINA ENVASADORA } \\
\hline Capacidad & 15 envases por minuto \\
\hline Fabricante & Welin \\
\hline Modelo & WL-RPM200 \\
\hline Material & Acero inoxidable \\
\hline Procedencia & China \\
\hline Consumo & $4.0 \mathrm{kw}$ \\
\hline Peso & $350 \mathrm{~kg}$ \\
\hline Dimensiones & $\begin{array}{l}\text { Alto: } 1.45 \mathrm{~m} \\
\text { Largo: } 1.62 \mathrm{~m} \\
\text { Ancho: } 1.50 \mathrm{~m}\end{array}$ \\
\hline \multicolumn{2}{|c|}{$\begin{array}{l}\text { Fuente: Alibaba (2017) } \\
\text { Elaboración propia }\end{array}$} \\
\hline \multicolumn{2}{|c|}{ Codificadora de tinta } \\
\hline \multicolumn{2}{|c|}{$\begin{array}{l}\text { Se usa para imprimir información relevante en el envase, incluyendo la fecha de } \\
\text { vencimiento, número de lote y código de barras. La opción elegida permite una } \\
\text { configuración más amigable gracias a la pantalla táctil de } 12.1 \text { pulgadas que cuenta con } \\
\text { opciones pre establecidas sobre códigos de barra, numeración, tipos de letra y más } \\
\text { características de impresión. Tiene capacidad para colocar un segundo cabezal de } \\
\text { impresión. }\end{array}$} \\
\hline
\end{tabular}

Figura 5.26.

Codificadora de tinta

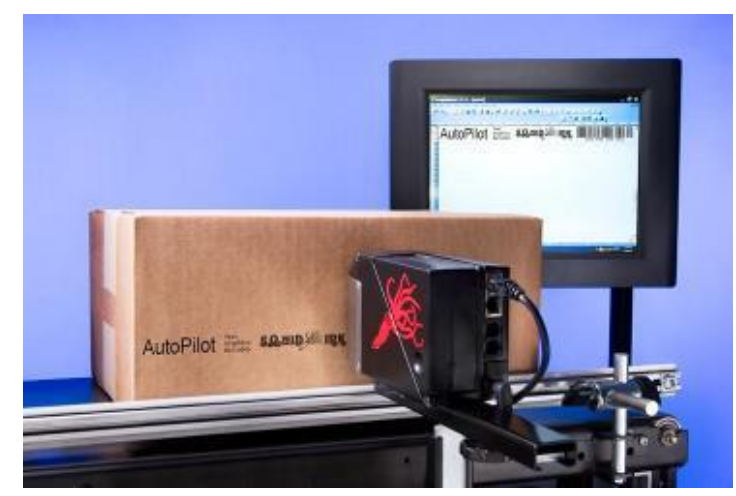

Fuente: SquidInk (2017) 
Tabla 5.6.

Especificaciones de la máquina codificadora

\section{MÁQUINA CODIFICADORA}

\begin{tabular}{|c|c|}
\hline Capacidad & 30 envases por minuto \\
\hline Fabricante & SquidInk \\
\hline Modelo & Autopilot \\
\hline Material & Acero \\
\hline Procedencia & Estados Unidos \\
\hline Potencia & $0.5 \mathrm{HP}$ \\
\hline Consumo & $0.8 \mathrm{kw}$ \\
\hline Dimensiones & $\begin{array}{c}\text { Alto: } 0.25 \mathrm{~m} \\
\text { Largo: } 0.2 \mathrm{~m} \\
\text { Ancho: } 0.16 \mathrm{~m}\end{array}$ \\
\hline
\end{tabular}

\section{$\underline{\text { Bomba de transferencia }}$}

Permite el bombeo de la mezcla de manera rápida sin afectar la calidad o propiedades desde la marmita hacia la tolva de dosificación. Cuenta con alta capacidad de succión y viene con un sensor óptico que se adapta a la tolva de dosificación que permite ajustar el flujo y la velocidad de la bomba. Puede transferir partículas de hasta $25 \mathrm{~mm}$.

\section{Figura 5.27.}

Bomba de transferencia

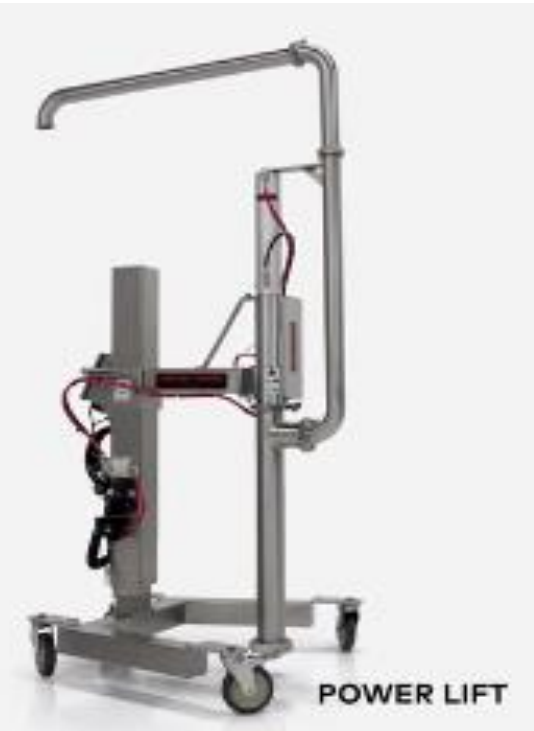

Fuente: Unifiller (2017) 
Tabla 5.7.

Especificaciones de la bomba de transferencia

\begin{tabular}{cc}
\hline \multicolumn{2}{c}{ BOMBA DE TRANSFERENCIA } \\
\hline Capacidad & 11 litros/min \\
Fabricante & Unifiller \\
Modelo & Hopper Topper Power Lift \\
Material & Acero inoxidable \\
Procedencia & España \\
Potencia & $1.5 \mathrm{HP}$ \\
Consumo & $1.5 \mathrm{kw}$ \\
Peso & $113 \mathrm{~kg}$ \\
& Alto: $1.78 \mathrm{~m}$ \\
Dimensiones & Largo: $0.97 \mathrm{~m}$ \\
& Ancho: $0.56 \mathrm{~m}$ \\
\hline
\end{tabular}

Fuente: Unifiller (2017)

Elaboración propia

\section{$\underline{\text { Equipos }}$}

\section{Faja transportadora}

Fabricada con acero y guías laterales de plástico. Se necesitan 2 tramos de faja transportadora, uno sirve para el transporte de los envases doypack vacíos hacia la primera estación de la máquina envasadora y la segunda para el transporte de los productos terminados hacia la estación de encajado.

\section{Figura 5.28.}

Faja transportadora

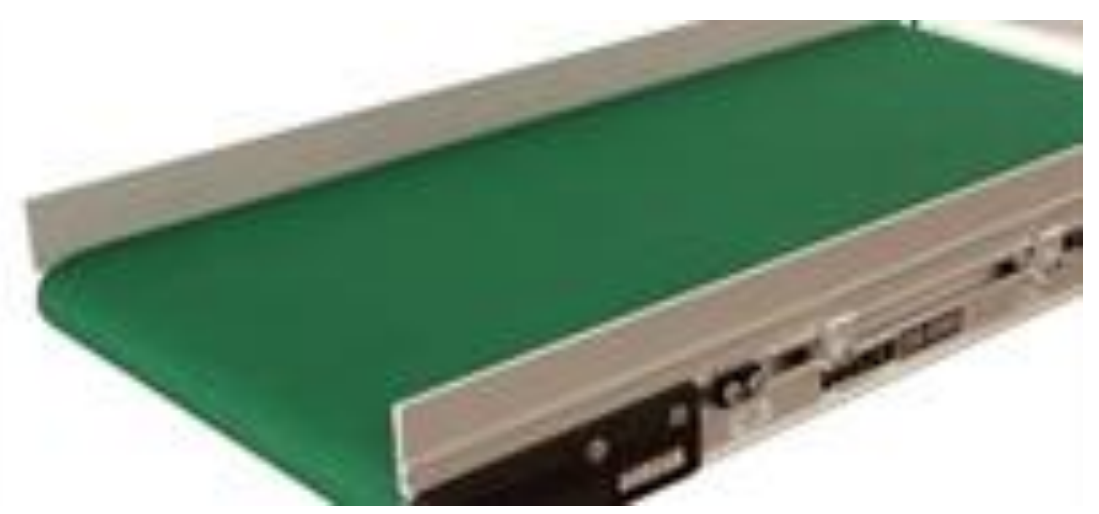

Fuente: Dorner Conveyors (2017) 
Tabla 5.8.

Especificaciones de la faja transportadora

\begin{tabular}{cc}
\hline \multicolumn{1}{c}{ FAJA TRANSPORTADORA } \\
\hline Capacidad & $113 \mathrm{~m} / \mathrm{min}-91 \mathrm{~kg}$ \\
Fabricante & Dorner Conveyors \\
Modelo & 2200 Precision moves \\
Material & Goma con aditivos \\
antimicrobianos \\
Erocedencia & Estados Unidos \\
Potencia & $1 \mathrm{HP}$ \\
Consumo & $1.4 \mathrm{~kW}$ \\
& Alto: $1.20 \mathrm{~m}$ \\
Limensiones & Ancho: $0.28 \mathrm{~m}$ \\
\hline Fuente: Dorner Conveyors (2017)
\end{tabular}

Fuente: Dorner Conveyors (2017)

Elaboración propia

\section{Balanza electrónica}

Esta balanza será utilizada para los controles de calidad y en ocasiones puntuales donde se deba agregar pequeñas cantidades de materia prima a la mezcla. Es resistente al agua y a la corrosión, y tiene una función especial de control de peso con señalización luminosa para el muestreo aleatorio de los envases terminados.

Modelo: IP68 Water Proof Scale

Material: Acero inoxidable

Dimensiones: $0.6 \times 0.6 \times 1.0 \mathrm{~m}$

Capacidad: $500 \mathrm{~kg}$

Figura 5.29.

Balanza electrónica

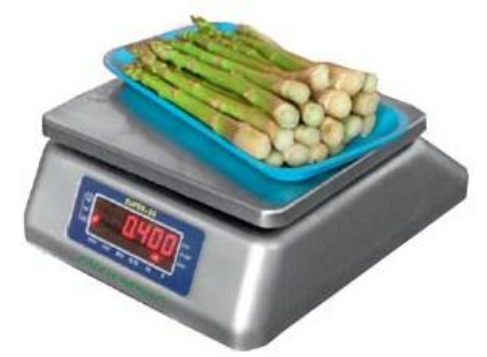

Fuente: Suminco (2017) 


\section{Balanza de plataforma}

Para facilitar el pesado de cantidades pequeñas y medianas durante varias etapas del proceso, se requiere una balanza de plataforma que además de su movilidad, ofrezca fácil manejo y gran precisión.

Modelo: 2056

Material: Acero inoxidable

Dimensiones: 0.6 × 0.6 x $1.0 \mathrm{~m}$

Capacidad: $500 \mathrm{~kg}$

Figura 5.30.

Balanza de plataforma

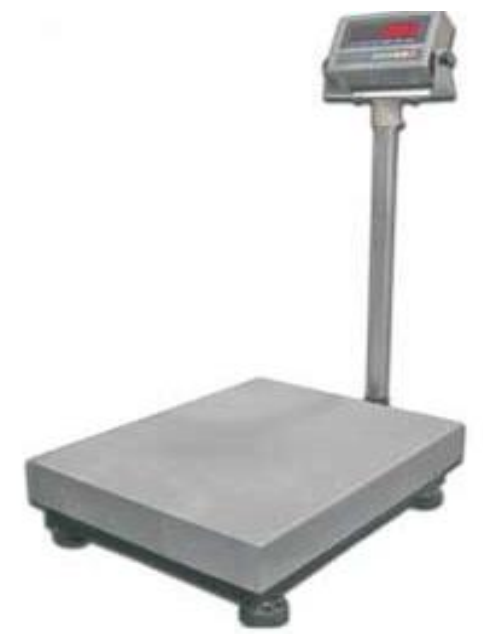

Fuente: Suminco (2017)

\section{$\underline{\text { Balanza de piso }}$}

Se requiere una balanza de mayores dimensiones para pesar la materia prima cuando ingresa a planta y para el producto terminado, ya sea cuando ingresa al almacén o cuando será despachado.

Modelo: Floorcell 2456

Material: Acero inoxidable

Dimensiones: 1.0 x $1.0 \mathrm{~m}$

Capacidad: $1,000 \mathrm{~kg}$ 
Figura 5.31.

Balanza de piso

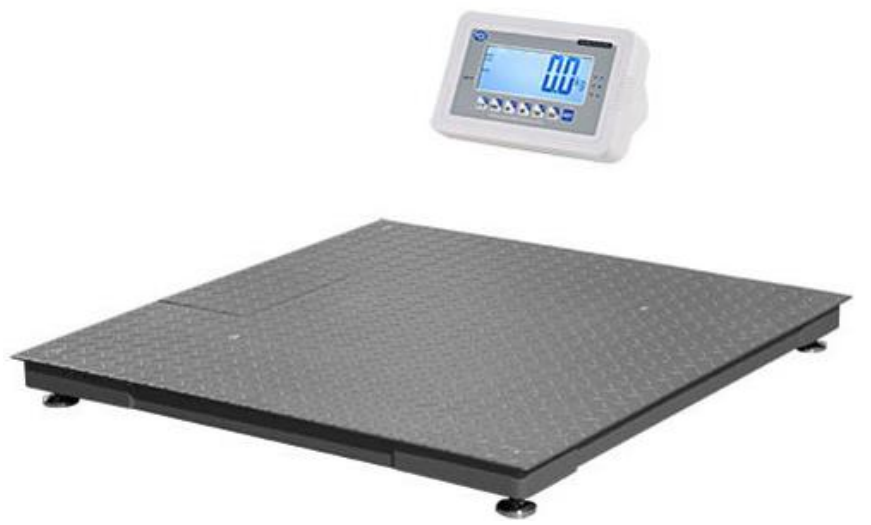

Fuente: PCE-Iberica (2017)

\section{Tina de Acero Inoxidable}

Se requiere 2 unidades, una para la hidratación de la quinua con agua caliente y otra para el enfriamiento inmediato con hielo del brócoli y espárrago, con el objetivo de detener la cocción de inmediato y mantener su consistencia y color.

Material: Acero inoxidable

Dimensiones: 1.10 x $0.6 \times 1.2 \mathrm{~m}$

Capacidad: $80 \mathrm{~L}$

Figura 5.32.

Tina de acero inoxidable

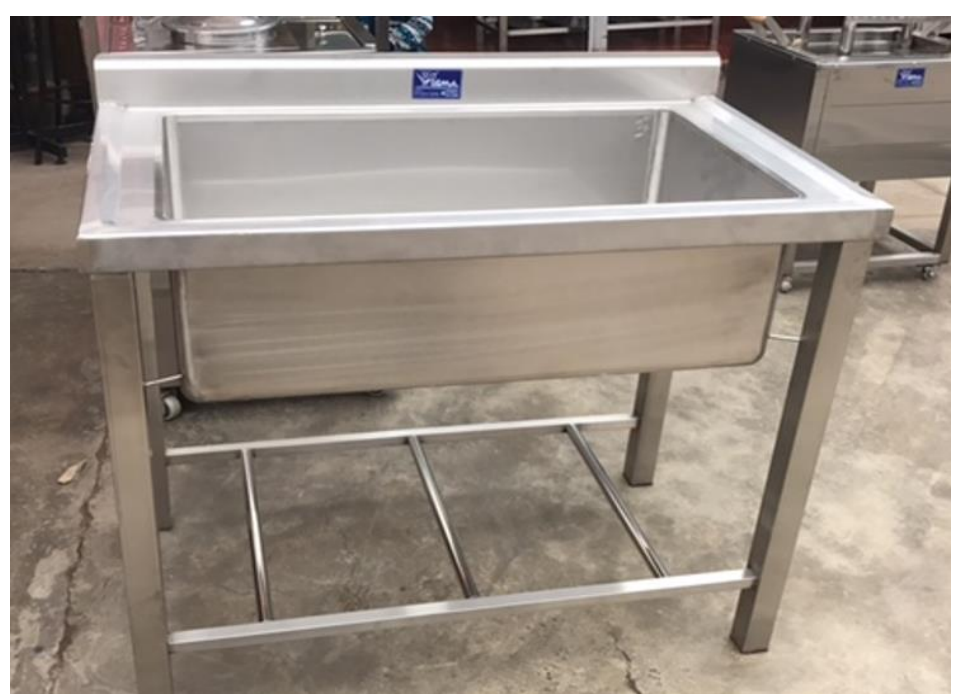

Fuente: Parque Industrial de Villa El Salvador (2017) 


\section{$\underline{\text { Tamiz }}$}

Ayuda al filtrado de la quinua después de su hidratación, la malla debe ser apropiada para que solo pase agua.

Material: Acero inoxidable

Dimensiones: 1.05 x 0.55 x $0.3 \mathrm{~m}$

Figura 5.33.

Tamiz

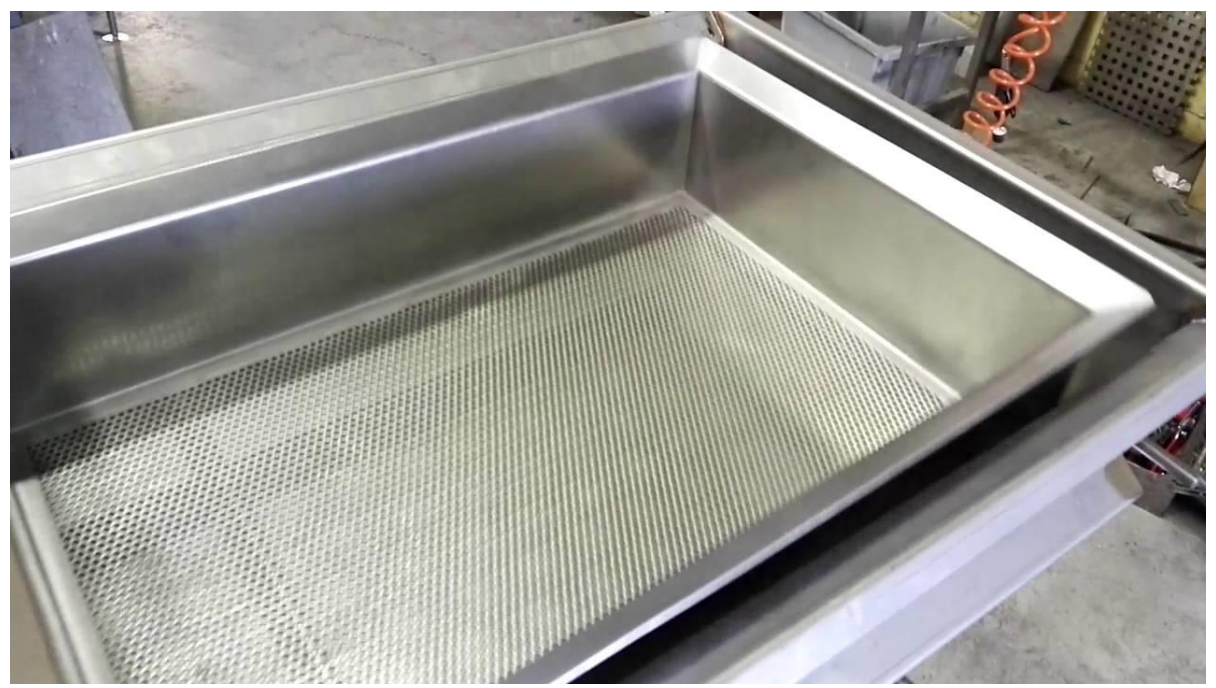

Fuente: Google (2017)

\section{Lavadero de 2 pozas}

Tiene como función principal el lavado de insumos al inicio del proceso. Contar con 2 pozas permitirá mejorar el tiempo de lavado y optimizar el consumo de agua. La superficie plana servirá como apoyo para colocar bandejas o colocar un tacho en la parte inferior para los residuos.

Material: Acero inoxidable

Dimensiones: 1.40 x 0.6 x $1.20 \mathrm{~m}$

Capacidad: $30 \mathrm{~L}$ por poza 
Figura 5.34.

Lavadero de 2 pozas

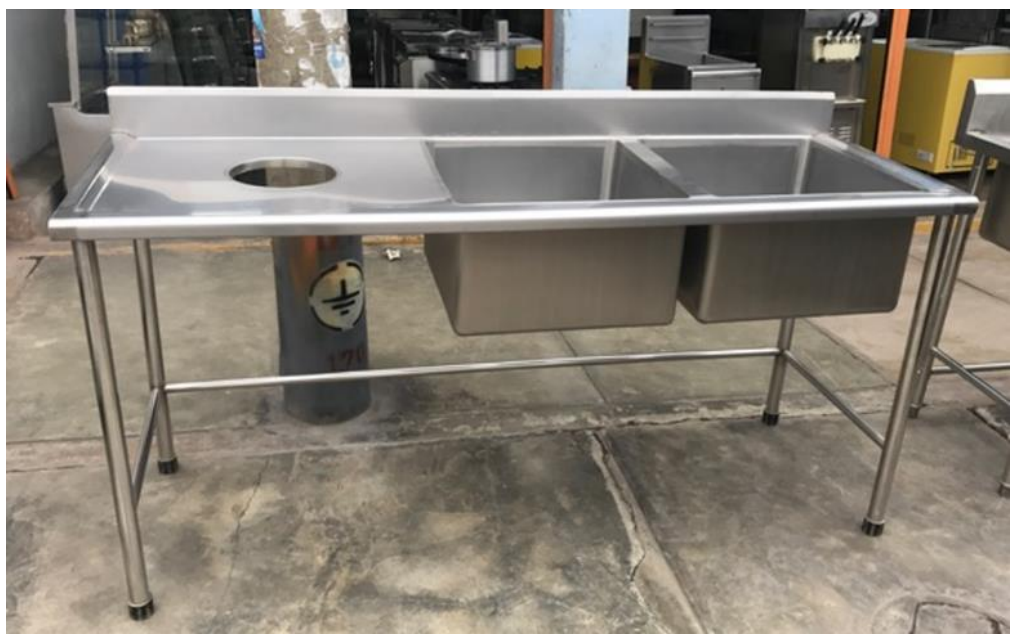

Fuente: Parque industrial de Villa El Salvador (2017)

Mesa de trabajo

Dos mesas se usarán exclusivamente para el cortado manual de los insumos de mayor tamaño, las otras para actividades de apoyo como pesado de insumos en balanza digital, muestreos de calidad, etc.

Cantidad: 04 unidades

Material: Acero inoxidable

Dimensiones: 1.10 x $0.60 \times 1.20 \mathrm{~m}$

Figura 5.35.

Mesa de trabajo

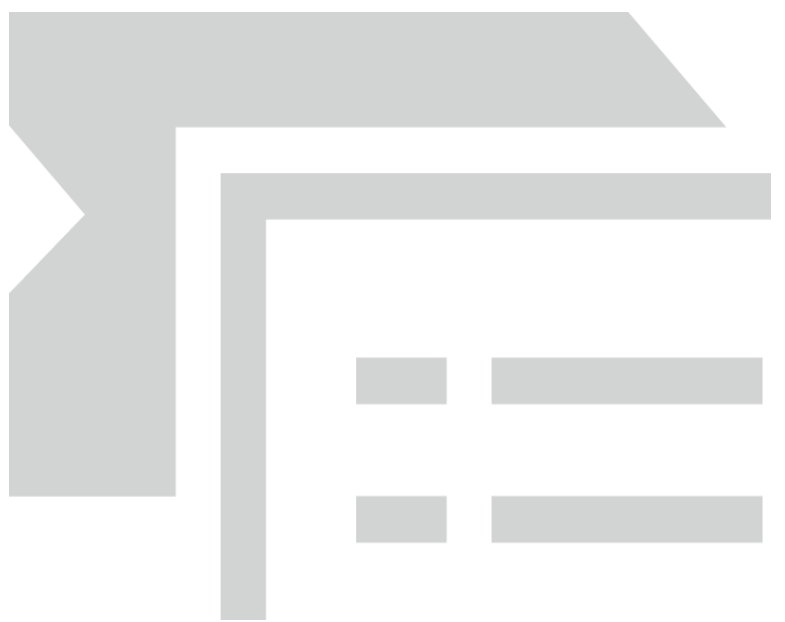

Fuente: Parque industrial de Villa El Salvador (2017) 


\section{Máquina para hacer hielo}

Se requiere hielo para el enfriamiento del brócoli y espárrago después de la cocción. Al ser de uso diario, es más económico conseguir una máquina para hacer hielo.

Modelo: Polar FH25

Material: Acero inoxidable

Capacidad: 25 kg/día

Potencia: $210 \mathrm{w}$

Figura 5.36.

Máquina para hacer hielo

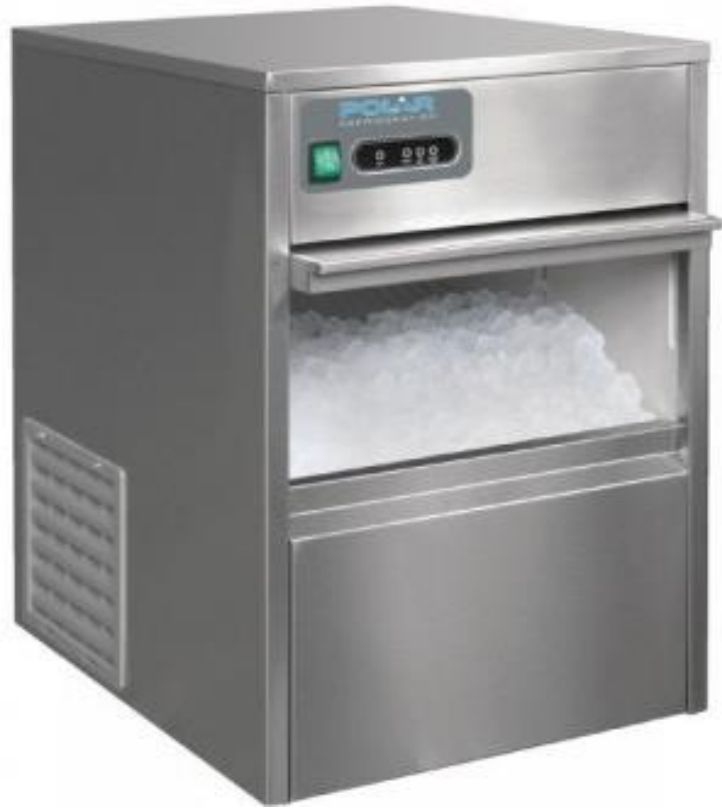

Fuente: Fábricas de hielo Polar (2016)

\section{$\underline{\text { Apiladores manuales }}$}

Los apiladores serán usados en el transporte de la materia prima e insumos, desde el almacén hasta el área de producción.

Capacidad: 2 ton

Dimensiones: $1.58 \mathrm{~m} \times 0.55$ x 1.22 
Figura 5.37.

Apiladores manuales

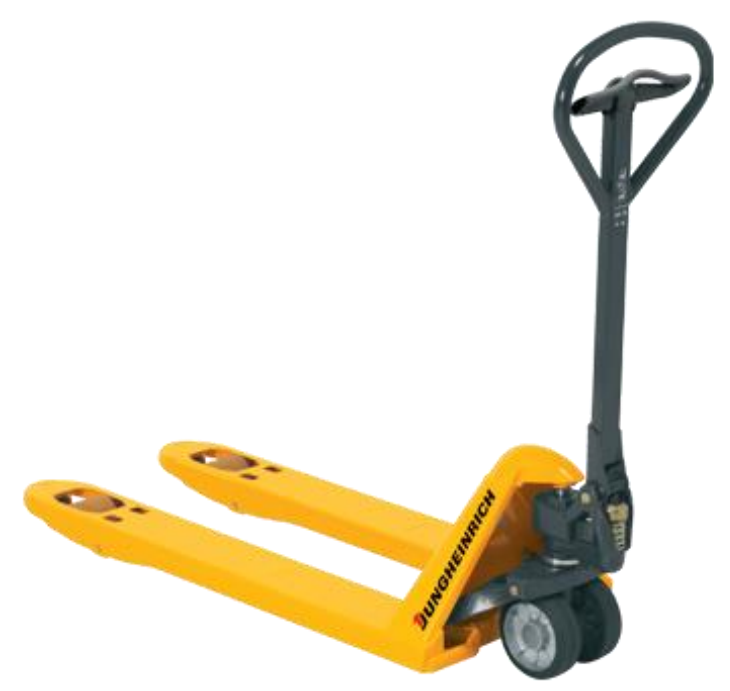

Fuente: Tracsa (2016)

\section{$\underline{\text { Ph-metro }}$}

Usado para medir el nivel de $\mathrm{pH}$ de la mezcla. Especial para el sector alimentario, incluye electrodo de $\mathrm{pH}$ y sensor de temperatura

Modelo: PCE 228M

Rangos de medición: 0 -14 pH / $0-60{ }^{\circ} \mathrm{C}$

Figura 5.38.

Ph-metro

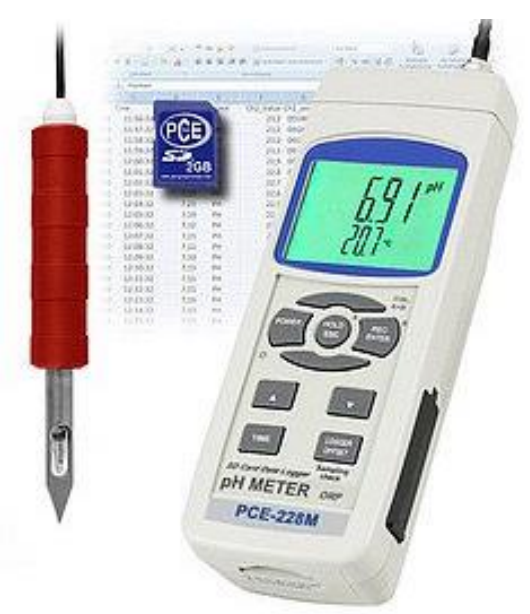

Fuente: PCE Instruments (2017) 


\section{Exprimidor}

Usado para obtener el jugo de limón a utilizar como conservante natural. Será de fácil limpieza y de aluminio. Incluye un filtro de semillas para evitar colar después.

Figura 5.39.

Exprimidor

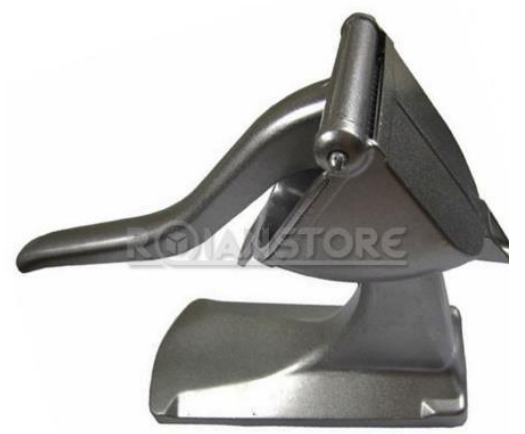

Fuente: Google (2016)

\section{$\underline{\text { Espumaderas }}$}

Es una pieza redonda con agujeros y un mango largo de aproximadamente $40 \mathrm{~cm}$. Será usada para colar la materia prima después del lavado.

\section{Figura 5.40.}

Espumadera

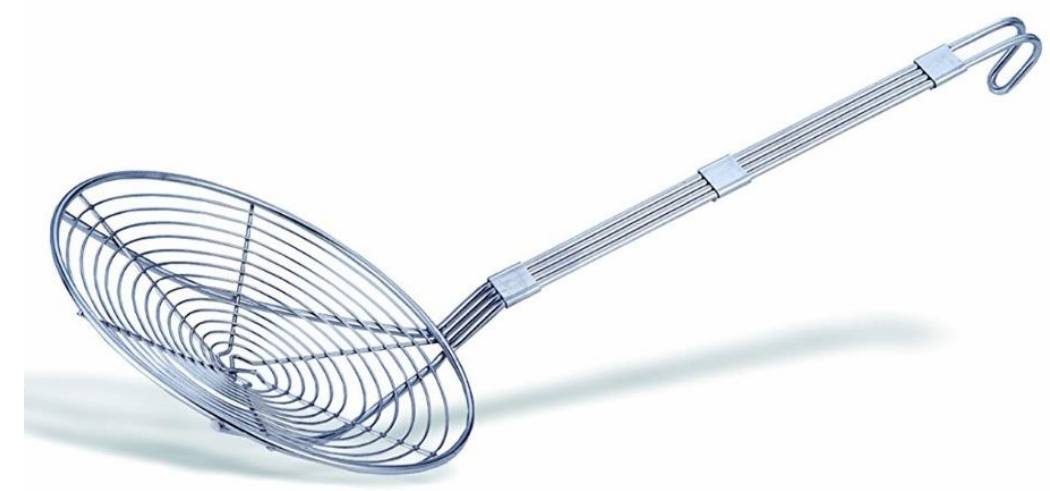

Fuente: Google (2016)

$\underline{\text { Tazas graduadas }}$

Requeridas para medir las cantidades de jugo de limón, ajo molido y pasta de cebolla. El material debe ser resistente y fácil de lavar. 
Material: Vidrio refractario

Capacidad: $500 \mathrm{cc}$

Figura 5.41.

Taza graduada

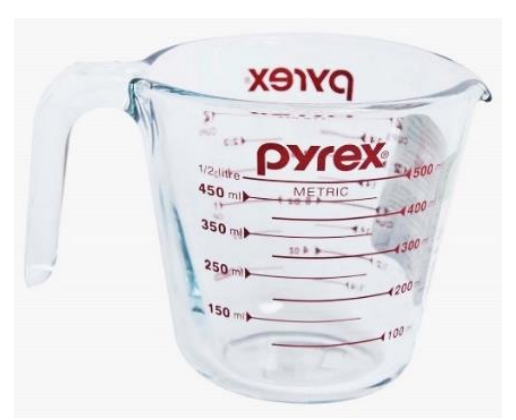

Fuente: Pyrex (2017)

$\underline{\text { Licuadora industrial }}$

Usada para obtener la pasta de cebolla. Cuenta con sistema para volcar la taza y estructura de acero inoxidable. Especial para licuar frutas y vegetales.

Modelo: LI-5A

Velocidad: $3500 \mathrm{rpm}-1$ velocidad

Potencia: 1.5 HP

Capacidad: $5 \mathrm{~L}$

Figura 5.42.

Licuadora industrial

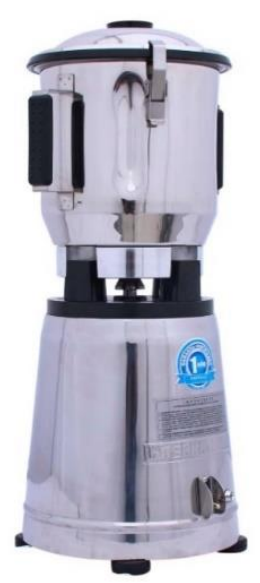

Fuente: Brimali Industrial (2017) 


\section{$\underline{\text { Rallador de queso }}$}

Utilizado para rallar los bloques de queso parmesano. Cuenta con tapa con bisagra para presionar el queso y con patas de jebe antideslizantes. Las cuchillas son de acero inoxidable y el gabinete en acero carbono.

Marca: Croydon

Velocidad: $540 \mathrm{rpm}$

Material: Acero

Figura 5.43.

Rallador de queso

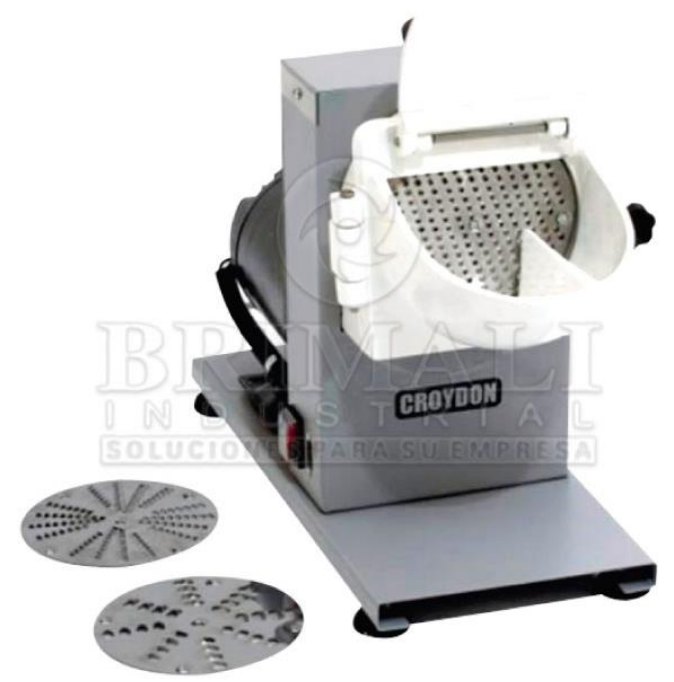

Fuente: Brimali industrial (2017)

\subsection{Capacidad instalada}

\subsubsection{Cálculo de la capacidad instalada}

Para poder determinar la máxima capacidad instalada de la planta es necesario contar con la capacidad de cada máquina, sus valores de utilización y eficiencia en un turno de trabajo.

Factor de Utilización (U): surge en consideración al tiempo dedicado al mantenimiento y preparación de equipos o paradas por cambio de turno o refrigerio. La fórmula se define en base al número de horas productivas y las horas reales de jornada por periodo. 


$$
U=\frac{N H P}{N H R}
$$

Factor de eficiencia (E): involucra la desviación estándar entre las horas estándar y las horas productivas utilizadas para realizar la misma cantidad de producto.

$$
E=\frac{N H E}{N H P}
$$

Las máquinas son de primer uso por lo que se espera que trabajen al $100 \%$ de la capacidad técnica, pero por un posible deterioro durante la duración del proyecto se considerará como factor de eficiencia 0.95 .

Tabla 5.9.

Cálculo de utilización

\begin{tabular}{ccccccc}
\hline Máquina & $\mathbf{E}$ & $\begin{array}{c}\text { Horas } \\
\text { disponibles } \\
(\mathbf{h d})\end{array}$ & $\begin{array}{c}\text { Horas } \\
\text { reales } \\
(\mathbf{h d} * \mathbf{E})\end{array}$ & $\begin{array}{c}\text { Horas de } \\
\text { mantenimiento } \\
\text { al año }\end{array}$ & $\begin{array}{c}\text { Horas } \\
\text { efectivas } \\
\text { al año }\end{array}$ & $\mathbf{U}$ \\
\hline $\begin{array}{c}\text { Marmita de } \\
\text { cocción }\end{array}$ & 0.95 & 2,080 & 1,976 & 234 & 1,742 & 0.88 \\
$\begin{array}{c}\text { Trozadora } \\
\text { Marmita de }\end{array}$ & 0.95 & 2,080 & 1,976 & 234 & 1,742 & 0.88 \\
mezclado & 0.95 & 2,080 & 1,976 & 130 & 1,846 & 0.93 \\
$\begin{array}{c}\text { Bomba de } \\
\text { transferencia }\end{array}$ & 0.95 & 2,080 & 1,976 & 130 & 1,846 & 0.93 \\
Envasadora & 0.95 & 2,080 & 1,976 & 130 & 1,846 & 0.93 \\
Codificadora & 0.95 & 2,080 & 1,976 & 130 & 1,846 & 0.93 \\
\hline
\end{tabular}

Elaboración propia 
Tabla 5.10.

Cálculo de capacidad instalada

\begin{tabular}{|c|c|c|c|c|c|c|c|c|c|c|c|c|c|}
\hline Proceso & $\begin{array}{l}\text { Cantidad } \\
\text { Entrante }\end{array}$ & $\mathbf{U M}$ & $\mathrm{Kg} / \mathrm{h}$ & $\begin{array}{c}\# \\
\text { Puestos }\end{array}$ & Días/año & $\begin{array}{l}\text { Horas } \\
\text { por } \\
\text { turno }\end{array}$ & $\begin{array}{l}\text { Turnos } \\
\text { por día }\end{array}$ & $\mathbf{U}$ & $\mathbf{E}$ & $\begin{array}{c}\text { Capacidad } \\
\text { Producción } \\
\text { (Kg/año) }\end{array}$ & $\begin{array}{l}\text { Factor de } \\
\text { Conversión }\end{array}$ & $\begin{array}{l}\text { Capacidad } \\
\text { Kg/año }\end{array}$ & $\begin{array}{c}\text { Capacidad } \\
\text { Und/año }\end{array}$ \\
\hline Selección & 161,563 & $\mathrm{Kg}$ & 500 & 1 & 260 & 8 & 1 & 0.90 & 0.95 & 889,200 & 1.14 & $1,010,849$ & $5,614,008$ \\
\hline Pesado & 182,251 & $\mathrm{Kg}$ & 750 & 1 & 260 & 8 & 1 & 0.90 & 0.95 & $1,333,800$ & 1.01 & $1,344,156$ & $7,465,111$ \\
\hline Lavado & 159,318 & $\mathrm{Kg}$ & 360 & 1 & 260 & 8 & 1 & 0.90 & 0.95 & 640,224 & 1.15 & 738,067 & $4,099,044$ \\
\hline Hidratado & 68,261 & $\mathrm{Kg}$ & 480 & 1 & 260 & 8 & 1 & 0.90 & 0.95 & 853,632 & 2.69 & $2,296,824$ & $12,760,133$ \\
\hline Cortado & 120,701 & $\mathrm{Kg}$ & 90 & 1 & 260 & 8 & 1 & 0.90 & 0.95 & 160,056 & 1.52 & 243,551 & $1,352,622$ \\
\hline Cocción & 315,300 & $\mathrm{Kg}$ & 200 & 1 & 260 & 8 & 1 & 0.88 & 0.95 & 348,400 & 0.58 & 202,947 & $1,127,485$ \\
\hline Enfriado & 330,912 & $\mathrm{Kg}$ & 480 & 1 & 260 & 8 & 1 & 0.90 & 0.95 & 853,632 & 0.56 & 473,791 & $2,632,171$ \\
\hline Trozado & 89,545 & $\mathrm{Kg}$ & 200 & 1 & 260 & 8 & 1 & 0.88 & 0.95 & 348,400 & 2.05 & 714,608 & $3,970,044$ \\
\hline Licuado & 4,228 & $\mathrm{Kg}$ & 50 & 1 & 260 & 8 & 1 & 0.90 & 0.95 & 88,920 & 43.44 & $3,862,721$ & $21,459,563$ \\
\hline Rallado & 2,245 & $\mathrm{Kg}$ & 20 & 1 & 260 & 8 & 1 & 0.90 & 0.95 & 35,568 & 81.81 & $2,909,859$ & $16,165,886$ \\
\hline Exprimido & 9,593 & $\mathrm{Kg}$ & 80 & 1 & 260 & 8 & 1 & 0.90 & 0.95 & 142,272 & 19.15 & $2,724,002$ & $15,133,347$ \\
\hline Bombeado & 189,552 & $\mathrm{Kg}$ & 660 & 1 & 260 & 8 & 1 & 0.93 & 0.95 & $1,218,360$ & 0.97 & $1,180,526$ & $6,558,479$ \\
\hline Envasado & 183,666 & $\mathrm{Kg}$ & 162 & 1 & 260 & 8 & 1 & 0.93 & 0.95 & 299,052 & 1.00 & 299,052 & $1,661,400$ \\
\hline Codificado & 183,666 & $\mathrm{Kg}$ & 324 & 1 & 260 & 8 & 1 & 0.93 & 0.95 & 598,104 & 1.00 & 598,104 & $3,322,800$ \\
\hline PT & 183,666 & $\mathrm{Kg}$ & & & & & & & & & & & \\
\hline PT & $1,020,367$ & und & & & & & & & & & & & \\
\hline
\end{tabular}

Elaboración propia

Se puede concluir que el cuello de botella es la etapa de cocción con 202,947 kg que representan 1,127,485 envases. 


\subsubsection{Cálculo detallado del número de máquinas requeridas}

Para calcular el número de máquinas que se necesitarán en el proyecto es necesario contar con la demanda anual y datos importantes como el número total de horas disponibles al año y el tiempo de operación por cada envase.

Demanda anual: Se obtuvo en el Capítulo II.

Total de horas disponibles al año: Se trabajará en un turno completo de 8 horas diarias, 5 días a la semana y 52 semanas al año.

Total de horas reales al año: Calculado en base al 0.95 de eficiencia

Tiempo de operación por kg por máquina: se obtuvo de las especificaciones técnicas.

Tabla 5.11.

Cálculo de máquinas requeridas

\begin{tabular}{cccccccccc}
\hline Máquina & $\begin{array}{c}\text { Capacidad } \\
\text { Teórica } \\
\text { (kg/h) }\end{array}$ & $\begin{array}{c}\text { Cap. } \\
\text { Teórica }\end{array}$ & $\begin{array}{c}\mathbf{P} \\
(\mathbf{k g} / \mathbf{a n ̃ o})\end{array}$ & $\mathbf{E}$ & $\begin{array}{c}\text { Horas } \\
\text { disponibles } \\
\text { (hd) }\end{array}$ & $\begin{array}{c}\text { Horas } \\
\text { reales } \\
\text { (hd * E) }\end{array}$ & U & $\begin{array}{c}\text { Número } \\
\text { de } \\
\text { máquinas }\end{array}$ & $\begin{array}{c}\text { Número } \\
\text { de } \\
\text { máquinas }\end{array}$ \\
\hline $\begin{array}{c}\text { Marmita de } \\
\text { cocción }\end{array}$ & 200 & 0.005 & 315,123 & 0.95 & 2,080 & 1,976 & 0.88 & 0.90 & 1 \\
$\begin{array}{c}\text { Trozadora } \\
\text { Marmita de } \\
\text { mezclado }\end{array}$ & 200 & 0.005 & 89,597 & 0.95 & 2,080 & 1,976 & 0.88 & 0.26 & 1 \\
$\begin{array}{c}\text { Bomba de } \\
\text { transferencia }\end{array}$ & 660 & 0.005 & 189,325 & 0.95 & 2,080 & 1,976 & 0.93 & 0.51 & 1 \\
Envasadora & 162 & 0.002 & 189,325 & 0.95 & 2,080 & 1,976 & 0.93 & 0.16 & 1 \\
Codificadora & 324 & 0.003 & 183,645 & 0.95 & 2,080 & 1,976 & 0.93 & 0.61 & 1 \\
\hline
\end{tabular}

Elaboración propia

\subsection{Resguardo de la calidad y/o inocuidad del producto}

Cuando un consumidor adquiere un producto para alimentación espera que haya cumplido con un rígido control de calidad tanto en los insumos utilizados como en su procesamiento.

Actualmente, existe un consumidor más informado y demandante, que revisa la lista de ingredientes, la tabla nutricional y que tiene gran poder en redes sociales y medios para sugerencias, quejas o cuestionamientos. De igual manera, le da más valoración a productos que cuentan con reconocimientos y certificaciones o a empresas con buena responsabilidad social, por lo que para ser competitivos es necesario apuntar a estos objetivos. 


\subsubsection{Calidad de la materia prima, insumos, proceso y producto}

La empresa velará en todo momento por la calidad de la materia prima e insumos a utilizar en cada una de las etapas del proceso, de tal manera que el producto a obtener cumpla con todos los estándares de calidad esperados.

\section{Materia prima}

La quinua, espárrago, brócoli y albahaca deben provenir de productores que impulsen medidas de calidad, higiene y sanidad, que no usen insecticidas y contribuyan al buen cuidado de las tierras y el ambiente.

Como un primer paso, se debe verificar que sea una cosecha fresca, que no tengan defectos que les de mala apariencia y pueda afectar a la integridad del insumo, ya que si no son separados al momento de selección afectarán todo el lote de producción.

Además, se evaluarán de manera sensorial algunos factores como olor, color, sabor, apariencia y textura; y de manera técnica con la ayuda de laboratorios externos la carga microbiana y composición.

\section{Insumos}

Los otros insumos que participan en la producción del dip deben pasar un estricto control de calidad de manera similar que la materia prima, ya que dentro de este grupo podemos encontrar vegetales, queso, aceites y materiales de empaque.

\section{Proceso}

Durante el proceso de producción se busca otorgar la calidad necesaria que satisfaga las expectativas de los clientes, se implementará el Análisis de Riesgos y Puntos Críticos de Control (HACCP) con el fin de mantener y garantizar la inocuidad del producto.

La aplicación del sistema HACCP es ahora un requisito para obtener la certificación de la División General de Salud Ambiental, el cual es comprendido para un solo producto o grupo de productos similares. Para la aprobación del Plan HACCP, la empresa deberá contar previamente con un Programa de Buenas Prácticas de Higiene conforme a lo señalado en los Principios Generales de Higiene del Codex Alimentarius (DIGESA, 2015). 
Habrá cuatro controles, el primero será iniciando la etapa de selección y pesado para revisar que la materia prima esté apta para continuar el proceso; el segundo será culminando la etapa de cortado y trozado de la materia prima, el tercero será después del llenado para asegurar que los envases tengan el peso correcto y el último, en el empacado revisando que todos los envases hayan sido sellados adecuadamente y no existan partículas ajenas al proceso.

Los operarios de cada máquina, así como los que realizan tareas manuales irán inspeccionando las etapas del proceso e informando al Supervisor de Planta sobre algún posible incidente en la producción.

Además, se establecerá principios de higiene dentro de la empresa como el lavado y enjuague de cuchillos, bandejas y equipos utilizados con frecuencia y el limpiado y desinfección de los pisos cada cierto tiempo, por lo cual será necesario contar con canaletas habilitadas en el piso para el desfogue del agua al desagüe.

Durante el proceso, se contará con controles de muestras al azar para poder registrar información observada y validar la tolerancia de las desviaciones. Se utilizarán herramientas como listas de verificación y gráficas de control. 
Tabla 5.12.

Puntos críticos de control - HACCP

\begin{tabular}{|c|c|c|c|c|c|c|c|c|c|}
\hline \multirow{2}{*}{$\begin{array}{c}\text { Puntos } \\
\text { Críticos } \\
\text { de Control } \\
\end{array}$} & \multirow{2}{*}{$\begin{array}{c}\text { Peligros } \\
\text { Significativos }\end{array}$} & \multirow{2}{*}{ Límite Crítico } & \multicolumn{4}{|c|}{ Monitoreo } & \multirow{2}{*}{$\begin{array}{c}\text { Acción } \\
\text { Correctora }\end{array}$} & \multirow{2}{*}{ Registro } & \multirow{2}{*}{ Verificación } \\
\hline & & & ¿Qué? & ¿Cómo? & Frecuencia & ¿A quién? & & & \\
\hline $\begin{array}{l}\text { Selección } \\
\text { y pesado }\end{array}$ & $\begin{array}{c}\text { Materia prima } \\
\text { no apta o } \\
\text { contaminada }\end{array}$ & $\begin{array}{l}\text { Mal estado o } \\
\text { aspecto }\end{array}$ & $\begin{array}{l}\text { Materia } \\
\text { prima }\end{array}$ & $\begin{array}{l}\text { Inspección } \\
\text { visual }\end{array}$ & Cada lote & $\begin{array}{l}\text { Asistente } \\
\text { de } \\
\text { almacén }\end{array}$ & $\begin{array}{l}\text { Revisión } \\
\text { minuciosa }\end{array}$ & $\begin{array}{c}\text { Registro } \\
\text { interno y } \\
\text { guía }\end{array}$ & $\begin{array}{l}\text { Inspección } \\
\text { visual }\end{array}$ \\
\hline $\begin{array}{l}\text { Trozado } \\
\text { de materia } \\
\text { prima }\end{array}$ & $\begin{array}{l}\text { Tamaño por } \\
\text { encima del } \\
\text { requerido }\end{array}$ & $\begin{array}{c}\text { Tamaño } \\
\text { máximo 3mm }\end{array}$ & $\begin{array}{l}\text { Materia } \\
\text { prima }\end{array}$ & $\begin{array}{c}\text { Evaluación } \\
\text { por } \\
\text { muestreo }\end{array}$ & Cada lote & $\begin{array}{l}\text { Supervisor } \\
\text { de calidad }\end{array}$ & $\begin{array}{l}\text { Calibrar } \\
\text { máquina }\end{array}$ & $\begin{array}{l}\text { Registro } \\
\text { interno }\end{array}$ & $\begin{array}{l}\text { Muestreo por } \\
\text { lotes }\end{array}$ \\
\hline \multirow[t]{2}{*}{ Llenado } & $\begin{array}{c}\text { Contaminación } \\
\text { por envases en } \\
\text { malas } \\
\text { condiciones }\end{array}$ & $\begin{array}{l}\text { Certificado de } \\
\text { BPM }\end{array}$ & $\begin{array}{c}\text { Envase } \\
\text { Doypack }\end{array}$ & $\begin{array}{c}\text { Evaluación } \\
\text { por } \\
\text { muestreo }\end{array}$ & Cada lote & $\begin{array}{l}\text { Supervisor } \\
\text { de calidad }\end{array}$ & $\begin{array}{c}\text { Auditorías a } \\
\text { Proveedor. } \\
\text { Posterior } \\
\text { cambio }\end{array}$ & $\begin{array}{l}\text { Guía de } \\
\text { Proveedor }\end{array}$ & $\begin{array}{l}\text { Muestreo por } \\
\text { lotes }\end{array}$ \\
\hline & $\begin{array}{c}\text { Cantidad } \\
\text { inexacta de } \\
\text { producto }\end{array}$ & $\begin{array}{l}\text { Cantidad igual } \\
\text { a } 180 \text { gr. de } \\
\text { dip }\end{array}$ & $\begin{array}{c}\text { Envase } \\
\text { Doypack }\end{array}$ & $\begin{array}{c}\text { Evaluación } \\
\text { por } \\
\text { muestreo }\end{array}$ & Cada lote & $\begin{array}{l}\text { Supervisor } \\
\text { de calidad }\end{array}$ & $\begin{array}{l}\text { Calibrar } \\
\text { máquina }\end{array}$ & $\begin{array}{l}\text { Registro } \\
\text { interno }\end{array}$ & $\begin{array}{l}\text { Muestreo por } \\
\text { lotes }\end{array}$ \\
\hline Empacado & $\begin{array}{c}\text { Presencia de } \\
\text { partículas } \\
\text { ajenas al } \\
\text { proceso }\end{array}$ & $\begin{array}{c}\text { Producto } \\
\text { contaminado }\end{array}$ & $\begin{array}{c}\text { Envases } \\
\text { Doypack } \\
\text { y cajas }\end{array}$ & $\begin{array}{l}\text { Muestreo e } \\
\text { inspección } \\
\quad \text { visual }\end{array}$ & Cada lote & $\begin{array}{l}\text { Supervisor } \\
\text { de calidad }\end{array}$ & $\begin{array}{c}\text { Cumplir con } \\
\text { BPM }\end{array}$ & $\begin{array}{l}\text { Registro } \\
\text { interno }\end{array}$ & $\begin{array}{c}\text { Análisis } \\
\text { microbiológico }\end{array}$ \\
\hline
\end{tabular}

Elaboración propia 


\section{Producto}

Se realizará un último control de calidad que garantice que el producto final cumple con las especificaciones detalladas en la ficha técnica. Serán evaluados diversos parámetros como el peso neto, valor nutricional, color, olor, mediante análisis químicos a través de la selección de una muestra del lote. Asimismo, se monitoreará el ambiente de almacenamiento como temperatura y humedad.

\subsubsection{Estrategias de mejora}

Mantener actualizados los sistemas de gestión y contar con manuales de procedimientos y políticas, de esta manera poder lograr estandarizar las operaciones de la empresa.

Buscar alternativas de abastecimiento en el posible caso de que algunos proveedores empiecen a fallar en la entrega de insumos de primera calidad. Como requisito para ser una empresa competitiva se tendrá como política contar con 2 o más proveedores aprobados por cada ítem, desde la materia prima hasta los materiales de empaque.

Mantenerse al tanto y constante capacitación de las nuevas normas y certificaciones que puedan aplicar a la Agroindustria y que son promovidas por las principales organizaciones y empresas del medio.

Programar un plan de visitas y/o auditorías a proveedores en coordinación con el equipo de calidad. Conocer la problemática del entorno ayudará a tener claro el posible impacto de una deficiencia en sus procesos.

\subsection{Estudio de Impacto Ambiental}

De acuerdo a Ley 27446 - "Ley del Sistema Nacional de Evaluación del Impacto Ambiental" - se evaluarán los posibles efectos a generarse durante todas las etapas del proceso, con el fin de lograr la aprobación por parte de la autoridad competente, en este caso el Ministerio del Ambiente. Se detallan las tres categorías existentes:

Categoría 1: Incluye aquellos proyectos cuya ejecución no origina impactos ambientales negativos de carácter significativo. 
Categoría 2: Incluye los proyectos cuya ejecución puede originar impactos ambientales moderados y cuyos efectos negativos pueden ser eliminados o minimizados mediante la adopción de medidas fácilmente aplicables.

Categoría 3: Incluye aquellos proyectos cuyas características, envergadura y/o localización, pueden producir impactos ambientales negativos significativos, cuantitativa o cualitativamente, requiriendo un análisis profundo para revisar sus impactos y proponer la estrategia de manejo ambiental correspondiente.

El proyecto estaría dentro de la Categoría 1 requiriendo una Declaración de Impacto Ambiental (DIA), estipulado por ley y se debe realizar antes de la operación de la planta. La DIA principalmente debe incluir la descripción del proyecto, las características del entorno y los posibles impactos, así como medidas de prevención y de reparación de daños. 
Tabla 5.13.

Matriz de impacto ambiental

\begin{tabular}{|c|c|c|c|c|}
\hline Etapa del proceso & Salida & Aspecto Ambiental & Impacto Ambiental & Medidas correctoras \\
\hline Selección y pesado & - & - & - & - \\
\hline Lavado & Efluentes & Agua sucia (saponina, partículas) & Potencial contaminación del agua & $\begin{array}{c}\text { Disposición de material sólido } \\
\text { y eliminación de líquidos por } \\
\text { desagüe }\end{array}$ \\
\hline Enjuague & Efluentes & Agua sucia (reutilizable) & Potencial contaminación del agua & Uso en ambientes exteriores \\
\hline Cortado & Residuos & Residuos sólidos (merma) & Potencial contaminación del suelo & $\begin{array}{l}\text { Controlar la eliminación de } \\
\text { desechos industriales }\end{array}$ \\
\hline Trozado & Ruido & Ruido generado por la máquina & $\begin{array}{l}\text { Afectación de la salud de trabajadores } \\
\text { Contaminación sonora }\end{array}$ & Protección auditiva \\
\hline Hidratado & Efluentes & Agua sucia (reutilizable) & Contaminación del agua & Uso en ambientes exteriores \\
\hline \multirow{3}{*}{ Cocción } & Calor & Aumento de temperatura & $\begin{array}{c}\text { Fatiga o afectación de la salud de } \\
\text { trabajadores }\end{array}$ & Ventilación adecuada \\
\hline & Efluentes & Agua sucia & Potencial contaminación del agua & $\begin{array}{c}\text { Eliminación de líquidos por } \\
\text { desagüe }\end{array}$ \\
\hline & Vapor de agua & Vapor de agua por evaporación & Contaminación del aire & \\
\hline Enfriado & Efluentes & Agua sucia & Potencial contaminación del agua & $\begin{array}{c}\text { Eliminación de líquidos por } \\
\text { desagüe }\end{array}$ \\
\hline Mezclado & Calor & Aumento de temperatura & $\begin{array}{c}\text { Fatiga o afectación de la salud de } \\
\text { trabajadores }\end{array}$ & Ventilación adecuada \\
\hline Envasado & - & - & - & - \\
\hline Sellado & - & - & - & - \\
\hline Codificado & - & - & - & - \\
\hline
\end{tabular}

Elaboración propia 


\subsection{Seguridad y Salud ocupacional}

Según estimaciones, cada 15 segundos ocurren 153 accidentes laborales causando la muerte de al menos un trabajador. Esta cifra resulta en 6,300 personas fallecidas por día a causa de accidentes o enfermedades relacionadas al trabajo (Organización Internacional de Trabajo, 2016).

Esto lleva a las empresas a tener que afrontar mayores cargas económicas derivadas del ausentismo laboral, gastos por reparo y pólizas cada vez más altas. Se estima que el costo de las malas prácticas llega a alcanzar el 4\% del PBI a nivel mundial, por eso la OIT tiene como consigna promover la salud y seguridad de los trabajadores creando conciencia en el mundo acerca de la gravedad de las consecuencias.

Ejecutar una política de SSO en una empresa se ha vuelto una obligación, no solo en el ámbito legal sino también de manera moral. Las condiciones seguras en el lugar de trabajo permiten que un empleado tenga la confianza suficiente para poder desempeñarse sin ningún problema o preocupación, por lo que influye directamente con su motivación y eficiencia laboral.

Cabe resaltar que contar con un sistema integral de SSO, permite a la empresa contar con las siguientes ventajas:

- Reducción de accidentes

- Evitar costos adicionales por cubrir accidentes

- Evitar multas y sanciones

- Mejoras en desempeño y productividad

- Mejorar imagen corporativa

- Menores costos de los seguros

- Demostrar compromiso con la seguridad y salud

Por estas razones, es necesario elaborar un plan de seguridad antes de iniciar con las operaciones. Se debe contar con las señalizaciones respectivas en planta en el caso de sismos e incendios, como también una correcta posición de los extintores y mangueras con fuente directa de agua. Adicionalmente, los trabajadores de planta contarán con el Seguro Complementario de Trabajo de Riesgo (SCTR), con el fin de estar protegidos ante 
cualquier accidente. Esta medida aplica también a los proveedores, transportistas y contratistas.

Monitorear de manera constante las variables que pueden causar molestia y posibles daños a los trabajadores, permitirá poder reaccionar de manera rápida para dar solución a los inconvenientes. En la tabla 5.6. se listan los parámetros que deberán controlarse.

Tabla 5.14.

Parámetros de principales agentes físicos

\begin{tabular}{ccc}
\hline Variable & Parámetros & Principales riesgos \\
\hline Ruido & $85-90 \mathrm{~dB}$ & Déficit auditivo hasta sordera total. \\
Iluminación & $200-500 \mathrm{lux}$ & Trastornos oculares, fatiga y dolor de cabeza. \\
Temperatura & $20-22^{\circ} \mathrm{C}$ & Deshidratación y fatiga. \\
Humedad relativa & $50-60 \%$ & Problemas respiratorios \\
Vibración & $1-20 \mathrm{~Hz}$ & Síntomas vasculares (flujo sanguíneo) y cambios \\
sensoneuronales en dedos.
\end{tabular}

Fuente: Módulo Europeo de Enseñanza de Pregrado en Medicina Ocupacional (2016); Instituto Nacional de Seguridad e Higiene en el Trabajo - España (2016)

Las charlas de prevención y capacitación deben ser realizadas por el Supervisor de Planta, quien debe liderar todo el proyecto de implementación en la planta y junto con el área de RRHH deben asegurar la participación de todo el personal, así como también hacerse cargo de que tengan los números de emergencia y que sepan qué hacer y a quién acudir en caso de algún accidente.

La norma emitida por el Ministerio de Trabajo y Promoción del empleo, es el decreto supremo $\mathrm{N}^{\circ}$ 007-2007-TR, que regula las medidas de seguridad en los sectores económicos del país, estableciendo penalidades de acuerdo a las actividades más complejas y que impliquen alto riesgo.

Con las medidas a adoptar señaladas anteriormente, se buscará cumplir con lo estipulado en la norma OHSAS 18001 basado en un sistema de gestión de salud y seguridad laboral que permitirá salvaguardar la integridad del personal de la empresa y por lo tanto la normalidad de los procesos. 
Es necesario que todas las áreas se encuentren involucradas y comprometidas con el plan de seguridad y asistan a las capacitaciones, fomenten las buenas prácticas y el uso de los equipos de protección personal requeridos en cada labor. Esta última medida será supervisada y recordada constantemente mediante imágenes en la planta, ya que el trabajador peruano tiene mucha resistencia al uso de equipamiento adicional por la incomodidad.

Para tener en cuenta todos los riesgos que hay en el proceso, se realizó la matriz de Identificación de peligros y evaluación de riesgos (IPER): 
Tabla 5.15.

Matriz de Identificación de Peligros y Evaluación de Riesgos

\begin{tabular}{|c|c|c|c|c|c|c|c|c|c|c|c|}
\hline \multirow[b]{2}{*}{ Proceso } & \multirow[b]{2}{*}{$\begin{array}{l}\text { Núm. de } \\
\text { operarios }\end{array}$} & \multirow[b]{2}{*}{ Riesgo } & \multirow[b]{2}{*}{$\begin{array}{l}\text { Medida de } \\
\text { control }\end{array}$} & \multicolumn{3}{|c|}{ EPP } & \multicolumn{4}{|c|}{ Evaluación de riesgos } & \multirow{2}{*}{\begin{tabular}{|c|} 
Plan de acción \\
Nuevas medidas de control
\end{tabular}} \\
\hline & & & & Guante & Masc. & Lentes & $\begin{array}{l}\text { Prob. } \\
\text { (P) }\end{array}$ & $\begin{array}{l}\text { Severidad } \\
\text { (P) }\end{array}$ & $\begin{array}{l}\text { Evaluación } \\
\text { del Riesgo }\end{array}$ & $\begin{array}{l}\text { Nivel de } \\
\text { Riesgo }\end{array}$ & \\
\hline \multirow{2}{*}{ Selección } & \multirow{2}{*}{1} & & $\begin{array}{l}\text { Carga máx. } \\
25 \mathrm{~kg}\end{array}$ & \multirow{2}{*}{$\mathrm{X}$} & \multirow{2}{*}{$\mathrm{X}$} & & 3 & 4 & 12 & Moderado & \multirow{2}{*}{$\begin{array}{l}\text { Implementar uso de fajas } \\
\text { Uso de repelente por presencia de } \\
\text { insectos }\end{array}$} \\
\hline & & Picaduras & Uso de EPP & & & & 3 & 4 & 12 & Moderado & \\
\hline Pesado & 1 & Lesión & $\begin{array}{l}\text { Carga máx. } \\
25 \mathrm{~kg}\end{array}$ & $\mathrm{X}$ & $\mathrm{X}$ & & 5 & 4 & 20 & Importante & $\begin{array}{l}\text { Implementar uso de fajas y zapatos con } \\
\text { punta de acero }\end{array}$ \\
\hline Lavado & 1 & Resfríos & Uso de EPP & $\mathrm{X}$ & $\mathrm{X}$ & $\mathrm{X}$ & 3 & 4 & 12 & Moderado & $\begin{array}{l}\text { Uso de guantes y bandas impermeables } \\
\text { para evitar contacto con agua }\end{array}$ \\
\hline Cortado & \multirow[t]{2}{*}{1} & Cortes & Uso de EPP & \multirow[t]{2}{*}{$\mathrm{X}$} & \multirow[t]{2}{*}{$\mathrm{X}$} & \multirow{2}{*}{$\mathrm{X}$} & 5 & 8 & 40 & Importante & $\begin{array}{c}\text { Máxima prevención en corte manual. } \\
\text { Uso de guantes. }\end{array}$ \\
\hline Trozado & & Cortes & Uso de EPP & & & & 5 & 8 & 40 & Importante & Capacitación en uso de trozadora \\
\hline $\begin{array}{l}\text { Exprimido/ } \\
\text { Licuado/ } \\
\text { Rallado }\end{array}$ & 1 & Cortes & Uso de EPP & $X$ & $\mathrm{X}$ & $\mathrm{X}$ & 5 & 4 & 20 & Importante & Prevención en el uso de equipos \\
\hline $\begin{array}{l}\text { Hidratado/ } \\
\text { Cocción }\end{array}$ & \multirow{3}{*}{1} & Quemadura & Uso de EPP & \multirow{3}{*}{$\mathrm{X}$} & & \multirow{3}{*}{$\mathrm{X}$} & 5 & 6 & 30 & Importante & $\begin{array}{l}\text { Supervisión frecuente en el uso de EPP } \\
\text { y manejo de procesos con calor }\end{array}$ \\
\hline Enfriamiento & & Quemadura & Uso de EPP & & & & 5 & 4 & 20 & Importante & $\begin{array}{l}\text { Supervisión frecuente en el uso de EPP } \\
\text { y manejo de procesos con calor }\end{array}$ \\
\hline Mezclado & & Lesión leve & Uso de EPP & & & & 3 & 4 & 12 & Moderado & Prevención en el uso de equipos \\
\hline Envasado & \multirow{2}{*}{1} & Lesión leve & Uso de EPP & \multirow{2}{*}{$\mathrm{X}$} & & & 3 & 4 & 12 & Moderado & Prevención en el uso de equipos \\
\hline Codificado & & Lesión leve & Uso de EPP & & & & 3 & 2 & 6 & Moderado & Prevención en el uso de equipos \\
\hline Empacado & 1 & Lesión leve & $\begin{array}{l}\text { Carga máx. } \\
25 \mathrm{~kg}\end{array}$ & $\mathrm{X}$ & & & 3 & 2 & 6 & Moderado & $\begin{array}{c}\text { Uso de fajas y disponer de espacio } \\
\text { libre }\end{array}$ \\
\hline
\end{tabular}




\subsection{Sistema de mantenimiento}

La implementación de este sistema se da con el objetivo de optimizar el funcionamiento de la maquinaria y equipos de la planta durante su vida útil, manteniendo así los costos dentro del presupuesto asignado al periodo y una producción ininterrumpida durante las jornadas de trabajo.

Mantener los mantenimientos al día permitirá brindar mayor seguridad a los trabajadores, emitir menos $\mathrm{CO}_{2}$ y vapor de agua, disminuir o mantener el mismo consumo de energía, conservar la calidad del producto y asegurar que la planta trabaje todo el tiempo programado. Esto permitirá confiar en las herramientas de producción y evadir costos extras que genera un plan de mantenimiento mal ejecutado.

Se determinó que el tipo de mantenimiento a usar en la planta es preventivo, que consiste en programar revisiones periódicas apoyándose en las fichas técnicas y los datos históricos con el fin de anticipar una posible falla o tratarla en su etapa inicial. Este servicio será tercerizado.

Las cuatro actividades básicas realizadas por personal de la empresa, a cargo del operario responsable de cada máquina y asistente de mantenimiento, son: inspecciones, ajustes, lubricación y limpieza.

Tabla 5.16.

Plan de Mantenimiento

\begin{tabular}{cccc}
\hline Equipo & Actividad & Frecuencia & Responsable \\
\hline \multirow{4}{*}{ Marmita } & Limpieza externa & Diaria & Operario \\
& Limpieza interna & Diaria & Operario \\
& Inspección & Mensual & Asist. de Mantenimiento \\
& Ajustes & Según inspección & Asistente - Operario \\
\hline \multirow{3}{*}{ Trozadora } & Limpieza externa & Diaria & Operario \\
& Limpieza interna & Diaria & Operario \\
& Inspección & Mensual & Asist. de Mantenimiento \\
& Lubricación & Cada dos semanas & Operario \\
\hline \multirow{2}{*}{ Dosificador } & Limpieza externa & Diaria & Operario \\
& Limpieza interna & Semanal & Operario \\
& Inspección & Mensual & Asist. de Mantenimiento \\
& Ajustes & Según inspección & Asistente - Operario \\
\hline
\end{tabular}

Elaboración propia 


\subsection{Programa de producción}

\subsubsection{Factores para la programación de la producción}

La vida útil para el proyecto será de 5 años desde la instalación de la planta, por lo que la producción se calculará inicialmente para ese lapso de tiempo. Se espera que con la aceptación del producto se pueda prolongar ese periodo.

Tabla 5.17.

Stock de seguridad

\begin{tabular}{cccc}
\hline Año & $\begin{array}{c}\text { Demanda anual } \\
\text { (envases) }\end{array}$ & $\begin{array}{c}\text { Stock de } \\
\text { Seguridad }\end{array}$ & $\begin{array}{c}\text { Stock } \\
\text { mínimo } \\
\text { (10 días) }\end{array}$ \\
\hline 2018 & 807,274 & 85,471 & 31,049 \\
2019 & 854,710 & 90,494 & 32,873 \\
2020 & 904,933 & 95,811 & 34,805 \\
2021 & 958,107 & 101,441 & 36,850 \\
2022 & $1,014,406$ & 107,402 & 39,016 \\
\hline
\end{tabular}

Elaboración propia

Se considera como stock de seguridad el 10\% de la producción del próximo año. Esta cantidad debe cubrir el stock mínimo de 10 días, el cual se calcula en base al tiempo máximo que le tomaría al proveedor del producto más crítico, en este caso quinua, poder abastecer suponiendo que tenga un retraso (15 días) menos el plazo de entrega en condiciones normales (5 días).

\subsubsection{Programa de producción}

Para cumplir con la demanda esperada, la planta no necesitará el máximo de su capacidad, por dicha razón, se considerará la posibilidad de ofrecer el servicio de maquila a terceros. Como se ha podido revisar en los cuadros anteriores sobre la competencia, gran porcentaje de los productos se venden bajo la marca propia del supermercado y son producidos en su mayoría por Danper y por la empresa Productos Encurtidos S.A.C.; siendo la maquila una medida atractiva para hacer más eficiente el uso de la maquinaria y generar ingresos extra. 
A continuación, se considera que las proyecciones de producción concuerdan con los requerimientos de compra del mercado. Se considera que la venta es constante para todos los meses.

Tabla 5.18.

Plan de producción anual

\begin{tabular}{cccccc}
\hline Año & Demanda & $\begin{array}{c}\text { Stock } \\
\text { Seguridad }\end{array}$ & $\begin{array}{c}\text { Plan de } \\
\text { Producción }\end{array}$ & $\begin{array}{c}\text { Plan } \\
\text { Mensual }\end{array}$ & $\begin{array}{c}\text { Plan } \\
\text { Diario }\end{array}$ \\
\hline 2018 & 807,274 & 85,471 & 892,745 & 74,396 & 3,434 \\
2019 & 854,710 & 90,494 & 859,733 & 71,645 & 3,307 \\
2020 & 904,933 & 95,811 & 910,250 & 75,855 & 3,501 \\
2021 & 958,107 & 101,441 & 963,737 & 80,312 & 3,707 \\
2022 & $1,014,406$ & 107,402 & $1,020,367$ & 85,031 & 3,925 \\
\hline
\end{tabular}

Elaboración propia

\subsection{Requerimiento de insumos, servicios y personal}

\subsubsection{Materia prima, insumos y otros materiales}

La cantidad requerida de materia prima, insumos y otros materiales se calcula en base a la información obtenida en el balance de materia realizado para la elaboración de un Dip a base de quinua y vegetales verdes en doypack de $180 \mathrm{~g}$.

Tabla 5.19.

Requerimiento de materia prima e insumos

\begin{tabular}{cccccc}
\hline \multicolumn{5}{c}{ Requerimiento en Kg } \\
\hline MP / Insumo & $\mathbf{2 0 1 8}$ & $\mathbf{2 0 1 9}$ & $\mathbf{2 0 2 0}$ & $\mathbf{2 0 2 1}$ & $\mathbf{2 0 2 2}$ \\
\hline Quinua & 25,675 & 24,726 & 26,179 & 27,717 & 29,346 \\
Esparrago & 54,441 & 52,428 & 55,509 & 58,770 & 62,224 \\
Brócoli & 41,218 & 39,694 & 42,027 & 44,496 & 47,111 \\
Albahaca & 4,635 & 4,464 & 4,726 & 5,004 & 5,298 \\
Cebolla & 4,492 & 4,326 & 4,580 & 4,849 & 5,134 \\
Limón & 8,929 & 8,599 & 9,104 & 9,639 & 10,205 \\
Queso Parmesano & 1,964 & 1,891 & 2,003 & 2,120 & 2,245 \\
Aceite de Oliva & 9,195 & 8,855 & 9,376 & 9,926 & 10,510 \\
Aceite de Girasol & 4,598 & 4,428 & 4,688 & 4,963 & 5,255 \\
Sal & 2,468 & 2,377 & 2,517 & 2,665 & 2,821 \\
Ajo & 1,839 & 1,771 & 1,875 & 1,985 & 2,102 \\
Doypack (und) & 892,745 & 859,733 & 910,250 & 963,737 & $1,020,367$ \\
Cajas (und) & 74,395 & 71,644 & 75,854 & 80,311 & 85,031 \\
\hline
\end{tabular}

Elaboración propia 
Tabla 5.20.

Requerimiento de otros materiales (unidades)

\begin{tabular}{cccccc}
\hline Material & $\mathbf{2 0 1 8}$ & $\mathbf{2 0 1 9}$ & $\mathbf{2 0 2 0}$ & $\mathbf{2 0 2 1}$ & $\mathbf{2 0 2 2}$ \\
\hline Guantes & 832 & 832 & 832 & 832 & 832 \\
Mascarillas & 240 & 240 & 240 & 240 & 240 \\
Lentes & 96 & 96 & 96 & 96 & 96 \\
Uniformes & 32 & 32 & 32 & 32 & 32 \\
Zapatos & 8 & 8 & 8 & 8 & 8 \\
\hline Elaboración propia & & & & &
\end{tabular}

\subsubsection{Servicios}

Las empresas que brindarán los servicios de energía eléctrica y agua serán Hidrandina y Sedalib respectivamente, cuyas tarifas se encuentran detalladas en las tablas 3.3. y 3.4. del capítulo III.

La mayor cantidad de agua se usará en el lavado, hidratación y cocción de la quinua, y en el lavado y cocción de los vegetales; y en menor proporción en el lavado de la cebolla y limón previo a ser cortados. También se considera el consumo de agua en la fabricación de hielo para el enfriamiento del brócoli y espárrago.

Tabla 5.21.

Consumo de agua en el proceso $\left(\mathrm{m}^{3}\right)$

\begin{tabular}{cccccc}
\hline Proceso & $\mathbf{2 0 1 8}$ & $\mathbf{2 0 1 9}$ & $\mathbf{2 0 2 0}$ & $\mathbf{2 0 2 1}$ & $\mathbf{2 0 2 2}$ \\
\hline Quinua & 137.50 & 132.41 & 140.19 & 148.43 & 157.15 \\
Espárrago & 229.90 & 221.40 & 234.41 & 248.18 & 262.77 \\
Brócoli & 175.76 & 169.26 & 179.20 & 189.73 & 200.88 \\
Albahaca & 13.37 & 12.88 & 13.63 & 14.43 & 15.28 \\
Cebolla & 8.98 & 8.65 & 9.16 & 9.70 & 10.27 \\
Limón & 26.79 & 25.80 & 27.31 & 28.92 & 30.62 \\
Hielo & 62.96 & 60.64 & 64.20 & 67.97 & 71.96 \\
\hline Total & $\mathbf{6 5 5 . 2 6}$ & $\mathbf{6 3 1 . 0 3}$ & $\mathbf{6 6 8 . 1 1}$ & $\mathbf{7 0 7 . 3 7}$ & $\mathbf{7 4 8 . 9 4}$ \\
\hline
\end{tabular}

Elaboración propia

Se considera que el consumo de agua a nivel administrativo que incluye comedor, servicios higiénicos y limpieza en general representa el 30\% del total. 
Tabla 5.22.

Costo total del consumo de agua

\begin{tabular}{cccccc}
\hline Año & $\mathbf{2 0 1 8}$ & $\mathbf{2 0 1 9}$ & $\mathbf{2 0 2 0}$ & $\mathbf{2 0 2 1}$ & $\mathbf{2 0 2 2}$ \\
\hline Costo Producción & $\mathrm{S} / 6,417$ & $\mathrm{~S} / 6,182$ & $\mathrm{~S} / 6,542$ & $\mathrm{~S} / 6,924$ & $\mathrm{~S} / 7,328$ \\
Costo Administrativo & $\mathrm{S} / 2,750$ & $\mathrm{~S} / 2,649$ & $\mathrm{~S} / 2,804$ & $\mathrm{~S} / 2,967$ & $\mathrm{~S} / 3,141$ \\
Total & $\mathrm{S} / \mathbf{9 , 1 6 7}$ & $\mathrm{S} / \mathbf{8 , 8 3 1}$ & $\mathbf{S} / \mathbf{9 , 3 4 6}$ & $\mathrm{S} / \mathbf{9 , 8 9 1}$ & $\mathrm{S} / \mathbf{1 0 , 4 6 9}$ \\
\hline
\end{tabular}

Elaboración propia

El consumo de energía eléctrica se considera constante para los 5 años del proyecto, ya que las máquinas operarán durante el mismo tiempo (8 horas/día), aunque podrían tener una pequeña variación en su consumo por el desgaste, pero al ser mínimo no será tomado en cuenta.

Tabla 5.23.

Consumo de energía eléctrica $(\mathrm{Kw})$

\begin{tabular}{ccc}
\hline Máquina & $\begin{array}{c}\text { Potencia } \\
\text { (kwh) }\end{array}$ & $\begin{array}{c}\text { Kw- } \\
\text { h/año }\end{array}$ \\
\hline Marmita de cocción & 1.50 & 3,120 \\
Marmita de mezclado & 1.50 & 3,120 \\
Trozadora & 0.90 & 1,872 \\
Envasadora & 4.00 & 8,320 \\
Codificadora & 0.80 & 1,664 \\
Bomba & 2.50 & 5,200 \\
Faja & 1.40 & 2,912 \\
Balanza electrónica & 0.01 & 21 \\
Balanza de plataforma & 0.03 & 62 \\
Balanza de piso & 0.10 & 208 \\
Máquina de hielo & 0.21 & 437 \\
Licuadora & 0.75 & 1,560 \\
Rallador de queso & 0.46 & 957 \\
Sub total & $\mathbf{1 4 . 1 6}$ & $\mathbf{2 9 , 4 5 3}$ \\
\hline
\end{tabular}

Elaboración propia

Tabla 5.24.

Costo total del consumo de energía

\begin{tabular}{cccccc}
\hline Año & $\mathbf{2 0 1 8}$ & $\mathbf{2 0 1 9}$ & $\mathbf{2 0 2 0}$ & $\mathbf{2 0 2 1}$ & $\mathbf{2 0 2 2}$ \\
\hline Costo producción & $\mathrm{S} / 16,753$ & $\mathrm{~S} / 16,753$ & $\mathrm{~S} / 16,753$ & $\mathrm{~S} / 16,753$ & $\mathrm{~S} / 16,753$ \\
Costo administrativo & $\mathrm{S} / 7,180$ & $\mathrm{~S} / 7,180$ & $\mathrm{~S} / 7,180$ & $\mathrm{~S} / 7,180$ & $\mathrm{~S} / 7,180$ \\
Total & $\mathrm{S} / \mathbf{2 3 , 9 3 3}$ & $\mathrm{S} / \mathbf{2 3 , 9 3 3}$ & $\mathrm{S} / \mathbf{2 3 , 9 3 3}$ & $\mathrm{S} / \mathbf{2 3 , 9 3 3}$ & $\mathrm{S} / \mathbf{2 3 , 9 3 3}$ \\
\hline
\end{tabular}

Elaboración propia 


\subsubsection{Determinación del número de operarios y trabajadores indirectos}

El número de operarios se calculó en base a la eficiencia y la cantidad de materia prima que ingresa al proceso en cada una de las máquinas. Para las actividades manuales se considera un rendimiento estimado.

Las actividades compartidas se basan en el porcentaje de saturación del operario, calculado en las actividades con máquinas.

Tabla 5.25.

Mano de obra directa

\begin{tabular}{cc}
\hline Operación & \# operarios \\
\hline Selección & 1 \\
\hline Pesado & 1 \\
\hline Lavado & 1 \\
\hline Cortado & \\
Trozado & 1 \\
\hline Licuado & \\
Rallado & \\
Exprimido & \\
\hline Hidratado & 1 \\
Cocción & \\
Enfriamiento & \\
Mezclado & 1 \\
\hline Bombeado & \\
Envasado & \\
Codificado & \\
\hline Empacado & \\
\hline Total & \\
\hline
\end{tabular}

Elaboración propia

Se considera que los cuatro controles de PCC del plan HACCP serán tareas del supervisor de Calidad y Supervisor de Planta. Se realizarán las inspecciones en la selección y pesado de materia prima, después del trozado y llenado y al finalizar el empacado. 
Tabla 5.26.

Mano de obra indirecta

\begin{tabular}{cc}
\hline Puesto & Cantidad \\
\hline Jefe de Operaciones & 1 \\
Supervisor de Planta & 1 \\
Supervisor de Calidad & 1 \\
Asistente de Mantenimiento & 1 \\
Asistente de Planificación & 1 \\
Asistente de Almacén & 1 \\
Total & $\mathbf{6}$ \\
\hline
\end{tabular}

Elaboración propia

\subsubsection{Servicios de terceros}

La empresa se encargará netamente de las operaciones y producción por lo que se buscará tercerizar algunos servicios complementarios. Sin embargo, de ser el caso, de manera anual se analizará cada servicio y la factibilidad de contratar personal perenne en la empresa con el objetivo de disminuir costos. Los servicios a contratar son los siguientes:

\section{Seguridad}

Se necesita personal de seguridad en diversas zonas de la planta, distribuidos de la siguiente manera: un vigilante en la zona de acceso de personal administrativo y visitas, un vigilante que realice el recorrido permanente a la planta y 2 vigilantes que apoyen en el ingreso de personal de planta y proveedores, incluyendo el acceso de camiones a la zona de carga y descarga.

\section{Mantenimiento}

Cada cierto tiempo será necesario contar con personal altamente calificado para el mantenimiento preventivo o para posibles problemas que sufran las máquinas y equipos. Se contratará a una empresa especializada para que dos veces al año o según requerimiento, envíe su staff de técnicos para que realicen el trabajo en planta.

\section{Limpieza Especializada}

Además de la limpieza a las máquinas y área de producción por parte de los operarios, será necesario contar con un personal de limpieza externo que esté a cargo del área de oficinas, planta en general y exteriores. 


\section{Transporte}

La venta principal se realizará a los supermercados por ser el canal más masivo hacia los consumidores, razón por la cual se necesitará contratar el servicio de transporte para llevar a los almacenes centrales de las principales cadenas.

Para las tiendas especializadas, grifos y bodegas es necesario camiones de menor capacidad y que tengan la flexibilidad suficiente para repartir en varios puntos.

\subsection{Disposición de planta}

\subsubsection{Características físicas del proyecto}

El terreno tendrá un tamaño de $576 \mathrm{~m}^{2}$ y estará distribuido entre los ambientes administrativos y la planta, que incluye el patio de maniobras, almacenes, laboratorio de calidad y zona de producción.

La construcción de la planta debe cumplir las condiciones detalladas en el presente capítulo para permitir su óptimo funcionamiento y conservación con el paso de los años.

\section{Factor edificio}

Para la construcción de la planta se debe comenzar haciendo un estudio de suelos y una cimentación adecuada, de modo que permita conseguir una estructura rígida que pueda soportar las condiciones desfavorables y asegurar la operación continua.

Además, la edificación debe estar orientada a un diseño sanitario que disminuya la suciedad, favorezca la limpieza de las superficies y facilite el mantenimiento de las instalaciones y equipos.

Pisos

Serán hechos de cemento pulido ya que es un buen antideslizante, fácil de desinfectar y lavar. Además, contará con canaletas para poder remover el agua y desperdicios que sobren de las operaciones de lavado, trozado, cocido y limpieza.

Paredes

Deberán ser de color blanco y construidas con materiales lisos lavables. La altura dependerá de los requerimientos de cada área de la planta y de la maquinaria. 
Techos

El tipo de techo será sólido y con cubierta de planchas de fibrocemento de $6 \mathrm{~mm}$, de gran resistencia a la corrosión y a la contracción. Las estructuras metálicas de soporte deben tener un diseño que reduzca la acumulación de suciedad.

\section{Ventanas}

Son necesarias para aportar ventilación e iluminación natural a la planta. Las ventanas deberán ser de fácil acceso para la limpieza e incluirán una malla para evitar el paso de insectos o roedores.

\section{Puertas}

El material a usar depende de la zona, para las oficinas se usará puertas de vidrio templado con una franja fosforescente para evitar accidentes y para la planta otro material como madera o planchas de metal de grosor considerable. Como una medida de seguridad y prevención, deberán abrir hacia afuera y deben mantenerse sin llave durante el día.

\section{Pasillos}

El ancho se calcula en base al tránsito de usuarios, sin embargo, no podrá ser menor a 90 cm. En el caso del almacén, se calcula en base a las medidas de los apiladores manuales y tamaño de racks.

\section{Factor servicio}

Se evalúan los aspectos de los servicios relativos al personal, materiales, maquinaria y edificio, resaltando lo siguiente:

\section{Iluminación}

Se debe precisar una luz constante y suficiente para permitir una eficiente operación por parte de los operarios durante todo el proceso. De esta manera, se facilita un mejor rendimiento y se evita accidentes por trabajar en condiciones poco iluminadas o inseguras. Se usará luz blanca en el área de producción y oficinas administrativas, donde habrá mayor presencia de LEDs. 
Patio de maniobras

Es la zona destinada para el ingreso de vehículos a la zona de carga y descarga. Es muy recomendable estar cerca a la caseta de vigilancia para llevar un control y a los almacenes para disminuir los tiempos.

Instalaciones sanitarias

Se contará con un número de baños adecuado para la cantidad de personas en la planta, según las especificaciones de OSHA. Debe haber un control de limpieza periódico para mantener un ambiente higiénico y controlar la disponibilidad de jabón, champú, papel higiénico, toallas y más.

\section{Comedor}

Debe ser amplio y contar con espacio de mesas y sillas para todo el personal. Habrá disponible dos microondas para que puedan calentar su almuerzo, una refrigeradora y lavavajillas para cuando terminen. Es indispensable revisar el tema de la ventilación para evitar la acumulación de olores.

\section{Oficinas}

Las oficinas del área administrativa deben ubicarse de manera independiente a la planta. Deben contar con equipos ser cómodas y a un extremo de la planta. Deben contar con materiales básicos como escritorio, computadoras, sillas ajustables que cumplan con la ergonomía necesaria. También, tendrá una sala de reuniones y aire acondicionado.

Vías de acceso

La puerta de ingreso y salida a la planta, debe estar lo más cerca posible a los almacenes para agilizar el tiempo de carga y descarga. Los pisos deben estar señalizados con franjas de pintura que indiquen el camino que se debe recorrer y las limitaciones de acceso.

Caseta de vigilancia

Estará ubicada a la entrada de la planta para controlar el ingreso del personal, proveedores y visitantes. Debe mantener un registro para el control de ingresos. Contará con un teléfono que permita la comunicación frecuente con todas las áreas. 


\section{Almacenes}

Se necesita contar con dos almacenes, uno destinado a la materia prima y otro para producto terminado. Dentro del espacio se debe considerar las medidas de las parihuelas y de los montacargas manuales usados para el transporte. Deben estar ubicados cerca de la zona de producción y patio de maniobras para disminuir tiempos.

\subsubsection{Determinación de las zonas físicas requeridas}

Una vez definido el proceso de producción, las máquinas, el número de operarios y personal administrativo, se determinan las áreas a considerar en la distribución de planta.

Zona de Selección y Pesado

Zona de Lavado

Zona de Desinfectado (personal)

Zona de Producción

Almacén de Materia Prima

Almacén de Producto Terminado

Laboratorio de Calidad

SSHH Planta

Patio de Maniobras

Área Administrativa

Comedor

Caseta de Vigilancia 


\subsubsection{Cálculo de áreas para cada zona}

Tabla 5.27.

Área mínima requerida según método de Guerchet

\begin{tabular}{|c|c|c|c|c|c|c|c|c|c|c|c|}
\hline Elementos Estáticos & $\mathbf{n}$ & $\mathbf{N}$ & $\mathbf{L}(\mathbf{m})$ & $\mathbf{A}(\mathbf{m})$ & $\mathbf{h}(\mathbf{m})$ & Ss & Sg & Se & St & Ss x n & Ss $\times n \times h$ \\
\hline Tanque de lavado & 1 & 2 & 1.05 & 1.15 & 1.1 & 1.21 & 2.42 & 2.88 & 6.50 & 1.21 & 1.33 \\
\hline Almacén Temporal & 1 & & 1.2 & 1 & 0.5 & 1.20 & & 0.95 & 2.15 & 1.20 & 0.60 \\
\hline Marmita para cocción & 1 & 2 & 1.05 & 1.15 & 1.1 & 1.21 & 2.42 & 2.88 & 6.50 & 1.21 & 1.33 \\
\hline Almacén Temporal & 1 & & 1.2 & 1 & 0.5 & 1.20 & & 0.95 & 2.15 & 1.20 & 0.60 \\
\hline Trozadora & 1 & 1 & 0.7 & 0.6 & 1.2 & 0.42 & 0.42 & 0.67 & 1.51 & 0.42 & 0.50 \\
\hline Almacén Temporal & 1 & & 1.2 & 1 & 0.5 & 1.20 & & 0.95 & 2.15 & 1.20 & 0.60 \\
\hline Tina de Hidratado & 1 & 2 & 1.1 & 0.6 & 1.2 & 0.66 & 1.32 & 1.57 & 3.55 & 0.66 & 0.79 \\
\hline Almacén Temporal & 1 & & 1.2 & 1 & 0.5 & 1.20 & & 0.95 & 2.15 & 1.20 & 0.60 \\
\hline Tina de Enfriado & 1 & 2 & 1.1 & 0.6 & 1.2 & 0.66 & 1.32 & 1.57 & 3.55 & 0.66 & 0.79 \\
\hline Almacén Temporal & 1 & & 1.2 & 1 & 0.5 & 1.20 & & 0.95 & 2.15 & 1.20 & 0.60 \\
\hline Máquina para hacer hielo & 1 & 1 & 1.58 & 0.55 & 1.22 & 0.87 & 0.87 & 1.38 & 3.12 & 0.87 & 1.06 \\
\hline Refrigerador & 1 & 1 & 1 & 0.7 & 1.5 & 0.70 & 0.70 & 1.11 & 2.51 & 0.70 & 1.05 \\
\hline Marmita para mezclado & 1 & 2 & 1.05 & 1.15 & 1.1 & 1.21 & 2.42 & 2.88 & 6.50 & 1.21 & 1.33 \\
\hline Almacén Temporal & 1 & & 1.2 & 1 & 0.5 & 1.20 & & 0.95 & 2.15 & 1.20 & 0.60 \\
\hline Bomba de tornillo & 1 & 1 & 1.45 & 0.3 & 0.3 & 0.44 & 0.44 & 0.69 & 1.56 & 0.44 & 0.13 \\
\hline Envasadora & 1 & 2 & 1.62 & 1.5 & 1.45 & 2.43 & 4.86 & 5.80 & 13.09 & 2.43 & 3.52 \\
\hline Almacén Temporal Doypack & 1 & & 1.2 & 1 & 0.5 & 1.20 & & 0.95 & 2.15 & 1.20 & 0.60 \\
\hline Faja transportadora & 1 & 1 & 4 & 0.28 & 1.2 & 1.12 & & 0.89 & 2.01 & 1.12 & 1.34 \\
\hline Balanza de plataforma & 1 & 2 & 0.6 & 0.6 & 1 & 0.36 & 0.72 & 0.86 & 1.94 & 0.36 & 0.36 \\
\hline Lavadero de 1 poza & 1 & 1 & 1.1 & 0.6 & 1.2 & 0.66 & 0.66 & 1.05 & 2.37 & 0.66 & 0.79 \\
\hline Lavadero de 2 pozas & 1 & 1 & 1.4 & 0.6 & 1.2 & 0.84 & 0.84 & 1.34 & 3.02 & 0.84 & 1.01 \\
\hline Mesa & 4 & 4 & 1.1 & 0.6 & 1.2 & 0.66 & 2.64 & 2.62 & 23.69 & 2.64 & 3.17 \\
\hline \multirow[t]{2}{*}{ Almacén Temporal Encajado } & 2 & $\mathrm{X}$ & 1.2 & 1.0 & 0.5 & 1.20 & & 0.95 & 4.31 & 2.40 & 1.20 \\
\hline & & & & & & & & Mínimo & 100.82 & 26.22 & 23.91 \\
\hline
\end{tabular}

Elaboración propia 
Para calcular el tamaño mínimo de las áreas se aplicó el método de Guerchet, el cual considera el número de operarios, las dimensiones de las máquinas y equipos. Si el almacén temporal es mayor al 30\% de la superficie total de la máquina, se considerará como espacio adicional.

\section{Tabla 5.28.}

Tabla de elementos móviles

\begin{tabular}{|c|c|c|c|c|c|c|c|c|c|c|c|}
\hline Elementos móviles & $\mathbf{n}$ & $\mathbf{N}$ & $\mathbf{L}(\mathbf{m})$ & $\mathbf{A}(\mathbf{m})$ & $\mathbf{h}(\mathbf{m})$ & Ss & $\mathbf{S g}$ & Se & St & Ss $x \mathrm{n}$ & Ss $\times n \times h$ \\
\hline Estibador manual & 4 & $\mathrm{X}$ & 1.58 & 0.55 & 1.22 & 0.87 & $\mathrm{X}$ & $\mathrm{X}$ & $\mathrm{X}$ & 3.48 & 4.24 \\
\hline \multirow[t]{2}{*}{ Operarios } & 8 & $\mathrm{X}$ & $\mathrm{X}$ & $\mathrm{X}$ & 1.65 & 0.50 & $\mathrm{X}$ & $\mathrm{X}$ & $\mathrm{X}$ & 4.00 & 6.60 \\
\hline & & & & & & & & & & 7.48 & 10.84 \\
\hline
\end{tabular}

Elaboración propia

El factor k es obtenido de la siguiente manera:

$$
k=\frac{\mathrm{h} 1}{2 * \mathrm{~h} 2}=\frac{1.45}{(2 * 0.91)}=0.8
$$

\section{Donde:}

h1: Altura promedio ponderada de elementos móviles

h2: Altura promedio ponderada de elementos estáticos 


\subsubsection{Dispositivos de seguridad industrial y señalización}

La planta tendrá extintores de polvo químico seco (PQS), que es la opción ideal para mitigar los fuegos de clase A y clase E, los cuales se originan a partir de materiales sólidos como papel, cartón y plástico y por cortocircuito eléctrico, respectivamente. Deberán situarse en lugares visibles y sin dificultades de acceso, y deben estar debidamente señalizados como en la imagen siguiente:

Figura 5.44.

Colocación de extintores

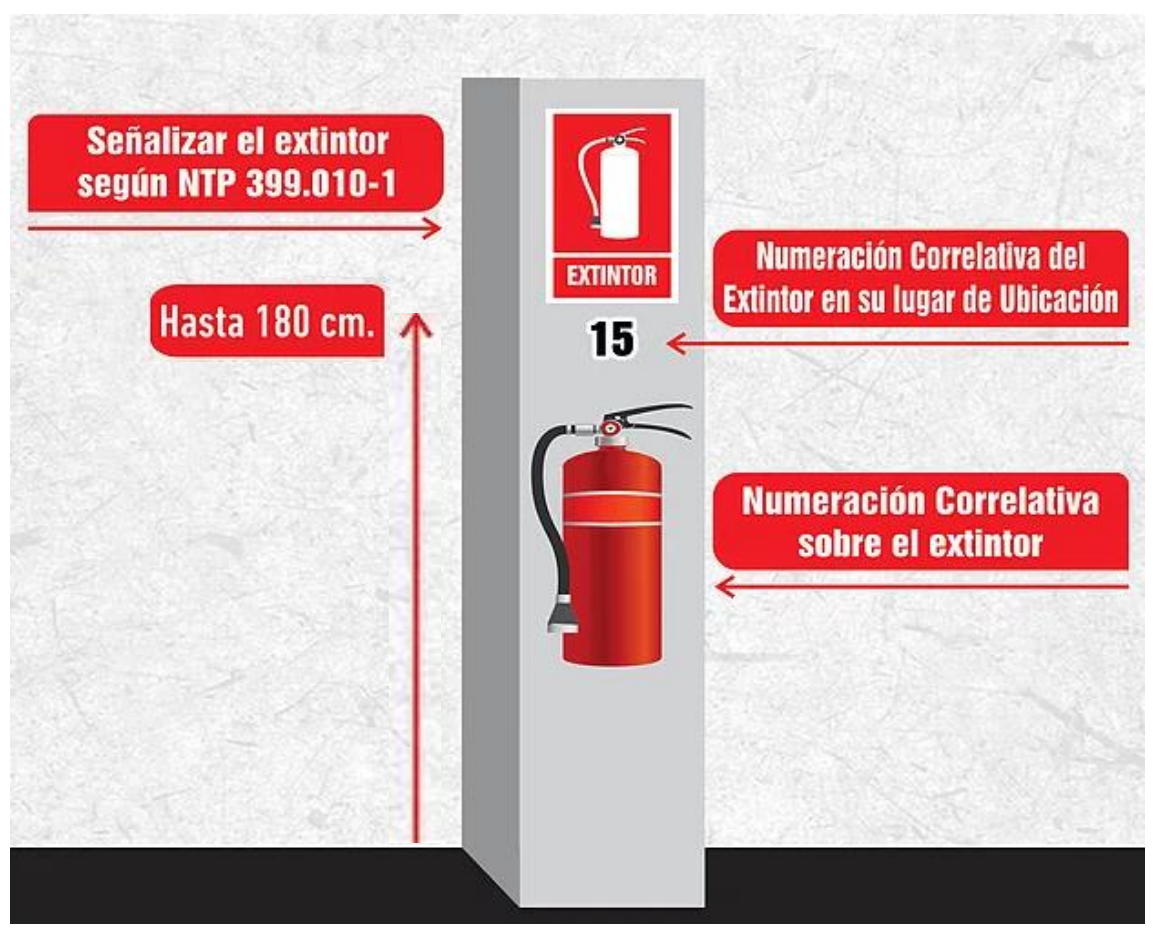

Fuente: Extinsafe (2017)

La señalización de las áreas cumple un papel fundamental en la prevención de accidentes, ayudan a los colaboradores a estar alerta sobre la manipulación de máquinas y orientan el camino hacia un lugar seguro o la salida. El material debe ser de PVC rígido para una mayor durabilidad y foto-luminiscente para que pueda iluminarse en la oscuridad.

Cabe precisar que la planta es de bajo riesgo. 


\subsubsection{Disposición general}

La disposición general hace referencia a la distribución o ubicación que tendrán las áreas dentro de la planta y se basa en la interacción que deben tener las áreas de producción con las demás a través del análisis relacional.

Tabla 5.29.

Valores de proximidad

\begin{tabular}{cc}
\hline Código & Valor de Proximidad \\
\hline $\mathrm{A}$ & Absolutamente necesario \\
$\mathrm{E}$ & Especialmente necesario \\
$\mathrm{I}$ & Importante \\
$\mathrm{O}$ & Normal \\
$\mathrm{U}$ & Sin importancia \\
$\mathrm{X}$ & No deseable \\
$\mathrm{XX}$ & Altamente no deseable \\
\hline Fuente: Díaz B., Noriega T. (2007)
\end{tabular}

Se debe establecer una lista de motivos para establecer la cercanía entre áreas, teniendo claro que se debe dar la continuidad al proceso y evitar la contaminación de los insumos.

Tabla 5.30.

Tabla de Motivos

\begin{tabular}{cc}
\hline Código & Motivo \\
\hline 1 & Para no contaminar el producto \\
2 & Para la continuación del proceso \\
3 & Para suministrar los insumos necesarios \\
4 & Para el control de la producción \\
5 & Para facilitar el trabajo administrativo \\
6 & Por no ser necesario \\
7 & Higiene \\
8 & Facilidad de carga y descarga \\
9 & Acceso a servicios \\
10 & Control \\
\hline Elaboración propia
\end{tabular}

Luego de elaborar la tabla relacional, se debe realizar el diagrama relacional de recorrido. Para ello se debe asignar un color y un símbolo según sea la actividad. 
Tabla 5.31.

Identificación de actividades

Operación (montaje o submontaje)
Operación, proceso o fabricación
Almacenaje
Control
Fuente: Díaz B., Noriega T. (2007)
Administración

Figura 5.45.

Tabla relacional de actividades

\begin{tabular}{|l|l|l|l}
\hline 1 & 1. Selección y Pesado \\
\hline 2 & 2. Lavado \\
\hline 3 & 3. Zona de Desinfectado \\
\hline 4 & 4. Zona de Producción & 5. Almacén de Materia Prima \\
\hline 7 & 6. Almacén de Producto Terminado & 7. Laboratorio de Calidad \\
\hline 8 & 8. Servicios Higiénicos de Planta \\
\hline 9 & 9. Patio de Maniobras \\
\hline 10 & 10. Área Administrativa & 11. Comedor \\
\hline 12 & 12. Caseta de Vigilancia \\
\hline 11
\end{tabular}

Elaboración propia 
Tabla 5.32.

Relación entre espacios

\begin{tabular}{cc}
\hline Código & Relación \\
\hline A & $(1,2)(1,3)(1,4)(1,5)(2,3)(2,4)(3,4)(3,5)(4,6)(4,7)(5,9)(6,7)(6,9)(9,12)$ \\
E & $(1,7)(1,9)(2,5)(4,5)(5,7)(6,8)$ \\
I & $(1,6)(2,7)(2,9)(3,9)(4,9)(5,12)(6,12)(7,8)(8,9)(8,11)(8,12)(9,10)$ \\
O & $(10,11)(10,12)(11,12)$ \\
U & $(1,12)(2,6)(2,12)(3,6)(3,7)(5,10)(6,11)(7,12)(9,11)$ \\
X & $(1,10)(3,12)(4,10)(4,12)(5,6)(5,11)(6,10)(7,9)(7,10)(7,11)(8,10)(1,11)(2,8)(2,10)(2,11)(3,8)(3,11)(4,11)(4,8)(5,8)$ \\
\hline
\end{tabular}

Elaboración propia

Figura 5.46.

Diagrama relacional de actividades

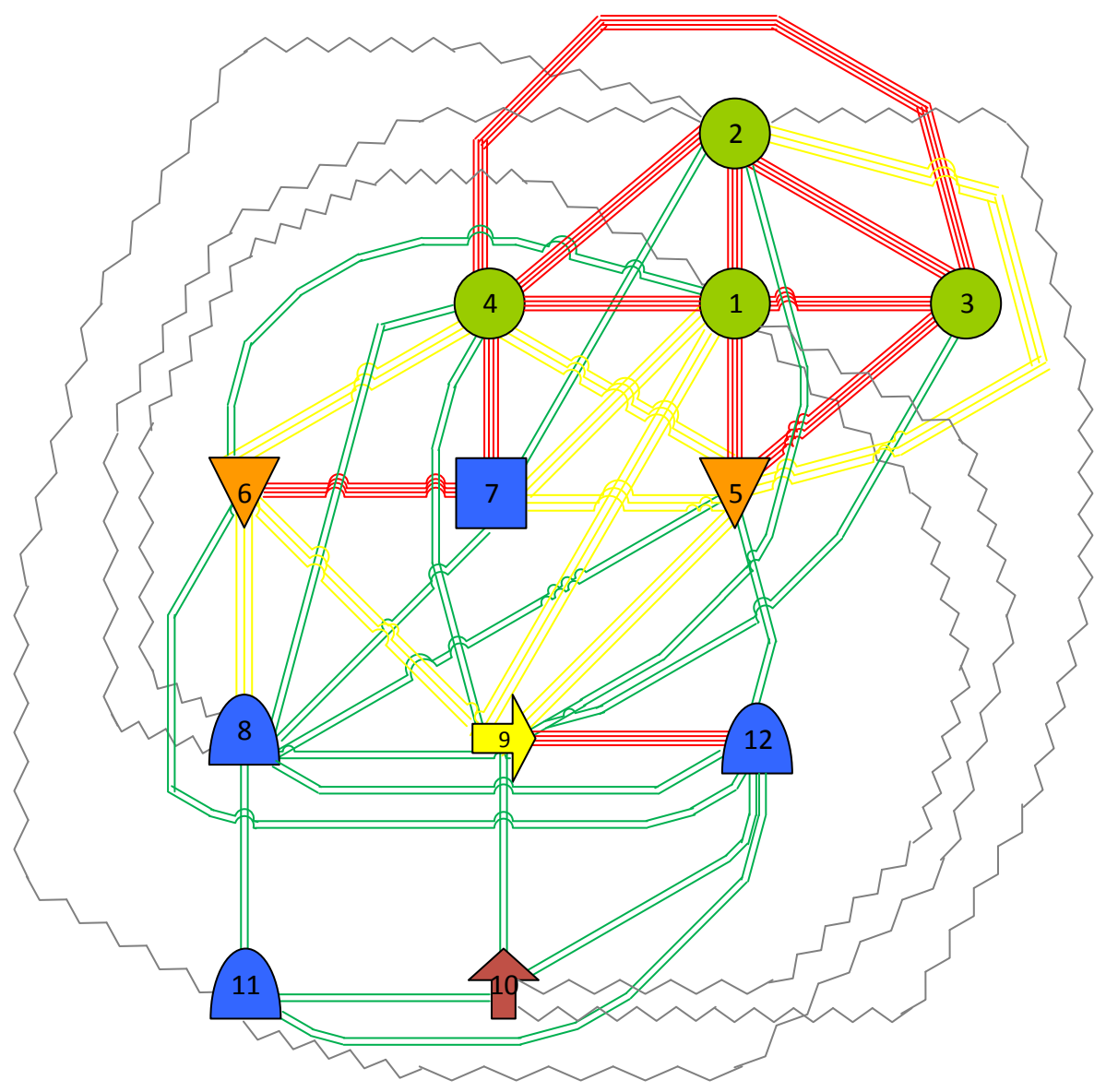

Elaboración propia 
Conociendo la ubicación posible para cada área y el tamaño para la zona de producción obtenido con el método de Guerchet, se procede a establecer las demás dimensiones.

Tabla 5.33.

Tamaños establecidos por área

\begin{tabular}{cc}
\hline Zona & Tamaño $\left(\mathbf{m}^{\mathbf{2}}\right)$ \\
\hline Vigilancia & 4 \\
Comedor & 25 \\
SSHH Planta & 28 \\
Almacén PT & 42 \\
Almacén MP & 24 \\
Calidad & 21 \\
Selección y pesado & 16 \\
Lavado & 12 \\
Desinfectado & 8 \\
Zona de procesamiento & 108 \\
Estacionamiento & 30 \\
Patio de maniobras & 102 \\
Área administrativa & 168 \\
Total & $\mathbf{5 7 6}$ \\
\hline
\end{tabular}

Elaboración propia 


\subsubsection{Disposición de detalle}

Figura 5.47.

Plano de distribución de planta

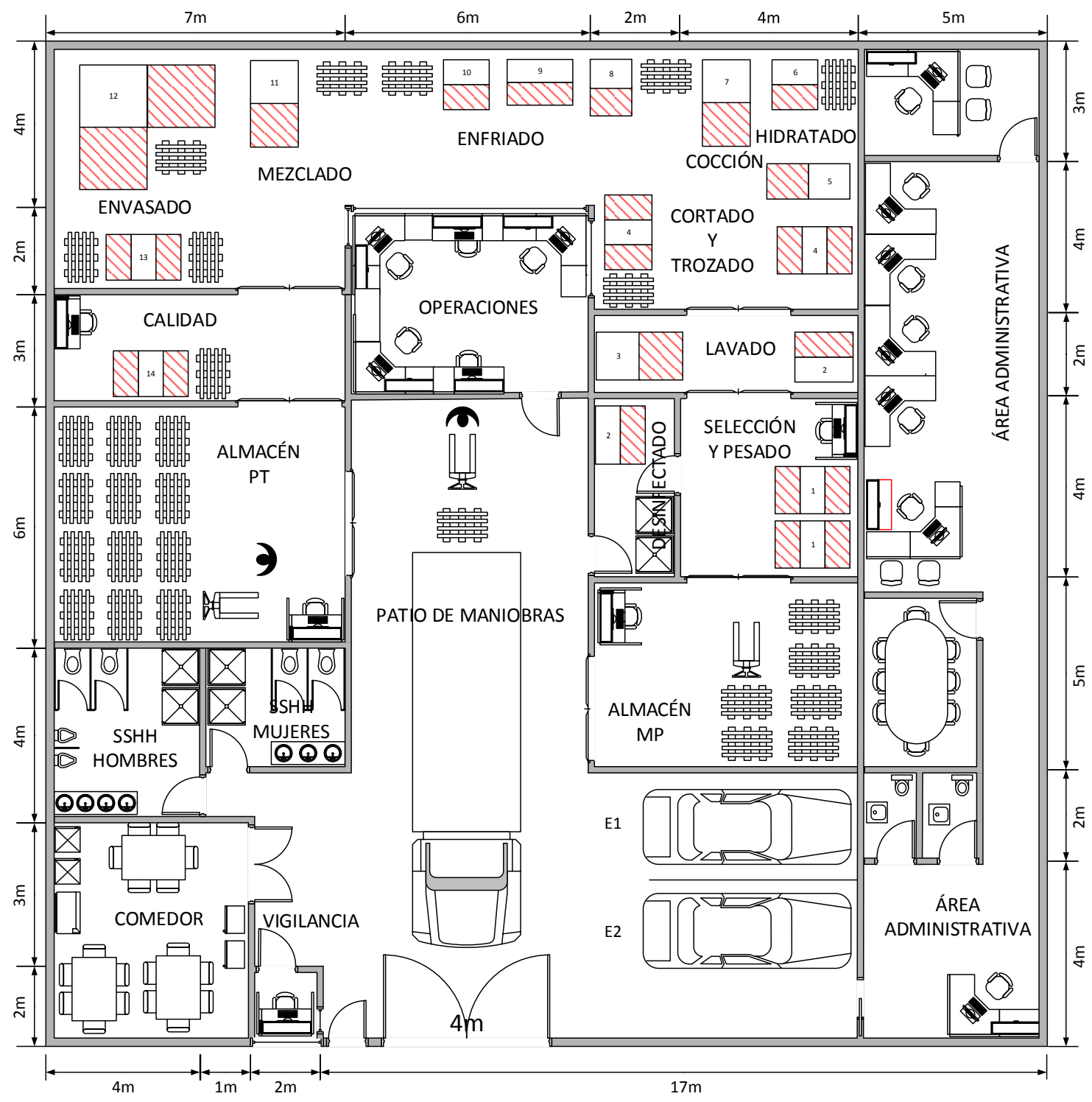

\begin{tabular}{|c|c|c|c|c|}
\hline \multirow[b]{2}{*}{ ஸ } & \multirow{2}{*}{$\begin{array}{l}\text { Universidad de Lima } \\
\text { Escuela de Universitaria de Ingeniería } \\
\text { Facultad de Ingeniería Industrial }\end{array}$} & \multirow[b]{2}{*}{$\begin{array}{l}\text { Plano de Planta Procesadora de Dip a base de } \\
\text { quinua y vegetales verdes }\end{array}$} & \multicolumn{2}{|c|}{ Leyenda } \\
\hline & & & $\begin{array}{l}\text { 1. Mesa de Selec. Y Pesado } \\
\text { 2. Lavadero } 2 \text { pozas } \\
\text { 3. Tanque de Lavado }\end{array}$ & $\begin{array}{l}\text { 8. Refrigerador de hielo } \\
\text { 9. Máquina para hacer hielo } \\
\text { 10. Tina de Enfriado }\end{array}$ \\
\hline $\begin{array}{c}\text { Escala: } \\
1: 100\end{array}$ & $\begin{array}{l}\text { Fecha: } \\
03 / 05 / 2018\end{array}$ & $\begin{array}{c}\text { Elaborado por: } \\
\text { Acosta Llaury, Carlos Javier } \\
\text { Sebastián Andrade, Diego Antonio }\end{array}$ & $\begin{array}{l}\text { 5. Trozadora } \\
\text { 6. Tina de Hidratado } \\
\text { 7. Tanque de Cocción }\end{array}$ & $\begin{array}{l}\text { 12. Envasadora } \\
\text { 13. Mesa de Encajado } \\
\text { 14. Mesa de Inspección }\end{array}$ \\
\hline
\end{tabular}

Elaboración propia 


\subsection{Cronograma de implementación del proyecto}

La duración de la fase preparativa de proyecto tiene una duración de 33 semanas, iniciando en abril del 2017 hasta fin de año. El inicio de operaciones de la planta tendría como fecha enero 2018.

Figura 5.48 .

Cronograma de implementación del proyecto

\begin{tabular}{|c|c|c|c|c|c|c|c|c|c|c|c|c|c|c|c|c|c|c|c|c|c|c|c|c|c|c|}
\hline \multirow[b]{2}{*}{ Nombre de tarea } & \multirow[b]{2}{*}{ Duración } & \multirow[b]{2}{*}{ Comienzo } & \multirow[b]{2}{*}{ Fin } & \multicolumn{8}{|c|}{$2^{\circ}$ trimestre } & \multicolumn{9}{|c|}{ 3er trimestre } & \multicolumn{6}{|c|}{$4^{\circ}$ trimestre } \\
\hline & & & & $\mathrm{P} M$ & $\mathrm{~F}$ & $\mathrm{P}$ & $\mathrm{M}$ & $\mathrm{F}$ & $\mathrm{P}$ & $\mathrm{M}$ & $\mathrm{F}$ & $\mathrm{P}$ & $\mathrm{M}$ & $\mathrm{F}$ & $P$ & $M$ & $\mathrm{~F}$ & $\mathrm{P}$ & M & $\mathrm{F}$ & $\mathrm{P}$ & $M$ & $\mathrm{~F}$ & $\mathrm{P}$ & $M F$ & $\mathrm{~F}$ \\
\hline Búsqueda de información & 4 sem. & Iun $3 / 04 / 17$ & vie $28 / 04 / 17$ & 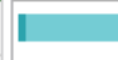 & & & & & & & & & & & & & & & & & & & & & & \\
\hline I. Aspectos Generales & 2 sem. & Iun $1 / 05 / 17$ & vie $12 / 05 / 17$ & & & & & & & & & & & & & & & & & & & & & & & \\
\hline II. Estudio de mercado & 6 sem. & Iun $15 / 05 / 17$ & vie $23 / 06 / 17$ & & & & & & & & & & & & & & & & & & & & & & & \\
\hline III. Localización de planta & 2 sem. & Iun $26 / 06 / 17$ & vie $7 / 07 / 17$ & & & & & & & & & & & & & & & & & & & & & & & \\
\hline IV. Tamaño de planta & 3 sem. & Iun $10 / 07 / 17$ & vie $28 / 07 / 17$ & & & & & & & & & & & & & & & & & & & & & & & \\
\hline V. Ingeniería del proyecto & 6 sem. & Iun $31 / 07 / 17$ & vie $8 / 09 / 17$ & & & & & & & & & & & & & & & & & & & & & & & \\
\hline $\begin{array}{l}\text { VI. Organización y } \\
\text { Administración }\end{array}$ & $1 \mathrm{sem}$ & Iun $11 / 09 / 17$ & vie $15 / 09 / 17$ & & & & & & & & & & & & & & & & & & & & & & & \\
\hline $\begin{array}{l}\text { VII. Aspectos económicos } \\
\text { y financieros }\end{array}$ & 4 sem. & Iun $25 / 09 / 17$ & vie $20 / 10 / 17$ & & & & & & & & & & & & & & & & & & & & & & & \\
\hline $\begin{array}{l}\text { VIII. Evaluación económica } \\
\text { y financiero del proyecto }\end{array}$ & 2 sem. & Iun $23 / 10 / 17$ & vie $3 / 11 / 17$ & & & & & & & & & & & & & & & & & & & & & & & \\
\hline $\begin{array}{l}\text { IX. Evaluación social del } \\
\text { proyecto }\end{array}$ & 2 sem. & Iun $6 / 11 / 17$ & vie $17 / 11 / 17$ & & & & & & & & & & & & & & & & & & & & & & & \\
\hline $\begin{array}{l}\text { Conclusiones y } \\
\text { recomendaciones }\end{array}$ & 1 sem & Iun $20 / 11 / 17$ & vie $24 / 11 / 17$ & & & & & & & & & & & & & & & & & & & & & & & \\
\hline
\end{tabular}

Elaboración propia 


\section{CAPÍTULO VI: ORGANIZACIÓN Y ADMINISTRACIÓN}

\subsection{Formación de la Organización empresarial}

La organización tendrá una estructura funcional; es decir, la división del trabajo estará agrupada por las principales funciones a realizarse como marketing y ventas, recursos humanos, administración y finanzas, operaciones, entre otras. Se trata de una estructura vertical; por ejemplo, el Jefe de Administración y Finanzas tendrá a su cargo el trabajo de todo el equipo del área; esto facilita la eficiencia operativa. (Universidad Esan, 2017)

Además, a fin de lograr el éxito esperado de forma constante y perdurar en el tiempo como compañía es de vital importancia definir como parámetros fijos la misión y visión.

- Misión: Somos una empresa peruana que ofrece un producto vegano buscando generar una alimentación saludable.

- Visión: Ser líderes en el mercado vegano gourmet, promoviendo la cultura de lo natural, saludable y orgánico en el país.

\subsection{Requerimientos de personal directivo, administrativo y de servicios}

\section{$\underline{\text { Personal directivo }}$}

Tendrá como principal función dirigir y guiar la empresa; es decir, planificar, organizar, dirigir, coordinar y controlar las funciones y recursos en todos los horizontes de tiempo. Estará conformado por el gerente general, quién a su vez reportará al directorio de accionistas.

\section{$\underline{\text { Personal administrativo }}$}

Conformado principalmente por las jefaturas encargadas de dirigir y planificar a cortomediano plazo las acciones para gestionar los recursos del equipo que lideran. Al contar con una estructura funcional, el personal administrativo reportará directamente al gerente 
general, y serán evaluados a través de indicadores claves aprobados en consenso desde inicio de año por el personal directivo. Cabe mencionar que forman parte de este tipo de personal: Jefes, secretarias, analistas, asistentes e inclusive practicantes de ser necesario.

\section{Personal operativo}

Conformado por los operarios involucrados y en relación directa con la cadena de abastecimiento de la empresa.

\section{$\underline{\text { Personal de servicios }}$}

Conformado por personal externo de limpieza, mantenimiento y seguridad.

Además, se detalle el perfil y objetivo de cada puesto:

- Gerente General: responsable de la dirección y representación legal, estableciendo las políticas generales que regirán a la empresa. Desarrolla y define los objetivos organizacionales. Planifica el crecimiento de la empresa a corto y largo plazo. Además, presenta al Directorio los estados financieros, el presupuesto, programas de trabajo y demás obligaciones que requiera.

- Jefe de Administración y Finanzas: responsable del cumplimiento de los principios administrativos, contables y comerciales de la empresa. Supervisa la formulación, ejecución y evaluación del presupuesto anual.

- Analista de Finanzas: responsable de evaluar la situación financiera de la empresa tomando en cuenta diversos ratios como liquidez, rentabilidad y endeudamiento, con el objetivo de proveer información relevante para la toma de decisiones. Realizar el proceso de administración financiera, gestión y contabilidad.

- Analista de Recursos Humanos: responsable de realizar el reclutamiento y selección del personal en general de la empresa. Mantener excelente clima 
laboral dentro de la empresa y dar seguimiento a las necesidades del personal. Hacer el ingreso de los expedientes laborales y de los requerimientos de documentación, así como inducción, procesos administrativos y comunicación interna.

- Analista Marketing y Ventas: responsable de analizar el mercado, diagnosticar las oportunidades de crecimiento y rentabilidad para el negocio, desarrollar la estrategia comercial y llevarla a la práctica, con el fin de generar ventajas competitivas y ventajas para el cliente.

- Ejecutivo comercial: responsable de realizar las negociaciones con los canales de venta, en primera instancia las grandes cadenas de supermercados y más adelante con las tiendas especializadas, ferias y venta en línea, estableciendo acuerdos a corto y mediano plazo.

- Jefe de Operaciones: responsable de programar, coordinar, ejecutar y controlar el abastecimiento oportuno de bienes materiales y prestación de servicios que requieren las unidades funcionales de la empresa, a fin que dispongan de lo necesario para cumplir su misión. Tiene a cargo las áreas de Logística, Calidad, Almacén y Producción.

- Supervisor de Planta: responsable de la totalidad de las operaciones de la planta: producción, calidad y mantenimiento de acuerdo con las directrices generales marcadas por el directorio. Dirige, controla y apoya a la estructura humana y técnica implicada en el proceso de fabricación.

- Supervisor de Calidad: responsable de dirigir, planificar, organizar y controlar los procesos relacionados a la gestión de calidad con el fin de cumplir con los estándares y normas establecidas por HACCP; para así, favorecer a la mejora continua. Además, dirige y controla las mejoras de organización de los procesos 
productivos según las normativas de calidad, medio ambiente y prevención de riesgos laborales.

- $\quad$ Asistente de Mantenimiento: responsable de la ejecución de los planes de mantenimiento asignado a las máquinas y equipos con el fin de asegurar su buen funcionamiento. Comprobar el correcto uso por parte de los operarios y coordinar con personal externo especializado los mantenimientos asignados periódicamente.

- $\quad$ Asistente de planificación: responsable de establecer la conexión entre el plan de producción y el requerimiento de compras, velando por las políticas de stocks establecidas por la empresa. Elaborar y mantener actualizado el plan de acción y hacer seguimiento a las actividades programadas.

- Asistente de almacén: responsable de llevar el registro de ingreso y salida de materia prima y producto terminado en el almacén respectivo. Realizar los cierres mensuales y verificar los niveles de stock periódicamente. Coordinar constantemente con ventas para preparar la entrega de pedidos.

- Secretaria: responsable de la organización de la oficina y la gestión de diversos proyectos de las jefaturas. Cumplirá un rol clave en la gestión y administración de las compañías, aportando soluciones a los conflictos, creatividad y dinamismo a los proyectos, y organización de las tareas cotidianas.

- Operarios: responsable de controlar y realizar los procesos de recepción, manipulación, transformación y elaboración de productos, respetando en todo momento las normas de calidad, de medio ambiente, seguridad y técnicosanitarias establecidas por la empresa. 


\subsection{Estructura organizacional}

Figura 6.49.

Estructura organizacional

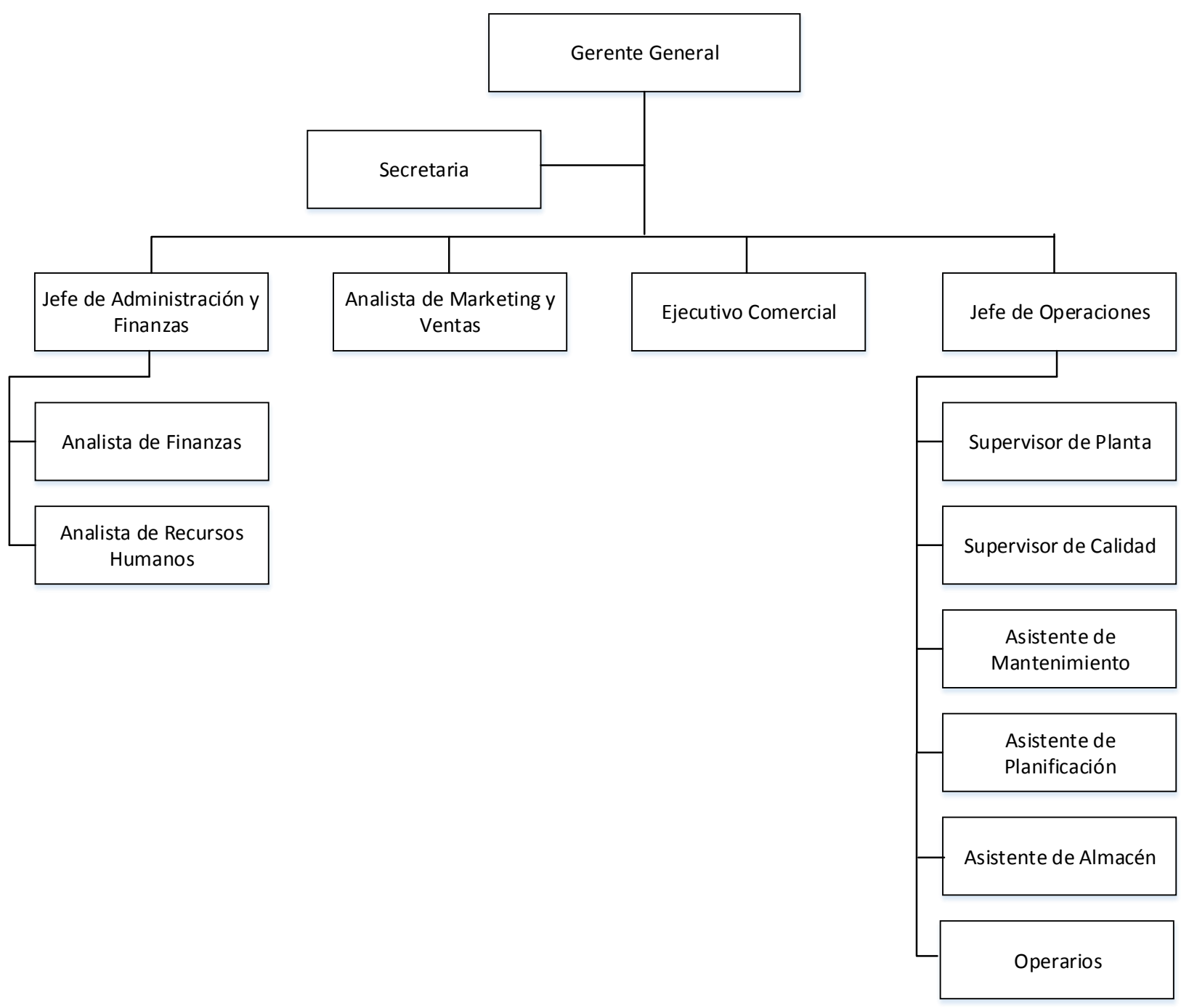

Elaboración propia 


\section{CAPÍTULO VII: ASPECTOS ECONÓMICOS Y FINANCIEROS}

\subsection{Inversiones}

La inversión total con la que se podrá poner en marcha el proyecto está dividida en la inversión fija, de donde se desprende la inversión fija tangible e intangible, y el capital de trabajo.

\subsubsection{Estimación de las inversiones de largo plazo}

\section{Inversión fija tangible}

Se considera a los activos físicos a usar a largo plazo en las operaciones de la empresa, los cuales, a excepción del terreno, van disminuyendo su valor con el paso de los años.

Tabla 7.1.

Inversión en activos tangibles (S/)

\begin{tabular}{cc}
\hline Activos tangibles & Total \\
\hline Terreno & 374,400 \\
Edificaciones & 172,800 \\
Máquinas & 146,570 \\
Equipos & 21,807 \\
Mobiliario & 71,684 \\
Total & $\mathbf{7 8 7 , 2 6 1}$ \\
\hline
\end{tabular}

Elaboración propia 


\section{Maquinaria y equipos}

Tabla 7.2.

Costo de Máquinas (S/)

\begin{tabular}{ccc}
\hline Máquinas & Cantidad & Total \\
\hline Marmita & 2 & 42,540 \\
Trozadora & 1 & 8,500 \\
Envasadora & 1 & 68,250 \\
Codificadora & 1 & 4,880 \\
Bomba de transferencia & 1 & 12,900 \\
Faja transportadora & 1 & 9,500 \\
Total & $\mathbf{7}$ & $\mathbf{1 4 6 , 5 7 0}$ \\
\hline
\end{tabular}

Elaboración propia

Tabla 7.3.

Costo de Equipos (S/)

\begin{tabular}{ccc}
\hline Equipos & Cantidad & Total \\
\hline Máquina para hacer hielo & 1 & 5,119 \\
Phmetro & 1 & 250 \\
Balanza electrónica & 1 & 119 \\
Balanza de Plataforma & 1 & 685 \\
Balanza de piso & 1 & 1,900 \\
Lavadero de 1 poza & 1 & 1,300 \\
Lavadero de 2 pozas & 1 & 1,400 \\
Mesas de trabajo & 4 & 3,600 \\
Tina de acero inoxidable & 1 & 1,300 \\
Exprimidor & 1 & 28 \\
Espumadera mediana & 2 & 32 \\
Cuchillos & 6 & 42 \\
Taza Graduada 600 cc & 4 & 32 \\
Montacarga manual & 4 & 6,000 \\
Total & $\mathbf{2 9}$ & $\mathbf{2 1 , 8 0 7}$ \\
\hline
\end{tabular}

Elaboración propia 
Tabla 7.4.

Costo de muebles de oficina, comedor y almacén (S/)

\begin{tabular}{ccc}
\hline Equipamiento & Cantidad & Total \\
\hline Laptops & 10 & 25,000 \\
Computadoras & 8 & 16,000 \\
Impresora & 2 & 598 \\
Fotocopiadora & 1 & 5,200 \\
Escritorios & 15 & 9,000 \\
Pizarras & 2 & 900 \\
Sillas con apoya brazo & 10 & 1,100 \\
Sillas gerenciales & 6 & 1,794 \\
Tachos & 16 & 160 \\
Proyector & 1 & 1,999 \\
Ecran & 1 & 300 \\
Reloj de pared & 4 & 80 \\
Router & 2 & 460 \\
Ventilador & 5 & 900 \\
Estante de madera & 10 & 3,200 \\
Archivador & 3 & 840 \\
Mesa & 2 & 800 \\
Sillas & 12 & 600 \\
Microondas & 2 & 598 \\
Juego de Menaje & 2 & 318 \\
Tacho de comedor & 1 & 30 \\
Bandejas plásticas & 12 & 168 \\
Refrigeradora & 1 & 999 \\
Estante de madera & 2 & 640 \\
Total & & $\mathbf{7 1 , 6 8 4}$ \\
\hline E & &
\end{tabular}

Elaboración propia

\section{Inversión fija intangible}

En esta parte de la inversión se considera los gastos realizados en activos que no pueden ser percibidos físicamente, y que han sido agrupados en cuatro categorías: gastos de organización, patentes y licencias, gastos de puesta en marcha y capacitación. 
Tabla 7.5.

Inversión en activos intangibles (S/)

\begin{tabular}{cc}
\hline Activos Intangibles & Total \\
\hline Estudios e investigaciones & $\mathbf{2 0 , 0 0 0}$ \\
Gastos de Organización & $\mathbf{5 5 , 7 0 0}$ \\
ERP & 50,000 \\
Diseño de Procedimientos & 5,000 \\
Gastos Legales Constitución Empresa & 700 \\
Patentes y Licencias & $\mathbf{4 , 0 0 0}$ \\
Patentes & 2,500 \\
Licencias Generales & 1,500 \\
Gastos de Puesta en Marcha & $\mathbf{3 9 1 , 0 8 5}$ \\
Publicidad & 100,000 \\
Remuneraciones & 187,928 \\
Gasto Preoperacional & 100,000 \\
Capacitación & $\mathbf{4 , 0 0 0}$ \\
Total & $\mathbf{4 7 4 , 7 8 5}$ \\
\hline Elaboración propia
\end{tabular}

\subsubsection{Estimación de las inversiones de corto plazo}

Se calculó el capital de trabajo con el método de desfase; es decir, en base a los gastos del primer año y el ciclo de caja. Teniendo en cuenta que la condición de pago para ingresos es 30 días y el de egresos, contra entrega.

$$
\begin{aligned}
& \text { Capital de trabajo }=\text { Gasto total año } 1 * \frac{\text { ciclo de caja(días })}{360} \\
& \text { Capital de trabajo }=3,270,086 * \frac{30}{360}=272,507
\end{aligned}
$$

Para estimar el total requerido en las inversiones de activo tangible e intangible se ha considerado un $10 \%$ adicional a ambos montos destinado a imprevistos y contingencias, valor que se refleja en la tabla 7.6. 
Tabla 7.6.

Inversión del proyecto (S/)

\begin{tabular}{ccc}
\hline Inversión Requerida & Total & \% \\
\hline Activo Tangible & 865,987 & $52.1 \%$ \\
Activo Intangible & 522,264 & $31.4 \%$ \\
Capital de trabajo permanente & 272,507 & $16.4 \%$ \\
Total & $\mathbf{1 , 6 6 0 , 7 5 7}$ & $\mathbf{1 0 0 \%}$ \\
\hline
\end{tabular}

Elaboración propia

\subsection{Costos de producción}

\subsubsection{Costos de las materias primas}

Para el cálculo del costo de materia prima anual se ha considerado el costo unitario de cada insumo sin tener en consideración un posible aumento del precio debido a que la inflación en alimentos en los últimos años no ha sido significativa, según el índice de precios al consumidor (IPC) en la categoría de Alimentos y Bebidas elaborado por el BCRP. Como se puede comprobar en la tabla 7.7 la variación del año 2017 fue casi imperceptible.

\section{Tabla 7.7.}

Variación anual promedio del IPC - Alimentos y Bebidas

\begin{tabular}{cccc}
\hline Año & $\mathbf{2 0 1 5}$ & $\mathbf{2 0 1 6}$ & $\mathbf{2 0 1 7}$ \\
\hline Variación porcentual & 0.44 & 0.29 & 0.03 \\
\hline
\end{tabular}

Fuente: BCRP (2018)

La tabla 7.8 que se muestra a continuación, ha sido elaborada con los precios obtenidos del Sistema de Información de Abastecimiento y Precios (SISAP) del Ministerio de Agricultura correspondiente a los precios del Mercado Mayorista de Lima. 
Tabla 7.8.

Costo de materia prima e insumos $(\mathrm{S} /)$

\begin{tabular}{cccccc}
\hline MP / Insumo & $\mathbf{2 0 1 8}$ & $\mathbf{2 0 1 9}$ & $\mathbf{2 0 2 0}$ & $\mathbf{2 0 2 1}$ & $\mathbf{2 0 2 2}$ \\
\hline Quinua & 295,266 & 284,348 & 301,056 & 318,746 & 337,476 \\
Esparrago & 489,971 & 471,853 & 499,578 & 528,934 & 560,014 \\
Brócoli & 216,396 & 208,394 & 220,639 & 233,604 & 247,331 \\
Albahaca & 30,243 & 29,124 & 30,836 & 32,648 & 34,566 \\
Cebolla & 9,838 & 9,474 & 10,031 & 10,620 & 11,244 \\
Limón & 80,270 & 77,301 & 81,844 & 86,653 & 91,745 \\
Queso Parmesano & 108,022 & 104,028 & 110,140 & 116,612 & 123,464 \\
Aceite de Oliva & 221,790 & 213,589 & 226,139 & 239,427 & 253,496 \\
Aceite de Girasol & 20,735 & 19,969 & 21,142 & 22,384 & 23,700 \\
Sal & 971 & 935 & 990 & 1,048 & 1,110 \\
Ajo & 27,292 & 26,282 & 27,827 & 29,462 & 31,193 \\
Doypack & 312,461 & 300,907 & 318,588 & 337,308 & 357,128 \\
Cajas & 215,747 & 207,769 & 219,977 & 232,903 & 246,589 \\
Total & $\mathbf{2 , 0 2 9 , 0 0 1}$ & $\mathbf{1 , 9 5 3 , 9 7 3}$ & $\mathbf{2 , 0 6 8 , 7 8 6}$ & $\mathbf{2 , 1 9 0 , 3 5 0}$ & $\mathbf{2 , 3 1 9 , 0 5 7}$ \\
\hline
\end{tabular}

Fuente: Ministerio de Agricultura y Riego (2018)

Elaboración propia

\subsubsection{Costo de la mano de obra directa}

La mano de obra directa es proporcionada por los operarios y tiene relación directa con la producción del dip, El costo se calcula en base al sueldo mínimo fijado recientemente en 930 soles, más gratificaciones, cts y aportaciones.

Tabla 7.9.

Costo de la mano de obra directa (S/)

\begin{tabular}{cccccc}
\hline Año & $\mathbf{2 0 1 8}$ & $\mathbf{2 0 1 9}$ & $\mathbf{2 0 2 0}$ & $\mathbf{2 0 2 1}$ & $\mathbf{2 0 2 2}$ \\
\hline MOD & 122,326 & 125,996 & 129,776 & 133,669 & 137,679 \\
\hline
\end{tabular}

Elaboración propia 


\subsubsection{Costo Indirecto de Fabricación}

Hace referencia a todos los costos de fabricación distintos a los materiales directos y mano de obra directa. En este caso, se ha considerado mano de obra del soporte de operaciones, servicios básicos, seguridad, mantenimiento de un tercero, telefonía y depreciación de planta.

Tabla 7.10.

Costos Indirectos de Fabricación (S/)

\begin{tabular}{cccccc}
\hline CIF & $\mathbf{2 0 1 8}$ & $\mathbf{2 0 1 9}$ & $\mathbf{2 0 2 0}$ & $\mathbf{2 0 2 1}$ & $\mathbf{2 0 2 2}$ \\
\hline MOI & 218,674 & 225,234 & 231,991 & 238,951 & 246,120 \\
Servicios Básicos & 23,170 & 22,934 & 23,295 & 23,677 & 24,081 \\
Seguridad & 117,000 & 120,510 & 124,125 & 127,849 & 131,685 \\
Mantenimiento & 60,000 & 61,800 & 63,654 & 65,564 & 67,531 \\
Telefonía & 18,234 & 18,781 & 19,344 & 19,925 & 20,523 \\
Depreciación Fabril & 44,991 & 44,991 & 44,991 & 44,991 & 44,991 \\
Total & $\mathbf{4 8 2 , 0 6 9}$ & $\mathbf{4 9 4 , 2 5 0}$ & $\mathbf{5 0 7 , 4 0 1}$ & $\mathbf{5 2 0 , 9 5 6}$ & $\mathbf{5 3 4 , 9 2 9}$ \\
\hline
\end{tabular}

Elaboración propia

\subsection{Presupuestos Operativos}

\subsubsection{Presupuesto de ingreso por ventas}

Para el cálculo del presupuesto de ingresos se ha considerado las dos principales variables:

precio al canal y demanda. Cabe resaltar que la condición de pago asignado a tiendas especializadas y retail es 15 y 30 días, respectivamente.

Tabla 7.11.

Presupuesto de ingreso por ventas (S/)

\begin{tabular}{ccccccc}
\hline Año & UM & $\mathbf{2 0 1 8}$ & $\mathbf{2 0 1 9}$ & $\mathbf{2 0 2 0}$ & $\mathbf{2 0 2 1}$ & $\mathbf{2 0 2 2}$ \\
\hline Ventas & Und & 807,274 & 854,710 & 904,933 & 958,107 & $1,014,406$ \\
Valor de venta & S/. & 4.90 & 4.90 & 4.90 & 4.90 & 4.90 \\
Ingresos & S/. & $\mathbf{3 , 9 5 5 , 6 4 3}$ & $\mathbf{4 , 1 8 8 , 0 7 9}$ & $\mathbf{4 , 4 3 4 , 1 7 2}$ & $\mathbf{4 , 6 9 4 , 7 2 4}$ & $\mathbf{4 , 9 7 0 , 5 8 9}$ \\
\hline
\end{tabular}

Elaboración propia 


\subsubsection{Presupuesto operativo de costos}

En la tabla 7.12 se muestra el presupuesto operativo de costos para la vida útil del proyecto, como margen de contribución se obtiene $40 \%$ en promedio.

Tabla 7.12.

Presupuesto operativo de costos (S/)

\begin{tabular}{cccccc}
\hline Año & $\mathbf{2 0 1 8}$ & $\mathbf{2 0 1 9}$ & $\mathbf{2 0 2 0}$ & $\mathbf{2 0 2 1}$ & $\mathbf{2 0 2 2}$ \\
\hline Mano de Obra Directa & 122,326 & 125,996 & 129,776 & 133,669 & 137,679 \\
Materia Prima Directa & $2,029,001$ & $1,953,973$ & $2,068,786$ & $2,190,350$ & $2,319,057$ \\
Costo Indirecto de Fabricación & 482,069 & 494,250 & 507,401 & 520,956 & 534,929 \\
Costo Total de Fabricación & $\mathbf{2 , 6 3 3 , 3 9 6}$ & $\mathbf{2 , 5 7 4 , 2 1 9}$ & $\mathbf{2 , 7 0 5 , 9 6 3}$ & $\mathbf{2 , 8 4 4 , 9 7 5}$ & $\mathbf{2 , 9 9 1 , 6 6 4}$ \\
Unidades Producidas & 892,745 & 859,733 & 910,250 & 963,737 & $1,020,367$ \\
Costo Unitario de Producción & 2.9 & 3.0 & 3.0 & 3.0 & 2.9 \\
Mg Contribución & $\mathbf{3 9 . 8 \%}$ & $\mathbf{3 8 . 9 \%}$ & $\mathbf{3 9 . 3 \%}$ & $\mathbf{3 9 . 8 \%}$ & $\mathbf{4 0 . 2 \%}$ \\
\hline
\end{tabular}

Elaboración propia

\subsubsection{Presupuesto operativo de gastos}

El presupuesto de gastos está conformado principalmente por el salario de personal administrativo detallado en el Capítulo VI; adicionalmente, se ha considerado servicios básicos, seguridad, mantenimiento, telefonía y materiales de oficina.

Tabla 7.13.

Gastos administrativos (S/)

\begin{tabular}{cccccc}
\hline Año & $\mathbf{2 0 1 8}$ & $\mathbf{2 0 1 9}$ & $\mathbf{2 0 2 0}$ & $\mathbf{2 0 2 1}$ & $\mathbf{2 0 2 2}$ \\
\hline Personal Administrativo & 295,950 & 304,829 & 313,973 & 323,393 & 333,094 \\
Servicios Básicos & 9,930 & 9,829 & 9,984 & 10,147 & 10,320 \\
Seguridad & 58,500 & 60,255 & 62,063 & 63,925 & 65,842 \\
Mantenimiento & 10,000 & 10,300 & 10,609 & 10,927 & 11,255 \\
Telefonía & 23,310 & 24,009 & 24,730 & 25,471 & 26,236 \\
Materiales de Oficina & 18,000 & 18,540 & 19,096 & 19,669 & 20,259 \\
Total Gasto Administrativo & $\mathbf{4 1 5 , 6 9 0}$ & $\mathbf{4 2 7 , 7 6 2}$ & $\mathbf{4 4 0 , 4 5 4}$ & $\mathbf{4 5 3 , 5 3 2}$ & $\mathbf{4 6 7 , 0 0 7}$ \\
\hline Elaboración propia
\end{tabular}

Elaboración propia 
Asimismo, para poder obtener los resultados deseados del proyecto es conveniente invertir en publicidad, distribución y venta a distancia.

Tabla 7.14.

Gastos de ventas y distribución (S/)

\begin{tabular}{cccccc}
\hline Año & $\mathbf{2 0 1 8}$ & $\mathbf{2 0 1 9}$ & $\mathbf{2 0 2 0}$ & $\mathbf{2 0 2 1}$ & $\mathbf{2 0 2 2}$ \\
\hline Publicidad & $\mathrm{S} / 120,000$ & $\mathrm{~S} / 123,600$ & $\mathrm{~S} / 127,308$ & $\mathrm{~S} / 131,127$ & $\mathrm{~S} / 135,061$ \\
Distribución & $\mathrm{S} / 96,000$ & $\mathrm{~S} / 98,880$ & $\mathrm{~S} / 101,846$ & $\mathrm{~S} / 104,902$ & $\mathrm{~S} / 108,049$ \\
Página web & $\mathrm{S} / 5,000$ & $\mathrm{~S} / 5,150$ & $\mathrm{~S} / 5,305$ & $\mathrm{~S} / 5,464$ & $\mathrm{~S} / 5,628$ \\
Total Gasto de Ventas & $\mathrm{S} / \mathbf{2 2 1 , 0 0 0}$ & $\mathrm{S} / \mathbf{2 2 7 , 6 3 0}$ & $\mathrm{S} / \mathbf{2 3 4 , 4 5 9}$ & $\mathrm{S} / \mathbf{2 4 1 , 4 9 3}$ & $\mathbf{S} / \mathbf{2 4 8 , 7 3 7}$ \\
\hline
\end{tabular}

Elaboración propia

En la tabla 7.15. se presenta el presupuesto de gastos totales, que incluye los gastos generales agregando los gastos financieros generados por la deuda.

Tabla 7.15.

Presupuesto de gastos totales (S/)

\begin{tabular}{cccccc}
\hline Año & $\mathbf{2 0 1 8}$ & $\mathbf{2 0 1 9}$ & $\mathbf{2 0 2 0}$ & $\mathbf{2 0 2 1}$ & $\mathbf{2 0 2 2}$ \\
\hline Gastos Administrativos & 415,690 & 427,762 & 440,454 & 453,532 & 467,007 \\
Gastos Ventas & 221,000 & 227,630 & 234,459 & 241,493 & 248,737 \\
Gastos Financieros & 158,750 & 134,008 & 106,174 & 74,860 & 39,632 \\
Depreciación No Fabril & 8,910 & 8,910 & 8,910 & 8,910 & 8,910 \\
Amortización Intangibles & 136,203 & 136,203 & 136,203 & 136,203 & 136,203 \\
Gasto Total & $\mathbf{9 4 0 , 5 5 2}$ & $\mathbf{9 3 4 , 5 1 2}$ & $\mathbf{9 2 6 , 1 9 9}$ & $\mathbf{9 1 4 , 9 9 7}$ & $\mathbf{9 0 0 , 4 8 8}$ \\
\hline
\end{tabular}

Elaboración propia

\subsection{Presupuestos Financieros}

\subsubsection{Presupuesto de Servicio de Deuda}

Se financiará el 70\% de la inversión con interés preoperacional, por un monto de S/1'270,000 con 1 año de periodo de gracia parcial. La TEA es $12.5 \%$ y se considera cuotas constantes. La entidad de financiamiento será el Banco de Crédito. 
Tabla 7.16.

Presupuesto de servicio a la deuda (S/)

\begin{tabular}{cccccc}
\hline Año & Capital & Amortización & Intereses & Cuota & Saldo \\
\hline 0 & $1,270,000$ & 0 & 158,750 & 158,750 & $1,270,000$ \\
1 & $1,270,000$ & 197,935 & 158,750 & 356,685 & $1,072,065$ \\
2 & $1,072,065$ & 222,676 & 134,008 & 356,685 & 849,389 \\
3 & 849,389 & 250,511 & 106,174 & 356,685 & 598,878 \\
4 & 598,878 & 281,825 & 74,860 & 356,685 & 317,053 \\
5 & 317,053 & 317,053 & 39,632 & 356,685 & 0 \\
\hline
\end{tabular}

Elaboración propia

\subsubsection{Presupuesto de Estado de Resultados}

En la tabla 7.17 se muestra el estado de resultados del proyecto de producción de un dip a base de quinua y vegetales verdes con un horizonte de 5 años, en el que se demuestra que desde el inicio se cuenta con utilidad disponible.

Tabla 7.17.

Estado de Resultados

\begin{tabular}{lccccc}
\hline \multicolumn{1}{c}{ Estado de Resultados Económico } & $\mathbf{2 0 1 8}$ & $\mathbf{2 0 1 9}$ & $\mathbf{2 0 2 0}$ & $\mathbf{2 0 2 1}$ & $\mathbf{2 0 2 2}$ \\
\hline INGRESO POR VENTAS & $3,955,643$ & $4,188,079$ & $4,434,172$ & $4,694,724$ & $4,970,589$ \\
(-) COSTO DE VENTAS & $2,381,276$ & $2,559,179$ & $2,690,156$ & $2,828,355$ & $2,974,187$ \\
\hline (=) UTILIDAD BRUTA & $\mathbf{1 , 5 7 4 , 3 6 7}$ & $\mathbf{1 , 6 2 8 , 9 0 0}$ & $\mathbf{1 , 7 4 4 , 0 1 5}$ & $\mathbf{1 , 8 6 6 , 3 7 0}$ & $\mathbf{1 , 9 9 6 , 4 0 2}$ \\
(-) GASTOS GENERALES & 750,052 & 768,754 & 788,276 & 808,387 & 829,107 \\
(-) GASTOS FINANCIEROS & - & - & - & - & - \\
(+) VENTA DE A TANGIBLE MERCADO & & & & & 298,243 \\
(-) VALOR RESIDUAL LIBRO A & & & & & 596,485 \\
TANGIBLE & & & & & \\
\hline (=) UTILIDAD DE OPERACIONES & $\mathbf{8 2 4 , 3 1 4}$ & $\mathbf{8 6 0 , 1 4 6}$ & $\mathbf{9 5 5 , 7 4 0}$ & $\mathbf{1 , 0 5 7 , 9 8 2}$ & $\mathbf{8 6 9 , 0 5 3}$ \\
(-) PARTICIPACIONES (8\%) & 65,945 & 68,812 & 76,459 & 84,639 & 69,524 \\
\hline (=) UTILIDAD ANTES DE IMP. & $\mathbf{7 5 8 , 3 6 9}$ & $\mathbf{7 9 1 , 3 3 4}$ & $\mathbf{8 7 9 , 2 8 1}$ & $\mathbf{9 7 3 , 3 4 4}$ & $\mathbf{7 9 9 , 5 2 9}$ \\
(-) IMPUESTO A LA RENTA (29.5\%) & 223,719 & 233,444 & 259,388 & 287,136 & 235,861 \\
\hline (=) UTILIDAD ANTES DE RESERVA & $\mathbf{5 3 4 , 6 5 0}$ & $\mathbf{5 5 7 , 8 9 1}$ & $\mathbf{6 1 9 , 8 9 3}$ & $\mathbf{6 8 6 , 2 0 7}$ & $\mathbf{5 6 3 , 6 6 8}$ \\
LEGAL & & & & \\
(-) RESERVA LEGAL (HASTA 10\%) & 53,465 & 55,789 & 647 & & $\mathbf{6 0 6 3 , 6 6 8}$ \\
(=) UTILIDAD DISPONIBLE & $\mathbf{4 8 1 , 1 8 5}$ & $\mathbf{5 0 2 , 1 0 1}$ & $\mathbf{6 1 9 , 2 4 5}$ & $\mathbf{6 8 6 , 2 0 7}$ & $\mathbf{5 6 3 , 6 6}$ \\
\hline
\end{tabular}

Elaboración propia 


\subsubsection{Presupuesto de Estado de Situación Financiera}

En la tabla 7.18. se muestra el estado de situación financiera para el año 0.

Tabla 7.18.

Situación financiera en el año 0

Corporación peruana de alimentos saludables S.A.

Estado de situación financiera

al 01/01/2018

(expresado en nuevos soles)

\begin{tabular}{|c|c|c|c|}
\hline Activo Corriente & & Pasivo Corriente & \\
\hline Caja & 398,712 & Impuesto a la Renta por pagar & - \\
\hline Bancos & - & Participaciones por pagar & - \\
\hline Mercadería & - & $I G V$ por pagar & - \\
\hline Cuentas por cobrar & - & Cuentas por Pagar & - \\
\hline Total Activo Corriente & 398,712 & Total Pasivo Corriente & - \\
\hline Activo No Corriente & & Pasivo No Corriente & \\
\hline Terreno & 374,400 & Préstamo a Largo Plazo & $1,270,000$ \\
\hline Edificaciones & 172,800 & & \\
\hline Maquinaria y equipos & 168,377 & Total Pasivo No Corriente & $1,270,000$ \\
\hline Mobiliario & 71,684 & & \\
\hline Estudios e investigación & 20,000 & Patrimonio & \\
\hline Gastos de Organización & 55,700 & Capital Social & 390,757 \\
\hline Patentes y Licencias & 4,000 & Reserva Legal & - \\
\hline Gastos de Puesta en Marcha & 391,085 & Ut. Retenidas & - \\
\hline Capacitación & 4,000 & Ut. Ejercicio & - \\
\hline Total Activo No Corriente & $1,262,046$ & Total Patrimonio & 390,757 \\
\hline Total Activo & $1,660,757$ & Total Pasivo y Patrimonio & $1,660,757$ \\
\hline
\end{tabular}

Elaboración propia 


\subsubsection{Flujo de caja de corto plazo}

En la tabla 7.19 se ha considerado como variable principal la condición de pago. Para el caso de los ingresos; es decir, los días de crédito a los canales tiendas especializadas y retail serán 15 y 30 días, respectivamente. Por otro lado, en cuanto a los egresos, al empezar una relación con proveedores se deberá enfrentar la barrera de pago contra entrega.

Tabla 7.19.

Flujo de caja año 1 (2018)

\begin{tabular}{|c|c|c|c|c|c|c|c|c|c|c|c|c|c|}
\hline & $\begin{array}{c}\text { Condición de } \\
\text { Pago }\end{array}$ & ene 18 & feb 18 & $\operatorname{mar} 18$ & abr 18 & may 18 & jun 18 & jul 18 & ago 18 & sep 18 & oct 18 & nov 18 & $\operatorname{dic} 18$ \\
\hline \multicolumn{14}{|l|}{ Ingresos } \\
\hline Venta (Und) & & 67,273 & 67,273 & 67,273 & 67,273 & 67,273 & 67,273 & 67,273 & 67,273 & 67,273 & 67,273 & 67,273 & 67,273 \\
\hline Precio & & 4.90 & 4.90 & 4.90 & 4.90 & 4.90 & 4.90 & 4.90 & 4.90 & 4.90 & 4.90 & 4.90 & 4.90 \\
\hline Venta a 15 días (S/.) & 15 días & 131,855 & 131,855 & 131,855 & 131,855 & 131,855 & 131,855 & 131,855 & 131,855 & 131,855 & 131,855 & 131,855 & 131,855 \\
\hline Venta a 30 días (S/.) & 30 días & 0 & 197,782 & 197,782 & 197,782 & 197,782 & 197,782 & 197,782 & 197,782 & 197,782 & 197,782 & 197,782 & 197,782 \\
\hline Total Ingresos & & 131,855 & 329,637 & 329,637 & 329,637 & 329,637 & 329,637 & 329,637 & 329,637 & 329,637 & 329,637 & 329,637 & 329,637 \\
\hline \multicolumn{14}{|l|}{ Egresos } \\
\hline Mano de Obra & & 10,194 & 10,194 & 10,194 & 10,194 & 10,194 & 10,194 & 10,194 & 10,194 & 10,194 & 10,194 & 10,194 & 10,194 \\
\hline Materia Prima & Contraentrega & 169,083 & 169,083 & 169,083 & 169,083 & 169,083 & 169,083 & 169,083 & 169,083 & 169,083 & 169,083 & 169,083 & 169,083 \\
\hline$C I F$ & & 40,172 & 40,172 & 40,172 & 40,172 & 40,172 & 40,172 & 40,172 & 40,172 & 40,172 & 40,172 & 40,172 & 40,172 \\
\hline Egresos Fabricación & & 219,450 & 219,450 & 219,450 & 219,450 & 219,450 & 219,450 & 219,450 & 219,450 & 219,450 & 219,450 & 219,450 & 219,450 \\
\hline Gastos Administrativos & & 34,641 & 34,641 & 34,641 & 34,641 & 34,641 & 34,641 & 34,641 & 34,641 & 34,641 & 34,641 & 34,641 & 34,641 \\
\hline Gastos de Ventas & 15 días & 18,417 & 18,417 & 18,417 & 18,417 & 18,417 & 18,417 & 18,417 & 18,417 & 18,417 & 18,417 & 18,417 & 18,417 \\
\hline \multicolumn{14}{|l|}{ Tributos por Pagar } \\
\hline \multicolumn{14}{|l|}{ Amortización Deuda } \\
\hline \multicolumn{14}{|l|}{ Interés Deuda } \\
\hline Total Egresos & & 272,507 & 272,507 & 272,507 & 272,507 & 272,507 & 272,507 & 272,507 & 272,507 & 272,507 & 272,507 & 272,507 & $\mathbf{2 7 2 , 5 0 7}$ \\
\hline Saldo & & $-140,652$ & 57,130 & 57,130 & 57,130 & 57,130 & 57,130 & 57,130 & 57,130 & 57,130 & 57,130 & 57,130 & 57,130 \\
\hline Caja Inicial & & 398,712 & 258,059 & 315,189 & 372,319 & 429,448 & 486,578 & 543,708 & 600,838 & 657,967 & 715,097 & 772,227 & 829,356 \\
\hline Caja Final & & 258,059 & 315,189 & 372,319 & 429,448 & 486,578 & 543,708 & 600,838 & 657,967 & 715,097 & 772,227 & $\mathbf{8 2 9 , 3 5 6}$ & $\mathbf{8 8 6 , 4 8 6}$ \\
\hline
\end{tabular}




\subsection{Flujo de fondos netos}

\subsubsection{Flujo de fondos económicos}

Tabla 7.20.

Flujo de fondos económico

\begin{tabular}{|c|c|c|c|c|c|c|}
\hline Año & $\mathbf{0}$ & 2018 & 2019 & 2020 & 2021 & 2022 \\
\hline INVERSION TOTAL & $-1,660,757$ & & & & & \\
\hline $\begin{array}{l}\text { UTILIDAD ANTES DE RESERVA } \\
\text { LEGAL }\end{array}$ & & 534,650 & 557,891 & 619,893 & 686,207 & 563,668 \\
\hline $\begin{array}{l}\text { (+) AMORTIZACION DE } \\
\text { INTANGIBLES }\end{array}$ & & 104,453 & 104,453 & 104,453 & 104,453 & 104,453 \\
\hline (+) DEPRECIACION FABRIL & & 44,991 & 44,991 & 44,991 & 44,991 & 44,991 \\
\hline (+) DEPRECIACION NO FABRIL & & 8,910 & 8,910 & 8,910 & 8,910 & 8,910 \\
\hline $\begin{array}{l}\text { (+) RECUP DE CAPITAL DE } \\
\text { TRABAJO } \\
\text { (+) VALOR RESIDUAL }\end{array}$ & & & & & & $\begin{array}{l}272,507 \\
596,485\end{array}$ \\
\hline $\begin{array}{l}\text { FLUJO NETO DE FONDOS } \\
\text { ECONOMICO }\end{array}$ & $-1,660,757$ & 693,003 & 716,244 & 778,246 & 844,560 & $\mathbf{1 , 5 9 1 , 0 1 3}$ \\
\hline
\end{tabular}

\subsubsection{Flujo de fondos financieros}

Tabla 7.21.

Flujo de fondos financieros

\begin{tabular}{|c|c|c|c|c|c|c|}
\hline Año & $\mathbf{0}$ & 2018 & 2019 & 2020 & 2021 & 2022 \\
\hline INVERSIÓN TOTAL & $-1,819,507$ & & & & & \\
\hline PRESTAMO & $1,270,000$ & & & & & \\
\hline $\begin{array}{l}\text { UTILIDAD ANTES DE } \\
\text { RESERVA LEGAL }\end{array}$ & & 411,092 & 450,380 & 530,435 & 617,060 & 517,370 \\
\hline $\begin{array}{l}\text { (+) AMORTIZACION DE } \\
\text { INTANGIBLES }\end{array}$ & & 136,203 & 136,203 & 136,203 & 136,203 & 136,203 \\
\hline (+) DEPRECIACION FABRIL & & 44,991 & 44,991 & 44,991 & 44,991 & 44,991 \\
\hline $\begin{array}{l}\text { (+) DEPRECIACION NO } \\
\text { FABRIL }\end{array}$ & & 8,910 & 8,910 & 8,910 & 8,910 & 8,910 \\
\hline $\begin{array}{l}\text { (-) AMORTIZACION DEL } \\
\text { PRESTAMO }\end{array}$ & & $-197,935$ & $-222,676$ & $-250,511$ & $-281,825$ & $-317,053$ \\
\hline $\begin{array}{l}\text { (+) RECUP DE CAPITAL DE } \\
\text { TRABAJO } \\
(+) \text { VALOR RESIDUAL }\end{array}$ & & & & & & $\begin{array}{l}272,507 \\
596,485\end{array}$ \\
\hline $\begin{array}{l}\text { FLUJO NETO DE FONDOS } \\
\text { FINANCIERO }\end{array}$ & $-549,507$ & 403,260 & 417,806 & 470,028 & 525,338 & $1,259,412$ \\
\hline
\end{tabular}

Elaboración propia 


\section{CAPÍTULO VIII: EVALUACIÓN ECONÓMICAY Y FINANCIERA DEL PROYECTO}

Primero se debe hallar el costo de oportunidad para los accionistas (COK). En este caso se utilizará el método CAPM, cuyos parámetros serán obtenidos de los indicadores del mercado peruano.

La fórmula a utilizar en el cálculo del COK es:

$$
\begin{gathered}
C O K=R f+\beta(R m-R f) \\
C O K=5.35 \%+1.62(17.31 \%-5.35 \%)=24.75 \%
\end{gathered}
$$

Donde:

Rf: Rendimiento de un activo libre de riesgo

Rm: Rendimiento del mercado

$\beta$ : Riesgo con respecto al portafolio del mercado

El $\beta$ a utilizar en la fórmula del $\mathrm{COK}$, denominado $\beta$ apalancado, debe ser recalculado en base al nivel de endeudamiento de la empresa, en este caso la deuda es 70\%. El $\beta$ no apalancado es 0.61 (Universidad de Nueva York, 2018).

La fórmula para el cálculo del $\beta$ apalancado es:

$$
\begin{aligned}
& \beta \text { apalancado }=\frac{\beta \text { no apalancado }}{1+\left[\left(\frac{\text { Deuda }}{\text { Aporte }}\right) *(1-\text { Imp. Renta })\right]} \\
& \beta \text { apalancado }=\frac{0.61}{1+\left[\left(\frac{0.7}{0.3}\right) *(1-0.295)\right]}=1.62
\end{aligned}
$$


Tabla 8.1.

Cálculo del COK

\begin{tabular}{lc}
\hline \multicolumn{1}{c}{ Variable } & Valor \\
\hline Rf & $5.35 \%$ \\
Rm & $17.31 \%$ \\
$\beta$ del sector - Food Processing & 0.75 \\
$\beta$ no apalancado & 0.61 \\
Deuda & $70 \%$ \\
$\beta$ apalancado & 1.62 \\
COK & $\mathbf{2 4 . 7 5 \%}$
\end{tabular}

Fuente: Economática (2018); Bloomberg (2018) y Damodarán (2018)

Elaboración propia

\subsection{Evaluación económica}

Con el flujo de fondos económicos previamente realizado en el capítulo anterior, se procede a realizar la evaluación económica para comprobar la rentabilidad del proyecto.

Tabla 8.2.

Evaluación del flujo económico

\begin{tabular}{lc}
\hline \multicolumn{2}{c}{ Resultados de Evaluación Económica } \\
\hline VAN Económico & S/ 631,155 \\
Relación B/C & 1.380 \\
Tasa Interna de Retorno & $39.97 \%$ \\
Periodo de recuperación (años) & 3.70 \\
\hline
\end{tabular}

Elaboración propia

Con estos resultados, se concluye que el proyecto es rentable por tener un VAN superior a cero y se superan las expectativas de los inversionistas por tener una TIR mayor al COK y a la TEA. Existe una buena relación beneficio-costo ya que por cada sol invertido se obtiene un beneficio de 0.38 soles. Además, se recuperará la inversión en 3 años y 9 meses, lo cual está dentro del plazo de los 5 años designados como horizonte de vida al proyecto.

\subsection{Evaluación financiera}

Con el flujo de fondos financiero previamente realizado en el capítulo anterior, se procede a realizar la evaluación financiera para comprobar la rentabilidad del proyecto. 
Tabla 8.3.

Evaluación del flujo financiero

\begin{tabular}{lc}
\hline \multicolumn{2}{c}{ Resultados de Evaluación Financiera } \\
\hline VAN Financiero & $\mathrm{S} / 918,065$ \\
Relación B/C & 2.671 \\
Tasa Interna de Retorno & $80.11 \%$ \\
Periodo de recuperación (años) & 1.84 \\
\hline Elaboración propia &
\end{tabular}

Se puede comprobar que los valores del VAN y TIR son mejores en el flujo financiero, lo cual quiere decir que es preferible financiar una parte del proyecto y no realizarlo con $100 \%$ de capital propio.

\subsection{Análisis de ratios e indicadores económicos y financieros del proyecto}

Los principales ratios a evaluar corresponden a liquidez, solvencia y rentabilidad, los cuales serán detallados a continuación.

\section{Liquidez}

Se cuenta con un capital de trabajo de S/ 398,712 para el inicio de las operaciones del primer año, cantidad suficiente para hacer frente a los movimientos de efectivo.

\section{Solvencia}

Tabla 8.4.

Ratios de Solvencia

\begin{tabular}{llc}
\hline \multicolumn{1}{c}{ Ratio } & \multicolumn{1}{c}{ Fórmula } & Resultado \\
\hline Razón Deuda-Patrimonio & Pasivo total / Patrimonio & 3.25 \\
Razón de Endeudamiento & Pasivo total / Activo total & 0.76 \\
Razón de Cobertura de intereses & UAII / Gastos Financieros & 3.67 \\
\hline
\end{tabular}

Elaboración propia

Al inicio del proyecto, por cada sol aportado por los accionistas se tiene 3.25 de deuda, lo cual era de esperarse al contar con un financiamiento por el $70 \%$ de la inversión total. Del mismo modo, se ve reflejado al notar que el $76 \%$ de los activos han sido 
financiados. La empresa cuenta con buena disponibilidad para poder cubrir su obligación de pago de intereses.

\section{Rentabilidad}

Tabla 8.5

Ratios de Rentabilidad

\begin{tabular}{llc}
\hline \multicolumn{1}{c}{ Ratio } & \multicolumn{1}{c}{ Fórmula } & Resultado \\
\hline Margen Bruto & Utilidad Bruta / Ventas & $39.8 \%$ \\
Margen Neto & Utilidad Neta / Ventas & $16.0 \%$ \\
Rentabilidad Neta del patrimonio & Utilidad Neta / Patrimonio & $105.2 \%$ \\
\hline
\end{tabular}

Elaboración propia

El proyecto genera márgenes positivos desde el primer año, como se puede comprobar en ambos indicadores de margen bruto y margen neto. Además, se tiene una buena capacidad de generar utilidades con la inversión de los accionistas.

\subsection{Análisis de sensibilidad del proyecto}

Para realizar el análisis de sensibilidad del proyecto se tendrá en cuenta tres escenarios, los cuales son optimista, conservador y pesimista. El escenario conservador está presentado en el capítulo VII y considera la operación en escenarios normales de acuerdo a la demanda del mercado.

Ante un mercado cambiante que afronta nuevas y constantes tendencias se ha dispuesto incrementar la demanda en $10 \%$ en el escenario optimista y hacer lo opuesto en el escenario pesimista.

\section{Escenario optimista}

Tabla 8.6.

Presupuesto de ventas en escenario optimista

\begin{tabular}{ccccccc}
\hline Año & UM & $\mathbf{2 0 1 8}$ & $\mathbf{2 0 1 9}$ & $\mathbf{2 0 2 0}$ & $\mathbf{2 0 2 1}$ & $\mathbf{2 0 2 2}$ \\
\hline Ventas & Und & 888,002 & 940,181 & 995,427 & $1,053,918$ & $1,115,847$ \\
Valor de venta & S/. & 4.90 & 4.90 & 4.90 & 4.90 & 4.90 \\
Ingresos & S/. & $\mathbf{4 , 3 5 1 , 2 1 0}$ & $\mathbf{4 , 6 0 6 , 8 8 7}$ & $\mathbf{4 , 8 7 7 , 5 9 2}$ & $\mathbf{5 , 1 6 4 , 1 9 8}$ & $\mathbf{5 , 4 6 7 , 6 5 0}$ \\
\hline Elaboración propia & & & & & &
\end{tabular}


Tabla 8.7.

Evaluación económica y financiera en escenario optimista

\begin{tabular}{ccc}
\hline Indicador & Económico & Financiero \\
\hline VAN & $1,026,100$ & $1,313,010$ \\
TIR & $48.85 \%$ & $101.82 \%$ \\
B/C & 1.61 & 3.32 \\
PR & 2.95 & 1.37 \\
\hline
\end{tabular}

Elaboración propia

\section{Escenario pesimista}

Tabla 8.8.

Presupuesto de ventas en escenario pesimista

\begin{tabular}{ccccccc}
\hline Año & UM & $\mathbf{2 0 1 8}$ & $\mathbf{2 0 1 9}$ & $\mathbf{2 0 2 0}$ & $\mathbf{2 0 2 1}$ & $\mathbf{2 0 2 2}$ \\
\hline Ventas & Und & 726,547 & 769,239 & 814,440 & 862,297 & 912,966 \\
Valor de venta & S/. & 4.90 & 4.90 & 4.90 & 4.90 & 4.90 \\
Ingresos & S/. & $\mathbf{3 , 5 6 0 , 0 8 0}$ & $\mathbf{3 , 7 6 9 , 2 7 1}$ & $\mathbf{3 , 9 9 0 , 7 5 6}$ & $\mathbf{4 , 2 2 5 , 2 5 5}$ & $\mathbf{4 , 4 7 3 , 5 3 3}$ \\
\hline Elaboración propia & & & & & &
\end{tabular}

Tabla 8.9.

Evaluación económica y financiera en escenario pesimista

\begin{tabular}{ccc}
\hline Indicador & Económico & Financiero \\
\hline VAN & 236,212 & 523,122 \\
TIR & $30.62 \%$ & $57.15 \%$ \\
B/C & 1.14 & 1.98 \\
PR & 4.81 & 2.82 \\
\hline
\end{tabular}

Elaboración propia

Como se puede verificar en la evaluación económica del escenario pesimista, el proyecto podría soportar una disminución del 10\% de las ventas; sin embargo, se contaría con retornos más bajos. 


\section{CAPÍTULO IX: EVALUACIÓN SOCIAL DEL PROYECTO}

\subsection{Identificación de las zonas y comunidades de influencia del proyecto}

La evaluación del capítulo III sobre localización de planta determinó que la mejor alternativa para la implementación del proyecto sería la ciudad de Trujillo.

Se tendrá un impacto directo en la generación de puestos de trabajo para personas que vivan cerca de la planta en el caso de operarios, y para puestos administrativos se dará preferencia a postulantes locales como una señal de apoyo y compromiso con la ciudad. De manera indirecta, también se favorecerá a transportistas, subcontratistas e intermediarios que puedan participar en la cadena de abastecimiento.

La Libertad es conocida por ser una zona esparraguera, pero con un crecimiento importante en quinua en los últimos años, especialmente en la parte de la sierra, donde pequeños y medianos agricultores han ido creando su camino a base de esfuerzo. Por esta razón, la empresa buscará trabajar con pequeños empresarios que además de tener un producto de excelente calidad, tengan plena disposición para afrontar este reto y estén dispuestos a formalizarse.

De esta manera, se generará un impacto positivo económico y social en los distritos cercanos a la planta como Moche, Trujillo y Virú. En la Sierra, las provincias de Sánchez Carrión, Otuzco y Santiago de Chuco serán las más beneficiadas.

\subsection{Análisis de indicadores sociales}

\section{Valor agregado}

Tabla 9.1.

Valor agregado anual

\begin{tabular}{cccccc}
\hline Año & $\mathbf{2 0 1 8}$ & $\mathbf{2 0 1 9}$ & $\mathbf{2 0 2 0}$ & $\mathbf{2 0 2 1}$ & $\mathbf{2 0 2 2}$ \\
\hline Ventas & $3,955,643$ & $4,188,079$ & $4,434,172$ & $4,694,724$ & $4,970,589$ \\
Materia prima e insumos & $2,029,001$ & $1,953,973$ & $2,068,786$ & $2,190,350$ & $2,319,057$ \\
Valor agregado & $\mathbf{1 , 9 2 6 , 6 4 1}$ & $\mathbf{2 , 2 3 4 , 1 0 6}$ & $\mathbf{2 , 3 6 5 , 3 8 5}$ & $\mathbf{2 , 5 0 4 , 3 7 5}$ & $\mathbf{2 , 6 5 1 , 5 3 3}$ \\
\hline
\end{tabular}

Elaboración propia

El valor actual del Valor Agregado considerando el periodo de 5 años es S/ 6,143,378. 


\section{Densidad de capital}

$$
\frac{\text { Inversión total }}{\text { Núm. de trabajadores }}=\frac{1,819,517}{21}=\mathrm{S} / 86,643.67
$$

Este resultado quiere decir que se invierten $\mathrm{S} / 86,643.67$ por puesto de trabajo.

\section{Intensidad de capital}

$$
\frac{\text { Inversión total }}{\text { Valor agregado actual }}=\frac{1,819,517}{6,143,378}=\mathrm{S} / 0.30
$$

Es un buen indicador decir que se debe invertir S/ 0.30 para generar S/1 de valor agregado.

\section{Generación de divisas}

No hay comercio exterior en el desarrollo del proyecto por lo que, en este caso, la generación de divisas es cero. 


\section{CONCLUSIONES}

- Existe la posibilidad de llevar a cabo el proyecto ya que la tecnología requerida está disponible, la materia prima se puede encontrar localmente y se puede acceder a un crédito para cubrir la inversión inicial.

- Al revisar las condiciones del producto y del mercado se determinó que el público objetivo, por hábitos de consumo y por capacidad de compra, es el nivel socioeconómico A-B de Lima Metropolitana.

- La composición del dip, resaltando la presencia de quinua principalmente, es una razón importante para la buena aceptación del producto en personas que busquen consumir alimentos nutritivos y de calidad.

- Trujillo y La Libertad en general, forman parte de una región agrícola por excelencia, pues alberga la mayor producción de espárrago en el país y un volumen importante de quinua y demás ingredientes del dip; por dicha razón se puede asegurar el abastecimiento oportuno de materia prima.

- De acuerdo a la investigación de mercado sobre la competencia, se puede comprobar que el producto presenta una mezcla innovadora de ingredientes y que el precio está ligeramente por debajo del promedio, convirtiendo al dip de quinua y vegetales verdes en presentación de $180 \mathrm{gr}$. en un producto competitivo.

- $\quad$ El proyecto es rentable, pues como se comprobó en el Capítulo VII y VIII, después de los 5 años de operación se obtiene un VAN positivo de S/ 631,155 y una TIR de $39.97 \%$, la cual es superior al COK (24.5\%), superando así las expectativas de los accionistas. 


\section{RECOMENDACIONES}

- Llevar a cabo el proyecto, pues representa una oportunidad de inversión rentable sustentado por el presente documento. Además, no se cuenta con ninguna limitación en cuanto a tecnología, materia prima, servicios o mercado.

- Buscar alianzas a largo plazo con proveedores y clientes con el fin de explotar el potencial comercial en beneficio del desarrollo de la empresa.

- Con el inicio de las operaciones será muy importante conocer los tiempos y rendimientos reales, y en base a eso poder establecer indicadores que ayuden en la gestión de recursos.

- Considerar en un futuro cercano al sector socioeconómico $\mathrm{C} 1$ ya que la tendencia de una alimentación saludable está creciendo rápidamente, y este grupo podría tener la posibilidad económica de adquirir el producto.

- Revisar la posibilidad de venta del producto en Trujillo y en el norte del país en general, ya que al tener la planta allá los gastos de venta son menores. Esto dependerá de la acogida del producto en Lima y de la capacidad de producción.

- Si el crecimiento de las ventas en los años siguientes amerita la adquisición de nuevas máquinas es recomendable volver a revisar los aspectos e impactos ambientales del proyecto.

- Evaluar la posibilidad de ofrecer el servicio de maquila a terceros y así optimizar el uso de las máquinas, haciendo que la operación sea más eficiente y rentable.

- Determinar si es factible la exportación del producto hacia mercados con alto consumo de alimentos saludables como Estados Unidos, Canadá y países europeos. Se deberá realizar un análisis detallado de las barreras de ingreso y la competencia. 


\section{REFERENCIAS}

Asociación Peruana de Empresas de Investigación de Mercado. (Agosto, 2016). Niveles Socioeconómicos 2016. Recuperado de: http://www.apeim.com.pe/wpcontent/themes/apeim/docs/nse/APEIM-NSE-2016.pdf

A.T. Kearney. (2016). The Global Retail Development Index 2016. Recuperado de: https://www.atkearney.com/documents/10192/8226719/Global+Retail+Expansi on+at+a+Crossroads\%E2\% 80\%932016+GRDI.pdf/dc845ffc-fe28-4623-bdd4b36f3a443787

Bojanic, A. (2011). La quinua, cultivo milenario para contribuir a la seguridad alimentaria mundial. Recuperado del sitio de internet de la Organización de las Naciones Unidas para la Alimentación y Agricultura (FAO): http://www.fao.org/docrep/017/aq287s/aq287s.pdf

Decreto Supremo N007-2007-TR. (2007). Ministerio de Trabajo y Promoción de Empleo. Diario El Peruano. Recuperado de:

http://www.mintra.gob.pe/contenidos/archivos/prodlab/legislacion/DS_007_200 7_TR.pdf

Díaz, B. y Noriega, M. (2017). Manual para el diseño de instalaciones manufactureras y de servicios. Lima: Universidad de Lima. Fondo Editorial.

El Peruano. (11 de agosto del 2018). Las seis reformas estructurales. Recuperado de https://elperuano.pe/noticia-las-seis-reformas-estructurales-44769.aspx

Extinsafe. (Septiembre, 2015). Ubicación e instalación de extintores. Recuperado de: https://www.extinsafe.com/single-post/2015/09/24/UBICACI\%C3\%93N-EINSTALACI\%C3\%93N-DE-EXTINTORES

Gestión. (24 de mayo del 2017). Citi: Economía peruana crecería 3.3\% el 2017 por optimismo en la reconstrucción. Recuperado de:

https://gestion.pe/economia/citi-economia-peruana-creceria-3-3-2017optimismo-reconstruccion-135776

Gestión. (17 de enero del 2017). Conoce las 10 principales tendencias globales de consumo para 2017. Recuperado de: https://gestion.pe/tendencias/conoce-10principales-tendencias-globales-consumo-2017-126718

Gestión. (28 de septiembre del 2015). Digesa reglamentará los alimentos industrializados. Recuperado de: https://gestion.pe/economia/digesareglamentara-alimentos-industrializados-101080

Inkanatural. (s.f.). Quinua. Recuperado de: http://www.inkanatural.com/es/arti.asp?ref=quinua 
Instituto Nacional de Estadística e Informática. (Diciembre, 2017). Índice de precios al consumidor a nivel nacional. Recuperado de:

https://www.inei.gob.pe/biblioteca-virtual/boletines/informe-de-precios/1/

Instituto Nacional de Estadística e Informática. (Diciembre, 2017). Informe de Precios N¹2 Diciembre 2017 - Variación de los indicadores de precios de la Economía. Recuperado de: https://www.inei.gob.pe/media/MenuRecursivo/boletines/12informe-tecnico-n12_precios-nov2017.pdf

Instituto Nacional de Estadística e Informática (s.f.). Series Nacionales de Población Total. Recuperado de: https://www.inei.gob.pe/

Instituto Nacional de Seguridad e Higiene en el Trabajo. (Diciembre, 2015).

Iluminación en el puesto de trabajo. Recuperado de:

http://www.insht.es/InshtWeb/Contenidos/Documentacion/Iluminacion\%20en\% 20el\%20puesto\%20de\%20trabajo.pdf

Kantar TNS. (Abril, 2016). Concern Monitor, un estudio sobre preocupaciones y consumo. Recuperado de:

https://www.kantarworldpanel.com/ar/Noticias/Concern-Monitor-un-estudiosobre-preocupaciones-y-consumo

Kantar TNS. (Septiembre, 2015). Estudio Google y TNS, Micro-Momentos en Argentina, Colombia, Chile, México y Perú. Recuperado de: http://www.fao.org/americas/noticias/ver/es/c/463396/

Kantar Worldpanel. (2016). Un estudio sobre preocupaciones y consumo. Recuperado de https://www.kantarworldpanel.com/ar/Noticias/Concern-Monitor-un-estudiosobre-preocupaciones-y-consumo

La República. (6 de septiembre del 2015). La Libertad ocupa el primer lugar en producción de espárragos. Recuperado de:

https://larepublica.pe/economia/879842-la-libertad-ocupa-el-primer-lugar-enproduccion-de-esparragos

Ministerio de Agricultura y Riego. (s.f.). Anuario Estadístico de Producción Agrícola y Ganadera 2016. Recuperado de:

http://siea.minagri.gob.pe/siea/sites/default/files/anuario-agricolaganadera2016_210917_0.pdf

Ministerio de Agricultura y Riego. (s.f.). Producción de quinua. Recuperado de: http://minagri.gob.pe/portal/459-f-innovaquinua/9605-produccion-de-quinua

Ministerio de Vivienda, Construcción y Saneamiento. (2013). Reglamento Nacional de Edificaciones. Lima

Nielsen. (2017). Investigación: 62\% de los consumidores pagarían más por productos saludables. Recuperado de http://brandsmkt.com/investigacion-nielsen-62-delos-consumidores-pagarian-mas-por-productos-saludables/ 
Nielsen. (2014). Tendencias del mundo saludable. Recuperado de http://multipress.com.mx/wp-content/uploads/2014/11/NIELSENCONSUMER-FACTS-PRODUCTOS-SALUDABLES-2014.pdf

Organización de las Naciones Unidas para la Alimentación y Agricultura. (2013). Año Internacional de la Quinua. Recuperado del sitio de internet de la Organización de las Naciones Unidas para la Alimentación y Agricultura (FAO): http://www.fao.org/quinoa-2013/publications/es/

Organización de las Naciones Unidas para la Alimentación y Agricultura. (Enero, 2017). Sobrepeso afecta a casi la mitad de la población de todos los países de América Latina y el Caribe salvo por Haití. Recuperado de: http://www.fao.org/americas/noticias/ver/es/c/463396/

Organización Internacional del Trabajo. (s.f.). Seguridad y salud en el trabajo. Recuperado de: http://www.ilo.org/global/topics/safety-and-health-at-work/lang-es/index.htm

Organización para la Cooperación y el Desarrollo Económicos. (2017). Obesity Update 2017. Recuperado de: https://www.oecd.org/els/health-systems/Obesity-Update2017.pdf

Organismo Supervisor de la Inversión en Energía y Minería. (s.f.). Pliegos tarifarios aplicables al cliente final. Recuperado de:

http://www.osinergmin.gob.pe/seccion/institucional/regulacion-tarifaria/pliegostarifarios/electricidad/pliegos-tarifiarios-cliente-final

Perú Retail. (Junio, 2017). Consumo en supermercados de Lima crece más que el canal tradicional. Recuperado de: https://www.peru-retail.com/supermercadosvolumen-compra-canal-tradicional/

Perú Retail. (Junio, 2017). Perú mantiene liderazgo de desarrollo de sector retail en América Latina. Recuperado de: https://www.peru-retail.com/peru-desarrollosector-retail-america-latina/

Perú 21. (11 de octubre del 2017). Perú es el tercer país de Latinoamérica con más casos de sobrepeso y obesidad. Recuperado de:

https://peru21.pe/vida/salud/peru-tercer-pais-latinoamerica-casos-sobrepesoobesidad-379670

Popescu, F. y Hanna, M. (Noviembre, 2012). Módulo Europeo de Pregrado en Medicina Ocupacional: Agentes físicos. Recuperado de: http://www.emutom.eu/files/chapter2/Capitulo\%202.4.1\%20Agentes\%20f\%C3 $\%$ ADsicos.pdf

Sapag, N. (2007). Proyectos de inversión: Formulación y evaluación (1 $1^{\mathrm{a}}$ ed.). Naucalpan de Juárez, México: Pearson Education.

Servicio Nacional de Sanidad Agraria (Agosto, 2017). USDA: Producción de espárragos en Perú crecería ligeramente en el presente año. Recuperado de: 
http://www.senasa.gob.pe/senasacontigo/agraria-pe-usda-produccion-deesparragos-en-peru-creceria-ligeramente-en-el-presente-ano/

Superintendencia Nacional de Servicios de Saneamiento. (s.f.). Consulta de tarifas. Recuperado de: http://www.sunass.gob.pe/websunass/index.php/eps/tarifasvigentes

Think with Google. (Septiembre, 2016). Estilo de vida: la nueva tendencia hacia un consumo saludable. Recuperado de: https://www.thinkwithgoogle.com/intl/es419/recursos-y-herramientas/video/estilo-vida-saludable-tendencia-consumo/

Universidad de Nueva York. (2018). Beta, Unlevered Beta and other risk measures. Recuperado de: www.stern.nyu.edu/ adamodar/pc/datasets/betaemerg.xls 


\section{BIBLIOGRAFÍA}

Aguilar M., Guerrero C. (2017). Estudio de prefactibilidad para la instalación de una planta de producción de panela granulada a partir de caña de azúcar (Saccharum officinarum) para el mercado de la región de Lima (Tesis para optar el título de Ingeniero Industrial). Universidad de Lima.

Aguirre, L. (2016). Proyectos: formulación y evaluación (1.a ed.). Lima: Macro.

Agurto, A., Bendezú, J., Del Pozo, M., y Díaz, M. (2013). Plan de negocios para la producción y comercialización de salsas y tapenades orgánicos (Tesis para optar el título de Master en Administración). Universidad ESAN.

Álvarez M., De Lama P. (2016). Estudio de prefactibilidad para la instalación de una planta procesadora de hojuelas de quinua (Tesis para optar el título de Ingeniero Industrial). Universidad de Lima.

Barra Zamalloa, A. (Agosto, 2017). Las fuentes del valor de la marca de una empresa. Actualidad Jurídica $\mathrm{N}^{\circ} 285,210-214$.

BSI Group. (s.f.). Guía de Implementación de OHSAS 18001. Recuperado de: https://www.bsigroup.com/LocalFiles/esES/Documentos\%20tecnicos/OHSAS\%2018001/BS-OHSAS-18001-GuiaImplantacion-web.pdf

Carreño, S.A. (2017). Cadena de Suministro y Logística (1.a ed.). Lima: Pontificia Universidad Católica del Perú, Fondo Editorial.

Francia Simauchi, F. F. (2015). Estudio de prefactibilidad para la instalación de una planta productora de salsa pesto instantánea (Tesis para optar el título de Ingeniero Industrial). Universidad de Lima.

Kotler, P., Armstrong, G., y Amador, A.L. (2017). Fundamentos de Marketing (13.a ed.). México Distrito Federal: Pearson Educación.

Lira Sumaria, C. (2010). Estudio de prefactibilidad para la instalación de una empresa procesadora de pasta de alcachofa (Tesis para optar el título de Ingeniero Industrial). Universidad de Lima.

López, F. (Enero, 2018). El auge de la quinua. Business: Negocios en el Perú, n 247, 28-30.

Maticorena F., Larrauri K. (2017). Estudio de prefactibilidad para la instalación de una planta productora de bebidas nutritivas a base de quinua, kiwicha y naranja (Tesis para optar el título de Ingeniero Industrial). Universidad de Lima.

Meza Orozco, J. (2017). Evaluación financiera de proyectos (4.a ed.). Bogotá: Ecoe Ediciones. 
Neufert, E. (2010). Arte de proyectar en arquitectura. Manual para arquitectos, ingenieros, arquitectos técnicos, constructores profesionales y estudiantes. Barcelona: Gustavo Gili.

Organización de las Naciones Unidas para la Alimentación y Agricultura. (1997). Sistema de análisis de peligros y de puntos críticos de control (HACCP) y directrices para su aplicación. Recuperado de:

http://www.fao.org/docrep/005/y1579s/y1579s03.htm 
ANEXOS 


\section{Anexo 1: Glosario de Términos}

\section{Glosario de términos}

- Dip: proveniente del término en inglés "Dipping Sauce", es una salsa que acompaña ciertos aperitivos.

- $\quad$ Salsa: es una mezcla líquida o semilíquida de ingredientes que sirve para acompañar un plato.

- Tapenade: es una pasta que lleva como insumo principal aceitunas; sin embargo en el mercado se puede encontrar en combinación con otros ingredientes como alcachofa, espárrago, pimiento, entre otros.

- Pasta: es una masa de consistencia homogénea que se obtiene del mezclado de insumos sólidos molidos con sustancias líquidas como agua y/o aceite.

- Producto orgánico: se refiere a cualquier producto que haya sido cultivado o elaborado sin usar fertilizantes, conservantes y/o aditivos químicos.

- $\quad$ Piqueo: porción de alimentos para compartir entre dos o más personas.

- $\quad$ Doypack: bolsa de plástico sellada que está diseñada para mantenerse de pie. En este caso se usará con tapa.

- Producto vegano: es un producto que no incluye insumos alimenticios de origen animal.

- Biocomercio: conjunto de actividades de producción y comercialización de bienes y servicios en base a la biodiversidad. Busca sostenibilidad económica, social y ambiental. 


\section{Anexo 2: Información Nutricional Completa}

\begin{tabular}{cccccccccccc}
\hline Ingrediente & Cantidad & Unidad & Porcentaje & Calorías & Proteínas & $\begin{array}{c}\text { Carbohidratos } \\
\text { totales }\end{array}$ & $\begin{array}{c}\text { Grasas } \\
\text { totales }\end{array}$ & $\begin{array}{c}\text { Fibra } \\
\text { Alimentaria }\end{array}$ & Calcio & Fósforo & Hierro \\
\hline Quinua & 68 & gr & $37.78 \%$ & 68.68 & 2.24 & 11.08 & 0.88 & 3.40 & 18.36 & 41.48 & 1.09 \\
Espárrago & 44 & gr & $24.4 \%$ & 10.12 & 0.97 & 2.02 & 0.09 & 0.92 & 15.40 & 15.40 & 0.53 \\
Brócoli & 37 & gr & $20.6 \%$ & 14.80 & 1.81 & 2.11 & 0.33 & 0.96 & 34.41 & 31.82 & 0.44 \\
Albahaca & 3 & gr & $1.7 \%$ & 1.29 & 0.09 & 0.22 & 0.04 & 0.12 & 9.75 & 1.14 & 0.16 \\
Aceite de oliva & 10 & $\mathrm{ml}$ & $5.6 \%$ & 88.40 & 0.00 & 0.00 & 10.00 & 0.00 & 0.00 & 0.00 & 0.00 \\
Aceite de girasol & 5 & $\mathrm{ml}$ & $2.8 \%$ & 44.20 & 0.00 & 0.00 & 7.00 & 0.00 & 0.00 & 0.00 & 0.00 \\
Cebolla & 4 & $\mathrm{gr}$ & $2.2 \%$ & 1.96 & 0.06 & 0.45 & 0.01 & 0.06 & 0.80 & 1.40 & 0.05 \\
Queso parmesano & 2 & $\mathrm{gr}$ & $1.1 \%$ & 8.80 & 0.78 & 0.04 & 0.61 & 0.00 & 25.20 & 7.86 & 0.01 \\
Sal & 1 & $\mathrm{gr}$ & $0.6 \%$ & 0.00 & 0.00 & 0.00 & 0.00 & 0.00 & 0.29 & 0.08 & 0.00 \\
Limón & 4 & $\mathrm{ml}$ & $2.2 \%$ & 0.60 & 0.01 & 0.00 & 0.19 & 0.01 & 0.72 & 0.56 & 0.02 \\
Ajo & 2 & $\mathrm{gr}$ & $1.1 \%$ & 2.58 & 0.11 & 0.61 & 0.02 & 0.04 & 1.88 & 3.60 & 0.03 \\
Total & $\mathbf{1 8 0}$ & gr & $\mathbf{1 0 0 \%}$ & $\mathbf{2 4 1 . 4 3}$ & $\mathbf{6 . 0 7}$ & $\mathbf{1 6 . 5 4}$ & $\mathbf{1 9 . 1 6}$ & $\mathbf{5 . 5 1}$ & $\mathbf{1 0 6 . 8 1}$ & $\mathbf{1 0 3 . 3 4}$ & $\mathbf{2 . 3 4}$ \\
\hline
\end{tabular}

Fuente: Instituto Nacional de Salud (2016) 


\section{Anexo 3: Segmentación de Mercado Objetivo}

\section{DISTRIBUCIÓN DE PERSONAS SEGÚN NSE 2016 - LIMA METROPOLITANA}

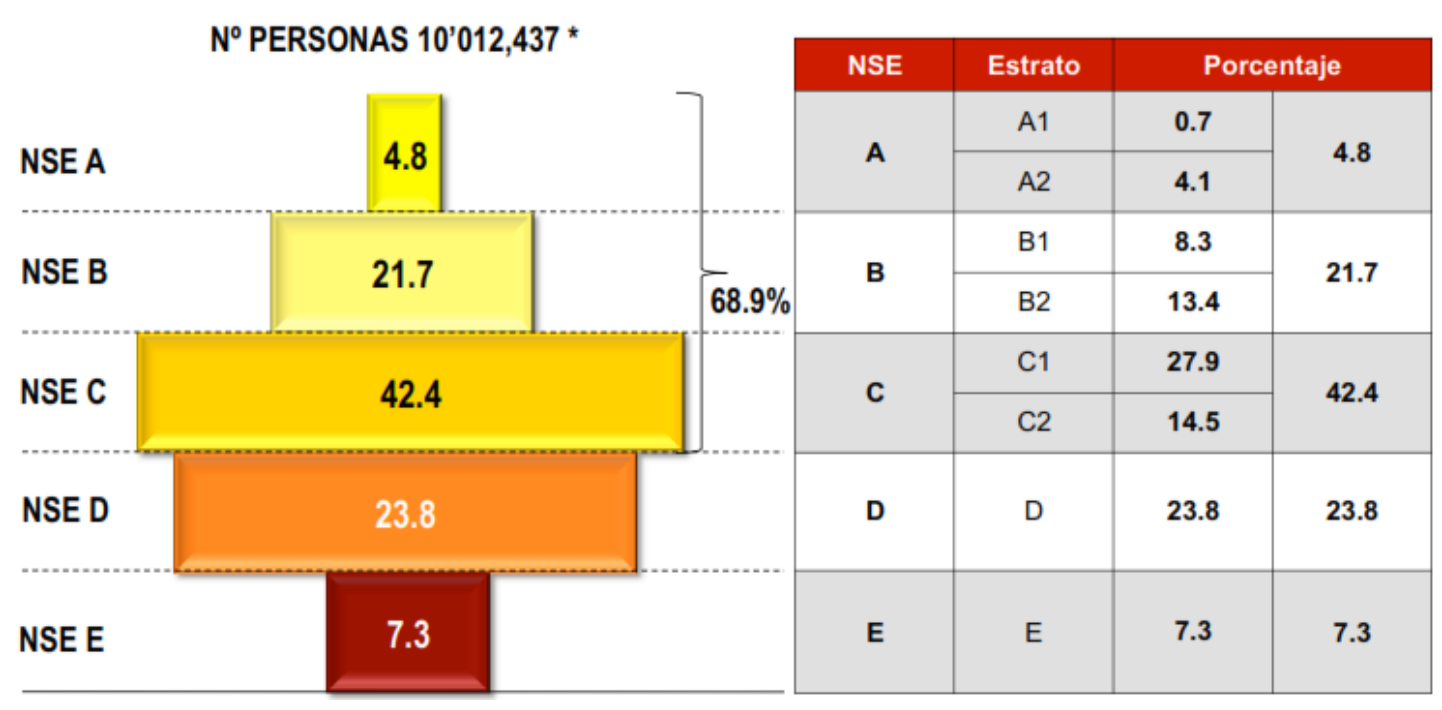

Fuente: APEIM (2016)

DISTRIBUCIÓN DE NIVELES POR ZONA APEIM 2016 - LIMA METROPOLITANA

PERSONAS - $(\%)$ HORIZONTALES

\begin{tabular}{|c|c|c|c|c|c|c|}
\hline \multirow{2}{*}{ Zona } & \multirow[b]{2}{*}{ TOTAL } & \multicolumn{5}{|c|}{ Niveles Socioeconómicos } \\
\hline & & NSE A & NSE B & NSE C & NSE D & NSE E \\
\hline Total & 100 & 4.8 & 21.7 & 42.4 & 23.8 & 7.3 \\
\hline Zona 1 (Puente Piedra, Comas, Carabayllo) & 100 & 0.5 & 10.9 & 46.6 & 29.8 & 12.2 \\
\hline Zona 2 (Independencia, Los Olivos, San Martín de Porras) & 100 & 2.0 & 23.7 & 52.1 & 19.8 & 2.4 \\
\hline Zona 3 (San Juan de Lurigancho) & 100 & 0.0 & 19.1 & 44.2 & 26.7 & 10.0 \\
\hline Zona 4 (Cercado, Rimac, Breña, La Victoria) & 100 & 4.3 & 27.1 & 44.6 & 20.2 & 3.8 \\
\hline $\begin{array}{l}\text { Zona 5 (Ate, Chaclacayo, Lurigancho, Santa Anita, San Luis, EI } \\
\text { Agustino) }\end{array}$ & 100 & 2.1 & 12.3 & 42.6 & 34.0 & 8.9 \\
\hline Zona 6 (Jesús Maria, Lince, Pueblo Libre, Magdalena, San Miguel) & 100 & 13.7 & 58.0 & 22.2 & 5.4 & 0.8 \\
\hline Zona 7 (Miraflores, San Isidro, San Borja, Surco, La Molina) & 100 & 35.9 & 43.2 & 14.9 & 4.5 & 1.4 \\
\hline Zona 8 (Surquillo, Barranco, Chorrillos, San Juan de Miraflores) & 100 & 3.9 & 26.6 & 44.5 & 20.5 & 4.4 \\
\hline Zona 9 (Villa El Salvador, Villa María del Triunfo, Lurin, Pachacamác) & 100 & 0.0 & 6.3 & 45.7 & 36.6 & 11.4 \\
\hline $\begin{array}{l}\text { Zona } 10 \text { (Callao, Bellavista, La Perla, La Punta, Carmen de la Legua, } \\
\text { Ventanilla) }\end{array}$ & 100 & 1.2 & 19.7 & 44.3 & 23.8 & 11.1 \\
\hline Otros & 100 & 0.0 & 8.1 & 47.6 & 25.4 & 18.9 \\
\hline
\end{tabular}

Fuente: APEIM (2016) 
DISTRIBUCIÓN DE ZONAS APEIM POR NIVELES 2016 - LIMA METROPOLITANA

PERSONAS - (\%) VERTICALES

\begin{tabular}{|l|c|c|c|c|c|}
\hline \multirow{2}{*}{\multicolumn{1}{|c|}{ Zona }} & \multicolumn{4}{c|}{ Niveles Socioeconómicos } \\
\cline { 2 - 6 } & NSE "A" & NSE "B" & NSE "C" & NSE "D" & NSE "E" \\
\hline Total & 100.0 & 100.0 & 100.0 & 100.0 & 100.0 \\
\hline Zona 1 (Puente Piedra, Comas, Carabayllo) & 1.3 & 5.8 & 12.7 & 14.4 & 19.3 \\
\hline Zona 2 (Independencia, Los Olivos, San Martin de Porras) & 5.9 & 15.2 & 17.2 & 11.6 & 4.7 \\
\hline Zona 3 (San Juan de Lurigancho) & 0.0 & 10.5 & 12.4 & 13.4 & 16.4 \\
\hline Zona 4 (Cercado, Rimac, Breña, La Victoria) & 8.4 & 11.6 & 9.8 & 7.9 & 4.9 \\
\hline Zona 5 (Ate, Chaclacayo, Lurigancho, Santa Anita, San Luis, El Agustino) & 4.5 & 5.7 & 10.1 & 14.4 & 12.4 \\
\hline Zona 6 (Jesús Maria, Lince, Pueblo Libre, Magdalena, San Miguel) & 15.1 & 13.9 & 2.7 & 1.2 & 0.6 \\
\hline Zona 7 (Miraflores, San Isidro, San Borja, Surco, La Molina) & 55.5 & 14.6 & 2.6 & 1.4 & 1.5 \\
\hline Zona 8 (Surquillo, Barranco, Chorrillos, San Juan de Miraflores) & 6.7 & 9.8 & 8.4 & 6.9 & 4.9 \\
\hline Zona 9 (Villa El Salvador, Villa Maria del Triunfo, Lurin, Pachacamác) & 0.0 & 3.4 & 12.5 & 17.9 & 18.2 \\
\hline Zona 10 (Callao, Bellavista, La Perla, La Punta, Carmen de la Legua, Ventanilla) & 2.7 & 9.3 & 10.8 & 10.3 & 15.6 \\
\hline Otros & 0.0 & 0.2 & 0.7 & 0.7 & 1.6 \\
\hline
\end{tabular}

Fuente: APEIM (2016)

PERFIL DE PERSONAS SEGÚN NSE 2016 - LIMA METROPOLITANA

\begin{tabular}{|c|c|c|c|c|c|c|c|c|c|}
\hline & \multicolumn{8}{|c|}{ Lima Metropolitana } \\
\hline & & Total & NSE A & NSE B & NSE C & NSE C1 & NSE C2 & NSE D & NSE E \\
\hline \multirow{2}{*}{ Sexo } & Hombre & $48.6 \%$ & $47.7 \%$ & $47.5 \%$ & $48.5 \%$ & $48.7 \%$ & $48.1 \%$ & $49.4 \%$ & $50.1 \%$ \\
\hline & Mujer & $51.4 \%$ & $52.3 \%$ & $52.5 \%$ & $51.5 \%$ & $51.3 \%$ & $51.9 \%$ & $50.6 \%$ & $49.9 \%$ \\
\hline \multirow{8}{*}{$\begin{array}{l}\text { ¿Qúe edad tiene en año cumplidos? } \\
\text { (En años ) (agrupado) }\end{array}$} & $<=12$ & $18.9 \%$ & $16.5 \%$ & $13.9 \%$ & $18.4 \%$ & $17.5 \%$ & $20.1 \%$ & $23.1 \%$ & $25.0 \%$ \\
\hline & $13-17$ & $7.4 \%$ & $4.8 \%$ & $5.9 \%$ & $7.6 \%$ & $7.9 \%$ & $7.1 \%$ & $7.6 \%$ & $11.6 \%$ \\
\hline & $18-25$ & $13.7 \%$ & $10.9 \%$ & $13.2 \%$ & $13.7 \%$ & $13.5 \%$ & $14.0 \%$ & $14.2 \%$ & $15.3 \%$ \\
\hline & $26-30$ & $7.6 \%$ & $8.2 \%$ & $7.6 \%$ & $7.6 \%$ & $7.6 \%$ & $7.8 \%$ & $7.4 \%$ & $7.8 \%$ \\
\hline & $31 \cdot 35$ & $7.5 \%$ & $6.4 \%$ & $9.0 \%$ & $6.8 \%$ & $6.5 \%$ & $7.3 \%$ & $8.1 \%$ & $6.9 \%$ \\
\hline & $36-45$ & $13.7 \%$ & $14.5 \%$ & $11.9 \%$ & $14.7 \%$ & $15.4 \%$ & $13.5 \%$ & $13.7 \%$ & $12.4 \%$ \\
\hline & $46-55$ & $11.7 \%$ & $14.0 \%$ & $14.6 \%$ & $11.3 \%$ & $11.1 \%$ & $11.9 \%$ & $9.8 \%$ & $9.5 \%$ \\
\hline & $56+$ & $19.5 \%$ & $24.7 \%$ & $23.9 \%$ & $19.9 \%$ & $20.6 \%$ & $18.4 \%$ & $16.2 \%$ & $11.5 \%$ \\
\hline \multirow{6}{*}{ ¿Cuál es su estado civil o conyugal? } & Conviviente & $18.7 \%$ & $5.0 \%$ & $8.8 \%$ & $18.5 \%$ & $16.5 \%$ & $22.5 \%$ & $27.6 \%$ & $33.4 \%$ \\
\hline & Casado (a) & $28.0 \%$ & $46.7 \%$ & $39.3 \%$ & $27.6 \%$ & $29.8 \%$ & $23.1 \%$ & $18.2 \%$ & $12.4 \%$ \\
\hline & Viudo (a) & $4.7 \%$ & $5.6 \%$ & $4.8 \%$ & $4.5 \%$ & $4.3 \%$ & $4.9 \%$ & $5.0 \%$ & $4.0 \%$ \\
\hline & Divorciado (a) & $0.9 \%$ & $2.0 \%$ & $1.3 \%$ & $0.9 \%$ & $1.0 \%$ & $0.8 \%$ & $0.5 \%$ & $0.5 \%$ \\
\hline & Separado (a) & $9.3 \%$ & $4.8 \%$ & $6.5 \%$ & $10.0 \%$ & $9.7 \%$ & $10.5 \%$ & $11.1 \%$ & $12.0 \%$ \\
\hline & Soltero (a) & $38.3 \%$ & $35.8 \%$ & $39.3 \%$ & $38.5 \%$ & $38.7 \%$ & $38.1 \%$ & $37.6 \%$ & $37.8 \%$ \\
\hline \multirow{2}{*}{$\begin{array}{l}\text { En el mes anterior, ¿ hizo uso del } \\
\text { servicio de Internet? }\end{array}$} & Si & $58.2 \%$ & $90.8 \%$ & $77.0 \%$ & $57.3 \%$ & $60.9 \%$ & $50.0 \%$ & $41.4 \%$ & $37.4 \%$ \\
\hline & No & $41.8 \%$ & $9.2 \%$ & $23.0 \%$ & $42.7 \%$ & $39.1 \%$ & $50.0 \%$ & $58.6 \%$ & $62.6 \%$ \\
\hline \multirow{6}{*}{$\begin{array}{l}\text { En el mes anterior ¿Dónde usó } \\
\text { Internet? (Respuesta Múltiple) }\end{array}$} & Elhogar & $57.1 \%$ & $89.5 \%$ & $80.2 \%$ & $55.0 \%$ & $61.2 \%$ & $40.0 \%$ & $21.9 \%$ & $1.3 \%$ \\
\hline & El trabajo & $19.8 \%$ & $43.5 \%$ & $29.6 \%$ & $15.0 \%$ & $16.2 \%$ & $12.3 \%$ & $7.5 \%$ & $6.8 \%$ \\
\hline & $\begin{array}{l}\text { Un establecimiento } \\
\text { educativo }\end{array}$ & $8.5 \%$ & $9.0 \%$ & $8.7 \%$ & $8.7 \%$ & $9.0 \%$ & $8.1 \%$ & $7.4 \%$ & $7.4 \%$ \\
\hline & Una cabina pública & $20.4 \%$ & $.8 \%$ & $5.6 \%$ & $19.3 \%$ & $15.7 \%$ & $28.1 \%$ & $45.8 \%$ & $66.7 \%$ \\
\hline & En casa de otra persona & $5.6 \%$ & $1.8 \%$ & $4.0 \%$ & $5.1 \%$ & $5.4 \%$ & $4.3 \%$ & $9.6 \%$ & $13.6 \%$ \\
\hline & Otro & $40.5 \%$ & $53.2 \%$ & $45.6 \%$ & $38.5 \%$ & $38.8 \%$ & $37.7 \%$ & $35.2 \%$ & $25.6 \%$ \\
\hline
\end{tabular}

Fuente: APEIM (2016) 
DISTRIBUCIÓN DE PERSONAS SEGÚN NSE 2016 - DEPARTAMENTO (URBANO)

\begin{tabular}{|l|c|c|c|c|c|}
\hline \multirow{2}{*}{$\begin{array}{l}\text { DEPARTAMENTO } \\
\text { Amazonas }\end{array}$} & \multicolumn{3}{c|}{ PERSONAS - NIVEL SOCIOECONÓMICO - URBANO (\%) } \\
\cline { 2 - 6 } & TOTAL & AB & C & D & E \\
\hline Ancash & $100 \%$ & 6.2 & 22.8 & 34.6 & 36.4 \\
\hline Apurimac & $100 \%$ & 12.4 & 33.0 & 34.2 & 20.3 \\
\hline Arequipa & $100 \%$ & 8.3 & 18.1 & 29.1 & 44.5 \\
\hline Ayacucho & $100 \%$ & 21.8 & 34.2 & 31.9 & 12.0 \\
\hline Cajamarca & $100 \%$ & 6.4 & 14.8 & 27.4 & 51.4 \\
\hline Cusco & $100 \%$ & 9.9 & 29.7 & 38.2 & 22.3 \\
\hline Huancavelica & $100 \%$ & 15.6 & 21.7 & 30.0 & 32.6 \\
\hline Huanuco & $100 \%$ & 3.8 & 23.9 & 31.3 & 41.0 \\
\hline Ica & $100 \%$ & 11.2 & 27.3 & 33.0 & 28.5 \\
\hline Junin & $100 \%$ & 15.0 & 40.5 & 33.9 & 10.6 \\
\hline La Libertad & $100 \%$ & 11.5 & 24.8 & 35.9 \\
\hline
\end{tabular}

Fuente: APEIM (2016) 


\section{Anexo 4: Encuesta}

\section{ENCUESTA - DIP DE QUINUA CON ESPÁRRAGOS, BRÓCOLI Y ALBAHACA}

La presente encuesta tiene como objetivo conocer su opinión sobre productos gourmet a base de vegetales.

El producto propuesto es un dip, que consiste en una salsa a base de quinua con vegetales verdes, queso parmesano y aceite de oliva. Es utilizado como aperitivo saludable y tiene como propósito satisfacer la necesidad de consumidores muy cuidadosos de su alimentación. Puede consumirse acompañado con galletas, tostadas, pan, ensaladas, papas y más.

Por lo mencionado anteriormente, le solicitamos pueda responder las siguientes preguntas:

1. Edad
a) $18-25$
b) $26-35$
c) $36-45$
d) 46 a más

2. Sexo

a) Hombre

b) Mujer

3. ¿Consume y/o ha consumido alguna vez un dip?
a) $\mathrm{Si}$
b) $\mathrm{No}$

4. ¿En qué lugar suele o le gustaría comprar el producto?
a) Supermercados
b) Tiendas especializadas
c) Estación de servicio (grifo)
d) Bodega
e) Otro:

5. ¿Qué factores son determinantes al momento de comprar o escoger un dip?
a) Sabor
b) Precio
c) Alimentación sana
d) Hambre
e) Sustitución de alimento
f) Otro: 
6. ¿Compraría un dip a base de quinua y vegetales verdes? (Si la respuesta es no, la encuesta ha concluido)
a) $\mathrm{Si}$
b) No

7. Por favor señale el grado de intensidad de su compra, siendo 1 probablemente y 10 de todas maneras.
a) 1
b) 2
c) 3
d) 4
e) 5
f) 6
g) 7
h) 8
i) 9
j) 10

8. ¿Con qué frecuencia consume Dips?
a) Una vez a la semana
b) Quincenal
c) Mensual
d) Ocasionalmente

9. ¿Con qué frecuencia cree usted que compraría este nuevo producto frente a productos similares?
a) Igual frecuencia
b) Mayor frecuencia
c) Menor frecuencia
d) Rara vez
e) Nunca

10. ¿Cuánto estaría dispuesto a pagar por un envase de $180 \mathrm{~g}$ ?
a) Menor a $\mathrm{S} / 5.90$
b) $\mathrm{De} \mathrm{S} / 5.91$ a $\mathrm{S} / 6.90$
c) $\mathrm{De} S / 6.91$ a $\mathrm{S} / 7.90$
d) $\mathrm{De} S / 7.91$ a $\mathrm{S} / 8.90$
e) De $S / 8.91$ a más 


\section{Anexo 5: Resultados de la Encuesta}

Pregunta 1. Edad

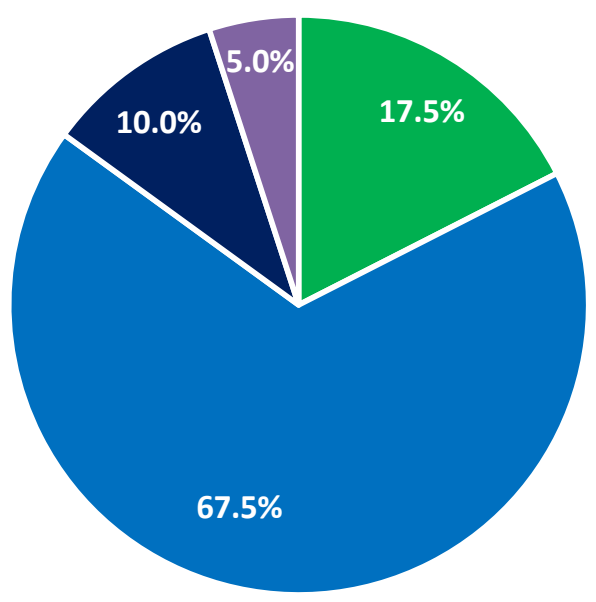

- 18 a 25 años

- 26 a 35 años

- 36 a 45 años

- 46 a más

Elaboración propia

Pregunta 2. Sexo

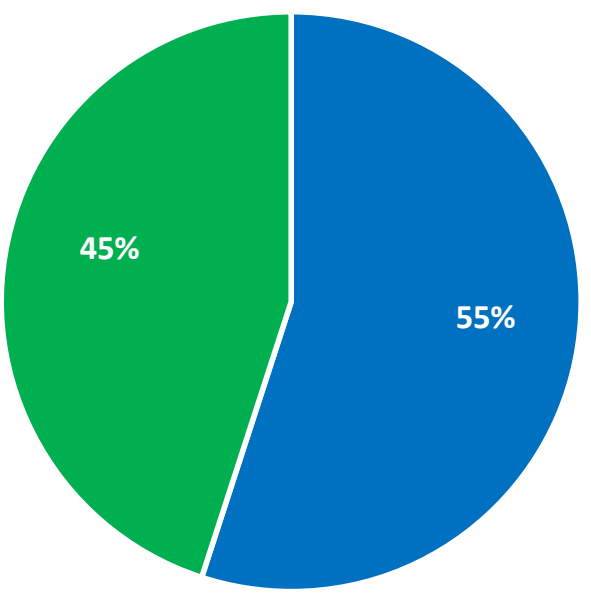

- Hombre

- Mujer

Elaboración propia 
Pregunta 3. ¿Consume y/o ha consumido, alguna vez, un dip?

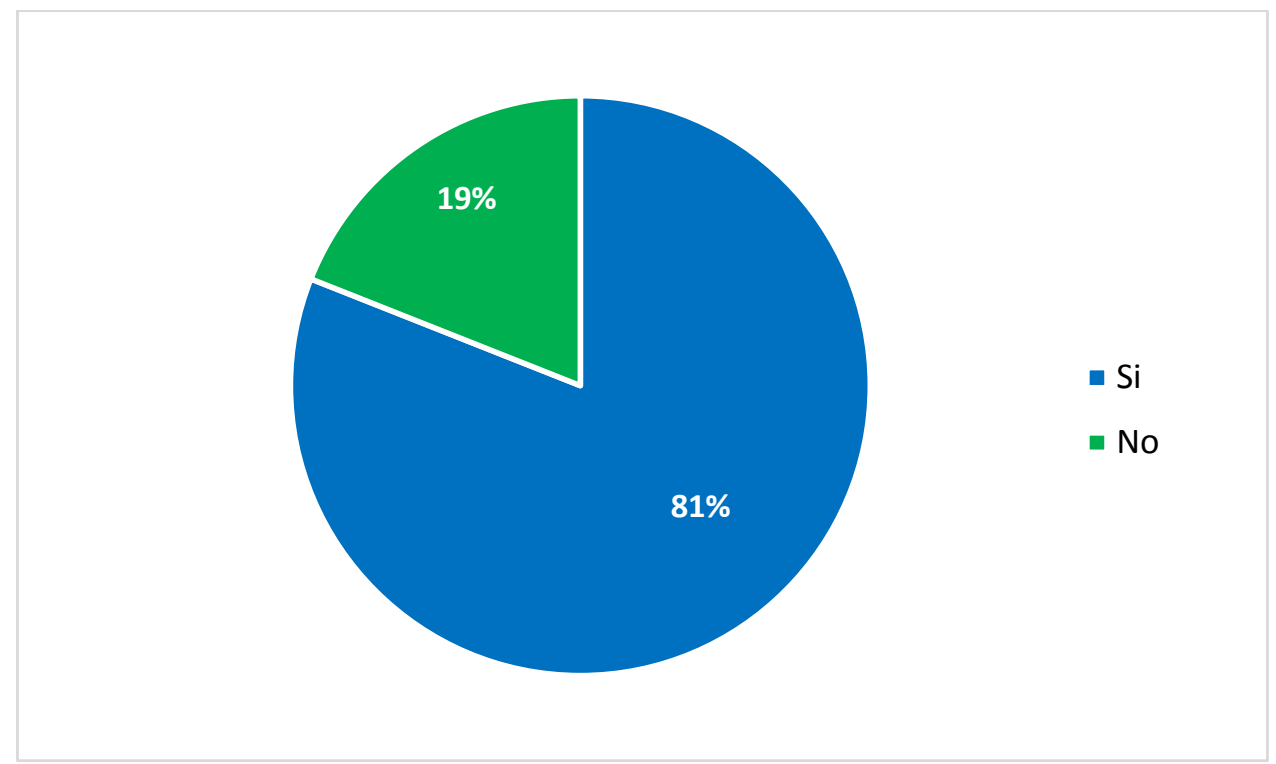

Elaboración propia

Pregunta 4. ¿En qué lugar suele o le gustaría comprar el producto?

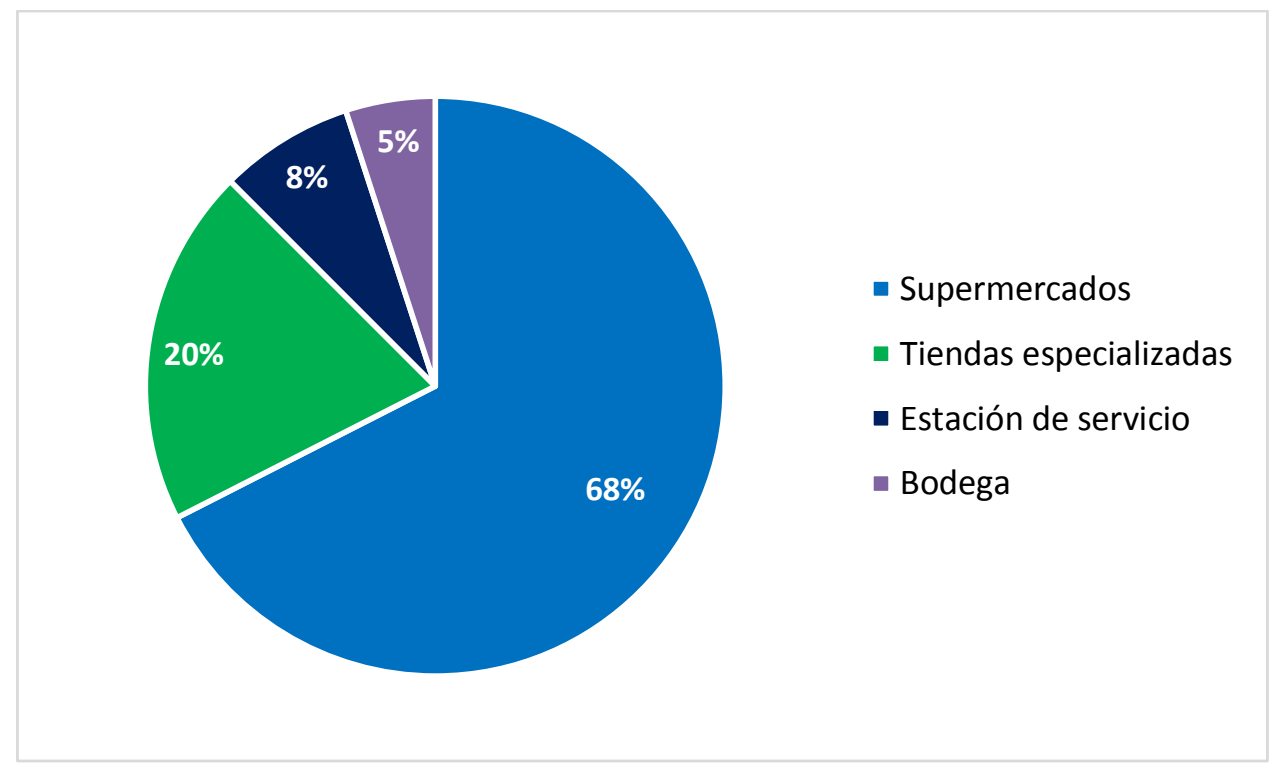

Elaboración propia 
Pregunta 5. ¿Qué factores son determinantes al momento de comprar o escoger un dip?

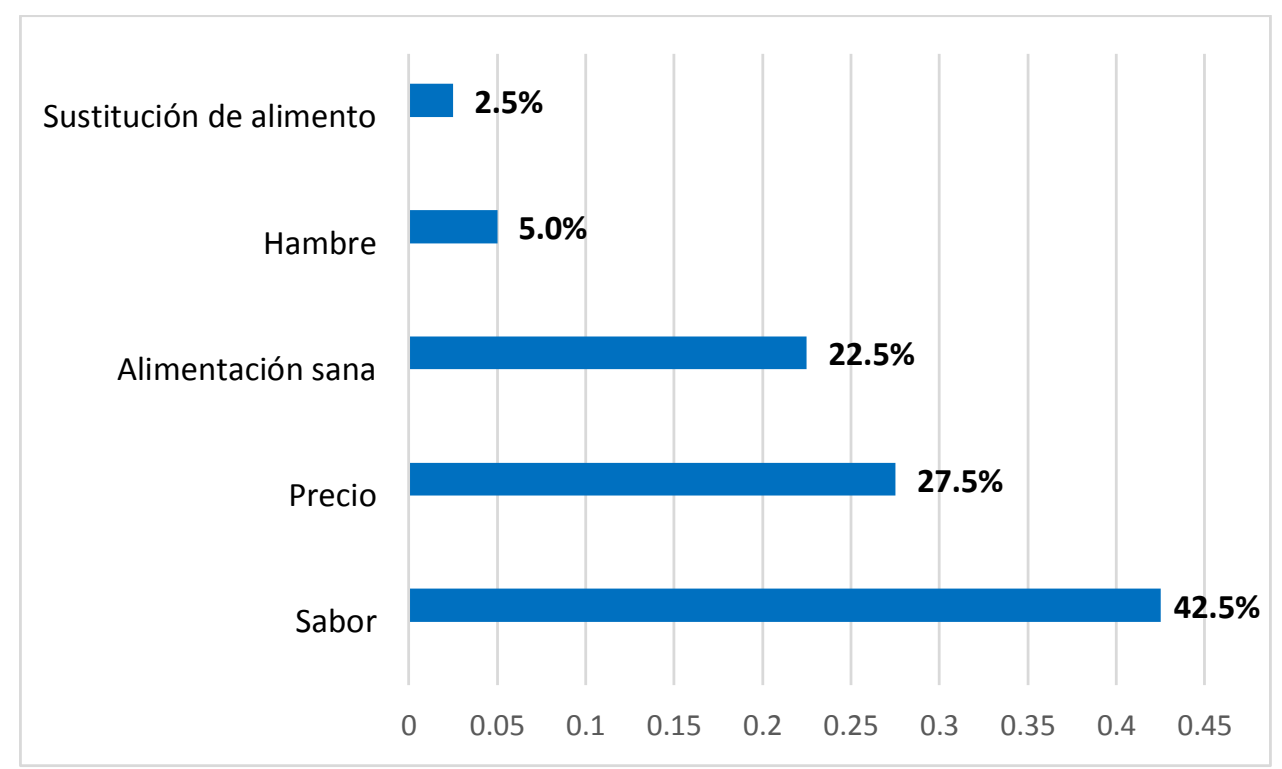

Elaboración propia

Pregunta 6. ¿Compraría un dip a base de quinua y vegetales verdes?

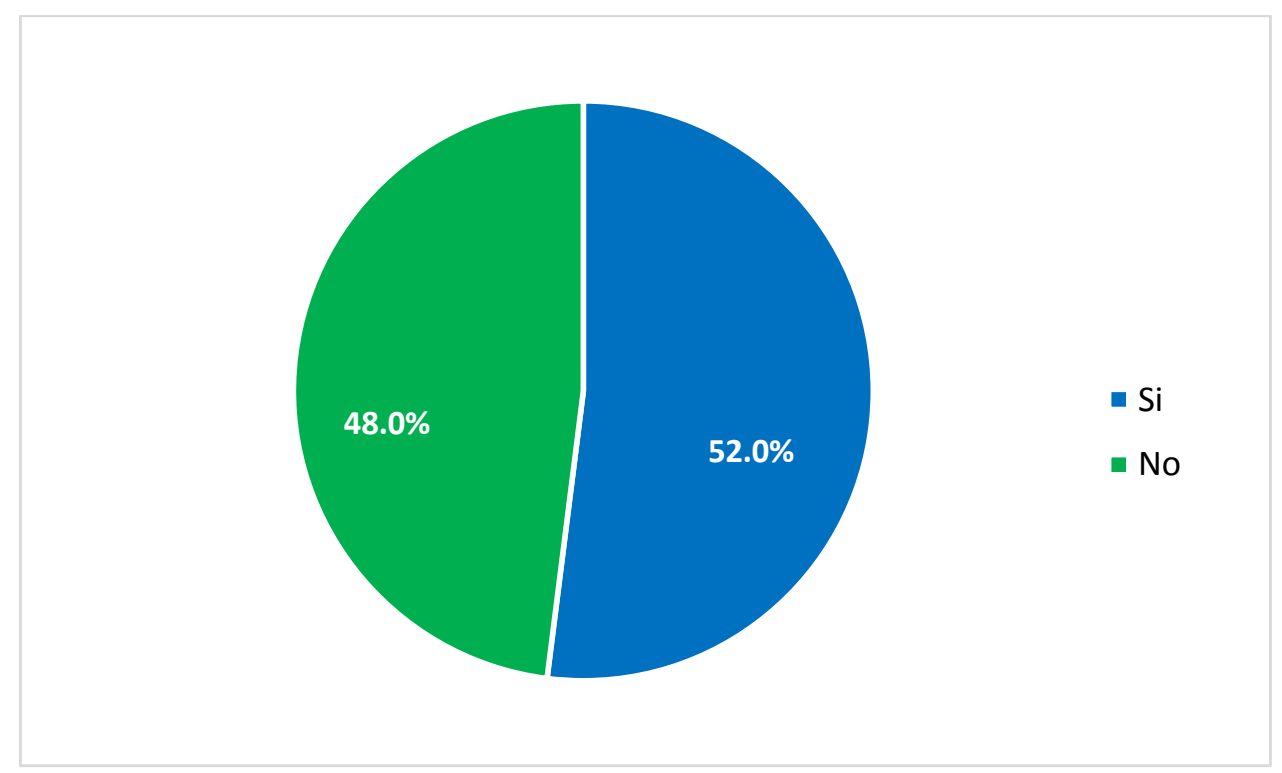

Elaboración propia 
Pregunta 7. Intensidad de compra

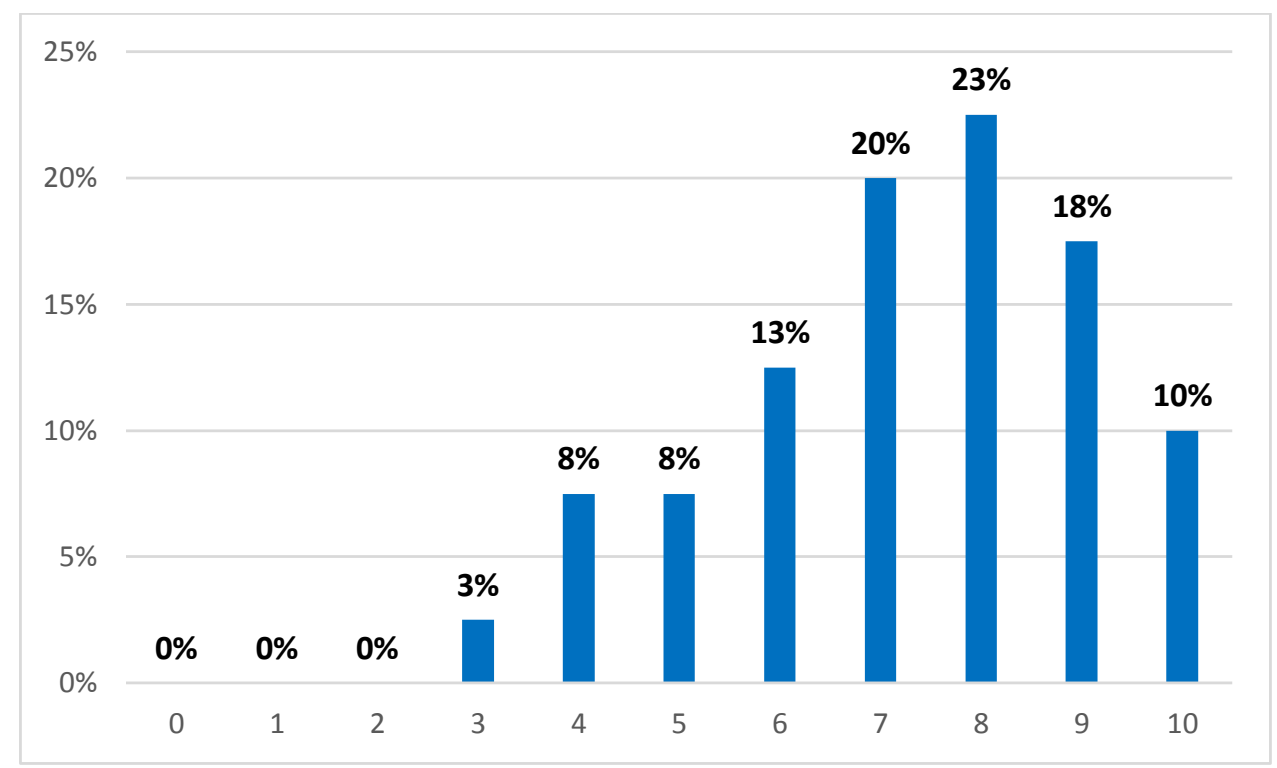

Elaboración propia

Pregunta 8. ¿Con qué frecuencia consume salsas untables (hummus, pesto, queso crema, paté, etc)?

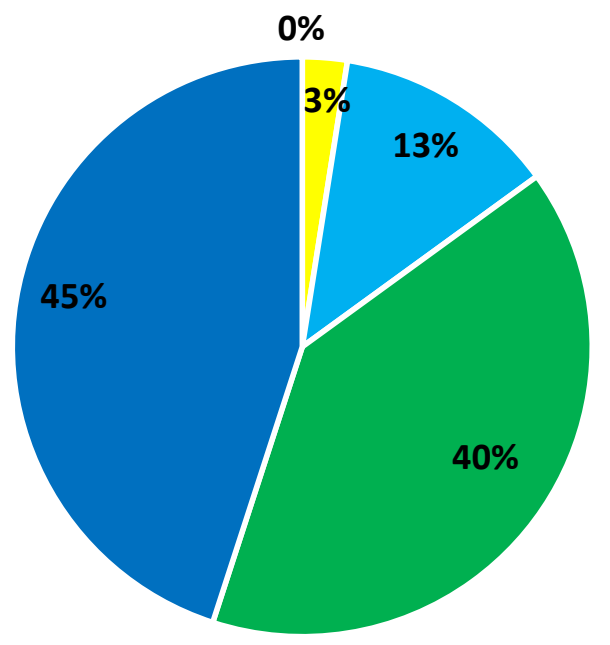

- Una vez a la semana

Quincenal

- Mensual

- Trimestral

- Anual

Elaboración propia 
Pregunta 9. ¿Con qué frecuencia cree usted que compraría este nuevo producto frente a productos similares?

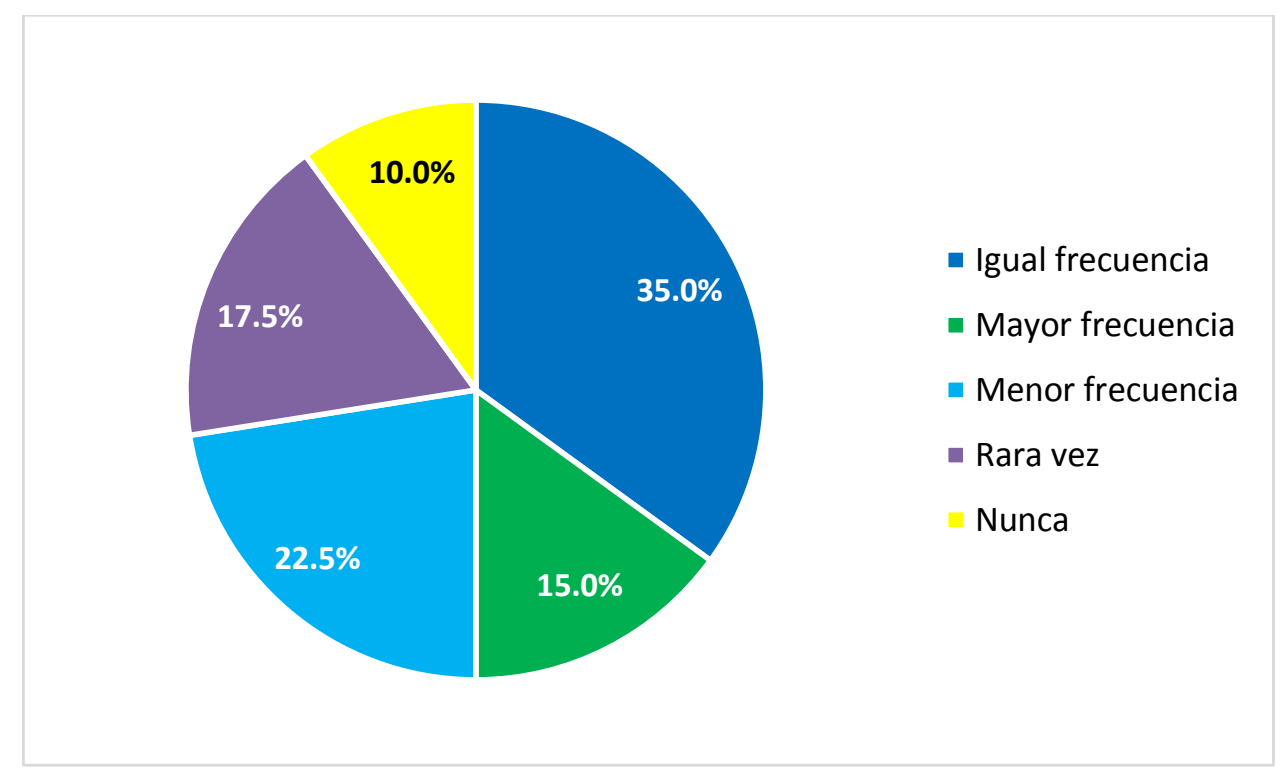

Elaboración propia

Pregunta 10. ¿Cuánto estaría dispuesto a pagar por un envase de $180 \mathrm{~g}$ ?

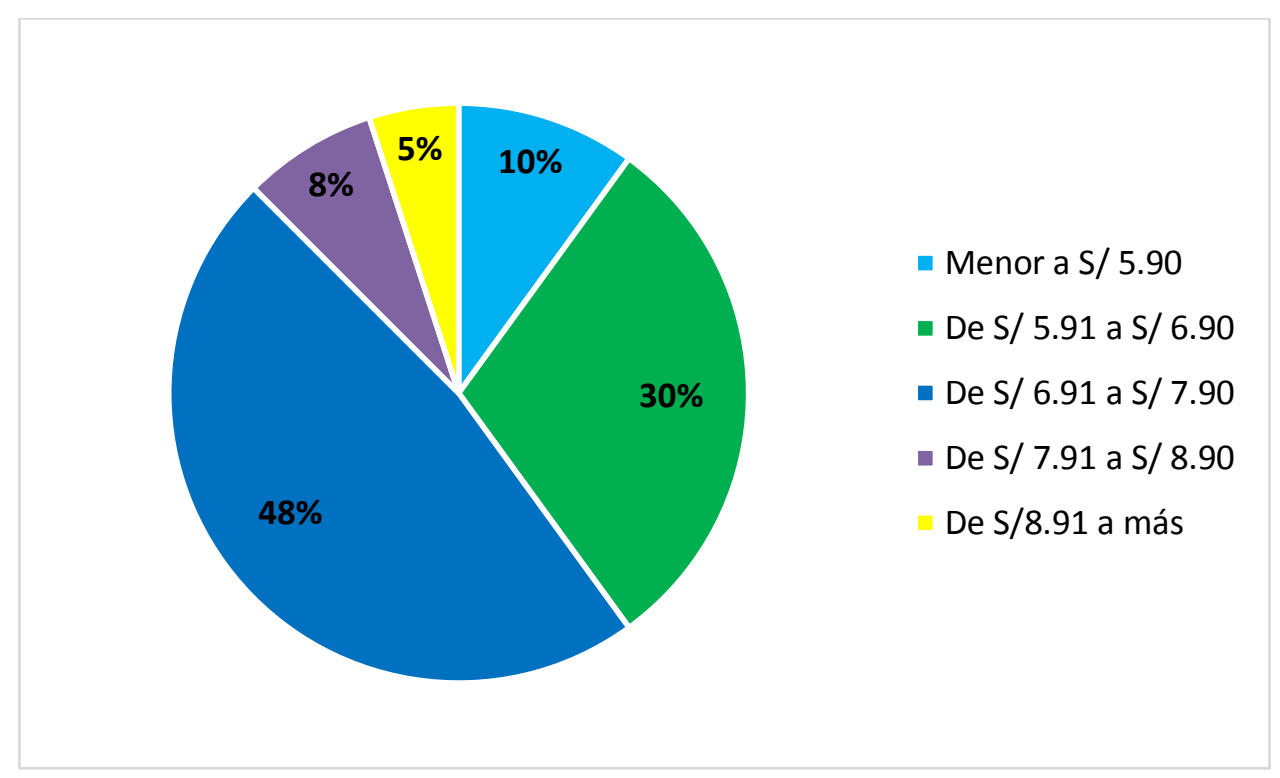

Elaboración propia 